\title{
The impact of new technologies on economic growth and trade : a case study of biotechnology
}

Citation for published version (APA):

Acharya, R. (1995). The impact of new technologies on economic growth and trade : a case study of biotechnology. [Doctoral Thesis, Maastricht University]. Datawyse / Universitaire Pers Maastricht. https://doi.org/10.26481/dis.19950126ra

Document status and date:

Published: 01/01/1995

DOI:

10.26481/dis.19950126ra

Document Version:

Publisher's PDF, also known as Version of record

\section{Please check the document version of this publication:}

- A submitted manuscript is the version of the article upon submission and before peer-review. There can be important differences between the submitted version and the official published version of record.

People interested in the research are advised to contact the author for the final version of the publication, or visit the DOI to the publisher's website.

- The final author version and the galley proof are versions of the publication after peer review.

- The final published version features the final layout of the paper including the volume, issue and page numbers.

Link to publication

\footnotetext{
General rights rights.

- You may freely distribute the URL identifying the publication in the public portal. please follow below link for the End User Agreement:

www.umlib.nl/taverne-license

Take down policy

If you believe that this document breaches copyright please contact us at:

repository@maastrichtuniversity.nl

providing details and we will investigate your claim.
}

Copyright and moral rights for the publications made accessible in the public portal are retained by the authors and/or other copyright owners and it is a condition of accessing publications that users recognise and abide by the legal requirements associated with these

- Users may download and print one copy of any publication from the public portal for the purpose of private study or research.

- You may not further distribute the material or use it for any profit-making activity or commercial gain

If the publication is distributed under the terms of Article $25 \mathrm{fa}$ of the Dutch Copyright Act, indicated by the "Taverne" license above, 


\section{The Impact of New Technologies on}

Economic Growth and Trade 


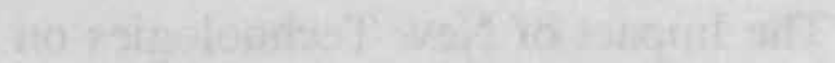

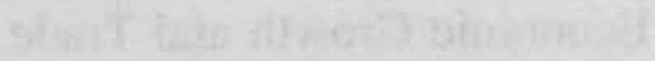




\section{The Impact of New Technologies on Economic Growth and Trade}

A Case Study of Biotechnology

PROEFSCHRIFT

ter verkrijging van de graad van doctor

aan de Rijksuniversiteit Limburg te Maastricht, op gezag van de Rector Magnificus, Prof. dr. H. Philipsen, volgens het besluit van het College van Dekanen, in het openbaar te verdedigen op donderdag 26 januari 1995 om 14.00 uur

door

Rohini Acharya

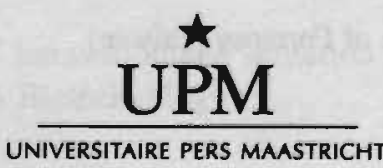




\section{Promotor:}

Prof. Dr. L.L.G. Soete

Co-promotor:

Dr. T.H.W. Ziesemer

Beoordelingscommissie:

Prof. Dr. J. Muysken (voorzitter)

Prof. C.M. Cooper (UNU/INTECH, Maastricht)

Prof. Dr. J. Hagedoorn

Prof. Dr. W.E. Steinmueller

Acharya, Rohini

The Impact of New Technologies on Economic Growth and Trade: A

Case Study of Biotechnology / Rohini Acharya - Maastricht:

Universitaire Pers Maastricht - III

Thesis Maastricht - With ref. - with summary in Dutch

ISBN 90-5278-173-7

Subject Headings: biotechnology; economic growth: international trade.

(c) 1995 Rohini Acharya, Maastricht

Cover illustration: The native people of Formosa (Taiwan)

Printing: Datawyse, Maastricht 


\section{Contents}

Foreword

1. Introduction and Methodologies 1

Introduction 1

1.1. Biotechnology: A Brief History 2

1.2. Quality and Variety: Three Problems 9

1.2.1. Non Genetically Engineered Biotechnologies

1.2.2. Biotechnology and Biodiversity: The Loss of Resource Variety 12

1.2.3. Consumer Preferences for Quality and Variety 15

1.3. Some Methodological Notes 18

$\begin{array}{ll}\text { 1.3.1. Introduction } & 18\end{array}$

1.3.2. Quality and Variety: A Framework for Research 18

1.4. Methodology and Outline of the Thesis 23

\section{Part I: Biotechnology: Some Observations about} the Nature of the Technology 27

2. The Potential of Modern Biotechnologies 29

2.1. Biotechnology: Definitions and Difficulties 29

2.2. The Technology Clusters 32

2.3. The Development of Biotechnology 34

2.4. Sectoral Developments in Biotechnology 39

2.4.1. The Pharmaceutical Sector 40

2.4.2. Agriculture 41

2.4.3. Environmental Biotechnologies $\quad 45$

Conclusions $\quad 46$

3. From Human Insulin to the Oncomouse:

Patterns of Innovation in the Triad 49

Introduction $\quad 49$

3.1. Biotechnology Policies and Industrial

3.2. Rates of Innovation: Some Evidence

from Patent Data $\quad 55$

3.2.1. Measuring Rates of Innovation and Imitation 60

3.2.2. The Role of Size in Biotechnology 64

Conclusions $\quad 68$ 
4. Biotechnology in Developing Countries:

Contrasts and Comparisons

$\begin{array}{ll}\text { Introduction } & 71\end{array}$

4.1. Biotechnology R\&D in Developing Countries 72

4.2. Building Technological Capability: The Case of South Asia $\quad 76$

4.2.1. The Role of Government Policy 77

4.2.2. Research and Training 79

4.3. Private Sector Commitment to Biotechnology 82

4.4. Patterns of Innovation in the South 90

4.4.1. Productivity Enhancing Innovations:

The Case of Cardamom in India $\quad 91$

$\begin{array}{ll}\text { Conclusions } & 100\end{array}$

5. Variety and Quality in Biotechnology 103

Introduction 103

5.1. New Qualities for Old 103

5.2. New Processes Driving Out Old Products and Processes 107

5.3. Variety, Quality and Consumer Preferences 114

Conclusion 116

Part II: Quantity, Quality and Variety:

The Theoretical Debate

119

Introduction

120

6. The Economics of Technical Change:

The Aggregate Approach 123

Introduction 123

6.1. Growth Theory and Technical Change 129

6.2. Endogenous Technological Change 126

$\begin{array}{ll}\text { Conclusions } & 129\end{array}$

7. Variety and Quality in Trade and Growth Models 131

Introduction 131

7.1. The Variety Models 132

7.1.1. Horizontal Differentiation in the Production Function 132

7.1.2. Horizontal Differentiation through Preferences 133

7.1.3. Trade and Growth and Increasing Variety 134

7.2. Trade and Growth in Higher Quality Products 139

Conclusions 146 


\section{Part III: Quality and Variety: Modelling}

Endogenous Growth and Trade

8. Closed Economy Model of Horizontal

and Vertical Product Differentiation

Introduction

8.1. The Model

8.2. Dynamics with Perfect Capital Markets 163

8.3. The Special Case of No Capital Markets 168

8.3.1. The Case of Delta $=1$ (Shell) 171

8.3.2. The Case of Delta $=0$ (Phelps) 172

8.4. Simulations for the No Capital Market Case 173

8.4.1. The Case of Strong Learning Effects 173

$\begin{array}{ll}\text { 8.4.2. Simulations for No Leaming (delta }=0) & 179\end{array}$

Conclusions $\quad 183$

9. Extensions to International Trade 185

$\begin{array}{ll}\text { Introduction } & 185\end{array}$

9.1. The Integrated Equilibrium 187

$\begin{array}{ll}\text { 9.1.1. Labour Allocation } & 194\end{array}$

9.2. Equilibrium with Perfect Specialization 198 Conclusions 204

10. Summary and Policy Conclusions 207 Introduction 207

10.1. Some Stylized Facts about the Nature of Biotechnology R\&D 207

10.2. Quantity, Variety and Quality: The Evidence Thus Far 209

10.3. Policy Implications and Avenues for Future Research 211

10.4. Conclusions and Research Linkages 220

Appendices $\quad 223$

Appendix I: List of Companies for which Data Collected 225

Appendix II: Calculating the Initial Value of $\dot{z}^{-} \quad 228$

Appendix III: Results of Simulations For No Capital Markets 231

$\begin{array}{ll}\text { References } & 249\end{array}$

Samenvatting (Summary in Dutch) 267

$\begin{array}{ll}\text { Curriculum Vitae } & 269\end{array}$ 
4. 20.

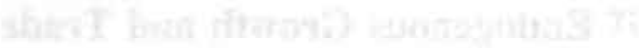

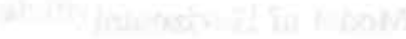

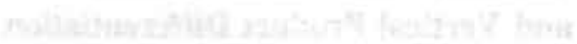

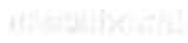

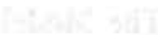

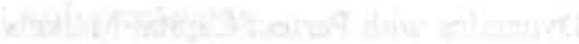

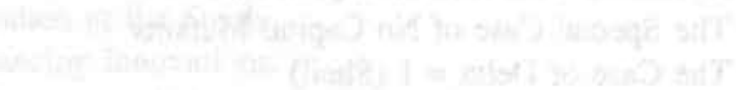

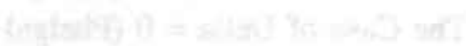

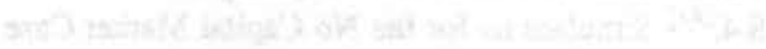

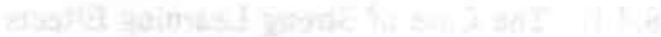

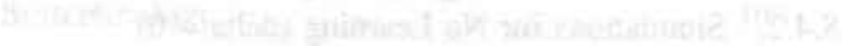




\section{FOREWORD}

The Arctic explorer, Peter Freuchen once described how while being trapped in a blizzard in Greenland, he built himself an igloo to protect himself from the elements only to discover that with every breath he took the walls of the igloo were closing in on him because of the condensation of his breath (Paul Auster, Groundwork). Writing a PhD very often felt like this and there are many that I am indebted to for their help in this accomplishment.

My primary debt is to my supervisors, Luc Soete and Thomas Ziesemer without whose support this endeavour would not even have been attempted. Thomas's painstaking reading and re-reading of earlier drafts especially, have made a major contribution to this document. The thesis began as a result of research at the Science Policy Research Unit (SPRU) and at the International Federation of Institutes for Advanced Study (IFIAS) on biotechnology and the international implications of this new technology. At the time, Frank Rijsberman, Calestous Juma and Norman Clark played a major part in encouraging me to begin a $\mathrm{PhD}$ by combining newly gained experience in biotechnology with my previous background in economics and international economics. I am grateful to them for encouraging me in this effort.

The many people at MERTT and at the Economics Faculty who have taken time to talk to me about issues directly and indirectly related to research, cannot all be individually mentioned, but I thank them all. There are however a few who have gone out of their way to help me. At MERIT, I thank Bart Verspagen for allowing me access to his computing acumen, Theon van Dijk for helping me to use patent data from the European Patent Office, Wilma Coenegrachts for all her help and encouragement over the years, Corien Gijsbers for translating the summary into Dutch, Mieke Donders, Lori Mees, JoAnn van Rooijen, Silvana de Sanctis and Ellen Boulanger.

Outside MERIT and Maastricht, there is also a long list of persons who have contributed to this thesis, especially government officials and researchers in India, China, Taiwan, South Korea, Thailand and the Philippines, whom I have had the opportunity of meeting over the years. I would especially like to mention Dr Padolina, Undersecretary at the Department of Science and Technology in the Philippines, Dr Yuthavong, Director of the National Centre for Genetic Engineering and Biotechnology, in Thailand, Professor Hong-lk Chung at Seoul National University and Dr Jang Liu, Director and Dr Han, former Executive Director at the Genetic Engineering Research Institute (GERI) in South Korea, Professor Jei-Fu Shaw at the Institute of Botany, Academia Sinica and Dr Leah Lo at the Development Centre for Biotechnology in Taiwan, Dr N.K. Jain at the Department of Biotechnology and $\mathrm{Dr}$ Chandrasekhar, Director of BCIL in India and Dr Yonghui Liu, Director of the China National Centre for Biotechnology Development (CNCBD) in the Peoples Republic of China. Furthermore, comments received from participants at various conferences on topics ranging from the economics of technological change to the conservation of biological diversity have also greatly enriched the contents of this thesis. In addition, Martin Fransman's comments were extremely useful in helping me to focus on my thesis topic. Lynn Mytelka has enabled me to continue doing research in this field.

It was also my privilege to receive financial and academic support for my work over the years. I especially thank Charles Cooper for giving me the opportunity of working at 
UNU/Intech as a visiting PhD student and all INTECH-ites, both past and present, for providing a challenging environment, both social and academic, the NWO, for their financial assistance which enabled me to carry out much of my field work in India, to the Faculty of Economics for providing me with a research grant to support that initial work and finally, I would like to thank the Finnish Development Agency (FINNIDA), for their financial contribution to a project on biotechnology capabilities to the African Centre for Technology Studies (ACTS), which made part of my own research possible.

Finally, I would also like to thank the members of the Examining Commission, for carefully reading this document. The thesis is a lot richer and more coherent as a result of their comments.

On a more personal note, I would like to thank all those I have known, in and outside the Trait d'Union, from Maastricht and from places further afield, who have supported me in this endeavour.

To my parents I owe this thesis in its entirety, especially Chapter 4, for which I would not have obtained enough data had it not been for their constant visits to the Department of Biotechnology. To my sisters, the environmental economist and the chemist, thank you for putting your faith in me. David and Jeanette, you probably understand me better than most and your presence was sorely missed. Finally, to MB, for showing me that it is the little things in life that matter. Merci pour tous! I know my french isn't quite up to standard, but it has been fun in english! 
To Appa and Amma For your faith

"This piece of information is, as far as I am aware, hitherto unrecorded in the extensive annotations which have been inflicted on the novel, and $I$ herewith offer it in a spirit of humility for use by professional scholars". 
Lit

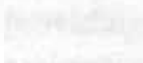

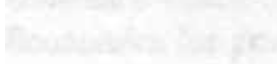

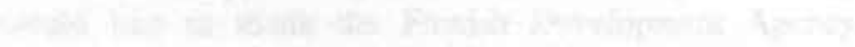

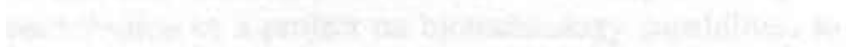

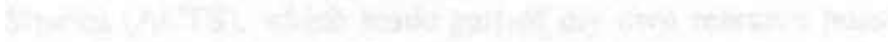

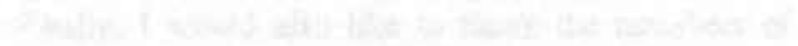

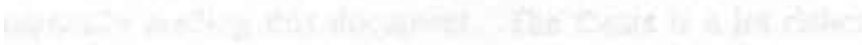

(5)

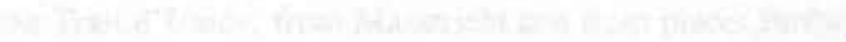

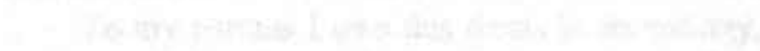

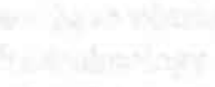

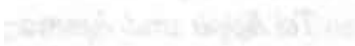

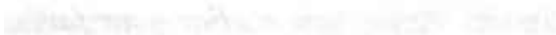

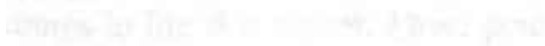

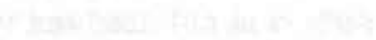


"Once upon a time and a very good time it was"...J. Joyce

\section{Introduction}

When James Watson, a young 23 year old who upon completing his $\mathrm{PhD}$ went to join Francis Crick at the Cavendish Laboratories at Cambridge, little did he realize that the discovery which they were to make would earn them the Nobel Prize a few years later, and would be the beginning of a chain of innovations which would revolutionize the field of biotechnology. Even if he did recognize the importance of mapping the structure of deoxyribonucleic acid (DNA), (see Watson, 1968), he could not possibly have imagined that by the late 1980s and early 1990 s he would first head the multi-national genome project, which set itself the task of mapping the human gene, or that he would be resigning from that position over a controversy over intellectual property rights.

In a little over four decades since that discovery, biotechnology today claims that it is one of the fastest growing new technologies in the world. It boasts radical changes not just in one sector, but across sectors as well. The potential of developing vaccines or cures for diseases which are as yet incurable, as well as the ability to increase food output in many developing countries has provided new hope to scientists across the world. However, biotechnology has also brought with it many controversies. Intellectual property rights and the trend toward granting process and product patents for a new generation of plants and animal species has led to conflicts, especially between the industrialized and the developing countries, or the innovators and the technological followers in this case. The granting of a patent for transgenic cotton to the biotechnology company Agracetus for example, implies that all future research on this plant will be closely controlled by Agracetus ${ }^{1}$. A growing technology gap is thus compounded by the innovator's control not only over the innovation, but future generations of new products. The developing country loses not only its traditional product which is displaced by the innovation, in this instance, transgenic cotton, but its access to the new product is also considerably lessened by the patent.

The exploitation of the world's biological diversity, a trend started by the previous generation of chemical technologies, such as those used during the green revolution, similarly, it is argued is being compounded by biotechnology. New generations of genetically engineered agricultural products will, it is argued by some (see for example Shiva, 1991), replace the rich species diversity found in many parts of the world with the new super strains,

I See for example the articles by Mestel (1994) and Kidd and Dvorak (1994), the latter arguing that the patent may not be as controversial as it is being made out to be. 
and in many cases, create new disasters as genetically altered products are released into the environment.

This study aims to examine the potential impact of biotechnology on international growth and trade, looking specifically at the impact of innovation and consumer preferences on product variety. In this chapter, the aims and outline of the thesis are presented.

\subsection{Biotechnology: A Brief History}

Biotechnology, or bioengineering, as its name suggests, straddles a number of scientific disciplines, including molecular biology and chemistry, and involves the engineering of biological material to produce a new product with completely different characteristics. The discovery of the structure of DNA by Watson and Crick in Cambridge, England in 1953, began a race to develop new products and processes based on this important discovery. A series of successes, led eventually to the insertion of a foreign gene in between two ends of DNA, and recombinant DNA (rDNA) or genetic engineering, discovered in 1973, has since formed the basis for modern biotechnology research. Since then, the "new" biotechnology which is the name commonly used for the generation of techniques which followed the gene splicing technique demonstrated by Cohen and Boyer, has enabled radical new changes in both processes and products, within established sectors, both in industrialized and in developing countries.

The success of basic research and discoveries made during the 1950s-1970s, were matched in the 1970s and 1980s by attempts to commercialize new products based on these important discoveries. The first country to make its mark in this endeavour was the USA, where a number of small companies built solely around genetic manipulation technologies and products, were established in the 1970 s and 1980 s. The 1980 s were characterized by heavy investment in biotechnology, as a number of these companies built up cash reserves for their initial investments. This was achieved through a number of methods, beginning with short term investment capital provided by venture capital and then later through public offerings. By the late 1980s however, recession coupled with low levels of product development, led to fewer successes than anticipated. This period also saw the beginning of takeovers and mergers between small biotech companies and the large pharmaceutical and chemical giants (US OTA, 1991). The first and largest of these companies, established solely for biotechnology research, Genentech, became one of the earlier examples of this in a much

2 In fact the Nobel prize for Chemistry in 1993 was awarded to two Chemists for their work on the genetic modification of DNA. K. Mullis developed the technique of Polymerase Chain Reaction (PCR) which has subsequently been used in gene sequencing and gene cloning research while $\mathbf{M}$. Smith's work on changing the structure of an amino acid is being used by biotechnologists working on human diseases to insert altered genes into organisms (Economic Times (N. Delhi), 30 October 1993. Similarly, the work done by Watson and Crick in the early 1950 s was done at the Department of Physics at Cambridge. 
publicised merger with Hoffman LaRoche, the pharmaceutical giant in $1990^{3}$. Two reasons are usually given for this rise in alliances between small, specialized companies and the large multinationals: first, the large companies had by now come to recognize the potential of biotechnology R\&D in medical technologies and second, the small companies came to realize that their skills really lay in research and that they could not compete with the extensive product development and marketing networks of the large multinational companies. Thus, the mergers and takeovers were the result of both groups of companies realizing and exploiting each others' complementary skills in biotechnology (US OTA 1991).

Elsewhere, especially in Europe and Japan, the 1980s saw the beginnings of strong pressure from governments to encourage both basic research as well as applied research, especially through public-private collaboration. In Europe, Germany quickly established itself as the strongest in biotechnology, while in Asia, Japan lagged only slightly behind. This is evident from patent statistics, used as a proxy measure for innovation and which are discussed below in Chapter $3^{4}$. Developing countries, with the exception of the NICs in east Asia were less successful, struggling not only with the technology gap that had developed, but also with imperfect or no capital markets and low levels of government funding (the experiences of the NICs and of other developing countries are discussed in more detail in Chapter 4 below). A severe shortage of trained personnel who would lead the new biotechnology sectors was another problem and much government effort has gone into funding for basic training and research. The private sector in developing countries however, is now responding to the economic incentives which most developing country governments provide, and is investing in biotechnology research and development of varying degrees of sophistication.

A chronology of events is given in table 1.1. below which provides the reader with a quick overview of the major developments in biotechnology during the last two decades. As is evident, it has not been an easy process, slow at times, with a spurt of growth and a flurry of activities coming in the 1980s. This was largely due to the excitement generated by the first new biotechnology patent, and the granting of the Cohen-Boyer process patent for their genetic engineering technique. These major landmarks, not only gave the green light to biotechnology companies, but also encouraged governments in industrialized and in developing countries to establish policy guidelines, both to encourage investment and R\&D in biotechnology, and also to regulate its environmental and economic effects.

The table also shows that activities in biotechnology appeared to have slowed down considerably since the late 1980 s, especially in industrialized countries, where a realization of the long time lag between investment in R\&D and profits from commercialization, has slowed investment in biotechnology firms. This last point is better demonstrated in table 1.2 below, where the figures on R\&D investment and net income show that biotechnology companies are still making a net loss despite increasing sales because their investment in $\mathrm{R} \& \mathrm{D}$ is still higher. This is despite the fact that product sales rose $20 \%$ in 1992 , implying

${ }^{3}$ Although fears were initially expressed about the disappearance of these small companies, it is evident, as discussed later, that this has not been as disadvantageous for the small company as earlier predicted.

4 See also Sharp (1985) for details on the German programme. 
that sales have to rise by a great deal more in order for companies to recover their initial and annual investment in R\&D.

\section{Table 1.1. Landmarks in the development of Biotechnology}

Watson and Crick discover the double helix structure of DNA

Nirenberg and Khorana decipher the genetic code

Founding of Cetus

General Electric apply for the Chakrabarty patent (see 1980 below)

Cohen and Boyer demonstrate the splicing of rDNA

Kohler and Millstein produce monoclonal antibodies using hybridoma technology

First firm to exploit rDNA technology, Genentech, formed in the US

Diamond vs Chakrabarty. First micro-organism patent granted in the US. Cohen-Boyer process patent granted. Spinks Report published in the UK. Germany's Biotechnology Plan (Leistungsplan) published. Genentech goes public.

First monoclonal antibody (MABs) diagnostic kits approved in the US. MITI in Japan declares 1981 to be "The Year of Biotechnology". Cetus goes public. Celltech established in the UK.

First rDNA animal vaccine (for colibacillosis) approved in Europe and first rDNA pharmaceutical product (human insulin) approved in US and UK. Taiwan declares biotechnology one of eight priority areas.

First time a plant gene is inserted in a plant of a different species. Thailand establishes the National Centre for Genetic Engineering and Biotechnology within the Ministry of Science and Technology. Government forms National Biotechnology Committee

Korea establishes the Genetic Engineering Centre.

India forms the Department of Biotechnology within the Department of Science and Technology to introduce new biotechnology in India. China also launches its biotechnology programme.

US NIH establishes the Human Genome Programme. First US patent granted for a living animal, a transgenic mouse. 
Bioremediation used in the Exxon Valdez oil spill. First US biotechnology firm (Gen-Probe) bought by a foreign company (Chugai Pharmaceuticals of Japan). Kenya makes life forms patentable under its Industrial Property Act provided they do not compromise principles of environmental conservation.

FDA approves first bioengineered food additive (renin used to produce cheese). Federal Republic of Germany introduces Gene Law to regulate biotechnology. Hoffman LaRoche declares its majority holding intent in Genentech.

1991 The Philippines establishes a programme on Biotechnology. A Kenyan outline for a a National Biotechnology Programme is drafted. India establishes the Biotech Consortium India Limited (BCIL), a cooperative venture between the government and private sector to stimulate cooperative research and development. Mexico passes its new patent law which some argue is even stronger than the US law and allows patenting of genetically engineered plants and animals. UPOV is altered, removing the "breeders exemption" clause. Merck signs agreement with the Instituto Nacional de Biodiversidad (INBio) in Costa Rica to obtain 1000 biological samples from Costa Rica in return for a promise of a share of the royalties from any patent granted to a product based on any of those samples provided by Costa Rica.

1992 The US refuses to sign the Biodiversity Convention in the UNCED meeting in Rio de Janeiro on the grounds that it would restrict US companies from doing their research. James Watson resigns as head of the Human Genome Project over a controversy regarding patent applications for DNA fragments identified by the project. FDA announces that henceforth no new testing will be required of genetically engineered foods. A Bioservice Unit set up to stimulate private sector activity in Thailand. The EPO patents the first genetically engineered mouse in Europes.

1993

US Biopharmaceutical firms record a slump in sales. Only 14 Biopharmaceutical companies make profits despite the recovery in the US economy.

5 Although genetically engineered plant and animal varieties are not patentable according to the EPO's rules, in this case, the mice were granted a patent because "the benefits to mankind outweighed the suffering of the mice" (van Wijk et.al. (1994), p 5). 
The NIH withdraws all patent applications for DNA identified by the genome project. Agrecetus is granted a patent which will henceforth give it rights over all future improvements made to the cotton plant. Hoffman LaRoche takeover of Syntex, a biotechnology company based in the USA. The use of Bovine Somatotropin (BST), a growth hormone, is approved for use on dairy cattle to increase yields in the USA. Genetically engineered food goes on sale in UK supermarket, the first in a European country. The US approves Calgene's genetically engineered tomato. US companies pick up again as the public's confidence grows in them, boosted by an increase in strategic alliances especially with large firms. The GATT accord on intellectual property rights agrees that countries should extend patent protection to a number of biotechnology related sectors and that the period of protection should be increased to 20 years. Some exceptions are provided for developing countries, especially those which are least developed. Taiwan changes its patent law to comply with this ruling in December.

Source: Compiled from Orsenigo 1989, US OTA 1991, Various issues of the Biotechnology and Development Monitor, Bio/Technology and own research (see Acharya and Mugabe (1995a), Acharya, (1993a) and also Chapter 4 below).

Table 1.2. Revenues and R\&D Investment (Biotech Industry \$ billions)

\begin{tabular}{|l|l|l|l|}
\hline & 1991 & 1992 & 1993 \\
\hline Product sales/revenues & $\$ 6.3$ & $\$ 8.3$ & $\$ 10.0$ \\
\hline R\&D expenditure & $\$ 4.4$ & $\$ 5.0$ & $\$ 5.7$ \\
\hline Net income (loss) & $(\$ 2.6)$ & $(\$ 3.4)$ & $(\$ 3.6)$ \\
\hline
\end{tabular}

Source: Taken from Emst and Young (1994), pp VIII and Ernst and Young (1993).

Governments are also facing a period of extensive debate, especially with respect to changing intellectual property environments and the need for achieving that fine balance which is required to enable the biotechnology industries to develop new products, without causing extensive damage to the environment through genetic testing.

It has been argued in various issues of Bio/Technology, during 1994, (see also the industry surveys by Ernst and Young (1993 and 1994)), that the 1990s, after an initial slump, will gradually see the stabilizing of biotechnology activities especially in the private sector. This is based on an increasing number of products entering the market, which will enable 
innovators to recover some of their initial investments, as well as a growing number of companies which are recording annual profits, rather than the losses of the previous decades, although the industry average was still negative as table 1.2. shows.

Rather than the extreme swings characterized by the 1980 s, a recognition of the very real problems and prospects associated with biotechnology, coupled with consumers who are better informed about the dangers and potentials of genetically engineered products appears to bode a period of consolidation and greater stability in biotechnology based sectors. Again, from table 1.1. one gets an idea that industrialized and to some extent developing countries are seeing a realisation of some of their research investment, as is evident from activities of the early 1990s which are related to commercialization rather than policy, perhaps a signal that the technology appears to be slowly coming of age.

Indeed, recent surveys of biotechnology, especially in industrialized countries (Ernst and Young, (1993) and (1994) for example), show that a number of changes have taken place since the 1970s and 1980s. While the 1970 s were an exciting time for researchers in biotechnology with a number of new and key discoveries being made, the 1980s were turbulent times for the new companies which had to survive in the face of heavy investments and low returns. In the 1990 s in contrast, an increasing number of strategic alliances especially arrangements between small biotech companies and large pharmaceutical and chemical multinationals for product development and marketing, have lent some stability to the industry. It has ensured the survival of the small companies, and especially with an increasing number of products being approved and being released on to the market, they now have an opportunity to recover their initial investments. Thus just as the 1970 s were a period of new discoveries in biotechnology and the 1980s of the small biotechnology firm, the 1990s appear to be a period of consolidation for the small biotechnology companies and also for the large companies. The period has been marked by an increasing number of strategic alliances, for R\&D, product development and marketing. A recent survey of small and large companies estimates that the cost of production in the smaller companies is still much lower (Ernst and Young, 1994), providing an advantage to the specialized biotechnology companies. However, the advantage of size and scale of operations (see appendix I below for a comparison of annual sales figures for small biotech companies and the multinationals), still gives the large company an edge in developing and distributing the final product. Thus, both groups of firms have come to rely on one another and the strategic alliances are an indication of the increasing interdependency between the small, specialized firm and the large, well-established multinational company.

This therefore, is the record of biotechnology thus far. There have been many problems on the way, and considerable obstacles still remain. For developing countries, the shortage of skilled labour, capital and a tendency for the public and private sectors to not talk to one another is hampering the further development of this technology. In industrialized countries, although these problems are not as severe, regulation, especially with respect to new agricultural products, is becoming a problem. The advanced nature of their capabilities has enabled companies in industrialized countries to produce genetically engineered products, which have to be tested before they can be released for public consumption. The testing however, has to be carried out under controlled conditions, so as to ensure public and environmental safety. For agricultural products, which have to be tested in the field, this is especially difficult and countries such as Germany have strict restrictions on this type of 
testing. Regulation will therefore be the next hurdle for industrialized countries and there are some indications that the EC is considering a loosening of restrictions, especially as many more agricultural products are developed, and competition from other regions, notably North America, increases.

What is it about biotechnology that has prompted such a quick response from governments and later from private companies? Why have huge sums of money been invested in a technology, where the results at present are small? Evidence shows that as early as 1983, when there were only about 600 firms in existence, by going public over US $\$ 500$ million was raised in the US public market alone ${ }^{6}$. By the early 1990 s the size of money raised publicly in the US had gone up to more than US $\$ 4$ billion while the number of companies had increased to 1,231 (Ernst and Young, 1993). This is despite the fact that the first drug produced from recombinant technologies. only became available in 1982 and there was to be a long gap before the next product was approved by the USDA in $1985^{7}$. Yet another question which arises is the potential impact of biotechnology on consumer and international welfare.

In this study. we look at the implications that biotechnology may have for economic growth, both in industrialized and developing countries. Its science based nature, presents enormous potentials for a wide range of countries, with different levels of technological capabilities. Not only does this new technology present the prospect of higher quality products, such as vaccines to prevent the occurrence of life-threatening diseases and drugs to treat widespread diseases such as cancer and AIDS, but it may potentially improve consumer welfare by increasing both the total quantity and the variety of products available. Such implications for increasing quality and increasing and decreasing variety of products form a major theme of this thesis and additionally the rationale for the structure of the model developed below.

In the next section, these questions of changing quality and variety of products produced and chosen by consumers are examined in more detail. First we look at debate on older technologies relating to agriculture, such as plant breeding and the green revolution technologies, and the literature on risk spreading by farmers and the impact on product variety; the second way in which the new biotechnologies can be related to increasing or declining variety is in the argument that the exploitation of genetic material by biotechnologists has a negative impact on the variety of biological diversity; finally, we look specifically at consumer preferences in biotechnology and their implications for the quality and variety of products preferred by consumers in different sectors.

Based on this analysis, section 1.3 presents methodologies, examining more closely such linkages between quantity, quality and variety especially as they relate to innovation in biotechnology. Two basic questions form the background to the methodological section: One is whether there is any evidence that modern biotechnology techniques and innovations are, or will, by increasing quality, also increase the total variety of products (old and new together), available to consumers. The second issue is that of the treatment of technological

\footnotetext{
${ }^{6}$ US OTA (1991), p. 4.
}

7 The table on page 77 of US OTA (1991) furthermore, shows that most of the 15 or so drugs that became available by 1991 , were only approved in the late 1980 s and early 1990 s. 
change in the theoretical literature, especially in its treatment of issues of product development. Each will be examined in turn in section 1.2, which as mentioned above presents the arguments, and 1.3 below which develops methodologies based on these arguments.

\subsection{Quality and Variety: Three Problems}

The question we are ultimately interested in examining, is that of consumer welfare and the improvements that new technologies, in this case biotechnology, can bring to consumer choice and to their consumption bundle. It was argued above that biotechnology introduces both quality improvements as well as differentiated products of the same quality into the market. However, the impact on consumer welfare is not immediately apparent because we do not know whether consumers will prefer a greater variety of products, or if a preference for higher quality products will always drive older qualities out of the market. In the literature on economic growth, there are a number of ways in which innovation and the impact on consumer preferences and welfare has been modelled. In this section, we discuss the manner in which the issue of consumer preferences and consumer choice are modelled and how this relates to the emerging relationships between quality and variety in biotechnology based innovations.

One way to model increasing variety or quality, as a number of the new growth and trade models have done, is through consumer preferences. Before the new growth models, consumer utility was modelled in such a way that consumers maximized their utility by consuming the maximum amount of a particular good or goods, given a budget constraint. Thus the larger the number of goods consumed, the higher is the consumer's utility. In the new variety based models, consumer utility (as modelled in the Spence-Dixit-Stiglitz manner), is maximized by consuming a maximum of differentiated products. Consumer choice, the way in which it is modelled here, ensures that the new varieties produced will always be added to the consumer bundle and will not replace other varieties (see for example, Grossman and Helpman 1991d). Consumers will therefore choose to buy all varieties, rather than preferring larger quantities of one variety over another. Thus, at all times, there are a number of differentiated products being supplied and demanded in the economy. In contrast, in the quality based models, consumer utility is maximized by consuming the highest price adjusted quality. Preference for the highest quality good, rather than a variety of goods, ensures that the consumer will choose the highest quality good as soon as it is produced and becomes available to the consumer. Demand in these quality models therefore immediately shifts to the new product, resulting only in the highest quality remaining in the market (see Aghion and Howitt, 1992, Grossman and Helpman 1991a, b and c). Older goods, i.e., those which are of a lower quality are immediately rejected and dropped from the consumer choice bundle.

The Flam and Helpman (1987), and Young (1991, 1993) models include income distribution to show that different budget constraints can lead to a number of different qualities being demanded at the same time. Here, rather than higher quality pushing out older products, or the production of horizontally differentiated goods simply adding to total variety, variety can either remain constant as in Flam and Helpman (1987) where higher quality goods always replace the same range of older products, as is also the case in Young (1993), or the 
production of higher quality goods results in an increasing range of varieties chosen by consumers as in Young (1991).

In biotechnology, the availability of higher qualities has resulted in an increase in demand for these products. In agriculture, the forerunner of biotechnology, the green revolution in the 1960s and 1970s, was successful largely because of farmers' choices with respect to high yielding varieties. Similarly, in pharmaceuticals, consumer utility will be maximized with higher quality medical products. This is already evident from a number of new products such as Tissue Plasminogen Activator (tPA), which is being used with great success to dissolve blood clots in heart attack patients. Another example is a vaccine for hepatitis $B$ and $C$ which afflict millions around the world and drugs to treat Acquired Immune Deficiency Syndrome (AIDS) related illnesses. Thus both the quality of goods as well as the variety of goods available to the consumer is increasing as a result of biotechnology.

In the next section, we examine the manner by which biotechnology has an impact on quality and variety, by looking at three specific problems, which also explain the impact of biotechnology on quality and variety in general. As the crux of the problem is how innovation in the form of higher quality and variety affects consumer welfare, the emphasis in each section will lie on consumer preferences and consumer choice for either higher quality and/or greater variety.

\subsubsection{Non Genetically Engineered Biotechnologies and Risk}

The use of biotechnology to introduce improved qualities of plants and animals into the environment has led to a controversial debate on the impact on the variety of products chosen by farmers. While the green revolution, at the time, created revolutionary new high yielding varieties, their introduction by farmers, led to the displacement of many traditional varieties. In some cases these were preserved in gene banks, but many were lost. The farmer's choice of higher quality products is often tempered by a number of other factors associated with agriculture, most notably risk. Agriculture, because it is subject to the vagaries of the weather is usually risk prone. The farmer, if he/she is risk averse will tend not to choose and plant only one variety, in this case the highest quality available, but will prefer to spread risk by planting a variety of different qualities. The risk loving farmer on the other hand, will choose the highest quality and his/her preference for variety will be low. In this way, the farmer's choice behaviour drives the displacement of older varieties, displacement occurring or not occurring depending upon the degree of risk averseness of the farmer as well as a number of other issues such as access to capital.

The theoretical literature (Ziesemer 1987, Ch.8, Newberry 1975, Bardhan, 1977 among others; for a further debate on the impact of adoption of new technologies on different groups of farmers, the reader is referred to Bhaduri, 1973, Ghosh and Saith, 1976, Newberry 1975 and more recently, Hayami and Ruttan, 1991) describes four types of agricultural systems which are generally used to classify agricultural activities and societies in the literature: sharecropping, fixed rental tenancy, wage labour and the independent family farm. In the latter case, under the assumption off decreasing absolute and increasing relative risk aversion, each type of farmer faces different degrees of climatic risk and moral hazard. With the introduction of technologies which increase the variance of output and the expected value of 
that output, a smaller portion of land is used for the new product, the greater the size of the farm. In addition, with credit restrictions, the closer the farmer is to the subsistence minimum, the greater his/her risk aversion and the less likely he/she will be to apply a new technique if it may reduce standards of living further. In fact, in the extreme, a high degree of risk aversion combined with credit restrictions may prevent technical change from leading to economic growth because the capital market fails to offer perfect insurance against a bad harvest.

Empirical analysis (Shiva, 1991, Juma, 1989), shows that different rates of adoption, although they occur, are not as extreme as shown to be possible in the theoretical literature. The introduction of high-response varieties during the green revolution did achieve their aim of increasing per capita agricultural output in a number of developing countries, but at the expense of variety. It has also been argued that the need of these varieties for fertilizer reduced variety in the crops grown. The introduction of high response varieties of wheat and rice displaced traditional varieties, creating vast areas of monoculture in many countries. This tendency toward monoculture they argue, is being aggravated by the introduction of biotechnologically developed crops which largely ignore locally adapted strains or the advantages of local planting techniques which are partial to maintaining diversity rather than increasing productivity ${ }^{8}$.

It is however, not clear from the studies which have been done about the impact of the green revolution, what the dominant tenancy system is in the regions being studied. As discussed above, this is an important determining factor in the relative and absolute risks depending upon farm size and therefore an important determining factor, according to the theoretical literature, of the impact on variety. This is discussed further in Chapter 5 below.

The tradeoff between variety and quality is also evident from discussions on traditional and modern agricultural systems. It has been estimated that local communities maintain a much higher degree of genetic variety in the crops they cultivate, than commercial agriculture, which relies on a much narrower genetic base, utilising only a few modern varieties ${ }^{9}$ with an infrastructure of seed companies and transport that have larger "reserve" variety. The isolation of characteristics which are beneficial, such as disease and pest resistance, response to climate and higher productivity, although ultimately beneficial for international consumer welfare, is the further cause of reduced genetic variety. There are several examples of entire species being lost as a result of monoculture in planting as well as the uniform characteristics of the plants replacing them ${ }^{10}$. The result is a loss of biological species and diversity, and although there is an international effort to preserve older species ex situ, in gene banks, there is some evidence to show that this is not proving to be sufficient. Another problem is a lack of sufficient documentation of wild varieties, especially those found in developing countries. The funds to support this effort are lacking and more funding is being provided now to accelerate this documentation process through activities such as biodiversity prospecting (see the section 1.2.2. below), it is not at all clear that the effort will be sufficient to match the pace of the loss of biodiversity.

8 UNEP (1990), p 6.

9 Grain (1990), p 3 .

10 Juma, C. (1989), pp 100-103. 


\subsubsection{Biotechnology and Biodiversity: The Loss of Resource Variety ${ }^{11}$}

Another area where the link between improved quality through biotechnology and decreased variety is becoming increasingly apparent, is in the impact of biotechnology on biological diversity. Biological diversity is defined as "the totality of genes, species and ecosystem in a region ${ }^{12}$. Biodiversity is usually divided into a hierarchical structure, comprising three parts: Genetic diversity, which includes variations of genes within one particular species; the second level consists of species diversity, which refers to the variety of species contained in a particular region. This is what is usually referred to in discussions about monoculture reducing variety, as older varieties die out, or are replaced by the new varieties; finally, ecosystem diversity, refers to a region or community which is contained within a particular ecosystem ${ }^{13}$. Farmers and plant breeders have relied for centuries on local varieties found in the wild to develop and cultivate domestic varieties that are consumed today. Similarly, in pharmaceuticals, it is estimated that over 5,000 species form the basis of Chinese traditional medicine, and 2,000 species have been used by Amazonian populations for medicinal purposes, while in modern medicine, more than 3,000 antibiotics alone, including penicillin and tetracycline, are derived from microorganisms ${ }^{14}$.

Thus biotechnology can actually increase the world's biological diversity by creating new species of plants and animals. The tradeoff for farmers between expected value of the high quality and the risk of losing the entire crop and investment, will determine whether they will choose for greater variety in their fields or for higher quality.

With respect to centres of biodiversity, or those areas which are rich in a wide variety of species, such as the tropical forests, however, a misuse of biological resources and environmental pollution has resulted in the destruction of large numbers of ecosystems. The signing of the biodiversity convention in 1992 by over 150 countries signalled an international recognition of this problem.

The convention accepts that genetic resources are rapidly being depleted (UNEP, 1992). Some of this is caused by growing human populations, as has been observed in the Amazon region in recent years, where the clearing of tropical forests for mining and farming have been a major cause of destruction. However, a much larger cause is the increasing degree of Biodiversity Prospecting, which is the search for previously unknown plant species

11 This section uses material from: Acharya, R. (1992a), "Intellectual Property, Biotechnology and Trade: The Impact of the Unuguay Round on Biodiversity" Biopolicy International, No. 4 (Nairobi: ACTS Press); Acharya, R. (1991), "Patenting of Biotechnology: GATT and the Erosion of the World's Biodiversity" Joumal of World Trade Vol. 25, No. 6, pp 71-88 and Acharya, R. (1994c), "Biodiversity Prospecting: Prospects for Private Sector Participation in the Asia-Pacific", paper presented to the Regional Conference on Biodiversity Conservation, organized by the Asian Development Bank in Manila, June 6-8 1994.

12 WR1, IUCN and UNEP (1992), p.2.

13 Ibid, p. 2.

14

Ibid, p. 4. 
in areas of rich genetic diversity for biotechnology research. Increasing interest in this activity is evident from the number of bioprospecting agreements and companies which have been formed in the last decade or $\mathrm{so}^{15}$. Except in those cases, where systematic documentation and preservation of these species is carried out, the possible result of prospecting activities is the loss of genetic and species diversity in the long run. Until now, prospecting has largely been carried out by a small number of multinationals, who are involved in new drug discovery related research. Their requirements in terms of the total volume of raw material is therefore relatively limited. Given that these activities have been carried out for many decades both by private companies as well as by public institutions such as Kew Gardens and other public sector research institutions, the magnitude of collection does not appear to have significantly harmed biological diversity thus far. However, if new interest in prospecting activity results in a race to extract more from available varieties, then these activities will pose a real danger to species diversity. There are two ways in which this could occur: first, as discussed above, if extraction and the collection of samples exceeds the rate of regeneration of wild varieties, resulting in a smaller base from which to regenerate vareities; and second, if the race to discover new drugs results in private deals being made between local institutions and multinationals, guaranteeing the private company some degree of exclusive access to the resources and the information collected, such as that between Merck and InBio, discussed in greater detail below, which may increasingly result in a privatization of knowledge based on these resources, and also a privatization of these resources themselves. Biotechnology thus may find itself in the peculiar position of being both beneficiary and potential destroyer of these resources.

Whether biotechnology increases or decreases the world's biological diversity depends upon two factors:

1. The first relates to access to biological resources and the ongoing debate on the privatization of the global commons. Genetic resources, it has been argued, form part of a common heritage and therefore, all nations and peoples should have access to these natural resources. Developing countries, where most of the centres of biodiversity are located, have argued, that unless they receive compensation for the use of their natural resources, these resources will no longer be available for biotechnologists or plant and animal breeders. Some countries have tried to halt the outflow of germplasm by making the export of some of these resources illegal (Reid et.al., 1993). However, the cost of monitoring their outflow has been much higher than the immediate benefits and many countries are unable to enforce their regulations. Thus biotechnology based industries may, in the long run, be destroying their research base if the rate of destruction of biological diversity continues at its present rate. The eventual losers may be the biotechnology research sector and all production sectors affected by it, which in tum will eventually affect consumers, whose potential move to a higher utility curve from consuming higher qualities and larger variety, will be halted in the long run. In the extreme case, it could be conceivable that improved quality will reduce variety which in turn will reduce quality. Unless gene banks are able to compensate for this loss, the end result will be a loss in both quality and in variety in the long run. 
2. The viability of ex situ conservation for example gene banks. The expansion of biotechnology research is increasing demand for biological materials. Some of this material has been preserved ex situ in gene banks around the world. However, the viability of the "banked" material and hence the method itself, is being questioned. In 1991, representatives of 13 national germplasm banks in Latin America reported losses of between 5 and 100 percent in batches of maize seed collected between 1940 and 1980 is no longer usable ${ }^{16}$. If this indicates a long term trend in maize seed banks, rates closer to the 100 percent level especially would imply catastrophic consequences for variety in species of maize.

There are normally three types of collections held by gene banks: working collections, which are normally kept in airconditioned surroundings for a period of one year, and are used primarily for annual breeding purposes. The medium term collections, can be kept between $\mathbf{0}$ degrees celsius and $\mathbf{- 5}$ degrees celsius and are normally dried first. The low temperatures ensure viability of the genetic material for a period of $10-20$ years usually. Finally, the base collections are dried and stored in aluminium foil in temperatures between -10 and -20 degrees celsius. Viability tests have to be carried out every so often to ensure that the genetic information is still intact. The tests which basically involve germination of a sample of the accession, require that for viability, at least 85 percent of the sample tested should germinate. Otherwise, there is a danger of genetic information being $\operatorname{lost}^{17}$.

While gene banks, if they can be made viable, may provide the answer in the long run, resources in the world are dwindling as they are being removed from their natural habitats faster than they are able to replenish themselves. The estimated increase is even greater, despite attempts of late to reduce this rate. In areas of rich biodiversity such as the tropical forests, it has been estimated that between 5 and 10 percent of species native to these ecosystems may disappear within the next 30 years. Furthermore, scientists have estimated that almost one fourth of the world's plant species will become extinct in the next three decades unless the rate of deforestation declines considerably ${ }^{18}$.

While the first has a potential to reduce biological and genetic variety if they are depleted through excessive use by biotechnologists, the second, if some of the problems highlighted above can be avoided or reduced, can contribute to ensuring that genetic diversity does not decline.

Biotechnology can actually help in increasing variety both in situ as well as ex situ: 1. Conservation ${ }^{19}$. Biotechnology has the potential to increase rates of regeneration of forest and biomass cover. In light of the recent concerns which have arisen over climate change and environmental damage, this is an important resource and there are also a number of private companies doing $R \& D$ in this area.

16 WRI, IUCN and UNEP (1992), p 11.

17 Mugabe, J. (1994), p 198.

18 Ibid, p 7 .

19 For an analysis of the international effort to increase conservation, please refer to Mugabe (1994), which also presents an analysis of institutional capability in Kenya to preserve both its animal and plant species, many of which are in immediate danger of extinction. 
2. Biodiversity Prospecting as briefly described above, is the actions of researchers or scientists who go into areas of biological diversity specifically seeking out species which may be useful for the development of biotechnology based products and processes, or for future scientific research. While developing countries have recently begun to make a record of their resources, the real impetus has come from private sector investment. The formation of INBio (Instituto Nacional de Biodiversidad) in Costa Rica ${ }^{20}$, which is being funded in part by the pharmaceutical giant Merck, is an example of the above. INBio has used its funding from Merck to hire researchers and maintain a sophisticated data base on information on local species collected by its researchers. In return for the information provided by INBio to Merck on the properties of Costa Rica's natural resources, and its freedom to use those resources for biotechnology research, Merck guarantees INBio a share of all future royalties (which can be viewed as compensation for the privatization of public resources), from any patents granted on products which use resources provided by INBio. In this way, a privatization of natural resources, or a privatization of the global commons, in some ways reminiscent of the enclosure laws in industrial revolution England, may be the only way in which private interests to develop new products based on biological resources, may coincide with global interests to conserve natural resources.

\subsubsection{Consumer Preferences for Quality and Variety}

When discussing the impact of biotechnology on product variety, we turn to evidence from the two most important sectors where biotechnology has had an impact in most countries, namely the agricultural and pharmaceutical sectors.

In agriculture, the different preferences of two kinds of players may lead to somewhat different implications for variety. Firstly, for farmers as discussed above, the demand for new varieties depends on their ability to spread risk. If the fears of conservationists become reality, then the tendency towards monoculture, as they accuse the green revolution of having caused, will be worsened because of biotechnology. On the other hand, if farmers are risk averse, genetic diversity will not necessarily decline and the production of biotechnology based higher qualities will only add to the varieties available to farmers. The crucial issue here is whether or not traditional varieties will be supplied by large seed companies, even though newer varieties are available. If the latter is the case, and old varieties are no longer supplied, and with the additional problem of little or no access to capital markets, the risk averse farmer will be driven out of the market altogether. The reality is probably somewhere in between these two extremes and empirical evidence appears to support this ${ }^{21}$.

A second case, which may result in increasing variety, is that of the development of biotechnology based substitutes which specifically replace traditional agricultural products. New products, produced either through more sophisticated technologies such as genetic engineering, or through using industrial biotechnologies, have the capacity to displace

Reid, W. et al. (1993).

${ }^{21}$ Hayami and Ruttan (1991), Juma (1989b). This point is also reiterated and discussed below in the main body of the thesis. 
homogenous products with a larger variety of new products. Thus in this case, a greater number of varieties are produced, and society has a preference for greater variety.

In the pharmaceutical industry, biotechnology is being used to improve the quality of a number of vaccines and diagnostics, among other medical products. The resulting benefit to consumers is higher utility from higher quality products. The structure of demand and supply in pharmaceuticals however is somewhat different from a number of other sectors. A number of reasons peculiar to the pharmaceutical sector can be attributed to this:

1. Medicines are never bought directly by the consumer or the patient from the producer or the manufacturer. Instead, they are usually sold to doctors, or hospitals or retailers such as chemists $^{22}$. Demand for pharmaceuticals can therefore be expected to combine quality and variety, as hospitals have to maintain a supply of all major drugs which can be supplied to patients, even those with a lower quality. In fact, both horizontal variety, as in brand names and like products, as well as vertical quality improvements, may increase in the long run.

2. Another argument for a preference for increasing variety is the variety of illnesses or different strains of the same illness which prevail among patients. In many cases, a combination of different medicines are prescribed for the same illness to different patients because of differences such as allergic reactions to particular medicines.

For these reasons therefore, a social planner or a doctor will always ensure that a sufficient variety of medicines or treatments are available for use. Preferences will therefore always be for increasing variety in this case.

This may however not be the case with the entire pharmaceutical sector. Unlike the demand for drugs, rDNA based products such as Somatotropin may have the effect of reducing variety in the same way as in agriculture. Bovine somatotropin (BST) is a growth hormone which has been developed through genetic engineering and is being used in animals, mostly cattle, to increase milk yields. Growth hormones are also being developed to increase the production of meat, especially the proportion of leaner meat. One step beyond this is to genetically alter the animal so that it produces higher levels of the hormone rather than having it administered artificially. The transgenic animals thus produced through the endogenous supply of the growth hormone will result in species which are larger than the original species. The method is also being used to experiment on fish and shellfish. The US OTA (1991), estimates that it will be the end of the century before this method becomes widespread enough to use transgenic livestock as food. As the development stage, where the gene is developed and adapted to individual species, is the most expensive and time consuming, once this hurdle is overcome, the cost of production declines substantially, implying that the use of genetic engineering to develop animals which are larger and leaner will become more widespread. It is likely that farmers, given the substantially higher yielding varieties of animals produced in this way, will switch production from the wider range of older species. to the one species which is higher yielding, in this case, the genetically engineered one. Although this is a somewhat dire prediction, it may not be so unrealistic, given the particular circumstances we face in the long run. In this way, even in pharmaceuticals, the development of genetic engineering may improve quality but may in the process also reduce the total amount of variety available in the world. 
Thus, in general, biotechnology innovations increase productivity or improve quality. Consumer preferences, especially in pharmaceuticals, indicate in general, a demand for increasing variety. In agriculture, the degree of risk averseness of farmers plays an important role in determining demand for variety. As discussed above, this is due to a range of factors including farm size and access to credit markets, as well as risk spreading. We have used in the model developed below in Chapters 8 and 9, the example of the pharmaceutical sector, where the social utility function indicates a preference for increasing variety even though higher quality products continue to be available. This is discussed in greater detail along with the results which have a variety of implications for variety.

To summarize therefore, there are three diverging directions of research or issues which have emerged from the discussion above.

(i) The first, discusses the ways in which risk aversion and moral hazard have played a role in determining farmers' use of higher quality products as opposed to maintaining greater variety.

(ii) the second deals with the impact of biotechnology upon the depletion of natural resources. The latter, is concerned largely with issues of depletion and regulation of resource depletion. The literature on this ${ }^{23}$, deals with the problems of regulation and enforcement of regulation, as it relates to monopolistic and oligopolistic market structures. Although the problem is an interesting one and certainly relevant to the international debate on biotechnology, it is beyond the scope of this thesis, which concentrates more on new growth and trade theories and the impact of technical change on economic growth and technology gaps.

(iii) Finally, we looked at consumer preferences and the role played by these in choosing variety over quality or vice versa. Evidence from pharmaceuticals especially, points to a preference for variety and for quality, implying therefore that increasing quality will just add to the total variety of products, rather than replacing it. This last point will form the background to the thesis. The question especially of how increasing quality may increase or decrease total variety, depending upon consumer preferences will be put with respect to biotechnology R\&D in industrialized and developing countries, and the theoretical literature on growth and trade, and will form the basis of the formal models developed in later chapters below.

We now turn to a discussion of methods upon which the framework of the thesis is based, and which can be used to examine the issues identified in this section, with respect to this thesis.

${ }^{23}$ See for example the textbook by Laffont and Tirole (1993) for a survey of this literature as well as a theoretical discussion of the problems related to the regulation of natural oligopolies in light of imperfections in incentive structures. Mugabe (1994) provides a more empirical discussion of the regulatory problems associated with the conservation of natural resources, especially in developing countries. 


\subsection{Some Methodological Notes}

\subsubsection{Introduction}

In the previous sections we have briefly described some of the developments in biotechnology and the degree of participation by both private and public sectors in developing and industrialized countries in biotechnology R\&D. While biotechnology's major achievement is in raising productivity and quality, thereby increasing utility from the same or new products, considerable controversy exists regarding the impact of biotechnology on the variety of products available to consumers. This was discussed in section 1.2 above. In this section we briefly define the main approach of this study and present reasons for this particular approach.

As already mentioned, biotechnology, whether in the pharmaceutical industry or in agriculture and chemicals, has demonstrated its ability to improve international consumer welfare. This it does either through improving products, increasing the productivity of existing products, such as in agriculture, or by creating new products for previously untreatable diseases and ailments. Another impact is increasing quantity. The production of enzymes such as Bovine somatotrophin (BST), for example, which was recently approved in the USA, can increase the yield of milk, lead to both leaner cows producing more beef per animal and larger fish. The production of recombinant human insulin in the early $1980 \mathrm{~s}$ resulted in a considerable increase in the total supply of insulin, thereby fulfilling the requirements of insulin users. The insertion of similar high yielding genes in plants has resulted in an increase in productivity, as well as an improvement in other characteristics such as disease and climatic resistance.

However, there is some controversy with regard to the impact of biotechnology on variety. A number of researchers have argued that while biotechnology improves quality, it has a tendency to introduce a certain uniformity into these improved products (Mooney 1979, Shiva 1991). The uniformity in turn results in a declining variety or diversity. This point has been made most vehemently with regard to agriculture, where it is argued that a preference for the newest or highest quality will result in farmers planting and harvesting genetically uniform fields, reducing variety in the area.

\subsubsection{Quality and Variety: A Framework for Research}

The central issue in this study is the impact of technical change on consumer utility and welfare, looking specifically at the question of whether technical change and consumer preferences, cause the quality as well as the variety of products to increase rather than decrease, within a dynamic framework.

There are a number of ways in which quality or variety enhancing innovation is modelled in new growth and trade models. Since the main theme of this thesis is the impact of new technologies on consumer welfare and economic growth, examining specifically, the way in which biotechnology improves consumer welfare, in what follows we look at those methods which relate directly to the features we have noted above about biotechnology and its impact on quality and variety and consumer welfare. 
1. Technical change is usually modelled as a shift parameter in the production function, as in the Solow aggregate production function model, or as a quality or variety increasing innovation often modelled as learning, human capital, or as investment in R\&D in a sector devoted to R\&D and knowledge accumulation, as in the new growth models. The source of this technological change in this latter group of models, is presented variously as improvements in the quality of human capital as in Lucas (1988), an increase in R\&D intensity as in Grossman and Helpman (for example, 1991c), or as a result of learning by doing as in Arrow (1962), or Young (1991).

2. Preferences, where some models include a consumer preference function which indicates a preference for the highest quality product at all times, while others model a utility function which indicate that consumers always prefer the largest variety of products, that is, old and new products, they can afford, given their budget constraints. In the former group of models thus, consumers will always prefer higher quality, whereas in the variety functions, consumers will prefer all the varieties available. The love of variety group of models in growth theory for example (Helpman and Krugman, 1985, Ch. 6.2) suggest that utility is increased by the consumption of a greater variety of products. In the quality models of Aghion and Howitt (1992), Grossman and Helpman (1991b and c) and Flam and Helpman (1987) on the other hand, consumer utility is maximized by consuming the highest quality or approaching the ideal variety (Helpman and Krugman, 1985, Ch. 6.3). Thus, as in the Grossman and Helpman models, once a higher quality product is produced, consumer preferences ensure that the old variant is immediately dropped from the demand function. In a slightly different approach, in the Flam and Helpman (1987) model, income distribution ensures that consumers with different incomes demand a different quality, which in turn results in a range of qualities being demanded at each particular time, in contrast to the Grossman and Helpman case.

3. The introduction of endogenous technological change and product differentiation has shifted the emphasis from perfectly competitive market structures to imperfect competition. The introduction of imperfect competition (Helpman and Krugman 1985, for example), changes the traditional results based on perfectly competitive markets considerably. Factor endowments together with the assumption of perfect competition in factor and product markets ensured the existence of a pareto optimal equilibrium based on those initial endowments. The introduction of monopoly profits from innovation, can provide an incentive for R\&D investment, leading to previous varieties being driven out of the market because of creative destruction as in the Aghion and Howitt (1992) model, which is developed further in Grossman and Helpman (1991b and c). By monopolizing the new innovation, perhaps through the granting of a patent, each previous innovator is driven out of the market because his or her monopoly profits are driven down by the new monopoly product. Thus, the expectation of monopoly profits as well as the driving out of previous monopolists, at least until the next innovation is developed, provides the incentive to innovate. The presence of monopolistic markets and the problem of property rights implies that pareto-optimal market equilibrium is no longer guaranteed and policy becomes relevant.

How does biotechnology relate to these arguments? 
With respect to the first, innovation, especially the use of the tools of molecular biology and genetic engineering, will result in the production of goods with a higher quality, or goods which are horizontally differentiated, presenting consumers with a larger range of varieties. Productivity increases in agriculture, will also raise output or quantity, consequently raising consumer utility through the availability of a larger basket of goods, or lower prices. Due to its close dependence on scientific research and training, especially the biological sciences, biotechnology places considerable demands on the skilled labour force in the country. A number of countries have recognized this demand, and more funding is being channelled through to universities and research institutes, both for training and also for specific research projects. R\&D funding for biotechnology research, both private and public has also increased (US OTA, 1991) over the last two decades. In the US especially, the participation of the private sector has been most apparent and the "biotechnology firm" has contributed in a large way to applied biotechnology research. Developing countries have emphasized the need for technology transfer and reverse engineering to learn by doing or by emulation.

In agriculture, developing countries are using techniques which to them are relatively superior, such as tissue culture and in some cases, restriction fragment length polymorphisms (RFLP) mapping, to select hardier plant varieties and to reproduce them, thereby increasing yield levels of the farmer significantly. Research on biopesticides and biofertilizers is also contributing significantly to soil fertility and agricultural yield increases in developing countries.

Agricultural biotechnology in industrialized countries is also a rapidly growing sector. Geneticists and molecular biologists have been successful in recent years in applying genetic engineering methods to develop plants with improved characteristics such as higher yield or adapted to specific climatic requirements, such as ice minus bacteria which are being used to develop plants which are resistant to frost. This method has already been demonstrated successfully in the tobacco plant which grows in the southern United States but has suffered from outbreaks of frost in the last decades which has severely damaged the annual harvest (US OTA, 1991). Thus technological change in the form of biological techniques have created products which are of a higher quality, in the sense of having characteristics which can produce higher quality substitutes and also give the consumer a variety of products to choose from. Both the appearance of higher quality products of this kind as well as having a greater variety of products to choose from, implies higher utility for the consumer. Thus, it is quite evident that technological change in this case will increase productivity, through the production function approach and will also increase quality and possibly variety. We examine these last two aspects in more detail below.

The second category discussed above was preferences, and from the evidence with respect to biotechnology, it is unclear whether increasing quality will have a positive or a negative impact on variety. We therefore look at the sector where the indications are most clear. In industrialized countries, the sector where biotechnology has made its main impact thus far, is the pharmaceutical and medical biotechnology sector. The breakthrough made in the 1950's, when the use of monoclonal antibodies (MABs), was demonstrated, has made major contributions to the detection of diseases and the development of diagnostic kits which are now widely marketed. Genetic engineering or rDNA technology has enabled scientists to produce a number of high quality drugs and vaccines, a number of which are being 
commercially produced, especially in industrialized countries. It appears that in this sector, consumers, in this case doctors, will prefer higher quality products over lower quality ones. However, as discussed above in this chapter, the nature of demand and supply in this sector indicates a consumer preference for higher quality products, but also for variety.

This impact of preferences and technological change on product selection and on variety will be demonstrated in the growth and trade model of Chapters 8 and 9 below in a manner that contains the love of variety (Krugman 1979, Judd 1985, Romer 1990) and highest quality choice (Grossman and Helpman 1991b and c) as special cases, appearing under different circumstances with respect to learning and $R \& D$ cost.

Finally, with respect to imperfect markets, there are two indications that this is becoming increasingly relevant to biotechnology:

(i) Economies of Scale: As any new technology becomes better established, biotechnology being no exception, especially in the pharmaceutical sector in industrialized countries, economies of scale and size of investment capital become more important. It has been pointed out that as technologies become mature, the importance of economies of scale become more important (Nelson and Winter, 1977). With biotechnology, the size of the initial investment and the length of the lag between the initial investment and innovation, has led to the downfall of many a biotechnology company (US OTA, 1991, Bio/Technology, 1994). Initial public offerings of biotechnology companies resulted in significant stock price increases. However, once it became clear that the potential returns were not going to be immediate, this source of funding dried up for many companies. This is also true in the 1990 s where public funds have become greatly reduced, and in order to overcome this, a number of new private sources of funding have appeared, perhaps prompting the formation of a number of new small companies, although many of them tied up with the larger biotechnology companies ${ }^{24}$.

Thus economies of scale and imperfect competition may have become more important for the development of biotechnology, especially in industrialized countries. Only in the USA has the dedicated biotechnology company managed to survive, largely because of imaginative investment options by the private sector, but significantly only the large ones are able to access capital on a regular basis. The number of companies in the US alone numbers around 1300 today. However, most of these are small, recent startupts, with signficant tie-ups to large established companies or to the larger biotechnology companies (Ernst and Young, 1994). A series of takeovers and mergers between these dedicated biotechnology companies and large established multinationals, again especially in the pharmaceutical sector during the 1980 s and 1990s has further demonstrated the degree of consolidation that appears to be taking place in biotechnology. However, as pointed out above, it is not clear whether there is a clear trend toward increasing size. An increasing number of strategic alliances, between

24 Some of the more creative ventures include Stock warrant, off-balance sheet, R\&D financings (SWORDS), which spin off a technology into a new company, which has no employees and Asset and risk deployment option with warrants (ARROW): the company Alza for example, recently contributed $\$ 250$ million to the new company TDC to apply Alza's drug delivery technology to several drugs. By doing this, Alza has transferred all potential risks associated with R\&D expenditure to the new company while maintaining control over its technology and the potential benefits from its application (Ernst and Young, 1994). 
small and large as well as between small firms have also characterised the development of biotechnology in recent years, and although these companies have faced an uphill battle during the late 1980s and early 1990s, there is some evidence that this may be changing ${ }^{25}$.

Thus, there appear to be no clear statistical evidence relating scale to profitability or to rates of innovation. This issue will be examined in greater detail below.

(ii) A second issue is that of an increasing use of patents to earn monopoly profits. Here, the changing role of intellectual property rights are important, both in biotechnology, and also in the new trade and growth literature. The USA was the first country to include biotechnology products and processes within its intellectual property rights regime. Patent protection is not as strong in most other countries but due to a number of recent changes especially in the World Intellectual Property Rights Organization (WIPO) and the General Agreement on Tariffs and Trade (GATT) and a number of agreements relating to biotechnology, as well as pressure from the US, the trend appears to be toward increasing strictness in intellectual property rights applied in bilateral trade relations. Patent protection as modelled in a number of the new growth and trade models, grants monopoly rights to the innovator, provides an incentive for innovation, and leads to Schumpeterian "creative gales of destruction" in the economy. In the north-south models however (Krugman, 1979, Grossman and Helpman (1991b), in general, a lack of enforcement enables southern countries to imitate. Although, to some degree, this is still relevant to many developing countries, who do not recognize biotechnology patents, this is changing rapidly, as we discuss below. Thus stricter IPRs internationally, imply an increasing degree of monopoly in biotechnology, although an increasing rate of innovation as a result of monopoly protection, would imply increasing entry by firms, thus reducing monopoly.

In the growth and trade model developed in Chapters 8 and 9 below and based on evidence gathered in Chapters 3, 4 and 5, instead of assuming away international patents which allows imitation or pirating, we assume that patents are enforced internationally, and that countries have to license technologies in order to make use of them.

Thus to summarise, technological change through the use of biotechnology will have the following tendencies:

(i) Quality improvements in the form of appearance of new products of a higher quality in the market.

(ii) Preferences for variety, especially from the pharmaceutical and medical sectors, indicate increasing variety and quality of products.

25 Recent articles on the state of the private sector in the US and UK, for example argue that despite the setbacks of the last decade, an increasing number of Biotechnology companies are making public offerings in the US in 1994, while in the UK small biotechnology companies are becoming more successful, especially as strategic alliances enable them to reach a wider range of markets (Bio/Technology, various issues 1994). Similarly, in the US, although public finance has largely dried up and investors have become more discriminating, private sector finance has increased, prompting the formation of a number of small companies. In 1993 for example, approximately three times as many companies were formed as in the previous year (Ernst and Young, 1994). 
(iii) Increasing patenting of biotechnology products and processes implies privatization, as resources are redistributed from public to private property, often at the cost of developing countries.

(iv) Patenting also implies monopoly profits, also strengthening the previous point of increasing privatization of resources.

In the next section, we describe the manner in which these issues will be addressed in the main part of the thesis.

\subsection{Methodology and Outline of the Thesis}

In the previous section we have presented the main approach and rationale of this study: namely examining the issue of quality and variety. Descriptive analyses of biotechnology, some based on older features of technical change (for example the tendency of the green revolution to introduce monoculture in large parts of the third world, thereby reducing the variety of species available), have argued that there is a tendency for modern biotechnology, especially genetic engineering, through its ability to create new species of a higher quality ${ }^{26}$, to cause variety to decline in the longer run. On the other hand, it will become quite clear from the chapters which follow, that biotechnology has the potential to make major contributions to increasing variety and quality. The production of new species for example will add to the genetic diversity of the planet. The use of biotechnology to preserve biological diversity, either in situ or ex situ has also been recognized and a number of techniques such as tissue culture and in vitro methods are being used to improve the quality of material which is conserved. These methods may be able to overcome some of the deficiencies of traditional conservation methods which have been used, with varying success, in the world's gene banks. Thus biotechnology, depending upon its applications may either increase quality and variety by technological means, or, by increasing quality destroying variety for economic reasons. In the later chapter where we develop a model of growth and trade, the tradeoffs between quality and variety will be discussed more explicitly.

The structure of the thesis itself is based on the conclusions we make from the discussion of quality and variety. The main body of the thesis is divided into three broad sections, each examining innovation within the framework of increasing quality and variety.

Part I contains four chapters. Chapter 2 which follows, presents a general overview of biotechnology and development patterns observed during the 1960s, through to the 1990s. A sectoral analysis shows the sectors in which biotechnology has made its mark thus far and sectors which are expected to benefit in the future.

The third and fourth chapters look in greater detail at the development of biotechnology, first in industrialized and then in developing countries. We argue that both the government and the private sector have played important, if different roles, in this development. A closer examination of this nature reveals characteristics that may have been

${ }^{26}$ The term quality used in this instance is a broad term which may also include other kinds of technological improvements such as productivity improvements which are cost reducing etc. 
instrumental for the early establishment and successes of biotechnology, for example, the much talked about phenomenon of private-public cooperation, or the emergence of the small, specialised biotechnology firm in the USA. In developing countries on the other hand, the government was crucial in encouraging public sector scientific research of a pre-competitive nature at a relatively early stage. The lack of an environment which would encourage private sector investment in this risky technology, has probably meant that the role of the government was much more instrumental in developing than in industrialized countries.

The objective of Part I, is however, also to examine the nature of innovation in the different environments of developing and industrialized countries. An analysis of patent statistics granted in the US and the European Patent Office, for a number of industrialized countries, provides a preliminary analysis of the rates of invention in biotechnology and the implications for sectoral development. In developing countries, patent statistics are not as relevant, as many developing countries do not grant or recognize patents for biotechnology inventions. In this case, productivity increases especially in agriculture, are the only currently available measure of biotechnology innovations. Recent field testing data on an agricultural crop in India was used as a proxy to calculate time trends and productivity increases in this particular crop.

Chapter 5, the concluding chapter in Part One, discusses the impact of biotechnology based quality and productivity improving innovations on older qualities and varieties. In specific, we ask whether innovations, either based on higher quality or on productivity, increase or decrease the total variety of products (old and new together) in the economy.

Part II examines the theoretical literature on economic growth and international trade. Once again, the theme of quality and variety is used to examine the implications of innovation on economic growth. We look at the new growth and trade models with respect to this analysis. The literature reveals preferences of three kinds which are relevant to our framework: the traditional utility function in which consumer utility is maximized through the consumption of a larger quantity of goods, in contrast to the more recent models, known as the "new" growth and trade models, which are characterized by consumer preferences where utility is increased through the consumption of a greater variety of products (or love-of-variety functions)(Romer 1990, Grossman and Helpman 1990b, 1989a) or by increased quality (or ideal variety functions)(Grossman and Helpman, 1991b and c. Flam and Helpman 1987, Aghion and Howitt, 1992). In Chapter 6, we examine each in turn, and their implications for quality and variety, which we relate to the economic growth and trade model which follows in Part III. Chapter 7 looks more explicitly at the issues of quality and variety in biotechnology, expanding upon some of the issues discussed in section 1.2.3. of this chapter.

Part III contains three Chapters, drawing together the structure of biotechnology R\&D and the treatment of quality and variety in the theoretical literature, first in a closed economy growth model which is discussed in Chapters 8 and subsequently in an open economy trade model presented in Chapter 9. The model itself is an economic growth and trade model, which is very much in the tradition of Judd (1985), Romer (1990) and Grossman and Helpman (see 1991c among others) in that invention takes place first in a R\&D sector and the patented product is then licensed to the differentiated good producer. Observations about consumer preferences in biotechnology are used to justify the use of a "love of variety" utility function combined with the ideal variety approach where the Spence-Dixit-Stiglitz quantity 
function receives quality weights of the Flam and Helpman (1987) type. Consumers therefore prefer greater variety, given the appearance of higher quality innovations in the economy.

Unlike the Grossman and Helpman models and perhaps more in the tradition of recent papers by Flam and Helpman (1987) and Young (1991 and 1993), the appearance of new qualities does not automatically mean the destruction of older varieties. Destruction of all older varieties such as in Grossman and Helpman (1991c) or pure love of variety after reappearance of varieties that had already been selected away are the results of simulations, as special cases after some time periods. In the absence of learning, variety vanishes. In the presence of learning, variety may increase if R\&D is not too expensive. Thus, some of the forces which determine the (non) vanishing of variety are identified by the model-theoretic formulation of the third problem discussed in section 1.2. above, i.e., whether increasing quality adds to or drives out older varieties from the market.

Thus the model adds to the literature in two ways: firstly by including both love of variety and quality improvements, we move closer to empirical observations with regard to consumer choice, and secondly by presenting a range of qualities available for the consumer to choose from at each point in time and where the appearance of new innovations does not immediately result in older varieties disappearing from the market. The difference between this model and the Flam and Helpman (1987) model, is that while in Flam and Helpman the analysis is static and the range of qualities remains the same with the number of old varieties which drop out of the market being equal to the number of new varieties entering the market, in this model we show in a dynamic analysis that the range of varieties present in the market initially remains constant or diverges, but converges in time for some cases.

Finally, the last chapter of Part III and the dissertation, summarizes and discusses the results of the model, making conclusions for biotechnology and growth and draws policy conclusions. 



\section{Part I}

\section{Biotechnology: Some Observations About the \\ Nature of the Technology}

"The time has come," the Walrus said, "To talk of many things: Of Shoes--and ships,--and sealing wax--Of cabbages --and kings--And why the sea is boiling hot--And whether pigs have wings".....L. Carroll 



\section{The Potential of Modern Biotechnologies}

A monkey is a machine that preserves genes up trees, a fish is a machine that preserves genes in the water;...DNA works in mysterious ways"...R. Dawkins

\subsection{Biotechnology: Definitions and Difficulties}

Biotechnology is a melange of scientific techniques which can be applied to alter the composition or genetic structure of an organism. These techniques have been in use for centuries in simple forms such as fermentation to produce cheese, wine and other alcohol and also to preserve foods in many eastern countries. Since the 1970 s however, a number of important scientific breakthroughs have been made, beginning with the development of recombinant DNA technology, when Stanley Cohen of Stanford University and Herbert Boyer of the University of California successfully spliced a foreign gene between the ends of bacterial DNA, ushering in the era of new biotechnology based largely on genetic information and techniques.

New biotechnology has been defined as "the industrial use of recombinant DNA, cell fusion and novel bioprocessing techniques"27. Broader definitions which are used predominantly by developing countries are also available, describing biotechnology as, "the application of scientific and engineering principles to the processing of materials by biological agents to provide goods and services" 28 and as "any technique that uses living organisms (or parts of organisms) to make or modify products, to improve plants or animals, or to develop micro-organisms for specific uses ${ }^{1129}$. In many cases, these broader definitions cover both new and old biotechnologies and are used by developing countries to describe biotechnology in general. In industrialized countries, where the use of advanced genetic engineering techniques is more predominant, the definition of biotechnology tends to be the narrower one. Thus there are often misunderstandings between scientists and policymakers when discussing biotechnology, depending on which definition is used. For our purposes, we shall be using the broader definitions, as these are the ones more relevant to and more widespread in developing countries.

27 US OTA (1991), p 5.

28 OECD (1982), p 21.

29 US OTA (1991), p 5. 
Another difficulty lies in analysing and measuring the impact of biotechnology on economic growth and also the factors that contribute to the growth of biotechnology. The two main indicators that have been used in the past, are R\&D funding, frequently referred to as an "input" indicator and patents which are known as "output" indicators ${ }^{30}$. Attempts to use such measures for analyzing the growth of biotechnology in industrialized countries have also been made ${ }^{31}$. However, there are also a number of problems with using such input and output data to measure rates of innovation.

Using R\&D as an input measure can often result in an underestimation of the size of biotechnology activity because data on the amount of R\&D funding devoted specifically to biotechnology is usually unavailable. Even at the level of the firm, disaggregated data on biotechnology funding is often unavailable. Reasons for this include secrecy, but more importantly, biotechnology is highly interdisciplinary and, because it is not a sector or an industry per se, spending on biotechnology can occur in many sectors and thus is not identified in the national accounts as spending on biotechnology ${ }^{32}$. In the same way, a number of the companies doing biotechnology research today have moved into this technology partly as a result of their previous expertise in a sector where biotechnology has resulted in radical changes. Companies in these sectors, such as those producing pharmaceuticals and products based on fermentation technologies, to give just two examples, do not separate R\&D spending on traditional research from that on biotechnology research. Their R\&D figures therefore, often do not reflect a division between old research and new biotechnology research. Care should therefore be taken in accepting R\&D figures at face value, especially in an interdisciplinary technology such as biotechnology.

Given this difficulty in measuring technological innovation through the use of R\&D data, many researchers have turned to another measure, namely patents. Patents are granted for inventions for a period ranging from 8 to 17 years in developing and industrialized countries respectively ${ }^{33}$. They are regarded as a measure of the output of innovation activity, as opposed to R\&D statistics which measure the input into innovative activity. Patents, since

30 Soete (1980, 1987) and Patel and Pavitt (1987), provide a thorough discussion of the major disadvantages and advantages of the various innovation indicators which can be used.

31 Wheale and McNally (1986) for example, use US patent data both for second generation biotechnologies as well as genetic engineering to examine trends in biotechnology innovations. They also project the number of biotechnology products which would be commercialized by the year 2000 based on market data for a number of research areas. Orsenigo (1989) uses both US patent data to project trends, as well as publications of articles in biotechnology and genetic engineering journals in OECD countries.

32 Sharp (1985) among others have used government spending on R\&D in biotechnology in the OECD, and especially in the US as an estimate of the size of biotechnology research, however, because of the reasons discussed above, this cannot usually be used as an indicator of the size of biotechnology R\&D in individual countries.

${ }^{33}$ The recently concluded Uruguay Round of Multilateral Trade Negotiations in the GATT has however extended the period to 20 years for all member countries, developing and industrialized although many of the former have been given a buffer period during which they can slowly phase in the new period of 20 years. 
they are granted for new inventions often are used as proxy measures for new innovations and therefore measure the rate of technological change in the particular technology or sector.

The need to find a proxy measure for technological change has led a number of economists to study the validity of using this specific indicator. Patents have for example been used as a straightforward proxy for technological change or innovative activity. The work done in this field by Schmookler (for example, 1966) initially tried to use patent statistics as a measure of innovation and discovered that because of the number of patents which are not necessarily worked, it was perhaps more accurate to use them as a measure of inventive activity, i.e., as an input measure.

Another usage was made of patents in the neotechnology hypothesis by Freeman (1963), which measures technology in terms of the temporary monopoly rights given to a product which is patented.

A number of researchers have also related this measure to that of input measures such as R\&D in order to check its significance as a measure of technological change. Intuitively, one would expect a significant relationship between these two measures, as the size of investment in R\&D would influence the number of inventions and hence patents applied for, while the number of patents granted would encourage a firm to invest more in $R \& D$ activities. In their survey, Pakes and Griliches (1984) for example found that there was a strong correlation between patenting activity and R\&D expenditures in general. This confirmed the earlier findings of Schmookler (1966) and Scherer (1984). They have also been used to check the correlation between firm size and inventive or innovative activities (Acs and Audretsch, 1989 and Griliches, 1990 for example). The results show significantly that patents can indeed be used as a fairly good proxy measure for firm activity devoted to invention and technological change. Soete (see for example 1981 and 1987) has also used patents extensively, as a proxy measure for technology gaps and technological change.

The use of output measures such as patents should however be kept in perspective, considering some of the problems one could encounter when using these statistics. This is especially true for modern biotechnologies such as genetic engineering for which patents were not granted at all until relatively recently. The first signs of acceptance that genetically modified organisms could become proprietary knowledge, came in 1980 in the landmark case of Diamond vs Chakrabarty, when the US Supreme Court granted the first patent to a "new" organism. Thus even in industrialized countries, patents granted recombinant DNA based products is relatively new and since it is not retroactive, this could create some discrepancies in using patents to measure technological change. For example, because monoclonal antibodies were never patented, all subsequent innovations based on hybridoma technology have not been granted patents either ${ }^{34}$. Thus in some cases, available patent statistics do not capture the importance of the invention or the appearance of new biotechnology based products.

Another reason is that with very sophisticated biotechnologies, where competition between the large multinational firms is very strong, the companies often tend to resort to trade secrecy rather than patenting ${ }^{35}$. In developing countries a further problem is that the

\footnotetext{
Orsenigo, L. (1989) and Daly, P. (1985).

${ }^{35}$ Orsenigo, L. (1989), p 58
} 
patent system has not as yet incorporated biological technologies, making the use of this measure impossible in their case. We could use the number of patents filed by developing country nationals in industrialized countries, as an indication of technological progress in these countries, however because their own national patent systems do not grant patents for biotechnology innovations, a use of these data for developing countries becomes meaningless when measuring innovation. The use of patent statistics in this thesis (see Chapter 3 below) is thus restricted to those granted to industrialized country nationals.

Despite these potential problems however, the use of patent statistics in the past (see for example, Soete 1981) has demonstrated a significant degree of success in measuring inventive activity in new technologies. Its close correlation with $R \& D$ investment as pointed out above, is also a good indication of its goodness of fit. Thus, although there are some problems with using patent statistics, and these problems should be kept in mind when examining patent statistics, they appear still to be a good measure of inventive activity by companies, both large and small. In Chapter 3 below therefore, we use statistics from the European Patent Office as well as the US Patent Office to examine technological change in biotechnology in industrialized countries. Developing countries in general, as mentioned above, have yet to recognize patents granted to genetically engineered products, and are hence not included in the analysis.

In what follows, we first describe the major, modern and not so modern biotechnologies which are in use today, before moving on to describing major developments in industrialized and in developing countries.

\subsection{The Technology Clusters}

Fransman (1991), describes three broad groups of biotechnologies in use at present:

1. Recombinant DNA ( $\mathrm{rDNA}$ ) which is also broadly referred to as genetic engineering. It has a wide range of applications such as in the pharmaceutical, chemical and food processing industries.

2. Cell fusion, which enables the combining of cells so that their desirable characteristics can be used to produce stronger and more resistant cells. Monoclonal antibodies (MABs) are one such example. MABs are pure antibodies which are produced by fusing antibody producing cells with cancerous cells. The antibodies produced from this fusion are stronger and more robust, with a greater resistance and an ability to multiply continuously. MABs today form the basis of many diagnostic kits which are widely available to diagnose a number of common diseases, both in industrialized countries, but also increasingly, in the advanced developing countries. 
3. Finally, bioprocess technologies allow biological processes to be upscaled into large industrial production. This is an important category given the increasing significance of scale in industrial biotechnology, especially in industrialized countries ${ }^{36}$.

Thus generally defined, modern biotechnology consists of these three groups of technologies. There are also two other kinds of techniques which can be added to this list, namely cell and tissue culture and bioinformatics.

4. Cell and tissue Culture: This technique was first developed in the late $1890 \mathrm{~s}^{37}$. After a century of improvements, the technique is relatively different than when first conceived. It enables the propagation of tissue in vitro, within the controlled environment of a laboratory, in which the tissue or cell can be exposed to the required conditions. The surviving cells adapt to the new environment, and form a callus, from which reproduction and eventual development of the new plant or tissue takes place. A number of different techniques are included within this technological cluster: clonal propagation which involves the asexual multiplication of plant tissue into new plants, somaclonal variation which occurs when callus tissue is regenerated into plants and is useful for selection of specific traits, anther culture where tissue culture is performed from pollen and is therefore much more difficult, and embryo rescue which is especially useful when unlike species are crossed and the likelihood of regeneration as a result is small. In addition, genetic tagging and engineering can also be used to select and introduce desired traits into plant tissue that is then regenerated with the new trait $^{38}$.

The goals of genetic engineering are similar to that of tissue culture, namely improving certain desirable characteristics, such as productivity and disease resistance. However the costs of genetic engineering are still high, requiring skills related to genetic manipulation, as well as sophisticated capital equipment required in the laboratory. The major difference between the two techniques is in the degree of precision. While tissue culture results in the production of plants similar to one another, genetic engineering is much more precise, in that it can produce plants with identical characteristics and replace unwanted characteristics altogether. Due to its highly scientific and costly requirements, genetic engineering is therefore only available to industrialized countries and also a few advanced developing countries.

5. Finally, a new group which is expanding rapidly, is Bioinformatics. As the name suggests, this is the use of information technology in biological screening and identification of genetic structure. The human genome programme is currently benefiting enormously from bioinformatics. The use of robots which use image-processing software to identify spots of DNA suitable for analysis contained on culture plates as well as to pick up the DNA. It is

36 Fransman, 1991, p 19 argues that scale appears to be becoming more important, largely an observation from most older technologies and sectors where scale appears to become more significant as the technology matures. We discuss this is more detail at a later stage in this chapter.

37 Kenney, M. (1986), pp 250-1.

38 Persley, G.J. (1990), pp 32-42 
estimated that this will save years of work in identifying the structure of the human genome $^{39}$. Similarly, the use of biosensors can be extended across sectors including health (monitoring glucose levels for example), pollution control (detecting pollutants in water and air) and industrial processes ${ }^{40}$.

In the next section we describe in turn, the major sectors where biotechnology is making a mark and follow its developments over the last two decades in industrialized and developing countries.

\subsection{The Development of Biotechnology}

The development of biotechnology as a commercial activity especially in the USA appears to have been facilitated by a complex set of interactions between governments, public research and development and regulatory institutions, and private sector entities. We describe these interactions in brief below, before examining the sectoral development and diffusion of this technology.

The pattern of development described below is perhaps more closely related to patterns of innovation in industrialized countries. However, although developing countries have had a somewhat different experience, there are a number of similarities which we explore in the following two chapters.

\section{a] Pure scientific research.}

The first stage in the development of biotechnology as a commercial activity, came mainly from research interests and programmes at universities and research institutions. Those institutions of higher learning which had a strong tradition in the life sciences and also specific medical and biological research, were especially important in developing a trajectory for generic research in new biotechnology in its early stages. The leading discoveries and techniques of the 1950s, 1960s and 1970s were the result of such generic research funding largely by university research programmes ${ }^{41}$.

\section{b] Industry-University Cooperation:}

Following close on the heels of these early successes, private sector recognition of their importance came in the form of research grants to universities and research groups. The 1970s also saw a stagnation in University research budgets which provided an impetus to increasingly look for outside sources of funding as well. Initially started as collaborative research projects between medical institutions and faculties and the pharmaceutical sectors, where the progression from biological technologies was most direct and advanced ${ }^{42}$, they

39 New Scientist (1994), February, p 20.

40 Ernst and Young (1992), p 21.

4i The most extensive study of University-Industry Research arrangements especially in the US during the 1970 s and 1980 s is probably Kenney (1986).

${ }^{42}$ Orsenigo, L. (1989), p. 85. 
soon expanded into a number of other sectors, including agriculture and environmental biotechnologies. A primary reason for this collaborative research on the part of industry appears to have been to make use of the public knowledge base built up at the universities in generic science and technology. The motivation for researchers and faculty members was provided by the finance, which would help them to maintain their research programmes which would otherwise have faced drastic cutbacks. Cooperation of this nature often also consisted of university professors being appointed as board members of private companies.

c] Formation of private companies or New Biotechnology Firms (NBTFs):

The 1970 s and 1980 s, especially the late 1970 s and the early 1980 s, saw a sudden increase in small scale firms which came to be known as the New Biotechnology Firms (NBTFs) (see figure 2.1. below). These firms were formed essentially to transfer knowledge and technology from universities and generic research institutions to industry and were frequently spinoffs from University research. Often, it was University professors and senior researchers who went a step beyond being board members of firms, to leave their faculty positions and form companies of their own, to continue their specific research activities. These NBTFs became most active in the pharmaceutical sector. Although the intention was to become full fledged companies researching and producing their own products, they were largely unable to achieve this goal for a number of reasons. Firstly they were formed by researchers, many of whom had worked in Universities, with no first hand knowledge of running a company. Secondly, the research done by these firms was often very narrow, relating to the specific research interests of the founders and researchers. Finally, the companies lacked the technical, managerial and marketing skills needed to combine their success at the pure and applied research levels with success at the commercial level (Kenney, 1986). Thus many of these companies became input suppliers to the large multinationals which possessed a combination of these skills essentially lacking in the NBTFs.

\section{d] Mergers and Takeovers}

In the late 1980s, many of these small companies, despite seeking help from the stock market were unable to match the long term funding requirements of biotechnology in pharmaceuticals, and either went out of business, or merged with other companies. The stock market crash in 1987 was part of the reason for funds drying up, leaving a number of companies unable to function effectively. In 1990, Hoffman LaRoche announced its partial takeover (60 percent) of the most successful genetic engineering company, Genentech, a merger which was overwhelmingly supported by Genentech's shareholders ${ }^{43}$. By the early 1990 s this trend had increased, with a number of small US firms being taken over by both national and foreign based multinationals or their subsidiaries (see table 2.1.).

In 1993 it was estimated that there were almost 1,300 registered biotechnology companies in the US ${ }^{44}$, although many were experiencing difficulties as evidenced from a

43 US OTA (1991), p. 56.

44 The figure given by Abrams (1993), p. 775 is closer to 1,200, while the Emst and Young (1993) estimate is closer to 1,300 . 
fall in venture capital offerings in 1993 and an overall drop in stock prices ${ }^{45}$. In the UK this number was almost 200 in 1992 . According to a recent survey of 166 firms in the UK $^{46}$, biotech efforts in the UK are approximately 6 years behind the USA, in terms of profit levels and sales. Nevertheless, according to the same survey, the companies should be doubling annual profits from US $\$ 627$ million in 1992 to approximately US $\$ 1.3$ billion by 1996 . As the number of biotechnology products which are commercialized, increases, the various industries will attract more and more entrants. This is especially so in the case of periods immediately following key innovations, such as the gene splicing technique demonstrated by Cohen and Boyer and the discovery of MABs, which have enabled the production of a number of products which can be patented individually.

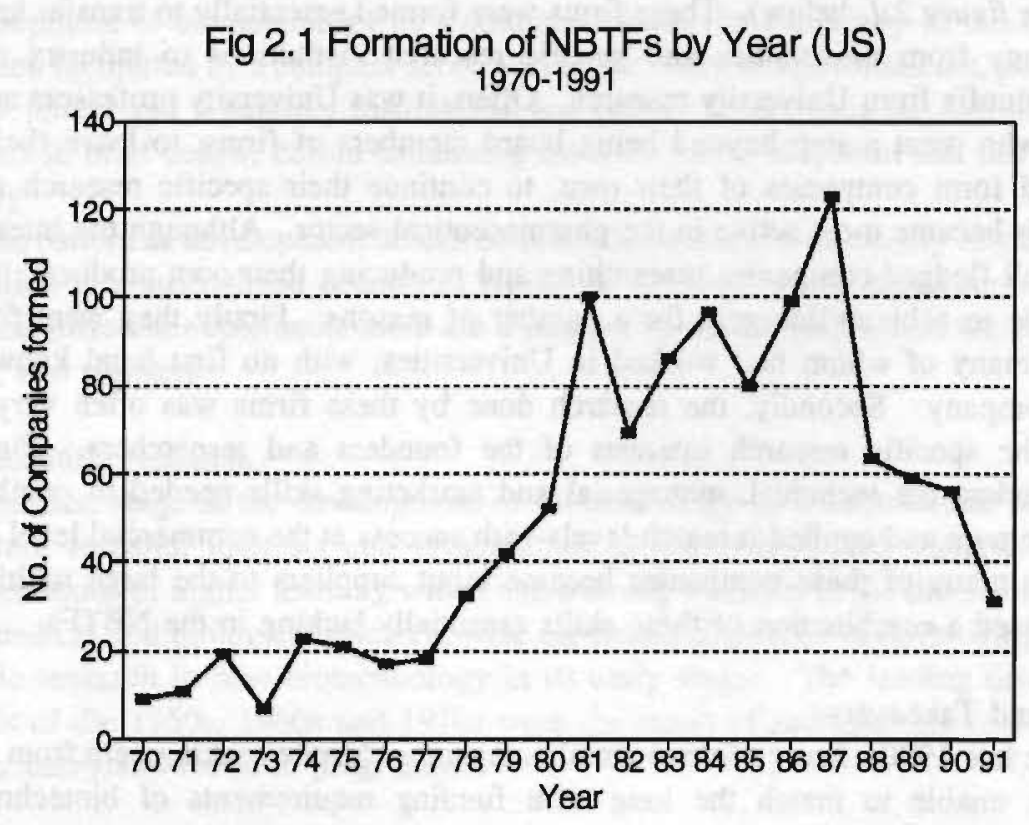

Biotechnology faces an uncertain future, depending very much upon the regulatory environment and upon building public confidence, where because of the long lag between investment and product development, the initial investments made have not yet provided investors with sufficient dividends. The public's confidence in the small biotechnology firm appear to have declined following the stock market crash of 1987 . This was compounded by a number of firms declaring losses and bankruptcy. The many buyouts and mergers shown in table 2.1., many between biotech companies and multinationals are also indicative of financial problems being faced by the small firm.

45 Bio/Technology (1994), March, Vol. 12, p 232.

46

Bio/Technology (1994), March, p 230. 
Table 2.1. Mergers and Acquisitions in Biotechnology (July 1991-June 92)*

\begin{tabular}{|c|c|c|}
\hline Acquirer & Acquisition & Date \\
\hline Mycogen & Soilserv & August 1991 \\
\hline Microprobe & Source Scientific & August 1991 \\
\hline Crop Genetics & Espro & September 1991 \\
\hline Ecogen & First Mississippi & September 1991 \\
\hline Idexx Laboratories & $\begin{array}{l}\text { Fermenta Animal } \\
\text { Health }\end{array}$ & October 1991 \\
\hline Cytel & GlycoGen & October 1991 \\
\hline Oncogene Science & $\begin{array}{l}\text { Applied } \\
\text { bioTechnology }\end{array}$ & October 1991 \\
\hline Biowhittaker & $\begin{array}{l}\text { 3M Diagnostics } \\
\text { Systems }\end{array}$ & October 1991 \\
\hline Repligen & AMIRA & November 1991 \\
\hline $\begin{array}{l}\text { DEKALB Plant } \\
\text { Genetics }\end{array}$ & $\begin{array}{l}\text { Plant Science } \\
\text { Research }\end{array}$ & November 1991 \\
\hline ALZA & Bio-Electro Systems & November 1991 \\
\hline Enzon & Genex & November 1991 \\
\hline Applied Bioscience & $\begin{array}{l}\text { Pharmaco Dynamics } \\
\text { Research }\end{array}$ & November 1991 \\
\hline Genzyme & $\begin{array}{l}\text { Genencor's Diagnostic } \\
\text { Enzyme Unit }\end{array}$ & November 1991 \\
\hline Somatix Therapy & GeneSys Therapeutic & November 1991 \\
\hline Chiron & Cetus & December 1991 \\
\hline Celtrix Laboratories & BioGrowth & December 1991 \\
\hline Idexx Laboratories & VetTest & January 1992 \\
\hline IG Laboratories & Genetic Design & January 1992 \\
\hline
\end{tabular}


Table 2.1. Continued

\begin{tabular}{|l|l|l|}
\hline Acquirer & Acquisition & Date \\
\hline Chiron & IntraOptics & January 1992 \\
\hline UniSyn Fibertec & BioProbe International & January 1992 \\
\hline $\begin{array}{l}\text { American Home } \\
\text { Products }\end{array}$ & Genetics Institute & January 1992 \\
\hline InnoVet & Brooks Feeds & February 1992 \\
\hline Miller Diversified & Genetic Engineering & February 1992 \\
\hline Intergen & Waitaki International & February 1992 \\
\hline $\begin{array}{l}\text { Environmental } \\
\text { Remediation }\end{array}$ & $\begin{array}{l}\text { The International } \\
\text { Biochemical Group }\end{array}$ & February 1992 \\
\hline Centocor & Mercia Diagnostics & February 1992 \\
\hline Waste-Tech Services & Ecova & February 1992 \\
\hline Sandoz & SyStemix & February 1992 \\
\hline Pharmatec & Pharmos & May 1992 \\
\hline Genzyme & Medix Biotech & June 1992 \\
\hline
\end{tabular}

* Only deals completed by June 1992

Source: Reproduced from Emst and Young (1992), p 54.

By mid 1992, deals between 62 of these firms had been completed while a number of others were still being negotiated, out of a total biotechnology sector of 1,231 firms (about $20 \%$ of all biotech firms).

Despite this however, recent reports argue that the growth in strategic alliances, especially between small companies, to some extent is ensuring their survival. This is evident from the number of large pharmaceutical companies who are seeking out the expertise of smaller companies, not through buyouts but through strategic alliances. Eli Lilly for example has ongoing alliances with at least 11 biotechnology firms $\mathrm{s}^{47}$. The return of the small biotechnology company, after a decade of financial problems, is also evident from the record

$47 \mathrm{Bio} / \mathrm{Technology}$ (1994), Vol. 12, July, pp 652-653. 
number of public offerings that have been made this year ${ }^{48}$. Ernst and Young for example has estimated that in 1993 biotechnology companies raised US $\$ 5.2$ billion, US $\$ 2.9$ billion of that coming from strategic alliances while $\$ 2.3$ billion was raised publicly and privately ${ }^{49}$. This increased confidence on the part of the investor, both private and corporate, may be due to a number of products which have recently been approved for use especially in the USA, and a greater incidence of companies recouping their initial investments as a result of increased product sales. Thus, the rumours of the early demise of the small biotechnology company may indeed have been greatly exaggerated.

\subsection{Sectoral Developments in Biotechnology}

Thus it appears that in general, industrial biotechnology has finally achieved success in commercial production of modern biotechnology products. However, the steps leading up to this achievement, especially in terms of market structure and linkages between private and public and generic and applied research, have been different in different countries. For example, the small, specialised biotechnology firm is a phenomena especially true for the USA, while the large firm and often the public sector, appears to be dominant in other countries. The differences across countries are discussed in more detail in the next two chapters. Sectoral changes however have tended to be more similar, especially across industrialized countries and across developing countries, primarily because of traditional strengths and the scientific, especially biological nature of biotechnology. The latter has been important in providing a primary boost to some sectors over others. In developing countries, the former appears to have played a more important role than the latter, perhaps because of the difficulties of linking basic and applied research, a problem which although present, was not as hard to overcome in the industrialized countries.

Sectoral developments in biotechnology can be broadly classified within three major sectors: (i) the pharmaceutical sector, which includes both human and animal health, (ii) the agricultural sector where some degree of overlap occurs with both environmental technologies and with animal husbandry and health technologies, and finally, (iii) the environmental sector which has gained importance during the last couple of decades due to an increasing occurrence of environmental problems and disasters.

The pharmaceutical sector, because of its requirements of large initial financial investment, but also large potential gains has grown most rapidly in industrialized countries, and as mentioned above, has formed the focal point for the NBTFs. The agricultural sector has been slower to use biotechnology, perhaps because of the longer lags between innovation and application and also lower returns, while the environmental sector is only taking off now. In developing countries on the other hand, traditional strengths in agriculture and low levels of financial capital have resulted in biotechnology applications being strongest in this sector.

${ }^{48}$ Bio/Technology (1994), March, 453-454. Although the observations are preliminary, they may point to a change in confidence in the small firm, whose likely cause is the number of recent product approvals by the FDA. 
Pharmaceutical technologies still tend to be based on older biotechnologies, while environmental technologies are strongly directed toward agricultural problems.

The Newly Industrialized Countries of the east, find themselves in an intermediate position aided greatly by large amounts of financial capital to invest in technology transfer, and traditional strengths in bioprocessing technologies to overcome the hurdle to industrial scale up. While this appears to be the general trend, below, we describe these sectors in more detail, highlighting some of the problems that have been faced by industrialized countries along the way, a taste perhaps of things to come for the developing countries.

\subsubsection{The Pharmaceutical sector:}

The US patent office approved the first biotechnology based drug, recombinant human insulin in 1982. Since then, the number of patents granted to pharmaceutical products has increased rapidly and by August 1991, there were as many as 19 biotechnology based-pharmaceutical products on the US market ${ }^{50}$.

\section{Table 2.2. Market value (mil US\$) and product estimates of selected US companies (1992)}

\begin{tabular}{|l|l|l|l|l|l|}
\hline $\begin{array}{l}\text { Therapeutics } \\
\text { Companies }\end{array}$ & $\begin{array}{l}\text { Market } \\
\text { Capitalization }\end{array}$ & $\begin{array}{l}\text { Clinical } \\
\text { Trials }\end{array}$ & $\begin{array}{l}\text { Awaiting } \\
\text { Approval }\end{array}$ & $\begin{array}{l}\text { Patented } \\
\text { Products } \\
\text { on market }\end{array}$ & $\begin{array}{l}\text { Product } \\
\text { Sales }\end{array}$ \\
\hline Amgen & 8131 & 6 & 1 & 2 & 645 \\
\hline Genentech & 3233 & 8 & 0 & 3 & 3833 \\
\hline Chiron & 1660 & 11 & 1 & 2 & 28 \\
\hline Synergen & 1170 & 3 & 0 & 0 & 0 \\
\hline Gensia & 1078 & 1 & 0 & 0 & 3 \\
\hline Genzyme & 1071 & 6 & 0 & 1 & 81 \\
\hline Biogen & 795 & 3 & 0 & 0 & 56 \\
\hline $\begin{array}{l}\text { Genetics } \\
\text { Institute }\end{array}$ & 706 & 3 & 2 & 1 & 0 \\
\hline Immunex & 465 & 6 & 0 & 2 & 34 \\
\hline Centocor & 463 & 5 & 3 & 0 & 44 \\
\hline US Bioscience & 452 & 4 & 1 & 1 & 3 \\
\hline
\end{tabular}

Source: Ernst and Young, 1992, p 22. 
A number of others are in the pipeline, awaiting patents on their inventions, or completing testing and trials before being approved by the FDA for commercialization. As mentioned before, the close links between generic biotechnology research and the medical and pharmaceutical sector has resulted in this sector becoming the largest and most successful (see table 2.2).

Although dominated by the US and especially small DBCs, there are also a number of European multinationals such as Hoffman LaRoche, Glaxo, Bayer etc. who rank as important contributors to biotechnology research and product development. Hoffman LaRoche's merger with Genentech and its involvement in Cetus and most recently, Syntex and other NBTFs, demonstrates the interest these companies are expressing in biotechnology research. There is therefore some indication that biotechnology research is attracting a larger range of companies especially as the pool of new products and innovations becomes larger, innovation not only adding to the variety of products available, but also to quality, in the form of new products which offer treatments for diseases which were unavailable previously. Thus, from a list of products, which are now available on the international market (US OTA 1991, Emst and Young, 1992, Bio/Technology, Various issues, 1994), it appears that innovation will result in an improvement in consumer utility through the production of both higher quality and also greater variety in this sector.

\subsubsection{Agriculture:}

In a world where there is a perennial shortage of affordable food and the search for cheaper food, the research community is constantly looking for ways in which to increase output, or increase the productivity of land. Biotechnology offers one such option, and the level of confidence in this is evident from its increased application to agriculture. In developing countries, less sophisticated biotechnologies are being used to improve the yield of grain and other essential products, whereas genetic engineering applications are also reaching the product development stage. The International Agricultural Research Centres such as CIMMYT, IRRI and ICRISAT devote their research in the main to improving agricultural output in various crops which are essential to the region.

Although less likely to be categorized as essential foods, the highly publicised introduction of Calgene's Flavr Savr Tomatoes ${ }^{51}$, which are said to have a better flavour and a longer shelf-live than ordinary tomatoes is only one of the many examples which exist due to the application of biotechnology in industrialized countries. Bovine growth hormone, through which milk production can be increased, is another example. Monsanto's Bovine Somatotropin (BST) has recently been approved for use by the US Federal Drugs Administration, and its sales to customers controlling 15 percent of the US dairy cattle, within the first three months after approval, have far exceeded all projections ${ }^{52}$. Growth hormones are also being tested on a number of other animal species to produce leaner meat, and also

si The US came a step closer to approving Calgene's tomato for marketing recently, and estimates are put at 90 days for full approval. (Bio/Technology, May 1994, pp 439-441). Similarly, DNA Plant Technologies recently introduced its VineSweet Brand of tomatoes on the market (Ernst and Young 1993).

\$2 Bio/Technology (1994), vol. 12, pp 570-71. 
in aquatic life to produce larger and healthier varieties. There are also close linkages with the pharmaceutical industry in the production of animal health products, such as vaccines and diagnostic products for the detection of diseases in animals. Many of the companies doing research on animal health are in fact the same companies which work on human health.

In applications to plants, there are also a variety of new products and new areas of research. The use of biopesticides and bioinsecticides are seen as an healthier alternative to their chemical counterparts. However, their applications are limited due to the fact that they have to be tailored to the needs of individual plants, or specific land requirements. The market for one such biopesticide would therefore be a limited one and perhaps not worth the trouble to many of the large agricultural concerns. Another area which is promising is herbicide resistance. Large companies such as Monsanto are doing research on developing plants which are resistant to their own herbicides and to collateral damage from their pesticides.

Table 2.3. Agricultural and Environmental NBTFs (US \$ millions (1992))

\begin{tabular}{|l|l|l|l|l|l|}
\hline $\begin{array}{l}\text { Agricultural and } \\
\text { Environmental } \\
\text { Firms }\end{array}$ & $\begin{array}{l}\text { Market } \\
\text { Capitalization }\end{array}$ & $\begin{array}{l}\text { Field } \\
\text { Testing }\end{array}$ & $\begin{array}{l}\text { Awaiting } \\
\text { Approval }\end{array}$ & $\begin{array}{l}\text { Products } \\
\text { on } \\
\text { market }\end{array}$ & $\begin{array}{l}\text { Product } \\
\text { Sales }\end{array}$ \\
\hline Calgene & 264 & 20 & 2 & 25 & 21 \\
\hline Mycogen & 209 & 19 & 0 & 6 & 13 \\
\hline Ecogen & 152 & 6 & 0 & 4 & 1 \\
\hline DNA Plant Tech & 145 & 16 & 0 & 18 & 9 \\
\hline Celgene & 93 & 0 & na & 1 & 2 \\
\hline ESCAgenetics & 34 & 3 & na & 3 & 1 \\
\hline
\end{tabular}

Source: Ernst and Young, 1992, p 22.

Yet another research area which is more complex but has a larger potential market is the improvement of the qualities of the plant itself. Older technologies such as tissue culture and micropropagation which are not recombinant based, have been used in the past to select certain desirable characteristics, which can then be reproduced in controlled environments. New genetic engineering techniques are much more powerful and effective in that they can be used to detect the genetic structure and the desired gene in a particular plant. That gene can then be reproduced and inserted into a plant to produce a new "genetically engineered" plant which contains the desired characteristic. Calgene's tomato is an example of such a technique. The development of transgenic plants which are resistant to particular pests or climatic conditions can result in major changes not only by increasing yield but also by 
changing the environmental zones in which particular plants can be grown due to their climatic requirements ${ }^{53}$.

Thus, although the initial research emphasis of biotechnology firms appears to have been pharmaceuticals, more recently, attention seems to have shifted substantially to agricultural biotechnologies ${ }^{54}$. The ag-biotech sector, as it is called, has experienced a major boost with the US Food and Drug Administration (FDA) approving a number of genetically altered products as well as its declaration in May 1992 that no new testing will be required for genetically engineered food products. During the period 1991-1992, the number of ag-bio companies grew from 89 to $123^{55}$. The largest of these (see table 2.3), are still smaller than their counterparts in the pharmaceutical sector, in terms of sales and stock market value (see Appendix I below), although all indications are that these are set to expand as more and more products are cleared for field testing and reach the market stage ${ }^{56}$.

Table 2.4. Approved Number of Field Trials of Transgenic Plants per year

\begin{tabular}{|l|l|l|}
\hline Year of Approval & Number of Approvals & Percentage of Total \\
\hline 1986 & 1 & 0.1 \\
\hline 1987 & 9 & 1.0 \\
\hline 1988 & 37 & 4.3 \\
\hline 1989 & 69 & 8.0 \\
\hline 1990 & 147 & 17.0 \\
\hline 1991 & 208 & 24.1 \\
\hline 1992 & 393 & 45.5 \\
\hline Total & 864 & 100 \\
\hline
\end{tabular}

Source: OECD (1993), p. 9

\$3 Such developments are also bringing major changes to agricultural production and international trade patterns. Developing countries which are often highly dependant upon their cash crop exports are especially vulnerable to the development of substitutes and "climatically engineered" varieties. This is the subject of Acharya (1993b) and is discussed further in Chapter 7 below.

54 Ernst and Young, 1992, pp 5-7

55

Ibid, p 21.

56

Ibid., p. 21 
However, the real problem with commercialization here appears to be a lag in government approval of products. This is in part because of testing requirements and the considerable lag which is common in agriculture between testing and application. Nevertheless, restrictions on testing have been reduced considerably as is evident from table 2.5. below which shows that permits for the release of genetically engineered crops have increased greatly since 1990 in the USA. This is also evident from data (tables 2.5. and 2.6.) collected by the OECD on the release of genetically engineered transgenic plants for field trials $^{57}$.

Table 2.5. Release Permits by Country (1986-1992 Total)

\begin{tabular}{|l|l|l|}
\hline Country & No. of Approvals Granted & Percentage of Total \\
\hline Australia & 6 & 0.7 \\
\hline Belgium & 62 & 7.2 \\
\hline Canada & 302 & 35.0 \\
\hline Denmark & 3 & 0.3 \\
\hline France & 77 & 8.9 \\
\hline Germany & 2 & 0.2 \\
\hline Japan & 1 & 0.1 \\
\hline The Netherlands & 22 & 2.5 \\
\hline New Zealand & 13 & 1.5 \\
\hline Norway & 1 & 0.1 \\
\hline Spain & 6 & 0.7 \\
\hline Sweden & 6 & 0.7 \\
\hline Switzerland & 2 & 0.2 \\
\hline United Kingdom & 45 & 5.2 \\
\hline United States & 316 & 36.6 \\
\hline Total & 864 & 100 \\
\hline & & \\
\hline
\end{tabular}

Source: OECD (1993), p. 10.

57 OECD (1993c). The study included a survey of field releases in the following countries: Belgium, Canada, Denmark, France, Germany, Japan, the Netherlands, Norway, Spain, Sweden, Switzerland, UK, USA, Australia and New Zealand. 
As the table shows, 45 percent of all permits issued thus far, were issued in 1992. Of this, table 2.6. shows that the USA and Canada by far account for the largest percentage of field releases since the late $1980 \mathrm{~s}$.

A recent interim report by the European Commission's Biotechnology Coordination Committee (BCC) comparing regulation and R\&D in Europe and the USA concluded that at the R\&D stage (ie., including testing), "there is a remarkable similarity between the US and EC as far as risk assessment of an environment release is concerned. However, in the US the scope of the regulations is different and within that defined scope there exists greater flexibility ${ }^{158}$. Thus there is some indication that European countries in general are more stringent with regard to environmental release for field testing, than the US. There does however, appear to be a tendency to relax these regulations through the $\mathrm{EC}^{59}$, as a recent directive on the banning of BST indicates. This may in part be due to the experience which has been gathered with previous field releases during the late 1980s, which give some indication of requirements and conditions that would minimize pollination with wild varieties or other varieties being grown around the testing site ${ }^{60}$.

Even if the product is eventually approved by the appropriate government body, consumer and environmental groups still tend to frown on genetically engineered products, and the next hurdle to be overcome will be socio-economic pressures such as these, rather than simply the regulatory environment. The appearance of genetically engineered foods in supermarkets, first in North America and more recently in the UK ${ }^{61}$, may be some indication that consumers will slowly begin to accept these products.

\subsubsection{Environmental Biotechnologies}

This is perhaps the most underdeveloped of the three sectors but is an important sector all the same because of the general interest in the environment and environmental technologies and because of the potential biotechnology holds for the environment, both with respect to industry and also in agriculture. In industry, a number of companies have developed methods to clean industrial wastes and to recover metals from wastewaters ${ }^{62}$. One of the world's worst oil spill at Prince William Sound earlier in the decade was partly cleaned using "oilrecovering" bacteria. Indeed the first patent granted to a genetically engineered organism in the US in 1980 was for such a microorganism which could break down the major components

58 European Biotechnology Information Service (EBIS)(1993), March, Vol. 3, no. 1, p.3.

59 Bio/Technology (1994), March, Vol. 12, p233.

${ }^{60}$ The study by the OECD (1993c) gives examples of cases of testing actoss various European and North American sites which have provided measures of buffer crops and distance from other crops in order to minimise cross pollination. Other factors such as wind have of course also to be taken into account, when releasing transgenic plants into the environment.

${ }^{61}$ Bio/Technology (1994), April, Vol. 12, p 351.

62 The process marketed under the name of AMT-BIOCLAIM contains a metal removal agent and has been successfully used to recover metals from wastewaters containing differing degrees of metal wastes. See Acharya and Spencer (1990b) for more details. 
of oil ${ }^{63}$. The sensitive nature of the environment and also the recent movement to control environmental pollution has led to strict legal arrangements regarding the release of environmentally sensitive biotechnologies. For most industrialized countries and also for a number of developing countries, the restriction of the release of genetically engineered organisms into the environment has become part of the regulatory framework. With the FDA's recent statement that no new testing will be required of genetically engineered food products however, there appears to have been some easing of this restrictive environment ${ }^{64}$. This is also apparent from the number of environmental release permits for the testing of products, issued in 1990 and 1991 (see tables 2.4 and 2.5).

Biopesticides are another environmental technology which, especially for agricultural nations, this provides a safer alternative to chemical pesticides which have caused groundwater pollution in the past. The excessive use of chemical pesticides during the green revolution has also caused severe problems in developing countries, where this technology may be highly relevant today.

The general sectoral pattern of development, with the pharmaceutical sector leading the others, is observed in a number of countries around the world. Private sector investment in this sector is also generally the highest, although a number of private companies are gradually becoming involved in agricultural research. In part, this is because of the tedious process of testing and approval as well as consumer disapproval associated with genetically engineered agricultural products and also partly because pharmaceuticals have potentially larger profit margins, providing companies with a greater opportunity to recover their initial costs. However, as the benefits of new agricultural products appear to outweigh the immediate risks to the environment and because of the size of the market, it is likely that biotechnology will become a major player in the agricultural and agri-business sectors as well. Similarly, environmental biotechnologies which have suffered from a lack of sufficient attention until now will gradually become more important as the environment becomes a more high-profile issue, not only in industrialized countries, but also in developing countries.

The challenges for policy, especially the regulatory environment, are to reach a balance between regulation and innovation. For example, excessively restrictive policy on the testing of genetically engineered organisms may hinder innovation, especially in agriculture. On the other hand, a weak regulatory framework may create other hazards associated with genetically engineered products, and the introduction of foreign genes into local varieties and into the local environment.

\section{Conclusions}

In this introductory chapter to biotechnology, we have described the way in which biotechnology has progressed from basic biological research at universities and research

${ }^{83}$ As pointed out earlier in the text, in the Diamond vs Chakrabarty case which involved a non recombinant microorganism, the Supreme Court in the US allowed the patent, ruling that it was, "the product of human ingenuity having a distinctive known character and use", (OECD 1985, p 104).

64 Ernst and Young (1992), p 10 
institutions, to a modem, applied technology with enormous potentials. Collaboration between universities and the private sector led to successful product development albeit after several years of research and investment. The private sector and public offerings were crucial in providing the large sums of money required for these initial investments which government funding for basic research was unable to provide. Thus as we saw above, the number of companies or New Biotechnology Firms as they were known expanded rapidly in the 1970s and the 1980s largely as a result of raising venture capital funds and stock market capital. More recently, and especially to compete with the all round expertise of the large multinational, these companies have increasingly resorted to marketing or R\&D alliances, to compensate for size and limited scope in marketing in various parts of the world.

The second portion of this chapter provided a brief survey of the major sectoral developments in biotechnology. For a number of reasons, the most important of which include linkages between medical faculties and modern biotechnology research, as well as the expectation of extraordinary economic profits in the long run, initially led to the establishment of modern biotechnology in the pharmaceutical sector, which has continued to grow and is by far the most successful, especially in the industrialized countries.

The relative successes and failures of companies and public sector holdings in developing capabilities in biotechnology and translating generic research into commercial products, were however different in different parts of the world. As we will see in the two chapters which follow, there are significant differences especially between industrialized and developing countries for a number of reasons, including technology gaps, infrastructure requirements, credit access and relationships between the centres for generic research and commercial ventures. Researchers and companies in developing and industrialized countries have therefore had to overcome very different problems in order to achieve their successes.

In the next two chapters, we describe the environment and infrastructure for biotechnology research and commercialization in industrialized and then in developing countries. The aim of the two chapters is to provide an overview of biotechnology R\&D and patterns of invention and innovation in these two groups of countries, in order to ascertain what the basic requirements are to facilitate the successful diffusion of this technology. The relationships between the invention of higher quality products, and the demand for greater variety, or alternatively higher quality, will also be examined. An interesting issue here would be the relationship between the diffusion of higher quality products and the impact on variety. A greater rate of diffusion in terms of increasing market share of the higher quality product, would necessarily reduce the market share of the older qualities, thus implying that a faster rate of diffusion would destroy variety. The conclusions may provide guidelines for government policy and the development of an environment which would facilitate both innovation and diffusion nationwide. 


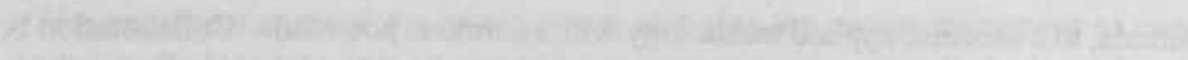

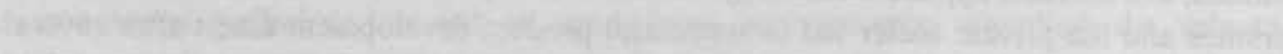

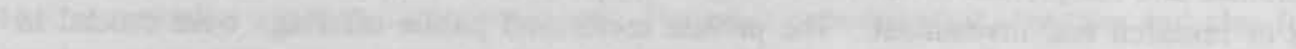

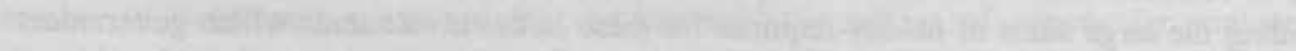

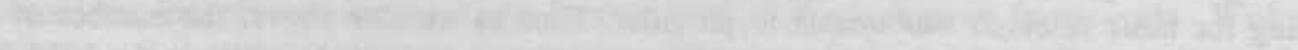

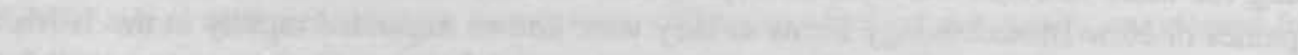

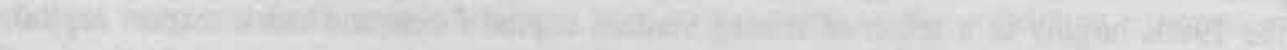

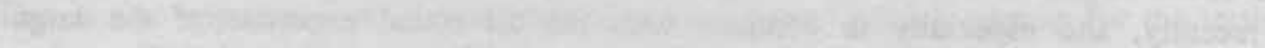

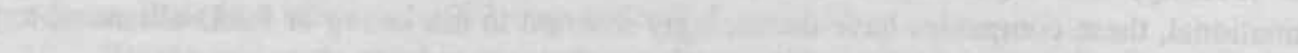

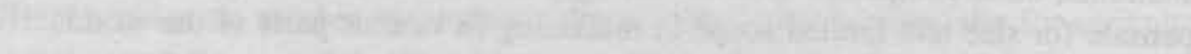

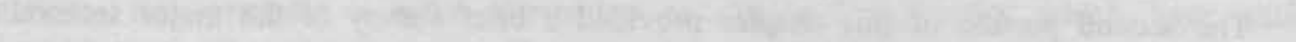

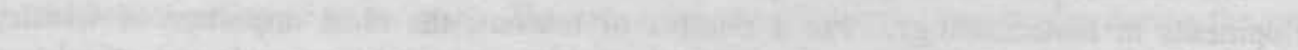
W

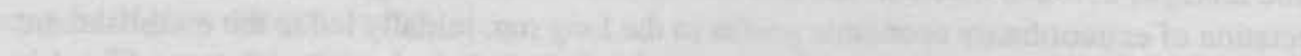

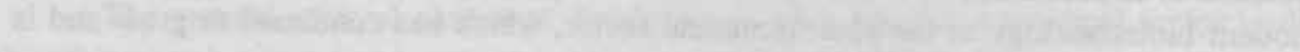
(a) che

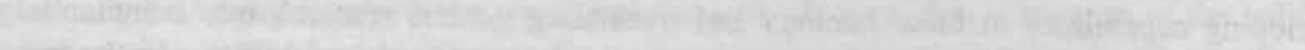

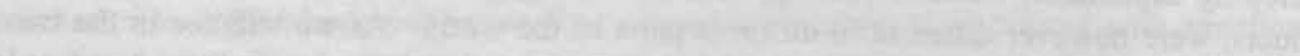

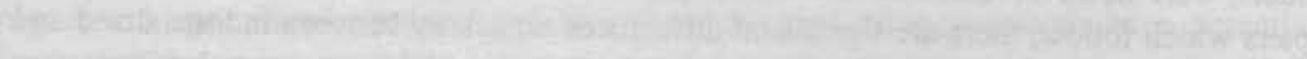

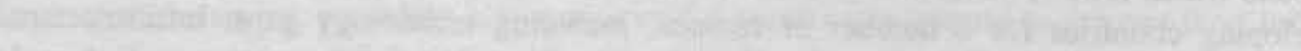

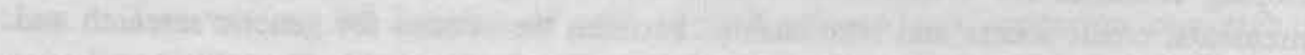

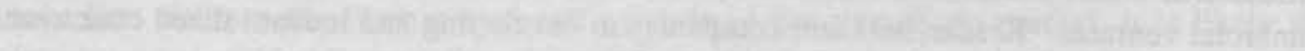

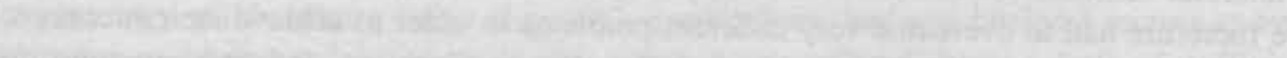

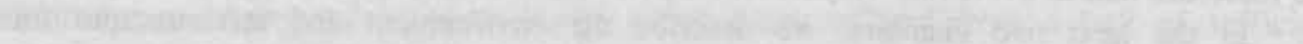

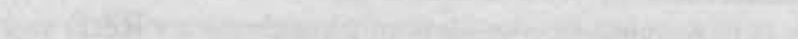

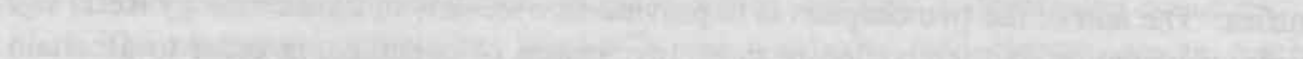

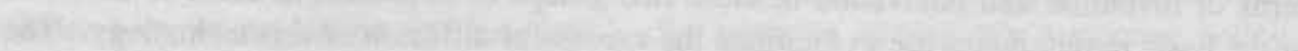

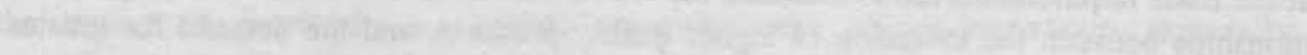

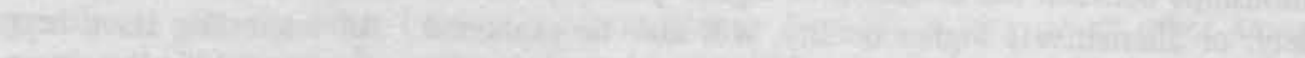
Ge

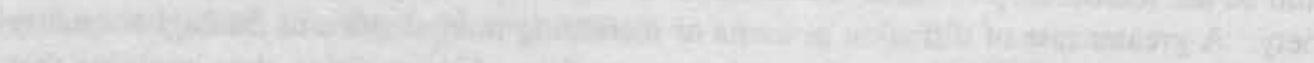

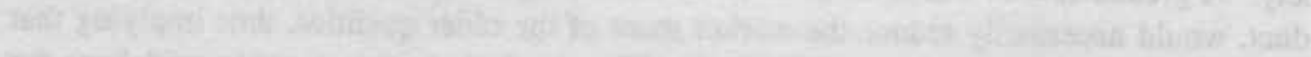

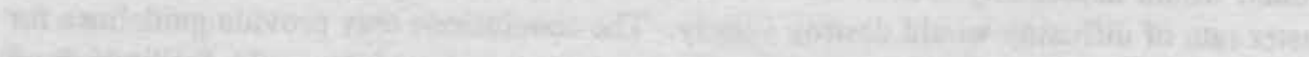
Cy

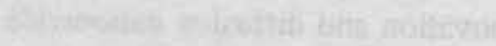


"And from this springs the extraordinary question: Did the Egyptians know about electricity?"....P. Kolosimo

\section{Introduction}

The establishment of biotechnology as a new technology has taken place most rapidly in the countries of the triad, North America. Europe and Japan. Early recognition of the potential of this technology, by the government who developed policy guidelines enabling its diffusion, by public sector research institutions and universities and by the private sector whose funding of basic research led the way in investment in new biotechnologies, is the main reason for the large technology gap that has developed between this group of countries and the rest of the world.

Implicit recognition of this technology came in the late 1970s and early 1980s in most of these countries, when the government established either guidelines or policy frameworks for the development of biotechnology. University-industrial collaboration as described in the previous chapter was also instrumental during this period and led to many of the key discoveries made during this period which established biotechnology.

In an attempt to understand some of the basic needs of a new science based technology such as biotechnology, this chapter and the next are devoted to outlining the basic patterns of development in industrialized (this chapter) and developing (next chapter) countries. From the point of view of this study, which examines the impact of new technologies on economic growth, technology gaps and trade, it is important to establish the interactions between sectors, institutions and the role played by basic scientific knowledge in developing technological capability. Institutional arrangements such as the scope of intellectual property rights are also important, especially for issues such as innovation and imitation, and may therefore relate directly to the technology gap in many cases.

In this chapter therefore, we look specifically at the countries of the triad and examine the patterns of development of biotechnology, looking especially at government policy and the interplay between industry and basic research in developing both generic scientific knowledge and also commercial products. The significance of these relationships will be expanded upon more theoretically in chapters 8 and 9 below, where we develop a growth and trade model, based on observations about the patterns of innovation from these chapters on biotechnology. 


\subsection{Biotechnology Policies and Industrial Research in Industrialized Countries}

The late 1970 s and especially the early 1980s appear to have brought with them many changes relating to issues of competitiveness and technological leadership. The challenge to Europe and to the US was especially strong from Japan and the Newly Industrializing Economies of East Asia. The rapid development of the electronics industry in Asia was a further demonstration of the potential of this latter group to narrow the technology gap between themselves and the industrialized countries ${ }^{65}$. Technological targeting therefore became the norm rather than the exception during this period.

Most industrialized countries established government policy frameworks during this period, with an aim to improving international competitiveness in biotechnology. The then Federal Republic of Germany has the distinction of being the first country to launch a concerted national effort in biotechnology. Established in 1972, the German Leistungsplan, focuses on traditional German strength, namely industrial biotechnology, primarily bioprocessing technologies, although a considerable amount of funding is also provided by the Ministry of Agriculture, for agricultural biotechnology ${ }^{66}$. The National Research Centre for Biotechnology was founded in 1974 and the initial government strategy was strengthened in 1984 with a broad framework outlining national priorities and objectives in biotechnology, including the following:

1. To enable top scientific performance through the proper allocation of political and financial resources

2. To foster industrial innovation

3. To promote $R \& D$ in the field of health

4. To evaluate risks associated with new techniques and to adopt safety regulations

5. To increase the pool of R\&D professionals through the support of young scientists, and

6. To encourage international cooperation and technology transfer ${ }^{67}$.

Downstream biotechnology in Germany has been dominated by the large companies such as Hoechst, Schering. Boehringer Mannheim, Bayer and BASF, building upon and exploiting their expertise in industrial biotechnology related techniques. Close linkages between the large chemical and pharmaceutical companies and universities have greatly aided in strengthening both generic and applied research in biotechnology. An important component of these contractual arrangements was training. Schering for example, made arrangements with universities in Berlin to train its scientists during the 1980s. Where there were weaknesses in basic research at German universities, companies used the option of moving further afield, notably to the USA. Examples of this include Hoechst's contract in the 1980s with Massachusetts General Hospital, to train its scientists in medical biotechnologies, and

\footnotetext{
${ }^{65}$ Daly, 1985, p 59.

6

OECD (1988), pp 21-22.

${ }^{67}$ US OTA (1991), p 233.
} 
Schering's contract with Genex, one of the more successful venture capital companies in the USA, to expand its basic research capacity. As a result of some of these linkages, Germany has recorded greater successes over the years in pharmaceuticals, although its traditional strength still lies in fermentation and bioprocess technologies ${ }^{68}$.

French expertise in biotechnology is based mainly in pharmaceuticals and in the food industry. As with Germany, there are a few large multinational firms which dominate the commercial biotechnology business, such as Rhône-Poulenc and Elf Aquitaine. RhônePoulenc has recently formed a company, Bio-Avenir, a collaborative research venture with public sector research institutions to provide a boost to the research network in France. The programme which initially has a duration of five years was started in 1991 and is supported by a budget of FFr 1.61 billion (about US $\$ 295$ million) of which government support amounts to about FFr 610 million (about US $\$ 115$ million) ) $^{69}$.

Despite this however, the establishment of biotechnology in France has been facilitated and led largely by the French government. The Programme Mobilisateur's aim is to provide seed money for R\&D research ${ }^{70}$. Unlike in Germany, where traditional research strength lies in the universities, in France the public research institutions have received much of the government's financing intended for biotechnology research. The programme, established in 1982, provides seed money especially in two areas of priority research: development of new diagnostics and vaccines especially an AIDS vaccine, and the development of expertise in agri-food biotechnology ${ }^{71}$. Since 1985 however, when French government funding peaked, low levels of funding especially when compared to other European countries with similar programmes in biotechnology, has led to a degree of weakness in the French programme ${ }^{72}$.

This is also the case in Britain, where following the publication of the Spinks Report in 1980, the government was initially mobilized into action. It increased funding to the research councils, specifically for biotechnology research and training and began a number of initiatives to bring public and private sector together to do both basic as well as applied research ${ }^{73}$.

Since then however, British universities have faced major staffing and budgetary cuts, as government funding dried up in the early 1980s. Although there is some private sector funding in terms of contract research, it has not been sufficient to compensate the loss of these government cutbacks and it is likely that Britain is falling behind a number of other European countries in basic research. As with France, Britain's major weakness lies in developing and strengthening existing relationships between generic research and the more downstream aspects of biotechnology R\&D. However, it has been argued that its long

See Sharp (1985), Ch. 5 for details and also Orsenigo (1989).

69

Ward (1993), p. 798.

70

OECD (1988), p 23.

${ }^{71}$ Ibid, $\mathbf{p} 23$.

72

US OTA (1991), pp 234-5

73

Sharp (1985), Ch.7. 
tradition in industrial research and development has helped British companies and research based firms to overcome some of these problems ${ }^{74}$.

The controversy over the patenting of Monoclonal antibodies (MABs) ${ }^{75}$, first developed in the UK, also led the government to establish the company Celltech, in 1980, soon after the Spinks Report. Celltech was formed by capital from the government and four private sector entities, mainly to facilitate the transfer of technologies, especially genetic engineering, from the public sector so that they could be developed further and commercialized. Today, it is a leading company in state of the art biotechnology research and has formed strategic alliances with a number of established companies, both for research and for marketing purposes ${ }^{76}$. Britain also has a far better developed venture capital market than most other European countries, and although Celltech was a creation of the British government, the strengthening of the venture capital market is already producing results (Bio/Technology, April 1994).

The absence of the small firm in Europe stands out in strong contrast to biotechnology in the US where biotech R\&D was led by the small venture capital firm. In Germany the first private venture capital fund was set up in 1983 and although a few firms have appeared, equity market restrictions and a tradition which favours links between academia and the large company $^{77}$, appears to have been opposed to such developments. Similarly, France does not have a well developed venture capital market and although there are a number of small scale biotechnology firms in the country, they tend to be offshoots of the large established companies. Britain on the other hand appears to have been more successful of late in encouraging investment in small scale firms. According to a recent survey, the UK now has 166 biotechnology startups, in biopharmaceuticals, diagnostics and ag-biotech. These companies it is estimated, will double their total turnover by 1996, making takeovers, especially by the large companies more likely ${ }^{78}$.

In the United States, although there are no specific policy guidelines on biotechnology as in many European countries, the government performs a central role in defining and creating an environment which is conducive to private sector R\&D in biotechnology. United States federal funding remains the largest in the world in absolute terms, although as a percentage of GDP, it has dropped ${ }^{79}$. There are indications that overall government funding, including the activities of the National Institutes of Health (NIH), National Science Foundation (NSF), the Environmental Protection Agency (EPA), the National Institute of

${ }^{74}$ US OTA (1991), p 80

75 Monoclonal Antibodies (MABs) were never patented because of the failure of the British National Research and Development Corporation to recognize the potential of this technique and to file on behalf of the inventors. Subsequently, a number of key innovations following from the initial technique were patented by researchers in the US (Fransman, 1991, p 16).

${ }^{76}$ Fransman, M. (1991), p 35.

$n$ Sharp (1985), 65

${ }^{78}$ Ward (1993), p 230.

79 US OTA, 1991, p 21-23. 
Science and Technology (NIST) and the Departments of Energy and Agriculture, is slated to increase by roughly 4 percent in the 1995 R\&D budget. The enormous human genome project is one such example where the NIH is estimated to receive and spend about US $\$ 152$ million in fiscal year 1995, an increase of 18 percent over the previous year ${ }^{80}$. This tradition of federal funding has meant that the development of basic biotechnology R\&D has been fastest in the US.

However, where the US stands out among the industrialized countries, is in the linkages between private and public sectors and in the market structure of biotechnology $R \& D$. Unlike many European countries, the early linkages between private companies and universities through research grants, led to the formation of the specialised biotechnology firm, which had all the advantages of a strong background in basic research (since many were formed by university researchers), combined with an emphasis on applied research and commercialisation. In Europe, although linkages between large private sector companies and universities followed a pattern similar to that established in the US, there were two reasons why the US has been more successful at commercialization of biotechnology: (i) firstly, in the US, these linkages were developed relatively early on in time, giving US companies a headstart in building up linkages between basic research skills and empirical research; and (ii) secondly, the structure of university contract research which was more accessible to academics in the US than in Europe, because of the close relationship which developed between university and industry during the early $1970 \mathrm{~s}^{81}$. This gives both companies as well as researchers the freedom to excercise their entrepreneurial tendencies, unlike in Europe where this is a relatively recent phenomena.

Private sector linkages with universities and research institutions have a long tradition in the US and much of the present biotechnology research infrastructure is based upon this tradition $^{82}$. Sharp (1985) argues that this tradition was further strengthened by the presence of a venture capital market willing to take on high risks in the short run. This supplementary funding which was used by a number of small companies, before eventually going public proved extremely useful in the beginning, especially in the pharmaceutical sector where it is estimated that the development of a new drug takes on average, 10 years and costs anywhere between US $\$ 100$ to US $\$ 150$ million $^{83}$.

Japan has perhaps been the most successful in overcoming some of its traditional weaknesses, notably in pharmaceuticals and its intellectual base. Its traditional strengths lie in fermentation and food preservation. Like in the European countries, biotechnology

${ }^{80}$ Bio/Technology (March 1994), p 222

81 Sharp, 1985, pp 42-3.

${ }^{82}$ For example, medical research especially targeted toward special topics or issues, such as cancer research in the USA have a long tradition of both government as well as private funding. Sharp (1985) and especially Kenney (1986), provide excellent analyses of the changing role of University-Industrial Cooperation in the USA. Sharp (1990) also discusses the strengths of the US research infrastructure over that of other countries, especially through the development of the small firm.

${ }^{83}$ Correa (1991), p. 7 referred to in Reid et.al. (1993) 
research and development in Japan is led by the large industrial houses and corporations. Unlike these countries and the US however, Japan does not have a tradition of strong university research in the life sciences $^{84}$, and has had to catch up in rDNA based technologies. While in the US and to a lesser extent in Europe, companies and universities had stepped up their efforts to make breakthroughs in biological research, Japan by the end of the 1970s lagged some 5-6 years behind the US ${ }^{85}$. Japan has therefore had to catch up with Europe and the US especially in areas such as rDNA and cell fusion where it has been particularly weak. This has been done largely through training, mainly in the US and through the formation of mergers and strategic alliances with European and American companies. According to the US Office of Technology Assessment, between 1982 and 1989, some 266 deals were signed between US biotechnology companies and research institutions and Japanese Companies ${ }^{86}$. Japanese companies have also made their mark in the US capital market by signing 12 equity arrangements during the same period, many of them specifically for marketing in Japan.

The Government effort to develop biotechnology has been led by the Ministry of Trade and Industry (MITI), whose role has been important in the shaping of the structure of industry in post-war Japan ${ }^{87}$. Others include the Science and Technology Agency, and the Ministries of Agriculture, Health and the Environment. MITI has also been instrumental in setting up and supporting the Protein Engineering Research Institute (PERI) which was established in $1986^{88}$. Thus through a combination of investment and strong policy guidance, the latter especially from MITI, combined with a private sector willing to invest in new technologies to overcome its traditional weaknesses, Japan has been able to catch up with most other European countries and overtake some. This is also evident from patent data, which we examine in the next section.

Thus while most industrialized countries in Europe, North America and Japan have set up national programmes to encourage research and development in biotechnology, they have all had varying degrees of success. The major causes of this appear to be industrial strength, regulations and government funding to support basic research. In Europe for example, the strongest country Germany, has had a strong national programme on biotechnology which has focused national biotechnology research on particular aspects of biotechnology. However, it has also been fortunate in that its intellectual and industrial strength has enabled German biotechnologists to not only improve basic research facilities and training of young researchers, but there has also been a translation of these efforts into commercial output by industry. France, on a smaller scale has also been able to use its strengths especially in immunology, using the skills of basic research institutions such as the

\footnotetext{
${ }^{84}$ Sharp (1985), p 41.

85 Ibid, p 49.

86 US OTA (1991), pp 59-60.
}

${ }^{87}$ See for example Johnson (1984) or Okimoto (1982) for a discussion of the role played by MITI in the development of industry in Japan. 
Institut Pasteur, while relying on large industrial companies such as Rhône Poulenc to commercialize.

Britain, especially the basic research sector has faced a decline in government spending on biotechnology related generic research. The emergence of private companies in the country may help to some extent in overcoming this funding bottleneck, however, private sector research tends to be more applied, and support for training is low, unless related to specific research projects. Unless universities and basic research organizations can find funds outside of government sources, in the long run, a decline in basic research may severely hamper the future of applied research and training.

Outside of Europe, Japan and the USA have both relied on a combination of government policy and funding, and the private sector to encourage biotechnology R\&D. Japan's traditional weakness in its natural science base meant that the government had to provide a stronger push to industry to invest in generic research and training as well as commercial development of products in Japan's areas of traditional strength, especially bioprocessing. In the USA, the phenomenal rise of the NBTFs was already discussed to some extent in the previous chapter. This, combined with traditional strengths in basic research, both at universities as well as national programme such as cancer research, not only provided a framework for research priorities but also enabled the government to strengthen these traditional areas, by funding basic research. These initial injections of money are paying off today, in the form of a highly developed pharmaceutical sector greatly aided by biotechnology research, a growing agro-biotech sector and projects which will earn US scientists and industry international recognition such as the human genome project.

\subsection{Rates of Innovation: Some Evidence from Patenting Data}

Having isolated some of the characteristics of and strengths and weaknesses of biotechnology programmes in various countries, what can we say about the specific products and inventions that are generated as a result of these programmes. As pointed out earlier (see chapter two above), it is difficult to measure the degree of innovativeness by using input indicators such as R\&D funding, which are not only difficult to obtain for most countries, but are often misleading because they may not reflect private sector investment adequately. Given the primary role played by the private sector in applied biotechnology research, this would most surely be a biased estimate.

Output indicators such as patents on the other hand, are also problematic and for biotechnology, the categories are not very clearly defined ${ }^{89}$. This may lead to double counting in some cases, especially if a disaggregated approach is taken. In a detailed study some years ago for example (Marstrand, 1981), some of the author's results tended to be biased because of this problem of double counting (Marstrand 1981, Wheale and McNally 1986, and OECD 1982). Despite these problems however, and keeping them in mind, we

89 Biotechnology patents are found in over 20 classes, spread out over 4 sections in the International Patent Classification published by the World Intellectual Property Organization (WIPO), which serves as a guide to most major patent systems across the world (Wheale and McNally, 1986, p. 640). 
look briefly in this section at two sets of international patent data: data from the US Patent Office and from the European Patent Office on biotechnology and examine the impact they may have on the future development of biotechnology.

The data on US patents refers only to patents granted by the US patent office, between the years 1962 and 1991, whereas the European data available, relate to the shorter time period of December 1978 to August 1993 in the case of filing, and from 1980 to August 1993 for patents granted.

As is evident from table 3.1 below, which shows patents granted for biotechnology products from 1965 to 1991, (category 435 includes genetic engineering, enzymes, immobilized enzymes, tissue culture and amino acid based technologies and products and 424 measures drugs and bio treating compositions which include both second generation and modern biotechnology based drug $\mathrm{s}^{90}$ ), there appears to have been a sharp increase, between 1970 and 1975, followed by a decline during the early 1980s (fluctuations from year to year can partly be attributed to the number of personnel employed at the patent office and whether they are able to analyse each application adequately in a given period of time $\mathrm{e}^{91}$ ), followed by a steady increase in patents granted during the latter half of the 1980s. Between 1988 and 1989 especially there was a large increase in these figures. The figures for 1991 are significantly lower than those for earlier years, because they are partial year figures.

Table 3.1. US Patents Granted for Biotechnology

(Categories 435 and 424$)^{2}$

$\begin{array}{lllllllllllllll}\text { Year } & 65 & 70 & 75 & 80 & 82 & 83 & 84 & 85 & 86 & 87 & 88 & 89 & 90 & 91 \\ \text { Categ } & & & & & & & & & & & & & & \\ 435 & 103 & 138 & 368 & 391 & 421 & 377 & 364 & 376 & 453 & 634 & 655 & 840 & 858 & 902 \\ 424 & 131 & 163 & 333 & 346 & 409 & 305 & 463 & 452 & 439 & 580 & 619 & 948 & 890 & 1000 \\ \text { TOT } & 234 & 301 & 701 & 737 & 830 & 682 & 827 & 828 & 892 & 1214 & 1234 & 1788 & 1748 & 1902\end{array}$

- Categories 435 and 424 are broad cluster classifications which include a wide range of secondary biotechnologies as well as genetic engineering.

Source: US Patent Statistics, US Patent Office 1993

Similarly in the case of the European patent office we see an increase in total biotechnology patents granted from 191 to 4,619 between 1980 and 1991 (table 3.2 below). while the total number of applications rose from 1,204 to 10,368 in the period 1978-1991 (usually it is estimated that European office patent statistics tend to be underrepresentative of international patents until 1986 or 1987 . This and the fact that these statistics only continue until august 1993, make the earlier years and 1993 figures rather unreliable).

90 US Department of Commerce/Patent and Trademark Office (1986). The use of such a broad spectrum of technologies, ensures that we measure both patenting activity in modern biotechnology based techniques, but also in products, most of which relate to new drug manufacture.

${ }^{91}$ US OTAF (1982), p. 10. See also the paper by Wheale and McNally (1986), p. 644. 
Patents granted by the European Patent Office, show that approximately 50 percent of patents filed seem to be granted for Japan and for France and Britain. There is an estimated time lag of 2 years (Bio/Technology, April 1994), between the filing of a patent and the patent being granted or rejected, so for example, in the case of Japan, out of 1811 and 2021 patents filed in 1989 and 1990 respectively, 997 and 1168 were granted. For the US, this ratio appears to be closer to one third.

Table 3.2. European Patents Granted

(1980 to 1993)

$\begin{array}{lllllllllllllll}\text { Year } & 80 & 81 & 82 & 83 & 84 & 85 & 86 & 87 & 88 & 89 & 90 & 91 & 92 & 93 \\ \text { US } & 3 & 145 & 289 & 561 & 709 & 793 & 965 & 848 & 814 & 1087 & 1198 & 1391 & 1623 & 1786 \\ \text { UK } & 2 & 72 & 139 & 233 & 240 & 246 & 279 & 206 & 224 & 257 & 281 & 368 & 388 & 390 \\ \text { GER } & 150 & 543 & 628 & 782 & 791 & 805 & 828 & 712 & 769 & 834 & 891 & 963 & 1053 & 1234 \\ \text { FRA } & 23 & 88 & 129 & 187 & 262 & 283 & 293 & 279 & 261 & 318 & 356 & 358 & 476 & 1056 \\ \text { JPN } & 2 & 35 & 110 & 226 & 369 & 443 & 530 & 460 & 508 & 651 & 749 & 997 & 1056 & 1271 \\ \text { TOT } & 191 & 1079 & 1579 & 2355 & 2866 & 3198 & 3498 & 3067 & 3178 & 3917 & 4252 & 5025 & 5597 & 6299\end{array}$

Source: European Patent Office, 1994

Table 3.3. European Patent Applications

(1978 to 1993)

$\begin{array}{lllllllllllllllll}\text { Year } & 78 & 79 & 80 & 81 & 82 & 83 & 84 & 85 & 86 & 87 & 88 & 89 & 90 & 91 & 92 & 93 \\ \text { US } & 297 & 769 & 1067 & 1357 & 1590 & 1983 & 2350 & 2603 & 2915 & 3026 & 3481 & 3670 & 3673 & 3777 & 2622 & 953 \\ \text { UK } & 141 & 321 & 359 & 402 & 474 & 495 & 543 & 570 & 606 & 725 & 731 & 763 & 833 & 702 & 578 & 135 \\ \text { GE } & 416 & 942 & 1164 & 1261 & 1220 & 1155 & 1430 & 1486 & 1513 & 1646 & 1829 & 1953 & 2067 & 1436 & 1338 & 861 \\ \text { FR } & 70 & 205 & 279 & 353 & 386 & 416 & 463 & 512 & 558 & 582 & 689 & 746 & 824 & 677 & 681 & 318 \\ \text { JPN } & 504 & 190 & 386 & 559 & 734 & 851 & 1066 & 1265 & 1299 & 1544 & 1790 & 1811 & 2021 & 1784 & 1291 & 752 \\ \text { tot } & 1204 & 2998 & 3928 & 4831 & 5353 & 5962 & 7064 & 7843 & 8411 & 9171 & 10339 & 11052 & 11904 & 10368 & 67843734 \\ \text { B }\end{array}$

Source: European Patent Office, 1993

In addition, we can also see, that in terms of absolute levels, Japan appears to be catching up with Europe and has even overtaken both Britian and France and is approximately at the same level as Germany. This is especially evident from the data in table 3.2. below. The data for 1993 in figure 3.3. below are partial year figures, which is why they appear to be significantly lower than those for the years before. 
In the case of patents granted by the US Patent Office, we see again, a sharp increase in patents granted during the latter half of the 1980s. We also see that Japan has surpassed all the European countries surveyed and is only second to the USA. The dominance of the USA may in part be due to the first to invent standard in the US versus the first to file standard in Europe and Japan. However, although this may explain the stronger showing of the US, it still does not explain the stronger performance of Japan over Germany, the pattern of which is somewhat different in the EPO's statistics. There may however be a tendency for a European preference to apply first for a patent at the European Patent Office or a Japanese preference to apply at the US Patent Office. Nevertheless, both sets of data do show the success of Japan in catching up with European countries and coming close to challenge the USA in terms of patents filed and granted in biotechnology.

Table 3.4. US Patents Granted for Biotechnology (Categories $\mathbf{4 3 5}$ and $\mathbf{4 2 4}$ for selected Countries) $^{2}$

$\begin{array}{lllllllllllllll}\text { Year } & 65 & 70 & 75 & 80 & 82 & 83 & 84 & 85 & 86 & 87 & 88 & 89 & 90 & 91 \\ \text { US } & 177 & 217 & 412 & 430 & 514 & 413 & 537 & 528 & 598 & 830 & 856 & 1222 & 1167 & 1298 \\ \text { UK } & 7 & 7 & 39 & 49 & 50 & 41 & 52 & 46 & 37 & 51 & 68 & 93 & 79 & 95 \\ \text { GER } & 21 & 15 & 49 & 64 & 63 & 53 & 63 & 60 & 63 & 82 & 89 & 135 & 120 & 108 \\ \text { FRA } & 7 & 20 & 45 & 64 & 44 & 40 & 31 & 33 & 32 & 48 & 61 & 83 & 76 & 81 \\ \text { JPN } & 19 & 35 & 144 & 118 & 143 & 128 & 133 & 152 & 159 & 179 & 183 & 237 & 276 & 287\end{array}$

Source: US Patent Statistics

Thus as expected, in general, the US tends to be the leader both in the European statistics as well as for patents registered and granted by the US patent office. In Europe, Germany, also as expected, is the leading innovator in the field of secondary and rDNA based biotechnologies. However, in both sets of statistics it is also apparent that the greatest degree of catching up has been achieved by Japan. Beginning with the lowest number of patents granted by the European patent office along with the UK in 1980. Japan has overtaken both the UK and France and for the last few years has even been granted a larger number of patents than Germany. A similar trend is observable in the US patent office's statistics, although the number of patents granted to Japan has been consistently higher than those granted to any of the European countries surveyed ${ }^{92}$. Thus in terms of closing technology gaps, from figure 3.2. below, Japan's catching up especially in the pharmaceutical sector where its traditional weakness ${ }^{93}$ lies has been especially notable (see also tables 3.2., 3.3. and 3.4. above).

92 This may be due to a European preference to apply first for a patent at the European Patent Office, or a Japanese preference to apply first to the US, rather than any inherent bias at the US Patent Office. This in itself is an interesting topic, but not particularly relevant to the present discussion. We therefore will not refer to this any further, only alluding to the possibility here.

93 Sharp, M. (1985). 
These are the general trends. A closer sectoral examination, also provides a preliminary measure of specialisation in these countries. The largest sector as indicated by the number of patent applications and patents granted each year appears to be pharmaceutical and medical biotechnologies. Table 3.5. below, shows the trends in this sector as indicated by patents granted for these technologies to those countries surveyed. We have used patent data from the European patent office (classifications $\mathrm{A} 61 \mathrm{~K}, \mathrm{C} 07 \mathrm{C}, \mathrm{C} 07 \mathrm{D}, \mathrm{C} 07 \mathrm{H}, \mathrm{C} 07 \mathrm{~K}$, $\mathrm{C} 12 \mathrm{~N}, \mathrm{C} 12 \mathrm{P}, \mathrm{C} 12 \mathrm{Q}$ and $\mathrm{G} 01 \mathrm{~N}$, which appear to cover most of the patents filed within this broad sector). The large increase in patents both filed and granted appears to support our earlier claim that because of the close linkages between medical research and modern biotechnologies, the sector affected earliest has been the pharmaceutical sector. Once again, the USA and Germany dominate, with the Japanese demonstrating their success in catching up. France also has done fairly well, especially in the most recent years, relating well to the earlier discussion of the French emphasis on medical biotechnologies, especially through funding of specific institutions or programmes.

Table 3.5. Pharmaceutical and Medical Biotechnologies Granted by the EPO (Granted 1980-1992)

$\begin{array}{lllllllllllllll}\text { Year } & 80 & 81 & 82 & 83 & 84 & 85 & 86 & 87 & 88 & 89 & 90 & 91 & 92 & 93 \\ \text { US } & 2 & 103 & 198 & 378 & 437 & 448 & 534 & 464 & 458 & 576 & 674 & 756 & 1037 & 1148 \\ \text { UK } & 0 & 49 & 99 & 158 & 143 & 164 & 165 & 123 & 132 & 134 & 170 & 216 & 262 & 256 \\ \text { GER } & 124 & 417 & 458 & 570 & 556 & 519 & 517 & 423 & 455 & 486 & 555 & 579 & 691 & 794 \\ \text { FR } & 21 & 66 & 83 & 118 & 165 & 184 & 168 & 156 & 145 & 168 & 206 & 198 & 320 & 357 \\ \text { JPN } & 2 & 28 & 91 & 173 & 272 & 292 & 347 & 293 & 300 & 383 & 479 & 632 & 754 & 878\end{array}$

$\begin{array}{lllllllllllllll}\text { TOT } & 158 & 812 & 1199 & 1649 & 1875 & 1978 & 2059 & 1752 & 1802 & 2179 & 2512 & 2927 & 3714 & 4132\end{array}$

Source: European Patent Office, 1994

Agriculture still tends to lag behind but appears to be making significant gains on the pharmaceutical industry in recent years, especially in the US (The classes we have used here include A01G, A01H, A01K and A01N which appear to cover most patents filed by companies active in agricultural biotechnology). Table 3.6. shows that Germany and the US tend to dominate with Japan and to some extent, France following close behind. Patents granted to Germany however appear to have fluctuated quite sharply, declining considerably during the latter half of the 1980s and rising again in the early 1990s. This may in part be due to the changing laws regarding the release of genetically engineered organisms into the environment, over which there has been considerable discussion in Germany.

The aggregate figures in table 3.6. show a considerable increase in agriculture patents granted in the late 1980 s and early 1990 s. This gain appears to be largely the result of a rising interest in developing biological pesticides and herbicides. 
Table 3.6. Agricultural Biotechnologies at the EPO

(Granted 1980-1992)

$\begin{array}{lllllllllllllll}\text { Year } & 80 & 81 & 82 & 83 & 84 & 85 & 86 & 87 & 88 & 89 & 90 & 91 & 92 & 93 \\ \text { US } & 0 & 6 & 19 & 16 & 33 & 26 & 26 & 16 & 23 & 37 & 33 & 38 & 43 & 67 \\ \text { UK } & 0 & 0 & 5 & 5 & 14 & 11 & 12 & 10 & 7 & 8 & 13 & 18 & 25 & 17 \\ \text { GER } & 4 & 19 & 32 & 31 & 27 & 47 & 48 & 11 & 19 & 36 & 44 & 50 & 49 & 66 \\ \text { FR } & 0 & 5 & 3 & 7 & 8 & 14 & 14 & 12 & 12 & 19 & 21 & 23 & 31 & 25 \\ \text { JPN } & 0 & 1 & 0 & 2 & 4 & 7 & 6 & 8 & 3 & 11 & 22 & 20 & 42 & 39 \\ \text { TOT } & 4 & 43 & 72 & 89 & 122 & 144 & 153 & 91 & 107 & 165 & 183 & 230 & 250 & 277\end{array}$

Source: European Patent Office 1994

Thus a preliminary look at patent data, both in the US and in Europe, shows a rising rate of patents granted, but especially of patent applications. While the US leads in both categories, Germany and especially Japan, have demonstrated considerable catching up abilities. The main difference between these two countries is that while German companies have traditionally been strong in secondary biotechnologies, as is evident from the slower rate of change in patents granted to German applicants and their high levels, Japanese applications began from low levels and have had high growth rates. This appears to support earlier observations about strengths and weaknesses of biotechnology in both countries and the success of Japan in overcoming its initial weaknesses through forming strategic alliances with foreign universities and companies.

\subsection{1.}

Measuring Rates of Imitation and Innovation

A lack of more precise data about input indicators such as basic and applied research expenditure for many new technologies, as well as figures on sales of new products, has often led to a reliance on patent statistics as measures of the impact of a new technology on the economy (Wheale and McNally, 1986). Because biotechnology is a new technology, biotechnology based products are only now beginning to appear on the market, while many others are still in the pipeline, waiting for approval from health authorities, or awaiting the results of field testing, before they can be put into production and offered on the market. Precise data on all these various stages is scanty and its use would therefore probably lead to large biases in any analysis. Patent data is often perceived as providing information of an intermediate kind, straddling both basic research as well as the final stage of product development. Its use as a measure of the degree of innovativeness in a sector or of a technology should however be viewed with caution, especially in sectors such as pharmaceuticals and techniques such as genetic engineering, where considerable lags may exist before a patented product (an invention), moves to the stage of becoming a product available to consumers (an innovation).

For our purposes, we use the patent data set described above, to calculate growth rates of patents granted, which can be used as a proxy for the degree of inventiveness in the 
biotechnology R\&D sector. As explained below, this approximation will be used in the model developed in chapters 8 and 9.

In the case of European patents granted (see table 3.2. above), growth rates were first taken over 13 years for which statistics were collected (1981-1993). Incomplete data for 1981 and for 1993 however reduced the sample size to 11 years, from 1982 to 1992 . The newness of the EPO and especially the particular difficulties associated with granting patents for biotechnology, meant that the sample was further reduced to 7 years, from 1986, when patents granted by the EPO are generally accepted to be more trustworthy, to $1992^{94}$. Similarly in the case of US patents (from table 3.4. above), the first set of growth rates were calculated for patent statistics over 28 years (1964-1991) for which data were available. The second set of growth rates for the US patent dataset measure change over the period 1981 to 1991. The reason for using this specific period was that patents for many modern biotechnology based inventions, especially genetically engineered products and processes, have only been granted since the early 1980s. Since the objective of this exercise is to determine the growth rate of modern biotechnology inventions in the USA and in Europe, the division of the US dataset into two periods in this manner, ensures that patents granted to older biotechnologies are not overestimated. The division also provides an estimate of inventive activity and relative strengths and weaknesses in modern biotechnologies, as opposed to older biotechnologies. As table 3.7. below, shows, this second set of statistics are indeed comparable to the rates of growth registered at the EPO (10.27 percent according to US statistics and 10.71 in Europe, averaging out to 10.487). We therefore use this as an estimate of the rate of inventiveness in biotechnology in industrialized countries.

The growth rates, when compared across countries, with the exception of Germany, are fairly compatible with expectations, demonstrating quite effectively relative strengths in old and new biotechnologies. The earlier period in the US data measures growth rates of both old and new biotechnologies, whereas the second period measures only the new technologies. As per expectations, the US and Japan register high growth rates during the second period. A comparison across the growth rates in Europe and in the US show that in Europe, the growth rates of European patents, again with the exception of Germany, tend to be higher than their growth rates in the US. This may be due to the first to invent requirement of US patent legislation which may put foreign inventors at a disadvantage during the application process in the US ${ }^{95}$. This may also be a reason for the higher growth rates at the EPO, although it is more likely that this is due to the shorter period of time that the EPO has been in existence for.

94 Data were also incomplete for 1993 which may have led to downward biases in total patents granted. This year was therefore omitted as well in the latter calculation.

95 Section 104 of the US patent law provides that a patent applicant cannot establish a date of invention by referring to an activity, ie. R\&D in a foreign country. This implies that the earliest date that can be used in many such cases to establish the date of invention, is either the filing date of a corresponding patent abroad or the date the invention was replicated in the US. (Bio/Technology, May 1994). This has recently been amended by Article 29 of the TRIPS agreement of the Uruguay Round of Multilateral Trade Negotiations (GATT, 1994). In addition, the plant variety protection act in the US also stipulates that the filing of a certificate in the US cannot take place more than one year after the patent was filed in a foreign country (Bent et.al. (1987)). 
Table 3.7. Percentage Growth Rates of Patents Granted by Country (US Patent Office and European Patent Office)

\begin{tabular}{|l|l|l|l|l|}
\hline & \multicolumn{2}{|l|}{ US Patents } & \multicolumn{2}{l|}{$\begin{array}{l}\text { European } \\
\text { Patents }\end{array}$} \\
\hline & $1964-1991$ & $1981-1991$ & $1982-1992$ & $1986-1992$ \\
\hline US & 9.08 & 12.17 & 29.92 & 13.94 \\
\hline UK & 16.23 & 8.49 & 21.30 & 9.73 \\
\hline GER & 10.56 & 6.475 & 7.64 & 5.86 \\
\hline FR & 20.45 & 5.775 & 19.46 & 10.63 \\
\hline JPN & 16.94 & 8.879 & 46.67 & 15.76 \\
\hline TOT & 9.34 & 10.267 & 18.52 & 10.71 \\
\hline
\end{tabular}

Source: Calculated from EPO and US Patent Data.

The general tendency in both sets of statistics for the US to be the leader is also as expected, as is the growth rate of Japanese patents. Germany however is an outlier as is the UK with its high growth rates of patents granted, especially in the US. However, the latter may also be attributed to the close ties between the US and the UK, especially during the 1980 s, when both countries were establishing their "special relationship" with each other. Germany's weak performance however is only in growth rates and not in levels, demonstrating an initial strength in secondary biotechnologies. The fact that the growth rate of its patents is rather low may also be an indication of closeness to the technological frontier, i.e. a high level of technological capability. Another reason for low growth rates may be due to the fact that there is some truth in the arguments of biotechnologists that the country's strict laws regarding genetic engineering may be stifling biotechnology activities by its firms (Bio/Technology, May 1994, pp 441-442) by preventing the handling of genetically engineered materials for research. However, this argument relates more to release of genetically engineered products into the atmosphere and therefore would be expected at a later stage, after the patent has been granted.

The growth rates measured above were calculated discretely, on a yearly basis for each country. In order to avoid any potential problems related to fluctuations because of patent office activity from year to year, as mentioned above, the growth rates were also calculated over both time periods in both the case of the US Patent Office and for the EPO, using a $\log$ linear time series regression, $\ln Y=\alpha_{0}+\alpha_{1} \ln X_{1}+u$, where $\alpha_{1}$ measures the slope or the growth rate of the function over time. The results are presented in table 3.8. below.

As is evident when comparing the two tables, the use of logs has greatly reduced the difference between the two sets of time periods for which data were examined. The average in the second case across countries is also different now from the earlier case. In the 
case of the US Patent Office this average is more or less the same at 10.6 percent during the 1964-1991 period and 10.47 percent for the 1981-1991 period whereas for the European Patent Office equivalent figures are 7.61 percent in 1982-1992 and 9.01 percent in the later period, from 1986-1992. Despite this difference however, the discrepancy is not that great, and we would conclude that the annual growth rate of patents or innovation, is in the area of 9 or 10 percent in both cases.

Table 3.8. Growth Rates of Patents Granted by Country (US Patent Office and European Patent Office)

\begin{tabular}{|l|l|l|l|l|}
\hline & \multicolumn{2}{|l|}{ US Patents } & \multicolumn{2}{l|}{$\begin{array}{l}\text { European } \\
\text { Patents }\end{array}$} \\
\hline Country & $1964-1991$ & $1981-91$ & $1982-1992$ & $1986-1992$ \\
\hline USA & 6.42 & 11.22 & 13.56 & 11.82 \\
\hline UK & 8.5 & 7.8 & 7.12 & 9.6 \\
\hline GER & 8.3 & 7.97 & 3.88 & 6.3 \\
\hline FR & 6.96 & 9.37 & 9.72 & 9.22 \\
\hline JPN & 7.89 & 8.69 & 18.73 & 15.38 \\
\hline TOTAL & 10.6 & 10.47 & 7.61 & 9.01 \\
\hline
\end{tabular}

Source: Calculated from Patent Data from the European Patent Office and the US Patent Office

The estimated growth rates of patents granted during the 1980s by the EPO and the US patent office, should however, be viewed with some caution for the following reasons:

1. Firstly, there are considerable differences, not only in the manner in which patents are granted $^{96}$, but also in the categories under which biotechnology patents are granted.

2. Secondly, there are still major differences between the US and the EPO in what can and cannot be patented. The most major difference between the two in relation to biotechnology is that while patenting of plant and animal varieties which are genetically engineered are not

96 For example, the US has a first to invent policy whereas the EPO uses a first to file policy to assess patents. In the US, it has been argued, this creates considerable lags because of the amount of research that has to be carried out to determine who invented first. 
allowed within the framework of the EPO ${ }^{97}$, the US allows the patenting of such species. This also causes some discrepencies in the data used above.

For these two reasons, there are considerable differences between US and EPO patent statistics in biotechnology and it is for this reason that we have used both. However, these arguments relate mostly to levels of patenting, and may not have much of an impact on growth rates in both set of data. Nevertheless, in calculating growth rates, we have used an average of both sets of growth rates, to serve as a measure of the rate of annual biotechnology inventions in industrialized nations. We do not have similar statistics for developing countries and so have to use another proxy which is discussed in the following chapter.

\section{2 .2}

The Role of Size in Biotechnology

As biotechnologies become well established, especially as is the case in pharmaceuticals and now in agriculture and agro-industry, there appear to be two major changes taking place. First, as we have already mentioned, there were a large number of takeovers especially of the small NBTFs by large multinationals in the 1980s. The Hoffman LaRoche-Genentech merger in 1990 created a stir in biotechnology circles and observers predicted an increase in such takeovers as the success of the small companies tempted the large companies, who until then had refrained from investing as heavily in biotechnology, into entering the market ${ }^{98}$. The easiest and most expeditious way to do this was to merge with or takeover the smaller companies. Although takeovers and mergers have increased since that time, most of them appear to have taken place between the smaller NBTFs rather than solely between the large companies and the NBTFs (see table 3.1. above). Nevertheless, it appears that the large chemical and pharmaceutical giants have become more heavily involved in biotechnology R\&D in the 1990 s than in the last decade. In an attempt to quantify the increased rate of participation by the large firm in biotechnology R\&D, as compared to the small biotechnology specific firms, we looked at patent data from the European patent office.

We took the 30 largest chemical and pharmaceutical companies (by total company sales in fiscal year 1992) as well as the top 25 NBTFs (only 25 NBTFs had been granted patents at the EPO in the dataset used), active in the pharmaceutical sector, (see appendix I below for a list of these companies). Patent statistics from the patent office for the pharmaceutical categories mentioned above were obtained and group averages during the period 1978 - 1992, in the case of applications and the period 1980 - 1993 in the case of patents granted, were taken. The samples were reduced to 15 as a number of the large companies registered patents below 3 and in some cases, zero patents over the period surveyed. The results are shown in figures 3.1. and 3.3. for applications and 3.2. and 3.4. for patents granted, below. The decline in the 1992-93 period is due to partial year figures on patents and cannot be therefore attributed to a declining trend in applications or patents granted.

97 As mentioned above, the major exception here is the oncomouse, which was first rejected in Europe, then patented in the US and finally patented in Europe, despite its laws against patenting animals, because it was deemed that the suffering caused to the mice which are used in cancer research, was more than compensated for by the benefits to human beings. 
Figure 3.1 European Patent Applications

Av. of Top 15 Corps and NBTFs 1978-91

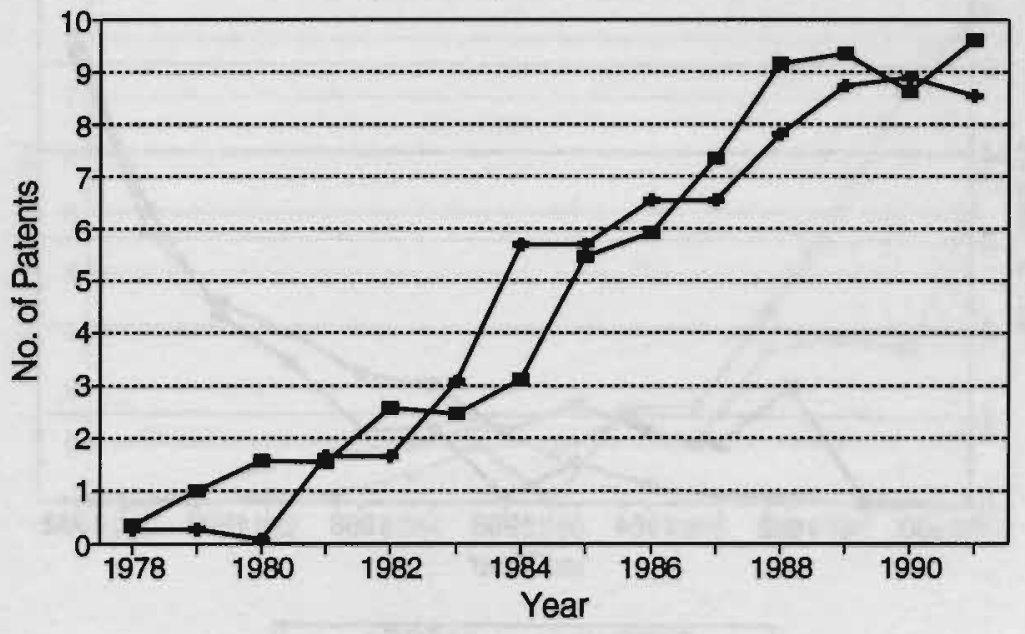

$\rightarrow-$ Corporations $\rightarrow$ NBTFs

The figures show constant growth, with minor annual differences in applications (figure 3.1.) especially for the top 15 firms, while for patents granted, the Corporations had tended to dominate but there was slow catching up by the NBTFs in terms of patents granted figure 3.2.), showing perhaps an increasing importance of small size. In the last year in fact it looks as though the NBTF has overtaken the large company.

In the case of the largest 6 companies and NBTFs, both for applications (figure 3.3.) and for patents granted (figure 3.4.), the small firm has dominated especially since the mid 1980s (for patent applications, which given the estimated time lag of 2 years before patents are granted, fits well with figure 3.4. in which patents granted to small companies overtook patents granted to corporations beginning in 1987). The early 1990s have shown an even greater tendency for small firms to dominate.

Thus from an initial analysis of patent data, there does not appear to be an indication that size is becoming increasingly important with respect to biotechnology R\&D. In fact, it appears that in some cases, smaller firms have been more successful at innovating, indicating a tendency toward small companies. The fact however that the top 6 NBTFs show a stronger performance in patenting than the top 15, demonstrates that size is important to some degree, but that it is a combination of size, skill, and research base, rather than just size which is important for consolidation in biotechnology R\&D. 
Figure 3.2. European Patents Granted Av. of Top 15 Corps and NBTFs 1980-92

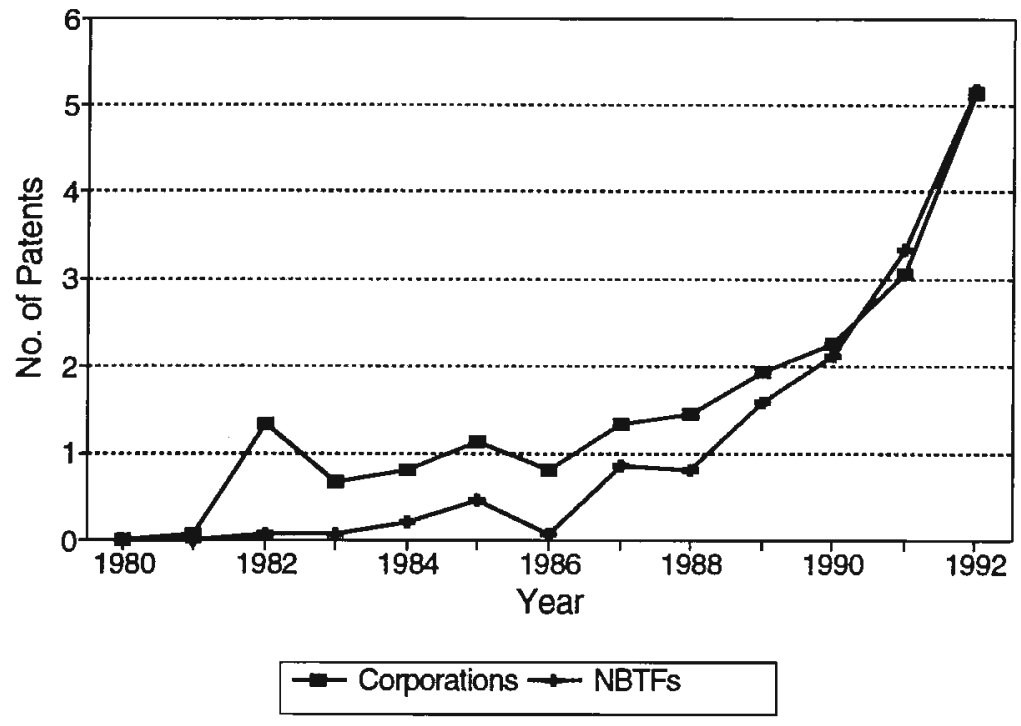

Figure 3.3 European Patent Applications Av. of Top 6 Corps and NBTFs 1978-91

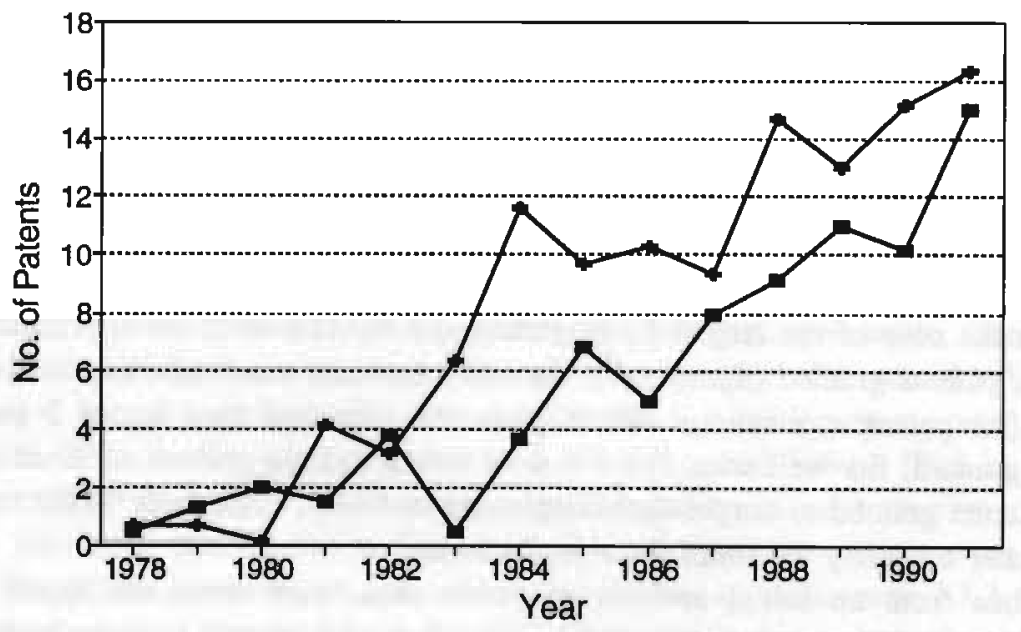

- Corporations $\rightarrow$ NBTFs 
Figure 3.4. European Patents Granted

Av. of Top 6 Corps and NBTFs 1980-92

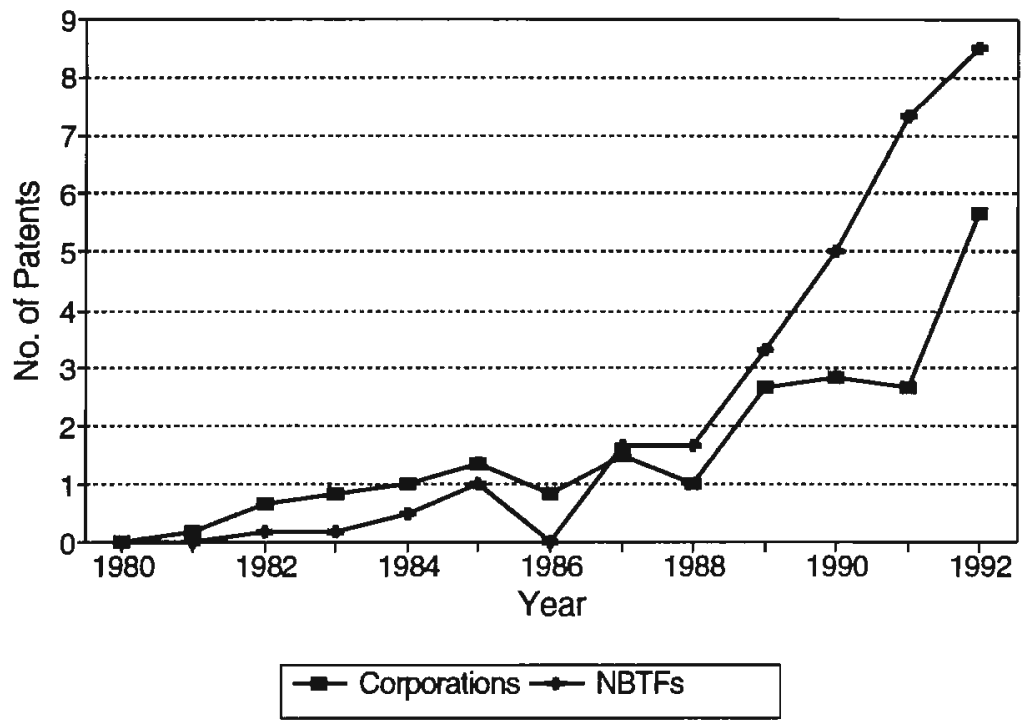

Second, as the industrial development of biotechnology accelerates, a number of researchers have pointed to increasing economies of scale. Fransman (1991), shows from data released by Celltech, that the cost of production declines significantly after batch yields rise above 100 grammes $^{99}$. Although this in itself does not point to significant economies of scale, it does imply that there is some point at which the cost of production declines. Given that the initial investment costs are still high, this implies that this cost reduction will only be achieved by those companies that have the means to make this initial investment.

If the case is that economies of scale become more significant in time, then the implications for developing countries are, that there will be a tendency towards greater concentration in the industries where biotechnology has made the greatest strides. Although the observations are rather preliminary, they do appear to imply, as one would expect, that as the industry consolidates its position, economies of scale become important. This may in turn mean that in the longer run, the larger companies may succeed in pushing the small companies out of the production process, pushing them either completely out of the market, or reducing them to centres of excellence for research, relying on their patent monopolies for further investment.

While economies of scale are becoming important however, fixed costs and demand are other important factors in determining total costs and the tendency toward larger or smaller firms will depend greatly upon the ability of these firms to lower fixed costs. There is some indication that the NBTFs are already beginning to react to this need. In the beginning when they were formed, they were largely research intensive. However, the 
intention was to build a successful marketing and commercial network by which they could compete with established pharmaceutical or ag-bio companies. Unfortunately, new biotech firms never had the resources nor the years of experience which could enable them to compete. The one notable exception is Amgen, which has succeeded in creating a fully integrated firm which does not require the kinds of marketing and licensing arrangements that even the most successful NBT companies such as Genentech, have required.

Strategic alliances have been an important aspect in helping NBTF's overcome some of their weaknesses, especially if it enables them to benefit from the complementary research or product development experiences of other companies. The evidence therefore is not clearly in favour of the large companies or of the NBTFs. There may be some consolidation as scale becomes more important. However, the advantage of the small firm came from its specialized line of research and its success in patenting new products. The expertise developed by these firms thus demonstrated, multinationals such as Hoffman LaRoche, although they have taken over smaller companies, have allowed them a great deal of flexibility in designing and running their own research programmes, in recognition of this excellence. In the future the survival of either the small firm or the large corporation in biotechnology will depend greatly upon the ability to reduce fixed costs and to develop means by which to reduce total costs. One way is through forming networks and strategic alliances, a path that many NBTFs are beginning to follow.

\section{Conclusions}

In this chapter, an examination of the patterns of invention and innovation in biotechnology in industrialized countries revealed a number of crucial elements. The presence of a strong scientific base, especially in molecular biology, and a trained labour force is vital especially in the initial stages when generic, pre-competitive research appears to be more important. Although cooperative agreements were formed between universities and the private sector, the role of the government at this stage of research was important especially for training and funding basic research ${ }^{100}$.

Government policies in all three groups of nations has focused on two aspects of biotechnology related activities:

1. Broad targeting of generic, basic research in the biological sciences and medical research.

2. Building and incentive and regulatory framework for applied biotechnology R\&D.

With respect to the first, the US Federal government has been the largest finance source for basic research institutions of which the National Institutes of Health have been one of the largest recipients. The enormous Human Genome programme is the latest in this targeting of the enormous skills present in the USA in basic research. In contrast, on the

100 Kenney (1986) for example provides a survey of the initial research effort in biotechnology, especially with respect to the influential relationship which was forged between government, university and private company, during the 1970 s and led to some of the most important breakthroughs as a result. 
other extreme, Japanese industry has been unable to benefit from such a resource base, as Japanese universities have in general been unable to compete with the US or with Europe in terms of basic research ${ }^{101}$. The involvement of the government in the form of guidance from the Ministry of Trade and Industry (MITI) has provided much of the impetus for overcoming some of these initial problems and Japan through this different approach is now in a position to compete with Europe and US in modern biotechnology. European biotechnology is dominated by a small number of large firms and its disadvantage has been a lack of venture capital funding to encourage start ups as in the USA. Countries such as France and Britain especially have faced difficulties in funding research because of a lesser capability in applied research, than in Germany (Sharp, 1985).

Given the number of cooperative arrangements which were made during the $1970 \mathrm{~s}$ and 1980s (see Kenney, 1986), it appears that the private sector is also highly dependant upon the skills and abilities of this scientific base. In fact many of the founders of the New Biotechnology Firms (NBTFs) which were established in the USA, were originally university Professors or involved in collaborative research with the public sector (Sharp 1985, Kenney 1986, Daly 1986). Thus the development of a strong base in scientific research and training appears to be an important prerequisite, as one would expect of a science based technology such as biotechnology.

The second conclusion we can reach is the relative importance of the private sector in industrialized countries at the applied research stage. Their experience in production and scale up, as well as their established sales and marketing networks have been crucial in transforming the results of generic research into production. In fact, it is pointed out (US OTA, 1991), that one of the inherent weaknesses of the NBTFs was a lack of development on the production side. In other words, their research capabilities were considerable, but many were unable to keep up with the downstream skills of the Multinationals, once the latter had entered the biotechnology market. Strategic alliances, especially in the area of marketing have therefore provided an important method by which the smaller firms are able to overcome some of their weaknesses.

Finally, an important implication for entry into R\&D, both for companies in industrialized countries, as well as in developing countries, that is the allegedly growing importance of size was also given some attention. Patenting data indicates, that although the large corporations are still lagging behind somewhat, the rate of catch up is quite rapid. This may in part be due to takeovers and mergers with the smaller, research intensive NBTFs. Other evidence from industrial processing, although still rather preliminary, also points to the fact that size may become more important as biotechnology establishes itself in economic production sectors (see Fransman above). On the other hand, recent evidence from stock market activities in the US and the UK (Bio/Technology, April, May 1994), indicate that there is growing interest in funding small biotechnology companies, and that small venture capital companies appear to be making a comeback to some extent. Although most of these discussions tend to be rather anecdotal, the implications for size may not be as drastic as have been suggested. In fact, as we have argued in the last section above, the earlier failures of some small biotechnology firms may have been due to the degree of their specialization in research. Strategic alliances, especially for downstream activities such as marketing, are being

${ }^{101}$ US OTA,1991, p 155. 
used more frequently by a number of small companies and may in the long run be key to their survival. The longer term implications for size may therefore be ambiguous ${ }^{102}$.

In the next chapter, we continue our examination of innovation patterns in biotechnology, by looking at a different group of countries, namely developing countries. The experiences of industrialized countries, as discussed in this chapter are compared and contrasted with the development of biotechnology in developing countries, especially as it may relate to rates of innovation.

${ }_{102}$ Developing countries, as we discuss in the following section however, will still face growing problems because of scale effects. This is also largely due to the increasing cost of entering the market and the additional problem of scale up compounds the size of the barrier they face. 


\section{4. \\ Biotechnology in Developing \\ countries: Contrasts and \\ Comparisons}

"According to our statistics sir, 50\% of the population lives below the poverty line in utter misery and 50\% above the poverty line in utter misery"...R.K. Laxman

\section{Introduction}

The survey of biotechnology in industrialized countries revealed two important components in biotechnology R\&D: first government guidance through policy, as well as its funding of basic research appears to have been important. Second, these have been combined with private sector funding of applied R\&D, leading to commercialization of products, either through the NBTFs as in the case of the USA, or through the large established firms as in Europe and Japan. In general however, despite differences between countries, the main trends seem to suggest that a combination of these two components to overcome traditional weaknesses and enhance their particular strengths in biotechnology related R\&D were used.

The reason for a combination of government policies and funding especially for basic research, rather than private sector funding which seems to be largely devoted to empirical research, lies in the linkages between productive sectors in the economy and basic and empirical research. In general, while basic research and training have benefited greatly from government support, and supplemented by industry, empirical research has tended to be largely dominated by the private sector and less so by the government. In the USA for example, we saw that the emergence of the NBTF ensured that research shifted from a more basic theoretical and training level, to applied product oriented research. The reasons for the close association of the private sector with product oriented research lie in a number of incentives such as monopoly profits from patents and the privatization of technology, as opposed to universities where in general technology remains within the public domain ${ }^{103}$.

103 In biotechnology however, a number of patents have also been granted to universities and public research institutions, for example, the granting of patents to universities in recent years, such as the Cohen-Boyer patent, has led a number of other public sector institutions, to seek similar protection, either through IPRs or through a restriction on exchange of sensitive material. The International Agricultural Research Institutions have thus far resisted this trend (see Barton and Siebeck, 1992). This is also partly due to a CGIAR directive which reaffirms that both genetic material as well as patented material used by the Centres should be made freely available to all clients although there is some evidence that this may change in the future as the availability of material even from public institutions becomes more restricted (van Wijk, Cohen and Komen, 1993). Thus, although universities and research institutions tend to patent proportionately less than private agents, this appears to be rapidly changing. 
Another important reason for why empirical research devoted to product development appears to be better served by the private sector (see for example Kim and Dahlman (1992)) is the private sector's close relationship to the market and to market trends and demands as well as well established marketing networks to diffuse the new product or technology more widely.

Government policies and frameworks, especially relating to regulation and intellectual property regimes have also played an important role in the development of this technology in industrialized countries. Where NBTFs did not emerge, such as in Europe and especially in Japan, the government has often been the compensating factor in providing financing in the form of loans or venture capital, or by developing links between research and production through the formation of networks. In countries such as Germany and Japan where linkages between industry and universities are strong, and there is a traditional emphasis on downstream product oriented training and research, the success rate of diffusion has been particularly high, while France and especially Britain have suffered because of weaker linkages between private and public sectors especially for applied research and commercialization.

One would expect the pattern of innovation and diffusion in developing countries to be somewhat different for a number of reasons, most obviously, low levels of scientific and technological capabilities both in basic research and training, and also in applications, and the high fixed costs required for basic and applied biological research, both for the government and for the private sector. In this chapter, it is the intention to examine the patterns of development of biotechnology in developing and newly industrializing countries and to attempt to compare and contrast their experiences with those of industrialized countries. In the first section, we present a general discussion of biotechnology in a number of developing countries and argue that because of a lack of private commitment early on, government policy was and still is especially important. This is followed by a more detailed sectoral and policy related examination of six countries in south Asia. The emphasis is placed upon the role of the government which was crucial for initiating basic research in biotechnology, and the private sector, whose involvement in accelerating applied research is now paying off.

The final section traces conclusions and patterns of biotechnology development in these countries, contrasted with the experiences of industrialized countries.

\subsection{Biotechnology R\&D in Developing Countries}

In sharp contrast to the developments in industrialized countries, most developing countries have as yet no modern industrial biotechnology. In fact most developing countries, those that have programmes on biotechnology, still tend to concentrate on second generation biotechnologies. Although many countries such as Brazil, Mexico, Cuba, India, and China are funding research on rDNA based technologies, applications in these countries are still by and large, restricted to the older biotechnologies.

Public programmes to promote biotechnology were established in most of these countries in the mid to late 1980s. However, even though these came close on the heels of similar programmes established in the early 1980s in Japan and Europe, biotechnology research has not progressed as rapidly in the developing countries. There are a variety of 
reasons for this, the most important perhaps being a lack of funding for both basic and applied research, weak linkages between basic and applied research and also a variety of restrictions on trade and capital investment, both of which have played important roles in the transfer of knowledge and capital equipment in industrialized countries.

The notable exceptions among developing countries are the countries we know as the Newly Industrializing Countries (NICs), not just the four tigers, but also other countries in south-east Asia ${ }^{104}$, such as Indonesia and Malaysia, which have made rapid strides in developing a capability in the new biotechnologies by establishing multiple centres of excellence (Komen and Persley, 1993). According to the US Office of Technology Assessment (henceforth, US OTA), Taiwan, of all these countries is perhaps the best placed in terms of its research potential as well as the amount of investment capital available to it 105. However, Korea and Singapore have also made important investments in the US market, which both countries are using to transfer knowledge and technology back to the home countries. Their weakness, as with Taiwan, lies in a shortage of trained technical staff and training programmes at home.

The second tier of developing countries who are making some progress in biotechnology research, are those who have developed some capability in scientific research, but who are still lagging behind the NICs, largely because of traditional bottlenecks, in infrastructure, in economic regulations and more often than not, a lack of access to capital markets.

In Latin America this has been the main problem despite the fact that biotechnology policies were implemented in the early 1980 s shortly after a number of industrialized countries defined their national programmes.

Although government policies to develop biotechnology began in Brazil in the early 1980s with the establishment of the National Biotechnology Programme (PRONAB), in 1981, this period marked the debt crisis in much of Latin America, and consequently PRONAB was unable to be very effective until the mid-1980s. Most of its funding was devoted to training and it is unclear what its impact on applied research has been ${ }^{106}$. However, Brazil's major difficulty appears to have been to obtain sufficient funding for its biotechnology programmes both for training and also for basic and applied research. The main task facing the government now, is to attract both foreign investment as well as to increase local private participation in biotechnology projects.

Argentina has had similar problems in funding biotechnology activities. The only two major sources are the Government, through its National Programme on Biotechnology which was established during the late 1980s and the United Nations Development Programme (UNDP), through its Regional Biotechnology Programme. Activities within the National Programme include funding of projects outlined and also training. With respect to the latter, Argentina has set up a number of undergraduate and postgraduate courses in biotechnology related areas, ranging from agriculture, a priority area, to more specific skill related areas,

104 For a more detailed discussion of the development of biotechnology in east and south Asia please refer to Acharya (1992b and 1993a).

108

US OTA (1991).

106

Clark, N. and C. Juma (1991), pp 63-66. 
such as gene mapping and genetic engineering. However, a lack of resources to expand and broaden its research infrastructure has led to considerable bottlenecks, in training and also in bridging the gap between generic research and commercial development ${ }^{107}$.

The Cuban biotechnology programme is often referred to as one of the success stories in the region. Its successes in modern medical biotechnology follow largely from the accomplishments of the Cuban revolution in medicine and health care, which included developing a distribution system which made modern medicines accessible to its urban and rural populations. The Centre for Biological Research (CIB), was established in 1982 to develop and produce interferon as an anti-viral agent ${ }^{108}$, and has grown to become the country's major research laboratory. Its success in a short period of time resulted in a recommendation by the Biological Front, a panel consisting of scientists and policy makers which operated outside the bureaucratic framework, to form a larger research institute, and the Centre for Genetic Engineering and Biotechnology was formed in 1986, with a mandate to do research on proteins and hormones, vaccines and medical diagnostics, energy and biomass, plant breeding and engineering and the genetics of mammalian eukaryotic cells ${ }^{109}$.

In contrast to the Cuban case, countries like India and China have been less successful in developing downstream biotechnology, despite having the capability in basic research. While India has a well developed infrastructure in agricultural research, largely following in the footsteps of the green revolution, it appears to have distributed its limited resources too thinly, across a wide range of sectors and technologies. The success of Cuba appears to largely have come from its use of one basic product, interferon, to enter the field of medical biotechnology, after which attempts to broaden the biotechnology base were more successful than in many other countries in the region.

In India, despite its traditional strengths in agricultural technologies, the Councils of Scientific and Industrial Research (CSIR), encouraged research in a wide variety of areas, including medical and industrial research, without much heed to downstream production. Thus although India boasts basic research skills that can compete on an international level, there are very few modern biotechnology based products which have emerged thus far. Instead, much more promise seems to be shown by the less sophisticated biotechnologies, notably tissue culture and micropropagation, where a growing interest has resulted in a sudden increase in producers and exporters, ranging from the very small scale farmer, to the large industrialist.

Similarly, Chinese scientists may be most effective in concentrating on biotechnology research in areas where China has traditional strength, such as the fermentation industry. Taiwan and South Korea both have recorded major successes in this sector and have used it to enter the biotechnology market, initially in this sector, but have later diversified.

The last tier of countries includes the least technologically developed countries. Many countries in Africa have only recently developed national programmes on biotechnology, and the majority still depend only upon university research programmes for research on

Acharya, R and J. Mugabe (1995b).

108

Fransman, M. (1991), p 63.

109

Ibid. 
biotechnology whose budgets tend to be small ${ }^{110}$. Kenya, Ethiopia and Tanzania have specific policy documents on biotechnology, outlining national priorities and goals for this technology. Ethiopia's National Science and Technology Plan identifies two major technologies as priority technologies: microelectronics and biotechnology. Zimbabwe is presently in the process of defining its Science and Technology Policy. Most of the other countries in east and west Africa are still lagging behind these countries and depend more on implicit Science and Technology policies defined within their national development goals, and already established institutions, to carry out biotechnology R\&D ${ }^{111}$.

Being largely agricultural countries, it is natural that most of their biotechnology activities are agricultural as well. Animal husbandry and diagnostics and vaccines to detect and prevent common diseases in the region are also important research activities. In agriculture, attempts are being made to improve local varieties and their productivity, largely through tissue culture. The crops are mainly subsistence crops which are grown predominantly in the area, such as cassava and sweet potato and which are important for the agricultural base in these countries, while some countries are also doing research on important cash crops, such as pyrethrum, tea and coffee in Kenya and coffee and tobacco in Zimbabwe. Similarly, animal biotechnology tends to concentrate on diseases common to the area. Here research is relatively advanced because of the presence of three major international research centres which are funded by the Consultative Group for International Agricultural Research (CGIAR), namely the International Laboratory for Research and Animal Diseases (ILRAD), the International Centre for Insect Physiology and Ecology (ICIPE) both based in Kenya, and the International Livestock Research Centre for Africa (ILCA) in Ethiopia. The work done by these centres, because it receives international funding and support from the international research community, is far more sophisticated and includes the use of genetic mapping and engineering techniques to develop vaccines for animal and insect diseases predominant in the region.

The combination of low skills and low R\&D investment in biotechnology, has placed these countries at a particular disadvantage vis a vis industrialized and industrializing countries. As the cost of developing new products declines and as the technology frontier is pushed further outward by these latter groups of countries, the least developed countries may be in a position to enter using lower level techniques. However, their ability to catch up or to narrow the technological gap between themselves and the more technologically advanced industrializing countries, will depend very much on access to information and training programmes, and a skilful management of their scarce financial and human resources.

In agriculture thus far, where a number of developing countries have established a research and training base, largely as a result of the research requirements of the green revolution, the greatest use has been made of biotechnologies in these countries, ranging from simple plant breeding techniques to the more powerful gene tagging and engineering techniques. With few exceptions agricultural research has remained largely a domain of the

110 Acharya, R. and J. Mugabe (1995b).

111 Ibid. 
public sector, especially for subsistence crops and to some extent cereals ${ }^{112}$. However, with the rise of ag-bio as it has come to be called, this is likely to change in a similar way, with entry barriers to modern agricultural biotechnology also slowly becoming higher especially for a number of developing countries who are already lagging behind.

This brief survey shows that in most developing countries, the majority of biotechnology research appears to be influenced by policy. Government policies have pushed biotechnology in a direction which addresses national problems of food security and health care, especially in developing medical products for local diseases. Government activities and funding in turn, have been dominated by basic research and training. The major problem faced by most developing countries, including the NICs, is that of developing a steady supply of skilled researchers who can contribute to biotechnology research. This problem is most acute in a number of African countries where the research and training base is still very weak.

While this section has given a broad overview of some of the problems faced by developing countries, from the point of view of this thesis however, the intention of examining biotechnology in developing countries is to study the patterns of imitation and innovation. A relatively more in depth analysis of biotechnology activities is therefore needed. For reasons of practicality, six countries in the region of south and south-east Asia were surveyed. These countries, i.e., China, India, Philippines, South Korea, Taiwan and Thailand, present a wide range of capabilities and comparative advantage, as well as an intermediate level of scientific and technological capacities and have demonstrated considerable skills in biotechnology R\&D, both of a basic and an applied nature.

\subsection{Building Technological Capability: The Case of South-Asia}

In this section, we examine research and development activities relating to biotechnology in countries which find themselves in an intermediate position, ie. having the technological capability for imitation, but not yet belonging to the group of countries who can be called innovators. Although much of the research in these countries is still confined to public sector laboratories, the private sector is slowly developing capabilities and investing in biotechnology in a changing international environment where interactions between countries especially with respect to the flow of goods and services, capital investment and exchange of knowledge is becoming more liberalized. Many of them have a comparative advantage in natural resource and agriculture based products. Biotechnology we argue will tend to enhance this comparative advantage based on endowments. However, the ability of countries to develop their scientific and technological capabilities will determine their ability to develop dynamic comparative advantage and indeed change their static comparative advantage in the long run through the acquisition and development of these new technological capabilities.

112 For example the system of Land Grant Universities and Experiment stations set up in the US to do the more experimental, applied work required of agriculture (Evenson, R. E. (1993)). Most developing countries have also established extensive networks of agricultural research institutions, many of them employing a number of extension workers to diffuse new varieties into national agricultural systems. 
This section is divided into two broad parts, covering government and private sector activities and their contribution to basic and applied research in biotechnology. The following section is a case study of productivity increasing technical change in agriculture and its implications for economic welfare and growth. The final section draws some basic conclusions on patterns of innovation and imitation in industrialized and developing countries and their implications for consumer welfare.

\subsubsection{The Role of Government Policy}

The lack of a large private sector has made government activities an important component of efforts to develop national capabilities in biotechnology. This as we saw in the previous chapter was also important especially for generic research and training in a number of industrialized countries. In developing countries, this component tends to be all the more important given the absence of private sector activities, especially during the early stages of R\&D. Table 4.1. provides some statistics of R\&D capabilities of selected developing and industrializing countries.

Table 4.1. A Comparison of R\&D Expenditures across Selected Countries (US \$ millions)

\begin{tabular}{|l|l|l|l|l|l|}
\hline Country & Year & $\begin{array}{l}\text { Total } \\
\text { R\&D } \\
\text { Expenditure }\end{array}$ & \% of GNP & $\begin{array}{l}\text { Researchers } \\
\text { per 10,000 } \\
\text { population }\end{array}$ & $\begin{array}{l}\text { R\&D per } \\
\text { researcher } \\
\text { (US\$ 1000) }\end{array}$ \\
\hline USA & 1989 & 140,486 & 2.69 & 39 & 142 \\
\hline & 1991 & 151,600 & 2.67 & 41 & -- \\
\hline Japan & 1989 & 76,049 & 2.69 & 37 & 165 \\
\hline & 1991 & 101,557 & 2.77 & 41 & 186 \\
\hline Korea & 1989 & 3,980 & 1.92 & 16 & 60 \\
\hline & 1990 & 4,481 & 1.91 & 16 & 64 \\
\hline Taiwan & 1989 & 2,094 & 1.38 & 20 & 63 \\
\hline & 1991 & 3,175 & 1.70 & 23 & 69 \\
\hline China & 1987 & 3,413 & 0.96 & 3 & 9 \\
\hline & 1988 & 3,873 & 1.01 & 4 & 9 \\
\hline India & 1988 & 2,494 & 0.7 & 3.12 & 20.79 \\
\hline
\end{tabular}

Source: National Science Council, Taiwan (1993), Report on the Survey of R\&D in Science and Technology, Korea (1993), Dr Tae Ik Mheen, Director Genetic Engineering Research Institute (Personal Communication). 
For the newly industrializing countries and the more advanced developing countries such as Taiwan and Korea, there is already evidence that overall government spending on R\&D forms a relatively high percentage of Gross National Product especially in Korea where spending has almost reached the two percent level. Countries such as China and India, where investment in R\&D is also quite high, are however still lagging behind.Nevertheless, that increasing importance is being placed on investment in both research and training, is clearly evident from these positive trends both in industrialized countries, and increasingly in lagging countries such as India and China where the number of researchers as a percentage of the labour force is still quite low, indicating a need for a large injection of funds in this direction.

Biotechnology has also formed part of this trend in both sets of countries. As with industrialized countries, most of the countries surveyed here, formed national programmes in the early to late 1980s. This followed closely the pattern established in industrialized countries, ie., national guidelines outlining priority areas of research as well as funding for basic research and training. National programmes on biotechnology have by and large been coordinated by national government departments or centres and laboratories of excellence. The former, as in the case of India, Thailand, China and the Philippines, are largely semiautonomous public sector bodies set up for coordinating national biotechnology policies, and disseminating funding for priority projects. These national coordinating agencies, the National Centre for Genetic Engineering and Biotechnology (NCGEB) in Thailand, the China National Centre for Biotechnology Development (CNCBD) in China, and the Department of Biotechnology (DBT) in India, were all set up in the 1980 s to perform the important task of implementing national policies on biotechnology and are in charge of overseeing national projects in priority areas. The Philippines' National Plan on biotechnology was approved in 1990 by the Science and Technology Coordinating Council (STCC), which implements and coordinates national science and technology policies. The plan outlines a number of projects within five priority areas of agriculture, aquaculture, health, industry and the environment.

In the case of Taiwan and Korea, the task of developing capabilities in biotechnology have been left up to national centres of excellence. The Development Centre for Biotechnology (DCB) in Taiwan and the Genetic Engineering Research Institute (GERI) in Korea, not only coordinate national research projects, but are used to set a standard for biotechnology R\&D. Supplied with modern equipment and some of the most highly trained staff in the country, these laboratories present all round excellence in modern biotechnology $\mathrm{R} \& \mathrm{D}^{113}$.

The importance of involving the private sector, especially through cooperation with basic research strengths, was recognized at an early stage. Most, with the possible exception of Korea, whose previous experience with industrialization led to the formation of large companies who were well equipped to deal with the large sums of up-front investment needed for modem biotechnology, recognized the need for investing in applied research. Public sector institutions, while possessing the capabilities for basic research, had in many cases very little experience with commercialization ${ }^{114}$. On the other hand, the relatively small size

113 Based on a survey conducted in 1991 in six Asian countries. For more details please refer to Acharya (1993a) 
of the private sector, when considering the size of investments that had to be made, made it difficult for private companies to operate alone in many cases. This recognition has led to efforts to try and pool the resources of these two sectors. In Korea, the Korean Genetic Engineering Research Association (KOGERA) and in India, the Biotechnology Consortium India Limited (BCIL) were formed to deal specifically with this task. KOGERA to date has been relatively successful in harnessing the potential of the private sector for large national projects, especially concerning environmental biotechnologies. The BCIL was only formed in 1991 and it remains to be seen how successful it will be in fulfilling its task.

Other countries, rather than setting up new organizations have used a previously established infrastructure to tackle this problem. In Taiwan for example the DCB's role is also to encourage and improve cooperative research between national universities and research institutions such as the Academia Sinica, and private companies, and has been instrumental in commercializing a number of products developed at the DCB through the private sector 115. Similarly, in China, the torch and spark programmes which were established to commercialize technology and diffuse it amongst the rural population respectively, have been used for biotechnology as well. Thailand's NCGEB has also been instrumental in performing this task, while in the Philippines the National Institutes of Biotechnology and Applied Microbiology (BIOTECH), is not only a national laboratory for biotechnology, with a large percentage of its staff seconded from academic institutions around the country, but has also been rather successful in commercializing a number of products in recent years.

\subsection{2.}

\section{Research and Training}

One of the most uphill tasks faced by most developing countries is that of acquiring qualified personnel. Biotechnology, although science based, straddles a number of different research areas, and breaks down traditional boundaries between natural science subjects. Most countries, until very recently, did not include specific biotechnology courses in their national curricula. A major portion of government funding for biotechnology in recent years therefore, has gone into designing and setting up courses in biotechnology. As a result, a number of universities in the region offer training courses or degrees in biotechnology.

In Korea, other than the GERI, of the 103 or so universities and colleges in the country, 17 universities have initiated new departments of biotechnology, both at the graduate and undergraduate levels. In addition, 15 universities and colleges have established biotechnology or genetic engineering centres on their campuses ${ }^{116}$. Taiwan, on the other hand, has relied more on sending students abroad for training, at least in the short term. The growth of biotechnology in the country in the last decade or so has however, lured a number of these researchers back and their expertise is being used to set up courses and a research network in Taiwan ${ }^{117}$.

115 Personal Communication with members of the DCB, December 1991.

116

Han, M. (1990), p, 14.

117 The National Science Council in Taiwan is the body in charge of funding public sector institutions. This funding includes both research programmes at prestigious institutions such as the Academia Sinica, and also programmes geared specifically for training young scholars in the biological 
Most of the other countries surveyed however, have been unable to overcome the problem of training as quickly, for two main reasons. First, many of them have not built up sufficient strength previously in science and technology, especially in terms of human capital. Second, a lack of financial resources have created major blocks to further investment in training or in collaborative projects with foreign universities or training institutions. Although statistics specifically on training are hard to obtain, if the figures on total government investment in biotechnology are anything to go by (public funding worth $\$ 3,430,217$ in 1991 for India ${ }^{118}, \$ 1,355,389$ in 1990 for Thailand ${ }^{119}$ and $\$ 1,056,500$ in 1991 in the Philippines ${ }^{120}$ compared to $\$ 17,469,400$ in 1989 in Korea ${ }^{121}$ ), the magnitudes invested by countries such as Korea are far higher, both in absolute and in relative terms, than those of the other countries in the region.

Those with some degree of previous capability, for example India have been somewhat more successful than Thailand or the Philippines, where a major shortage of skilled staff continues. The DBT in India has thus far helped over 19 universities across the country establish postgraduate training programmes in biotechnology. Short term training courses (2-4 weeks each) especially for those already working in the field and requiring an update on new biotechnology techniques as well as fellowships to study abroad are offered each year. Thailand and the Philippines still tend to rely largely on foreign training for their researchers, although the longer term goal is to develop local programmes of a similar nature. The Philippines at present makes efficient use of its few human resources through a system of exchanging and sharing researchers between research institutions and universities, while developing training programmes in biotechnology.

Research collaboration is another important manner by which technical knowledge can be transferred. Access to knowledge, especially information about regional R\&D programmes and research on matters of common interest, such as disease control and prevention, is vitally important in a fast moving field such as biotechnology. Although still in a stage of infancy, this method is also being pursued by a number of countries in the region. There are two major ways in which this is being tackled:

1. The setting up of centres to promote collaboration between researchers at an international level and also to exchange information and technologies between countries. One recent example of this is the China-EC Biotechnology Centre which aims to improve research in agricultural and medical biotechnologies. Housed by the China National Centre for

sciences It is estimated (personal communication with officials at the National Science Council in Taipei, August 1994) that as many as 2,000 Taiwanese researchers return from the US each year.

118 Estimated from the Annual Financial figures of the Department of Biotechnology 1991-2

119 Calculated from the Annual Report of the National Centre for Genetic Engineering and Biotechnology (NCGEB), 1990-91.

${ }^{120}$ Proposed budget for Biotechnology Mega-Projects in the Biotechnology Action Plan (Padolina, 1990).

121 See figure 4.2. in this chapter. 
Biotechnology Development (CNCBD) in Beijing, and supervised both by the CNCBD and the Commission of the European Communities, the Centre's main function is to provide a basis for improved cooperation between research institutes in China and in member countries of the European Community. The Centre was established in November 1991 and will also manage all forms of collaboration between the EEC and China, including doctoral and postdoctoral training, visiting exchange programmes, jointly organized workshops and symposia, as well as any form of joint research programmes. A newsletter has also just been launched which will keep researchers informed about ongoing events and research activities, both in European countries as well as in China (IBIS, 1991). Similarly, Thailand set up the USThailand Commercialization of Science and Technology Programme (UST/COST) in 1990 whose participants include the US Agency for International Development, the Board of Science and Technology for International Development (BOSTID) of the US National Research Council and Biotechnology International, a programme at the University of Maryland in the $\mathrm{USA}^{122}$.

2. To overcome the problem of access to information, a number of countries in the region have also established biotechnology databases, and computerised networks which can be accessed by researchers and industrialists across the nation. In India for example, the BCIL has established the Bio-Informatics Network in India which has contributed greatly to improving the flow of information to Indian researchers ${ }^{123}$. Similarly the NCGEB's documentation centre includes international newsletters about developments in the field of biotechnology, both in terms of scientific breakthroughs as well as policy changes (NCGEB, 1991).

Thus to summarize, while developing countries in the region followed shortly after most industrialized countries in establishing national R\&D programmes in biotechnology, the pace and method of R\&D has been very different. Developing countries in south-Asia, even with a relatively well established research network, have faced severe shortages of trained personnel and commercializing products developed through biotechnology. The main causes appear to have been financial and imperfect information flows, both of which are being addressed with varying degrees of success. However, the largest obstacle which most still face is the prospect of commercialization. The importance of the private sector in terms of its marketing and production experience was stressed in the previous chapter, and for developing countries, it is no less important. In the following section therefore, we examine the role played by the private sector thus far, and examine its importance both for basic research as well as in the production of higher quality products.

122 Biotechnology and Development Monitor (1992), no. 12, September, pp 11-13.

${ }^{123} \mathrm{BCIL}$ (1993). Although the network is relatively small and young, BCIL has had considerable success in a short period of time in providing this service to industrialists and also researchers in the country. Another, larger database, but which as yet only includes some information on biotech, is that maintained by the Technology Information, Forecasting and Assessment Council (TIFAC). TIFACLINE, a database which provides relevant information such as patent status and major producers and markets for energy, environmental and food technologies, has recently been established and is also accessible from nodal centres which have been established across the country (TIFAC, 1994). 


\subsection{Private Sector Commitment to Biotechnology}

In the previous chapter. it was argued that the private sector has played an important role especially in commercializing the results of basic research in biotechnology. This has been the case especially in the USA where the NBTF and its success gradually led to the involvement of the multinational firm in biotechnology R\&D. In developing countries as we show below, the private sector tends to be smaller, both in absolute size of sales, as well as in production scale. For example, the size of investment made by individual companies in India (figure 4.6.) is small compared to sales in Taiwan (figure 4.4.) which in turn is smaller than sales figures for biotechnology firms in the US and Europe (see appendix I for the annual sales figures for twenty five biotechnology companies in 1992). This, combined with little or no access to investment capital has meant that the private sector has been slower to respond. Nevertheless, a number of successes in recent years, especially in simpler technologies, have gradually revealed the nature of the relative strengths and weaknesses of the private sector and its potentials and problems.

Of the countries in the region. the private sector is perhaps most well established in Korea and Taiwan. Both countries established strong government led policies in the early 1980s and established national institutions and laboratories for innovation, as well as for linking basic research performed in public sector laboratories with downstream product development which was dominated by private companies. The importance of Korea's private sector is apparent from the size of its total contribution to biotechnology R\&D, which now exceeds similar government contributions (see table 4.2 below). It grew at an average annual rate of 44.5 percent, as compared to the government contribution which at 29.4 percent. was almost half that of the private sector, during the $1980 \mathrm{~s}$.

Table 4.2. R\&D Funding for Biotechnology in Korea

\begin{tabular}{|l|l|l|c|c|c|c|c|l|}
\hline $\begin{array}{l}\text { Source } \\
\text { (US\$ } \\
1000)\end{array}$ & 1983 & 1984 & 1985 & 1986 & 1987 & 1988 & 1989 & $\begin{array}{l}\text { Annual } \\
\text { Growth } \\
\text { Rate } \\
(\%)\end{array}$ \\
\hline Govt & 2,860 & 4,143 & 5,636 & 6,143 & 8,143 & 11,552 & $17,469.4$ & 35.92 \\
\hline Private & 6,857 & 16,571 & 22,429 & 22,714 & 27,430 & 33,871 & NA & 44.5 \\
\hline Total & 9,717 & 20,714 & 28,065 & 28,857 & 35,573 & 44,014 & NA & 40.22 \\
\hline
\end{tabular}

Source: Han, M.H. (1990), p 14 and Tae $\mathbb{k}$ Mheen, Director, GERI (Personal Communication).

The two kinds of large firms which dominate industrial production of biotechnology products are the chaebols, and the pharmaceutical companies. Many of these companies have 
reached an advanced stage of technological and scientific capability. This is evident from the number of companies which have invested in industrialized countries, either through direct buy outs or through collaboration, both at the industrial as well as the research level. Two of these for example, Cheil Sugar which is a part of Samsung and Lucky Limited, which is owned by the Lucky Goldstar group, not only have expansive R\&D facilities in Korea, but have also established wholly owned subsidiaries in the US. Cheil Sugar established Eugenetech in New Jersey which carries out research in cell biology and develops cell lines for the production of new drugs, for example alpha interferon. Lucky set up Lucky Biotech in California in collaboration with Chiron. The research skills, primarily in cloning and growth hormones, are concentrated in the subsidiary company which probably benefits immensely from collaboration with researchers in the USA, while the results are then sent back to the parent company for further development and scale up where production costs are lower ${ }^{124}$. Thus, while the company uses the knowledge intensive skills of researchers in industrialized countries, the actual production is carried out in Korea, where engineering and production, although requiring skilled labour, are cheaper than in the USA. It is also important to add here, that production costs can be lowered further by adapting the technology and the production process, to use abundant factors such as unskilled labour more intensively.

In the pharmaceutical sector the largest company, Dong-A controls $10 \%$ of the Korean market, while Chong Kun Dang and Yuhan have a market share of about 5\% each ${ }^{125}$.

The sector most active in biotechnology research as measured by sales is the fermentation industry where Korea has a natural comparative advantage arising out of traditional biotechnology applications in this industry. Output in the pharmaceutical sector, although less phenomenal, is also rising at an extremely rapid rate. Vaccines and diagnostics especially have shown high average growth rates and it is estimated that by the year 2000 Korea will produce $2 \%$ of the world's biologically produced pharmaceuticals ${ }^{126}$.

Although comparable figures on government and private sector investment in biotechnology, are not so readily available in the other countries surveyed, with the possible exception of Taiwan, the private sector is in general less active in biotechnology R\&D in terms of absolute size, in the region. Even in Taiwan, it appears that funding is dominated by the government, especially in the area of applied research, demonstrating perhaps a reluctance on the part of industry dominated by small and medium sized enterprises, to invest in biotechnology research ${ }^{127}$.

${ }^{124}$ Yuan, R. and M. Hsu (1991).

125

Ibid.

126

US OTA (1991), p 237.

${ }^{127}$ Personal communication with members of the Development Centre for Biotechnology in Taipei in October 1991. 
Table 4.3. Breakdown of Biotechnology R\&D in Taiwan in NT\$ in 1991

\begin{tabular}{|c|c|c|c|}
\hline Total & Basic Research & Applied Research & Experimental Devlpt \\
\hline $\begin{array}{c}2,765 \\
(\% \text { of Total })\end{array}$ & $\begin{array}{c}1,116 \\
(40.4 \%)\end{array}$ & $\begin{array}{c}1,423 \\
(51.5 \%)\end{array}$ & $\begin{array}{c}226 \\
(8.1 \%)\end{array}$ \\
\hline
\end{tabular}

Source: National Science Council, Government of Taiwan.

Nevertheless, it is clear that private investment is rising. This is demonstrated by the large number of firms active in biotechnology research and development as well as from the increasing number of products which are being marketed by these companies. For example, "new" biotechnology firms which have been formed since 1982 showed estimated total assets of US\$ 70 million in 1989 . This number has increased considerably since.

Table 4.4. Estimated assets of new biotechnology companies in Taiwan

\begin{tabular}{|l|l|l|}
\hline Company & Year Founded & $\begin{array}{l}\text { Assets 1989 } \\
\text { (US\$ million) }\end{array}$ \\
\hline Tai-Fu Pharmaceutical Corp. & 1982 & 6.0 \\
\hline Tai-Da Pharmaceutical Co. Ltd & 1982 & 1.5 \\
\hline General Biologicals Corp. & 1984 & 12.0 \\
\hline BGH Biochemical Co. Ltd & 1984 & 0.5 \\
\hline Life Guard Pharmaceutical Inc. & 1984 & 28.0 \\
\hline Ever New Biotechnology Co. Ltd & 1984 & 8.0 \\
\hline Search Biological Technology Corp & 1987 & 1.5 \\
\hline King Car Biotechnology Co. & 1988 & 1.5 \\
\hline $\begin{array}{l}\text { Ming-Shing Pharmaceutical Technology } \\
\text { Corp. }\end{array}$ & 1988 & 1.5 \\
\hline Taiwan Biotech Inc. & 1989 & 3.0 \\
\hline Hwa-Yang Pharm Technology Inc & 1989 & 1.5 \\
\hline Grand Biotech Corp. & 1989 & 5.0 \\
\hline TOTAL & & $\mathbf{7 0 . 0}$ \\
\hline
\end{tabular}

Source: Soong (1991), p17. 
As one can see from this list, unlike Korea, where the firms are mostly already established chaebols, new biotechnology in Taiwan appears to feature a number of biotechnology specific companies. This appears to be largely the result of a venture capital funding system which was initiated by the government, the result of which has been the establishment of 13 venture capital firms since 1986 (table 4.4).

Table 4.5. Market Projections of Products in Taiwan In NT Dollars (US Dollars) millions

\begin{tabular}{|c|c|c|c|c|c|c|c|}
\hline Product & 1990 & 1991 & 1992 & 1993 & 1994 & $1995^{\circ}$ & $1996^{\circ}$ \\
\hline $\begin{array}{l}\text { Tissue } \\
\text { Culture }\end{array}$ & $\begin{array}{l}4000 \\
(151)\end{array}$ & $\begin{array}{l}5000 \\
(185)\end{array}$ & $\begin{array}{l}6000 \\
(232.6)\end{array}$ & $\begin{array}{l}8000 \\
(305.3)\end{array}$ & $\begin{array}{l}10000 \\
(371.8)\end{array}$ & $\begin{array}{l}12000 \\
(446.1)\end{array}$ & $\begin{array}{l}16000 \\
(594.8)\end{array}$ \\
\hline $\begin{array}{l}\text { Hepatitis B } \\
\text { and vaccines }\end{array}$ & $\begin{array}{l}700 \\
(26.3)\end{array}$ & $\begin{array}{l}1000 \\
(36.9)\end{array}$ & $\begin{array}{l}1200 \\
(46.52) \\
\end{array}$ & $\begin{array}{l}1300 \\
(49.62) \\
\end{array}$ & $\begin{array}{l}1400 \\
(52.05) \\
\end{array}$ & $\begin{array}{l}1500 \\
(55.76) \\
\end{array}$ & $\begin{array}{l}1600 \\
(59.5) \\
\end{array}$ \\
\hline $\begin{array}{l}\text { Medical } \\
\text { Instruments }\end{array}$ & $\begin{array}{l}120 \\
(4.5)\end{array}$ & $\begin{array}{l}200 \\
(7.38)\end{array}$ & $\begin{array}{l}300 \\
(11.63)\end{array}$ & $\begin{array}{l}400 \\
(15.27)\end{array}$ & $\begin{array}{l}600 \\
(22.31) \\
\end{array}$ & $\begin{array}{l}1000 \\
(37.18)\end{array}$ & $\begin{array}{l}1500 \\
(55.76)\end{array}$ \\
\hline $\begin{array}{l}\text { Waste Water } \\
\text { Treatment }\end{array}$ & $\begin{array}{l}300 \\
(11.3) \\
\end{array}$ & $\begin{array}{l}400 \\
(14.7) \\
\end{array}$ & $\begin{array}{l}580 \\
(22.48) \\
\end{array}$ & $\begin{array}{l}700 \\
(26.72) \\
\end{array}$ & $\begin{array}{l}800 \\
(29.74) \\
\end{array}$ & $\begin{array}{l}900 \\
(33.46) \\
\end{array}$ & $\begin{array}{l}1000 \\
(37.18) \\
\end{array}$ \\
\hline $\begin{array}{l}\text { Specialty } \\
\text { Chemicals }\end{array}$ & $\begin{array}{l}10 \\
(0.38) \\
\end{array}$ & $\begin{array}{l}30 \\
(1.11) \\
\end{array}$ & $\begin{array}{l}60 \\
(2.33) \\
\end{array}$ & $\begin{array}{l}120 \\
(4.58) \\
\end{array}$ & $\begin{array}{l}300 \\
(11.15) \\
\end{array}$ & $\begin{array}{l}500 \\
(18.59) \\
\end{array}$ & $\begin{array}{l}800 \\
(29.74) \\
\end{array}$ \\
\hline Antibiotics & $\begin{array}{l}20 \\
(0.75)\end{array}$ & $\begin{array}{l}40 \\
(1.48)\end{array}$ & $\begin{array}{l}80 \\
(3.1)\end{array}$ & $\begin{array}{l}160 \\
(6.11)\end{array}$ & $\begin{array}{l}400 \\
(14.87)\end{array}$ & $\begin{array}{l}600 \\
(22.31)\end{array}$ & $\begin{array}{l}800 \\
(29.74)\end{array}$ \\
\hline $\begin{array}{l}\text { Diagnostic } \\
\text { Reagents }\end{array}$ & $\begin{array}{l}120 \\
(4.51)\end{array}$ & $\begin{array}{l}160 \\
(5.9)\end{array}$ & $\begin{array}{l}200 \\
(7.75)\end{array}$ & $\begin{array}{l}250 \\
(9.54)\end{array}$ & $\begin{array}{l}300 \\
(11.15)\end{array}$ & $\begin{array}{l}360 \\
(13.38)\end{array}$ & $\begin{array}{l}400 \\
(14.89)\end{array}$ \\
\hline
\end{tabular}

Source: National Science Council, Taiwan.

- Exchange rate for 1994 (US\$ 1 = NT\$26.9) used.

In terms of total sales, Taiwanese biotechnology companies recorded a figure of US\$ 22 million in 1987. In 1989, annual sales totalled US \$ 44.67 million for pharmaceutical products, US \$ 279 million for foodstuffs, US $\$ 65.96$ million for agricultural supplies and US $\$ 13.83$ million for services ${ }^{128}$. By the year 2000 Taiwan is aiming at about $2 \%$ of the world market in biotechnological products ${ }^{129}$. Projections made by the National Science Council in Taiwan also show the market value of a number of Taiwanese biotechnology products into the mid 1990s. Table 4.5 for example, shows phenomenal growth in some 
products, in terms of their market size in the early 1990s. For example, in the case of antibiotics and diagnostic reagents, the size of the market has expanded considerably, resulting also in an interest in developing capabilities in these areas. The Taiwanese pharmaceutical industry is dominated by foreign multinationals who largely use Taiwan for bulk packaging and formulation rather than scientific research. The pharmaceutical sector therefore is not well developed in Taiwan and one of the primary goals of the national biotechnology programme is to develop these capabilities further ${ }^{130}$.

Thus as projected by the National Science Council in Taiwan (table 4.5), the market for agricultural and medical products will be especially strong, a projection reflected in the number of companies in Taiwan which are involved in agricultural products such as biopesticides and insecticides and antibiotics and diagnostic R\&D ${ }^{131}$.

The success story in terms of agricultural exports in this region has been that of Thai exports of orchids. Although the technology is relatively low-tech in the traditional hierarchy of techniques in biotechnology, namely tissue culture and cloning, the success of Thai orchid growers and exporters is phenomenal. A large number of these private companies are concentrated around Bangkok and it is estimated that their average turnover is valued at about US $\$ 20$ million annually. Indications thus far are that this market, especially in industrialized countries, is likely to continue growing for a period. Moreover since Thailand's food processing industry has been expanding at the rate of about $20 \%$ per year, it is likely that government support, as well as private investment in agricultural biotechnology, will grow in order to take advantage of this expansion of value added products ${ }^{132}$. Present government policy, despite the emphasis on other export crops such as rubber and rattan, recognizes this success by encouraging the development of tissue culture based temperate flowers for which there is a large regional market.

In India, private firms have also been most successful in the agricultural sector. Indian producers of ornamental plants and flowers have largely followed in the footsteps of Thai exporters. India's local market however is large enough to absorb much of this surge in production and with a growing middle class, local companies are finding tremendous success in India itself. There are, however, some companies which have built up their export markets as well. This is largely in response to the incentive system built up by the Indian Government, which has set up export processing zones and provided tax incentives to companies to export. Two of the most successful tissue culture companies in India, have now established separate biotechnology divisions or laboratories where tissue culture techniques are being applied to a large number of indoor plants and commercial plants and although the size of the initial investment and sales is still small relative to industrialized countries, considerable interest has been generated as a result of the initial successes of tissue culture companies (see table 4.6 for a list of a few of these companies). 1995)

${ }^{130}$ The pharmaceutical sector in India and Taiwan is the subject of a forthcoming study (Acharya,

${ }^{131}$ Development Centre for Biotechnology (1994), lists all companies active in the various sectors which are dominated by biotechnology R\&D. 
Table 4.6. Important Tissue Culture Companies in India

\begin{tabular}{|c|c|c|c|c|c|}
\hline Name & $\begin{array}{l}\text { Investment } \\
\text { (US \$ mil) }\end{array}$ & $\begin{array}{l}\text { Foreign } \\
\text { Collaboration }\end{array}$ & Crops & $\begin{array}{l}\text { Tumover } \\
\text { (US \$ } \\
\text { mil) }\end{array}$ & $\begin{array}{l}\text { Capacity } \\
\text { plants/yr }\end{array}$ \\
\hline $\begin{array}{l}\text { A.V. } \\
\text { Thomas, } \\
\text { Cochin }\end{array}$ & 1.35 & $\begin{array}{l}\text { Phyto Nova } \\
\text { Shell, UK }\end{array}$ & $\begin{array}{l}\text { Cardamom, } \\
\text { Banana, } \\
\text { Lillies, } \\
\text { Ornamental }\end{array}$ & 9.675 & 6 million \\
\hline $\begin{array}{l}\text { Indo- } \\
\text { American } \\
\text { Hybrid } \\
\text { Seeds, } \\
\text { Bangalore }\end{array}$ & 2.9 & $\begin{array}{l}\text { Sunkee, } \\
\text { Australia }\end{array}$ & $\begin{array}{l}\text { Banana, } \\
\text { Ornamental } \\
\text { plants }\end{array}$ & 1.51 & $\begin{array}{l}10 \\
\text { million }\end{array}$ \\
\hline $\begin{array}{l}\text { Unicorn } \\
\text { Biotech } \\
\text { Hyderabad }\end{array}$ & 0.697 & $\begin{array}{l}\text { Godrej, } \\
\text { Hindustan Lever }\end{array}$ & $\begin{array}{l}\text { Banana, } \\
\text { Strawberry, } \\
\text { Ornamental }\end{array}$ & $\begin{array}{l}0.58 \text { total } \\
\text { order } \\
\text { from } \\
\text { Holland, } \\
\text { Italy }\end{array}$ & 6 million \\
\hline $\begin{array}{l}\text { Bio Tissue } \\
\text { laboratory } \\
\text { Hyderabad }\end{array}$ & 0.232 & $\begin{array}{l}\text { APIDC, IDBI, } \\
\text { CVF }\end{array}$ & $\begin{array}{l}\text { Banana, } \\
\text { Orchids, } \\
\text { Roses }\end{array}$ & - & 5 million \\
\hline $\begin{array}{l}\text { Harrison } \\
\text { Malayalam, } \\
\text { Bangalore }\end{array}$ & 7.74 & $\begin{array}{l}\text { Semundo } \\
\text { Saatzucht and } \\
\text { Agro Saten } \\
\text { (Germany) }\end{array}$ & $\begin{array}{l}\text { Vegetable } \\
\text { seeds, } \\
\text { orchids, } \\
\text { banana }\end{array}$ & - & $\begin{array}{l}10 \\
\text { million }\end{array}$ \\
\hline $\begin{array}{l}\text { SPIC } \\
\text { Madras/ } \\
\text { Coimbatore }\end{array}$ & 7.74 & - & $\begin{array}{l}\text { Ornamental } \\
\text { plants }\end{array}$ & - & $\begin{array}{l}10 \\
\text { million }\end{array}$ \\
\hline $\begin{array}{l}\text { ITC } \\
\text { Agrotech, } \\
\text { Hyderabad }\end{array}$ & 1.94 & $\begin{array}{l}\text { Continental of } \\
\text { Rains Australia }\end{array}$ & $\begin{array}{l}\text { Ornamental } \\
\text { plants, cash } \\
\text { crops, oil } \\
\text { seeds }\end{array}$ & - & - \\
\hline
\end{tabular}

Source: Department of Biotechnology, Government of India, (1992).

Similarly in the pharmaceutical sector, private companies are actively pursuing biotechnology research. While most of this research is geared to the local market, such as 
diagnostic kits, which have been developed for a number of diseases and are available on the local market, there appear to have been minor successes on the export front as well. Genei Limited is the country's first manufacturer of indigenously-designed recombinant DNA research tools. It presently exports some of its products to the USA.

In both Thailand and the Philippines, agricultural biotechnology will continue to dominate exports. There is also a large potential market in the industrialized world for exotic fruits such as star fruit, rambutan, durian, shiitake mushrooms and Amaryllis. Thailand is presently doing tissue culture research on a number of other agricultural products such as palm oil, rubber, rattan, banana and rice. Similarly, the Philippines is encouraging tissue culture in agricultural products which have a large potential export market, such as coconut, rattan and bamboo, the first two forming major exports. Biotechnology can be used to enhance production and strengthen already strong markets or to exploit potential ones. There is also considerable demand in south Asia for a number of temperate climate crops such as strawberries, asparagus, carnations and roses, some of which are already being produced in high altitude areas in this region. However, biotechnology research which enables the adaptation of some of these varieties to certain climatic regions, can potentially ensure their all-year round growth. Thus, especially for those countries with a large agricultural base and a diverse climate, the potentials for biotechnology based agricultural exports are enormous. However, the key to successful development is matching production and marketing capabilities. ${ }^{133}$

Another area where there is great scope especially for China, Taiwan, the Philippines and Thailand, is in aquaculture. Until recently, aquaculture in south-east Asia and other countries included in this survey such as India was largely dependent on traditional techniques such as controlling alkalinity, oxygen content and traditional breeding methods. Recently however, biotechnology methods have increased their attraction by improving productivity and product quality. Since the first international symposium on marine biotechnology held in Japan in 1989, there has been growing interest in the use of modern biotechnology techniques to improve marine output.

The market for shrimp and other aquaculture products, it has been estimated, has been growing since 1970 and is expected to continue to grow at about $5 \%$ per year, placing pressure on existing shrimp farmers to improve productivity. With the exception of India, most of the large producers and exporters of aquaculture based products in the region, have registered high growth rates in aquaculture production (see table 4.7), and the Indian government hopes to catch up through biotechnology, especially to produce shrimp, prawn and carp. The steadily growing aquaculture market has increased competition between a number of countries, with many of them stressing the use of biotechnology in aquaculture to improve productivity. Countries more advanced in biotechnology such as Taiwan will probably be quicker to benefit from this expanding market. 
Table 4.7. Aquaculture Production in selected Asian countries (1000 tons)

\begin{tabular}{|l|l|l|l|l|l|l|}
\hline Country & 1980 & 1986 & 1987 & 1988 & 1989 & $\begin{array}{l}\text { Average Annual } \\
\text { Growth Rate } \\
1980-89(\%)\end{array}$ \\
\hline China & 2552.9 & 5048.1 & 5705.2 & 6658.7 & 6557.8 & 11.1 \\
\hline India & 413.0 & 416.3 & 427.3 & 437.1 & 490.0 & 1.9 \\
\hline Philippines & 289.2 & 470.9 & 561.0 & 599.5 & 629.3 & 9.0 \\
\hline $\begin{array}{l}\text { Rep of } \\
\text { Korea }\end{array}$ & 541.6 & 993.6 & 876.8 & 900.3 & 859.8 & 5.3 \\
\hline Thailand & 94.6 & 128.4 & 174.5 & 219.1 & 215.8 & 9.6 \\
\hline
\end{tabular}

Source: FAO (1991), Selected Indicators of Food and Agriculture in Asia Pacific Region

Thus it appears that the private sector has largely determined its own priorities and often the public sector or policy making body has had to follow by offering funding for further research. This is especially so in agriculture and moreover in commercial agriculture, where private companies have been quicker to take advantage of the opportunities offered by export markets. This is perhaps not surprising, especially since the returns on subsistence agriculture, pharmaceuticals and industrial biotechnologies are longer term. Tax holidays and the creation of exclusive export processing zones have also played a role in encouraging investment from the private sector, especially in particular industries. In Taiwan for example, companies investing in biotechnology are provided a five year tax exemption as well as tax credit for R\&D. In Korea, foreign investment is encouraged by providing tax exemption on technology and also on customs duty. Local investment, especially for small companies, is provided in both countries by venture capital funding. which as discussed earlier has been more successful in Taiwan, perhaps because of an older emphasis on small and medium sized enterprises. In India and China also, both local and foreign private investment is being encouraged by the formation of exclusive export zones, where a hundred percent of production for a certain number of years is exported. Lower customs tariffs on raw material imports such as basic enzymes have also played a role in encouraging biotechnology research, especially in India where economic liberalization policies are reducing restrictions on international trade and investment.

The setting up of regions or areas of excellence, most notably the phenomenon of the Science Park has also recently found favour in many developing countries. Taiwan for example has set up the Hsinchu Science Park which is located 80 miles south of Taipei and contains many of the new biotechnology companies which were formed in the $1980 \mathrm{~s}^{134}$. Similarly, Daeduck (or Taejon) Science and Industrial Park in Korea, located in the centre of

${ }^{134}$ Science Based Information Park (SBIP) information package, 1994 
the country, is home to many of the large companies involved in modern biotechnology research. In India, although a number of export zones have been created by the Government, the city of Bangalore in the south has emerged as a centre for scientific research, and a number of biotechnology companies, both old and new have established laboratories and offices in and around the city ${ }^{135}$.

Thus, governments are increasingly taking the back seat, as applied research becomes the domain of the industrial sector, whether it be private or public. Increasing financial returns from the simpler biotechnologies such as tissue culture are also encouraging companies to invest in more expensive and advanced techniques in agriculture, and increasingly in industry and the true potential of these companies may only become apparent in a few years from now.

Having examined the attempts made by government and the private sector in encouraging biotechnology development, in the next section, the technology itself is examined. In Chapter 3 above, patents applied for and granted to inventors in industrialized countries were used as a proxy measure for invention in biotechnology. In this chapter, we look at the application of biotechnology to a specific sector which is highly relevant to developing countries, namely agriculture. Much of the research on improving productivity and increasing disease resistance in developing countries has concentrated on cash crops, because of their export value. In the following we present a case study of one such cash crop, where field trials we argue demonstrate the potential of this new technology and is a sign of success to come.

\subsection{Patterns of Innovation in the South}

Unlike the previous chapter, where international patterns of patents granted were used to observe and compute invention and innovation rates in industrialized countries, it is not possible to use this measure for most developing countries. In many of these countries, patents are not, as yet, granted for biotechnology innovations and international patents granted elsewhere for biotechnology products are not recognized either ${ }^{136}$.

As is evident from the last section on private sector activities in biotechnology in developing countries, however, attempts are being made to increase scientific and

135 It has been argued (see for example Reddy and Sigurdson, 1994), that the presence of a large pool of scientists, which graduate from one of the foremost scientific institutions in India, the Indian Institute of Sciences in Bangalore, has prompted many R\&D based ventures, both domestic and foreign to locate to this part of the country. In 1993, it was estimated that of a total of 337 biotechnology firms and public R\&D institutions across the nation, the greatest concentration were in the south (113) of which Bangalore is a major base (BCIL, 1994). Bangalore is also becoming a centre for Electronics R\&D where the Government is building a software technology park (Far Eastern Economic Review, December 1992). The government of the state of Kerala is also proposing a science park for biotechnology in that state (Personal communication, BCIL, august 1994).

136 With the TRIPs agreement in the Uruguay Round, this has changed, but most developing countries have been granted a grace period up to 10 years before they adjust their patent laws (GATT, 1994). 
technological capabilities and there is some evidence of the use of less sophisticated technologies. Much of this activity, as we have noted, is taking place in agriculture, where less sophisticated technologies, such as tissue culture, are being applied to agricultural products, primarily to increase productivity, but also to select preferred characteristics, which may raise the product's quality as well. In this section we take one such example of an agricultural product, whose productivity is being raised through tissue culture techniques in India. The success of field trials may have important implications, not only for raising its own productivity, but also by providing valuable information for raising the quality in a number of other important crops.

Thus, while private sector activities have been largely confined to particular sectors such as agriculture, where the innovations are incremental and therefore relatively less R\&D intensive than other sectors such as pharmaceuticals, it is evident that the desire to invest in biotechnology is there. What is lacking is an infrastructure, which will enable private sector companies to invest in more risky ventures such as health related biotechnologies, or industrial biotechnologies, which require greater investment in R\&D. The task facing the government therefore is to provide the private sector with economic incentives and a capital market structure enabling them to invest in these ventures, while at the same time ensuring that national goals are met by putting in place an appropriate regulatory infrastructure.

\subsubsection{Productivity Enhancing Innovations: The Case of Cardamom in India}

Cardamom is a widely used spice native to India. Of the two varieties, the small green cardamom is commercially produced both on plantations and on small holdings. India was, until the 1970s, one of the world's major producers and exporters of this high-value spice. Other cardamom producing countries are Guatemala, which today is the number one exporter of cardamom, Sri Lanka, Tanzania, Papua New Guinea, Nepal and Bhutan. In India, it is cultivated in elevated areas between 600 and 1500 metres above sea level, in the southern states of Karnataka, Tamil Nadu and Kerala. The total cultivated area in India is, at present, estimated to be about 100,000 hectares ${ }^{137}$

Approximately 50-60 percent of the cardamom produced in India is exported, its international price making it a valued foreign exchange earner. The main export markets for cardamom lie in the Middle East and Japan. Some is also exported to North America and Western Europe. However, while India used to control most of the export market, its position has slipped down to seventh place in recent years, while Guatemala has taken over as leader in cardamom exports.

Over the years, India's productivity and market position have steadily declined. While India's productivity averages only about $60 \mathrm{~kg}$ per hectare, Guatemala, the largest exporter, has a productivity of over $250 \mathrm{~kg}$ per hectare. There are several reasons for India's low productivity, including the age of the plantations, irrigation methods, the size of the landholdings, pests and climatic problems.

Following the success of a private cardamom plantation owner in using tissue culture to raise the productivity of the cardamom crop, the Indian government initiated a field trial in 1989 to determine the extent of productivity and quality increases that would be possible 
if tissue culture plantlets were used. The Managing Director of the private company, A V Thomas and $\mathrm{Co}$., argues that, through tissue culture, the production of cardamom can be raised from the present 4000 tonnes to about 8000 tonnes per year, i.e. doubled ${ }^{138}$. The company began using elite varieties, which were first isolated from old plantations and then multiplied. These varieties have the added advantage that they can be cropped in two years instead of the traditional three. By using these varieties, yield per hectare has increased from $70 \mathrm{kgs}$ to $250 \mathrm{kgs}$, and earnings per hectare grew from Rs 60,000 to Rs 250,000 (approximately US $\$ 2,400$ to US $\$ 10,000)^{139}$.

In response to this success, the Indian government initiated field trials, in cooperation with A V Thomas, to increase the productivity on its own small holdings, which are leased out to small scale farmers. From the initial results ${ }^{140}$ below, (figures 4.3 to 4.8 ), it appears, that the tissue culture varieties, on average, tend to have higher yields although there is some variance among and within the regions.

In order to determine the impact of a large scale adoption of this technology upon total production of cardamom a time series analysis was carried out to measure changes in productivity. The annual data relates to production, yield levels, international prices and annual area planted.

Figure 4.1. below shows the rate at which Indian production of cardamom has grown between 1960 and 1989. The estimates were obtained from time series data (annual) from 1960 to 1989. The linear equation estimated was $Y=\alpha_{0}+\alpha_{1} X_{1}+u$, where output $Y$, is a function of time and of an error term. The regression estimates an intercept $\alpha_{0}$, of 1122.4 tonnes with a slope of 28.87 . The low R squared of $10.8 \%$ is probably attributable to the substantial fluctuations in output from year to year, and also probably because there have been other factors that have affected yield levels such as variable productivity. Nevertheless, the estimation gives a time trend which is increasing, although not very steeply. Table 4.8 shows the results of two sets of time series regressions that were estimated. The first regressed the variable Indprod, corresponding to Indian output $Y$, on time, while the second repeated the regression using Gnprod or Guatemalan output, as the dependant variable.

The next equation estimated was $\log$ linear: $\ln Y=\alpha_{0}+\alpha_{1} \ln X_{1}+u$. The dependent variables are LnIndprod, which is the growth rate of Indian output and LnGnprod, the growth rate of output in Guatemala and are estimated as functions of time.

${ }^{138}$ Eapen George (1991), Financial Express, 11 July.

139 India Today (1991), 15 September, p 99

${ }^{140}$ These results are based on unpublished data, from field surveys which were obtained from the Cardamom Board of India, during 1991. 
Table 4.8. Trends in Production of Cardamom (India and Guatemala)

\begin{tabular}{lllll}
\hline Variable & Constant & Slope & Adj. $R_{2}$ & df \\
\hline Indprod & 1122.43 & 28.83 & 0.108 & 28 \\
Gnprod & -30521 & 355.5 & 0.885 & 19 \\
LnIndprod & 7.453137 & 0.0082 & 0.0816 & 28 \\
LnGnprod & -2.247 & 0.1281 & 0.9525 & 19 \\
\hline
\end{tabular}

The slopes in both cases, show that Guatemalan growth rates far exceed Indian ones.

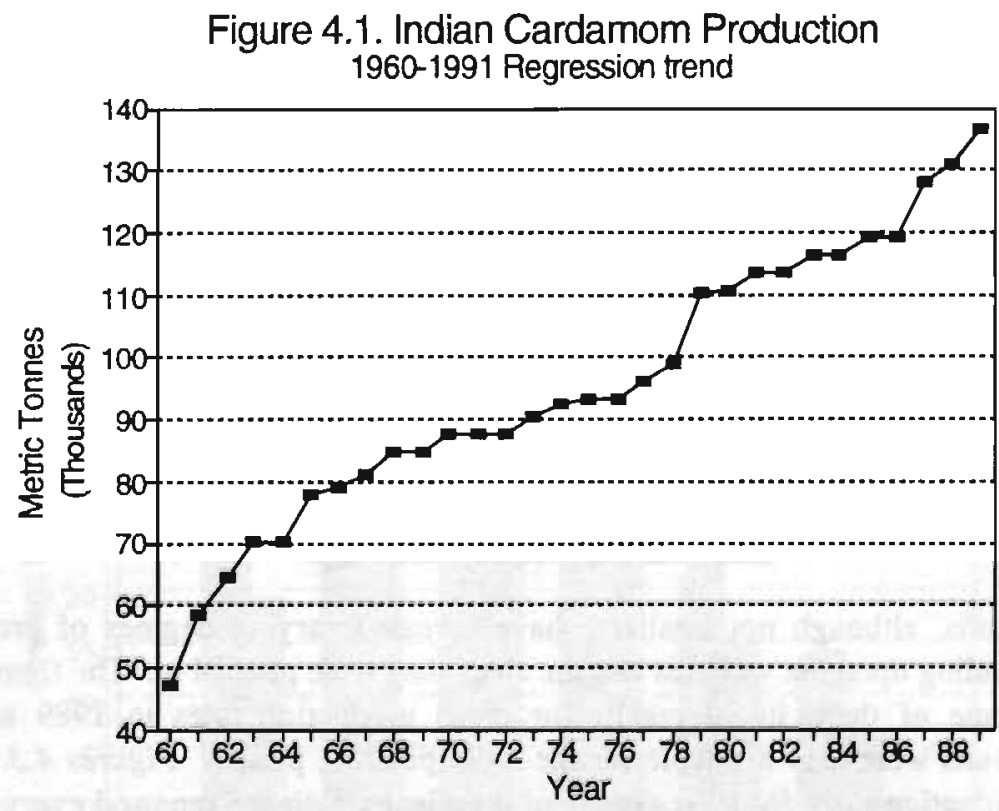

Whereas Figure 4.1. shows the trend for Indian production between 1960 and 1991. Figure 4.2. compares regression results of Guatemala and India, showing that while production in both countries has continued to rise over the years (in this case Guatemala was a late entrant into the market and therefore the trends are measured between 1970 and 1990), Guatemalan growth rates have outstripped Indian production by a magnitude of 6 . Thus any attempt by Indian farmers to recapture market share has to address the problem of productivity in Indian cardamom production. 
The Indian government, acknowledging the success of the private sector in improving cardamom productivity, launched the field trials in 1989. Although preliminary, the results of the field trial may prove interesting for overall Indian productivity in cardamom.

The question then is whether tissue culture in any way is able to affect this time trend and if so, what this affect will be. For this, we turn to the results from the tissue culture trials (Figures 4.3. to 4.8. below). The tissue culture trial, initiated in 1989, was expected to begin yielding results for full scale replantation of the total area devoted to cardamom production in India. A total area of 100 hectares was selected in various parts of traditional growing areas in the country and planted with tissue culture (TC) and open pollinated (OP) varieties in an 80 to 20 percent ratio respectively.
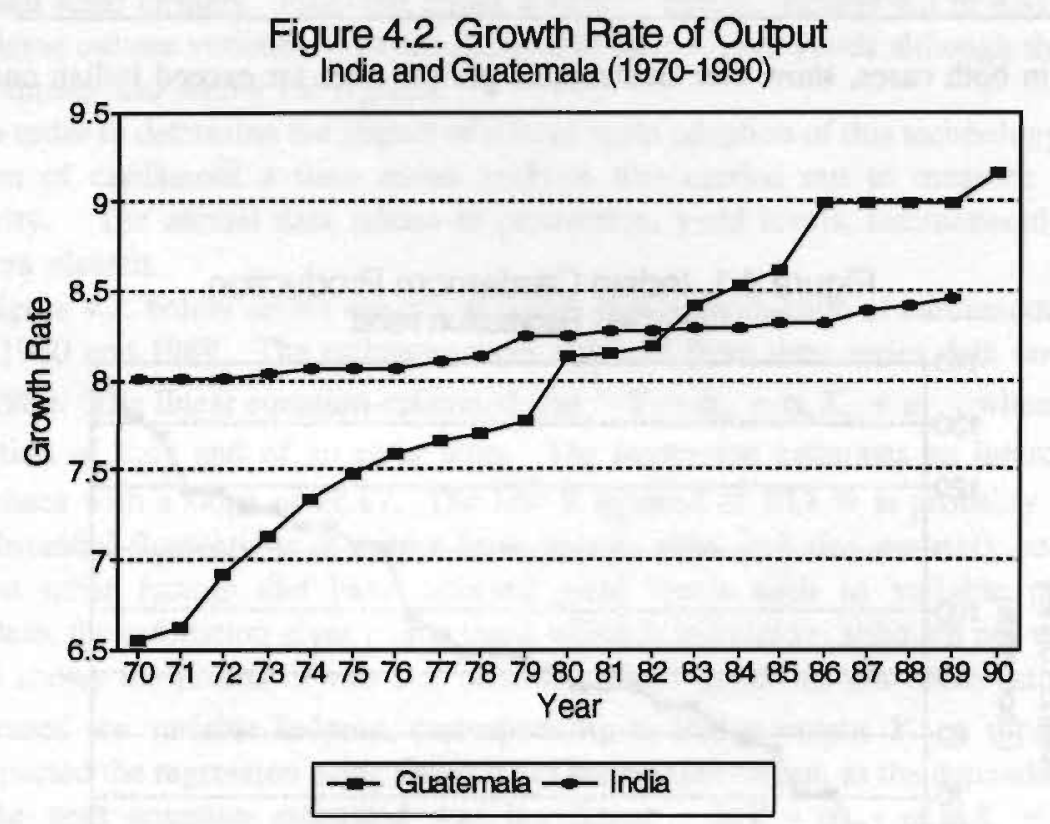

The results, although not finalized, have revealed varying degrees of productivity increases, depending upon the varieties and the areas they were planted in. The figures below demonstrate some of these initial results for mean production rates in 1989 and 1990. Preliminary results were also available for the 1991 planting period. Figures 4.3. and 4.6. show mean production rates for tiller (stems of the plant which are renewed every year and are related to the productivity of the plant. Measuring yield increases in tillers therefore is important for determining the overall productivity of the plant), ${ }^{141}$ production.

Already at this stage, mean production levels of the sample reveal an increase in productivity averaging $9.8 \%$ in 1990 and $15.27 \%$ in 1991 of the tissue culture varieties over the open pollinated ones.

141 The cardamom plant is a rhizome, ie. most of the plant is below the ground. The underground rhizomes produce tillers or stems which grow above the ground. These stems are renewed each year and add to the plant's productivity. A mature cardamom plant of five years usually possesses between 50 and 100 tillers and its productivity depends upon the number of tillers it produces. 
Figure 4.3. Tissue Culture Cardamom

Mean No. of Tillers produced/plant 1989

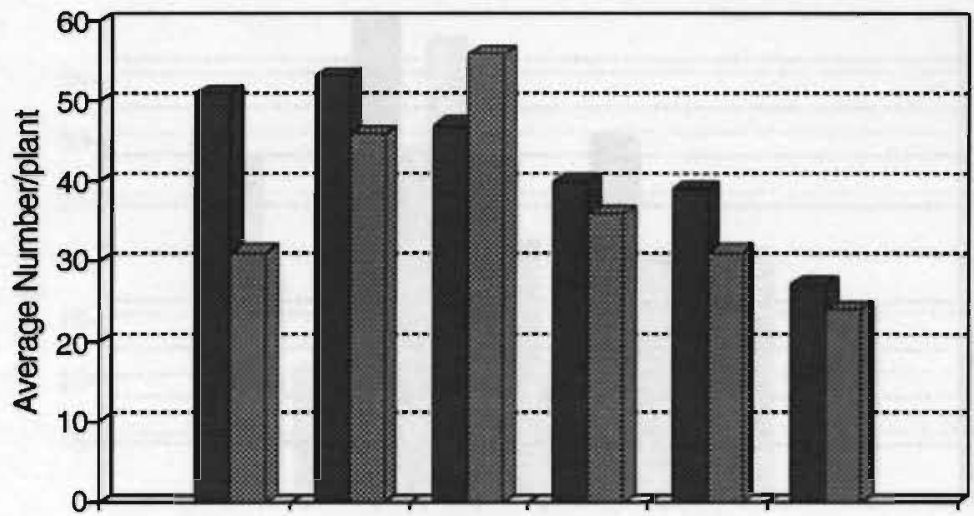

Zones 1-6

Tissue Culture Open Pollinated

Figure 4.4. Tissue Culture Cardamom

Mean no. Panicles produced/plant 1989

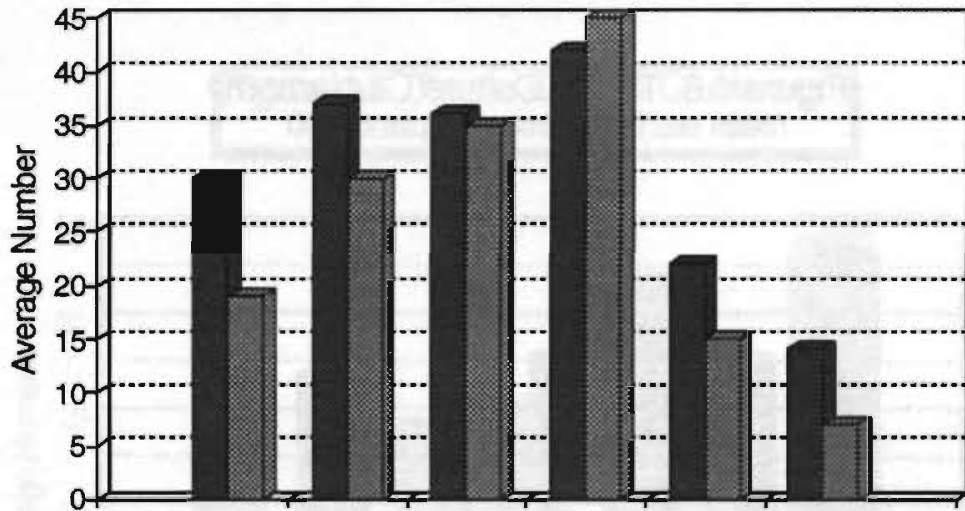

Zones 1-6

\section{Tissue Culture}

Open Pollinated

Similarly, overall productivity averages have also increased for panicle (These are offshoots from the tillers which contain the cardamom pod and an increase in panicle production implies a greater amount of cardamom produced per plant), production and also of the number of capsules containing cardamom, produced per panicle (Figures 4.4. and 4.5 are for 1989 data while figures 4.7 and 4.8 are for 1990 data). 


\section{Figure 4.5. Tissue Culture Cardamom}

Mean no. of Capsules/Panicle 1989

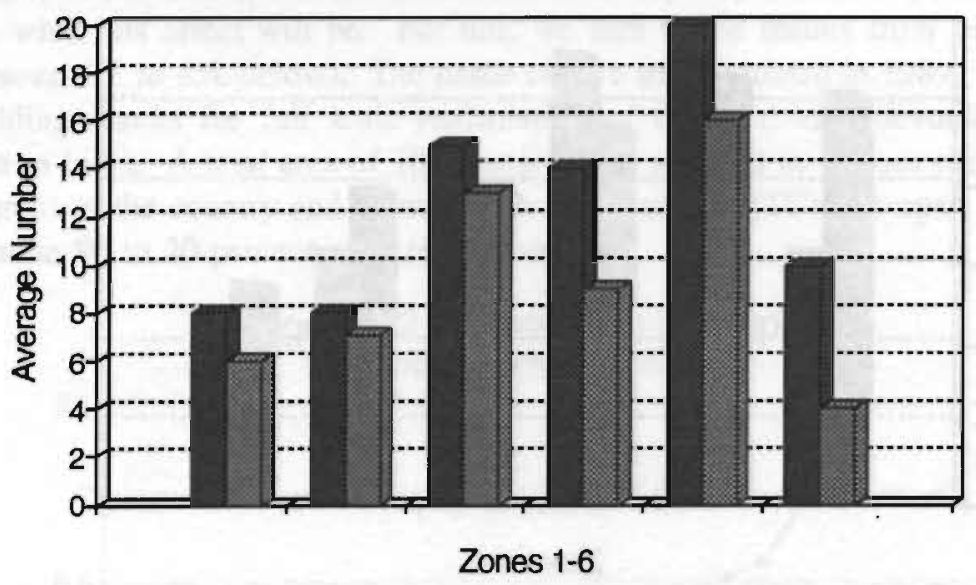

Tissue Culture Open Pollinated

Figure 4.6. Tissue Culture Cardamom

Mean no. Tillers produced/plant 1990

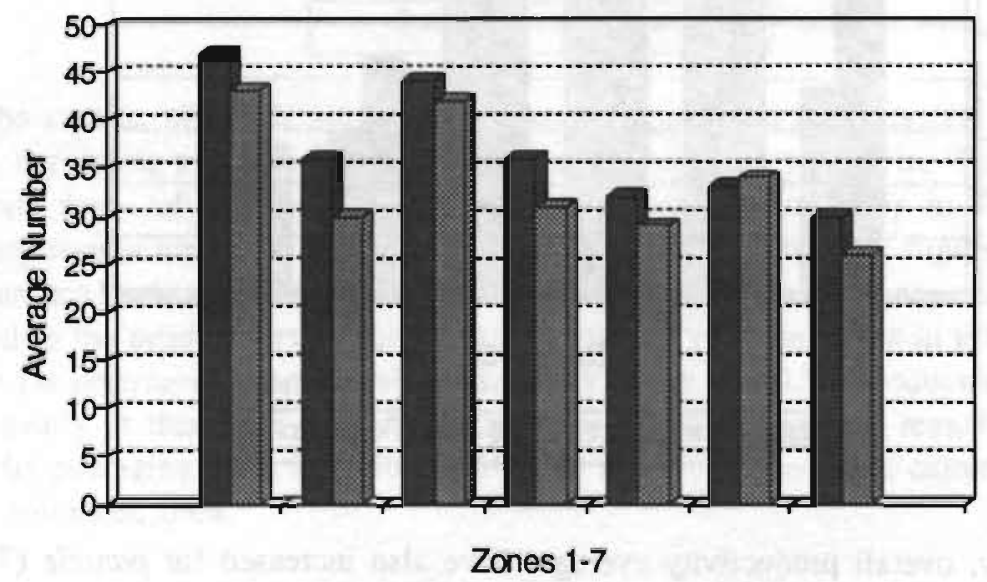

Tissue Culture Open Pollinated 
Figure 4.7. Tissue Culture Cardamom

Mean no. Panicles Produced/plant 1990

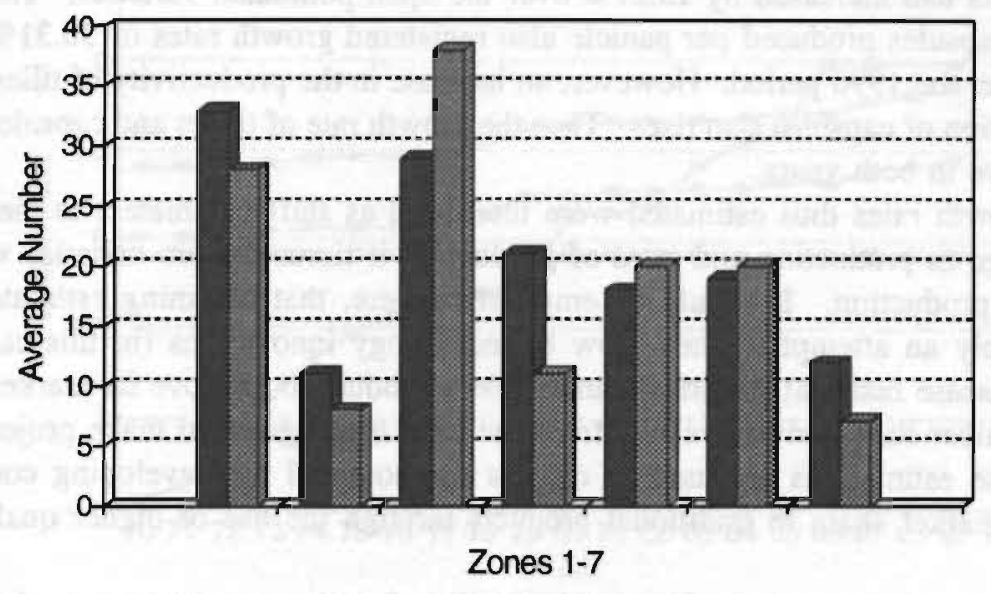

Tissue Culture Open Pollinated

Figure 4.8. Tissue Culture Cardamom

Mean no. of Capsules/Panicle 1990

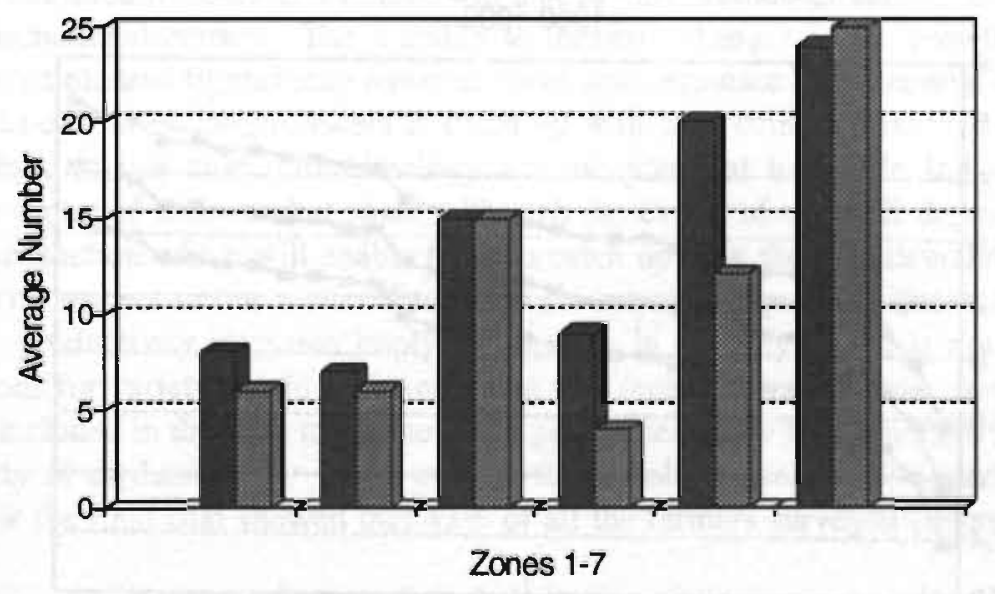

Tissue Culture

Open Pollinated 
These average an $8.32 \%$ increase in the mean number of panicles produced from the 1989 sample and of $19.8675 \%$ from the 1990 sample. Data gathered in the 1991 case was too preliminary to reveal any significant results about cardamom production, although the total number of tillers had increased by $15.27 \%$ over the open pollinated varieties. The number of cardamom capsules produced per panicle also registered growth rates of $36.31 \%$ in 1989 and $22.39 \%$ over the 1990 period. However, an increase in the productivity of tillers implies that the production of capsules also rises. Thus the growth rate of tillers and capsules is taken to be cumulative in both years.

The growth rates thus estimated were then used as shift parameters to measure the extent of change in production and rates of production if tissue culture varieties were used for cardamom production. It should be emphasized here, that obtaining estimates in this manner is simply an attempt to show how biotechnology innovations (in this case higher yielding and disease resistant varieties) can enable a product to improve its market share.

Thus, rather than deriving results from the field trial figures to make projections for the future, these estimations are used to discuss the potential for developing countries to increase their market share in traditional products through the use of higher quality tissue culture plants.

The projected growth rate of the total quantity of cardamom shows a steady increase, especially for the results extrapolated from the 1989 field trial figures. Even if one takes the lower estimate from the 1990 field trial figures, there is a considerable increase over current levels, although the growth rates remain the same, i.e.. there is simply a shift upward in both trends (see figure 4.9. below).

It should however be stated that since the figures are only for two years, it is difficult to estimate the growth effects of the new varieties. The estimates here only use the field trial results to estimate yield increases. The growth rates shown in these figures therefore most likely underestimate the growth rate of production if tissue culture raises productivity.

Figure 4.9. Growth Rate of Output:India 1960-1990

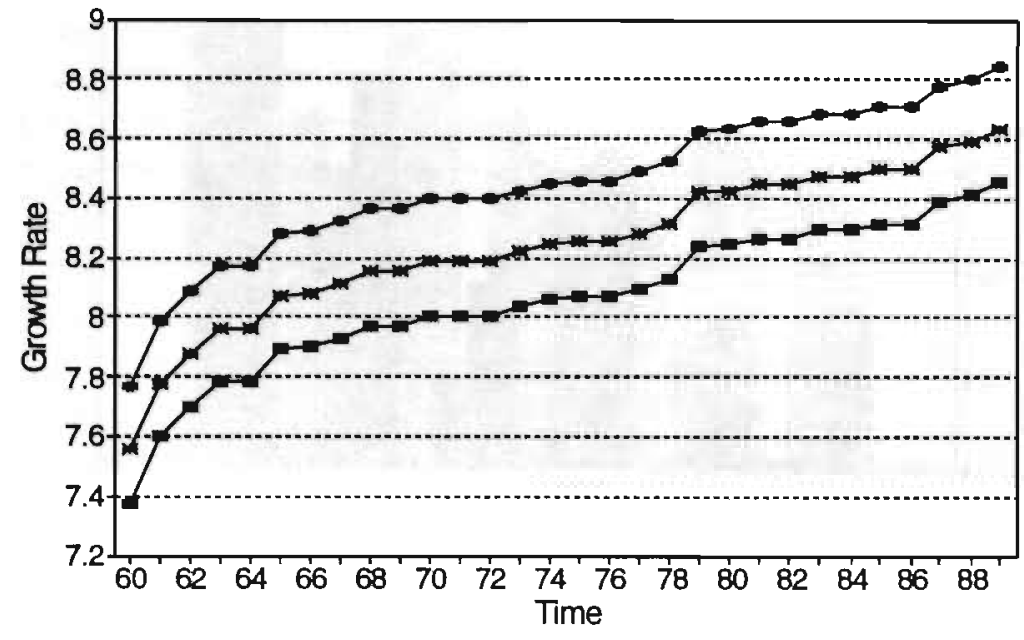

$\rightarrow$ actual $\rightarrow$ projected $(1989) \rightarrow-$ projected $(1990)$ 


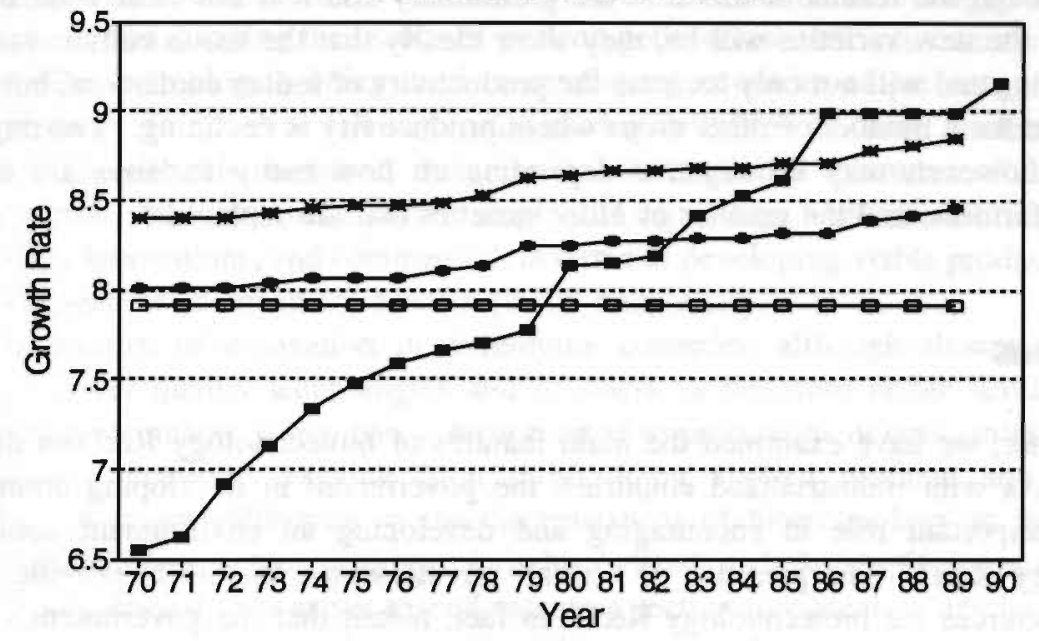

$\rightarrow-$ India projected $\rightarrow$ India projected

A comparison of these growth trends with the current trends in Guatemala (see figure 4.10.), show clearly that Indian productivity rates even given the estimated increase in productivity if tissue culture was used (assuming that the same results would hold in a more widespread use of the new varieties), are not sufficient to match Guatemala's, although there is some evidence of catching up, especially from the results of the 1989 field trials.

The results for recapturing market share by Indian producers from their competitors, especially Guatemala, are therefore not entirely convincing, although a rise in productivity of the rates measured from the field trials, will indeed make Indian cardamom more competitive in the international market. The inability to measure changes in the growth rate from the preliminary field trial figures may however, have underestimated the potential of tissue culture varieties to enable Indian producers to catch up with their competitors.

Thus, in this case, biotechnology has the potential to enable Indian producers to recapture a part of their market share, although the extent of this will depend upon growth rates in production which will enable them to catch up with their Guatemalan counterparts.

With respect to our earlier discussion on increasing quantity, quality and variety, in this case, productivity increases imply an increase in quantity, but it is not clear what the implications for variety would be. According to a recent survey (Kumar and Menon, 1992) of farms included in the field trials, there is a general tendency for farmers to plant more than one variety of cardamom ${ }^{142}$. In the case of tissue culture specifically, the survey of farms chosen for the field trial showed that $43 \%$ of all the farmers surveyed (including those who

${ }^{142}$ The survey found that in general there tends to be a bias in favour of larger than average size farms participating in the field trials (Kumar and Menon (1992), p 13). 
were not included in the biotechnology trial), have chosen to plant more than one variety of cardamom ${ }^{143}$, although it is not clear whether this will mean rising or declining variety.

Although the results of this trial are preliminary and it is not clear what the rate of diffusion of the new varieties will be, they show clearly that the tissue culture varieties are higher yielding and will not only increase the productivity of Indian cardamom, but may also hold promise for a number of other crops where productivity is declining. The implications for variety however, may be negative depending on how many varieties are eventually adopted by farmers, and the number of older varieties that are replaced.

\section{Conclusions}

In this chapter, we have examined the main features of biotechnology R\&D in developing countries. As with industrialized countries, the government in developing countries, has played an important role in encouraging and developing an environment conducive to biotechnology R\&D. The presence of a small private sector, unable to provide sufficient financial resources for biotechnology R\&D, in fact, meant that the government's role was further expanded in developing countries. However, as with industrialized countries, the most important contribution of the government has come in "public domain" activities such as training and the funding of pre-competitive research. A boost to the older research infrastructure additionally, has been provided by newer, more flexible policy making and research and development bodies.

In developing countries, despite efforts by the government, the private sector has been relatively slow in entering biotechnology and since it is the private sector which tends to have the expertise required to commercialize new technologies, commercialization has been relatively slow in these countries. The government has also faced greater problems than governments in industrialized countries, namely resource constraints and a weaker scientific and technological base needed for biotechnology R\&D. Finally, weaknesses in the tradition of cooperation between the private and public sectors, or the linkages between pre-competitive and competitive research, has also been a major problem in developing countries, one which governments have made a number of attempts to address.

The private sector, in turn, has had problems raising investment capital and has faced a continuous shortage of skilled staff. Despite their problems however, both the government and especially the private sector, have made major contributions to the development of biotechnology capabilities in the countries surveyed. The government has also introduced a

143 The survey which was carried out for the Department of Biotechnology, examined over 500 farms, and included both those taking part, as well as those not included in the trial. 71 out of 133 farmers $(53.38 \%)$, who took part in the field trials, responded to this questionnaire. The preference for variety will depend upon the variance of the expected harvest between the varieties. If the variance is large, then use will be made of the highest yielding variety only if (i) the farmer is risk neutral or (ii) the farmer is risk averse but has access to a capital market. Since the farms included in the trials on average tend to be large, the conclusion that $57 \%$ did not plant a number of varieties could be related back to the earlier discussion on the tendency of large farmers to have better access to capital markets or to be risk neutral. 
number of incentives, including tax holidays and lower import barriers, to which the private sector appears to be responding.

The private sector, although a relatively late entrant into biotechnology $R \& D$, has been instrumental in transforming the results of pre-competitive research into commercially viable products. The technologies being used in developing countries at present, are admittedly simple and many do not even fall within the narrow definition of "new" biotechnology (see chapter 2). Despite this, however, their use to commercialize a number of "new", higher quality products, demonstrates a certain degree of capability, both scientific in developing higher quality innovations, and commercial, in terms of developing viable products which can respond to consumer demand for greater quality and variety.

The pattern of innovation in developing countries, although slower in pace, and focused on lower quality technologies and products, is therefore rather similar to that in industrializing countries. It involves a separation of organizations or companies carrying out basic or pre-competitive research from those doing applied research and commercial production. A major difference in the circumstances of biotechnology at present, is the significantly different patent regimes in industrialized and developing countries. Most developing countries do not as yet extend patent protection to biotechnology based products. This situation is however changing rapidly and a number of countries, including Korea and Taiwan, among the countries surveyed here, have recently revised their patent laws to include biotechnology ${ }^{144}$. Thus, this difference may change significantly in the next few years as developing countries come under increasing pressure to recognize and adapt to international IPR regimes, as can be seen from recent GATT negotiations.

With respect to the 1990 s, we see a few major changes which may become more important in the coming decades. First, biotechnology companies in industrialized countries will slowly continue to consolidate their position, especially in the pharmaceutical industry. Their success has led to an increase in research by established pharmaceutical and chemical companies. This is evident from patent data (see chapter 3), which shows that the degree of patenting by large companies appears slowly to be overtaking a number of NBTFs. However, there is also a trend on the part of a number of NBTFs, towards forming research and marketing alliances with large companies, and also with other biotechnology firms to tap into their particular research or marketing expertise. Multinational companies are also forming similar alliances which, as Orsenigo (1989) argues, are not unlike their earlier alliances with universities, especially in the US, but also in some European countries. Thus, there is some evidence suggesting that economies of scale, especially in downstream product development may be becoming more important and therefore may become a determining factor in success in biotechnology in the coming years.

The least technologically developed countries will therefore find it more difficult to catch up, especially as the pace of biotechnology R\&D in the more technologically advanced developing countries increases. Success in entering biotechnology will depend greatly upon an efficient allocation of scarce financial and human resources. The success of Cuba has been discussed previously and can still be used as an example to show how a specified channelling of resources into an area of previously built technical capability, can be used to successfully develop expertise in incremental steps. Large countries with considerable basic research skills 
such as India, have quickly had to learn that possessing the scientific capability to do genetic engineering is simply not enough if government restrictions hinder the private sector from involving itself in downstream product development and transforming the invention into a productive innovation.

Having discussed patterns of innovation and institutional structures supporting those patterns of innovation in industrialized and developing countries, the next chapter returns to the question of the impact of biotechnology on product quality and variety. The impact of biotechnology based innovations of higher quality and productivity have had and will continue to have an impact on the variety of products available in the economy. This point was made with respect to consumer preferences briefly in Chapter 1 above. Chapter 5 below, focuses on this point and discusses the issue of quality and productivity improving innovations in biotechnology and their impact on variety. 


\section{Quality and Variety in Biotechnology}

"What does the fish remind you of?"

"Other fish."

"And what do other fish remind you of?"

"Other fish."...J. Heller.

\section{Introduction}

As the previous two chapters have shown, biotechnologies, especially modern techniques have been widely adopted by both industrialized and developing countries. For industrialized countries, biotechnology applications are strongest in the pharmaceutical and food processing sectors. For developing countries, biotechnology has addressed critical issues of food security and has increased value added for a number of exports. Its knowledge intensive nature has also enabled developing countries to diversify production and has therefore enormous potential to increase both the quality and variety of products available to consumers. Much of this has been achieved through building upon previously developed technological capabilities such as in agricultural biotechnologies which were built upon existing research networks developed during the green revolution in India, Thailand, and the Philippines, while the eastern countries of Korea and Taiwan have relied on their traditional strengths in bioprocessing industries. While their innovativeness has resulted in an increasing variety of production, with a promise of a lot more to come, the interesting question to ask is whether the new biotechnologies and the changing economic and institutional environment will increase or decrease the total amount of product variety, both old and new, available to consumers. In Chapter 1 above, the impact of biotechnology on variety and quality was discussed briefly. There, it was argued that increasing quality can have differing impacts on the variety of products available to consumers.

While thus far. Chapters 3 and 4 examined the impact of biotechnology on quality and productivity enhancing innovations, in this chapter we look more specifically at the nature of these changes and how they relate to consumer preferences across different sectors. The discussion in this Chapter will lay the foundation for the structure of the endogenous growth and trade models developed in Chapters 8 and 9 below.

This chapter is divided into three broad sections. The first two look at the impact of biotechnology on traditional products and techniques, while the final section discusses demand for this increased or decreased variety, as is expressed through consumer preferences. Examples come mainly from the agricultural and pharmaceutical sectors where the majority of biotechnology based innovations have taken place till the present time.

\subsection{New Qualities For Old}

As with most new technologies before it, biotechnology will bring about structural changes which will have implications for traditional production techniques and products. The 
ability of biotechnologies to identify genetic structures and transplant genes, has allowed the production of new species of crops. The scientist's job is to first identify the genetic structure of a particular species and then insert new, desirable characteristics and remove undesirable ones, producing a new species which is stronger than traditional varieties. Examples of this include: 1) the production of plants which are able to adapt to particular environmental conditions, such as frost which often destroys the citrus and tobacco crops in southem parts of the United States; 2) plants which are disease resistant or resistant to herbicides such as the work done by Monsanto to develop new genetically engineered varieties of crops which are resistant to Monsanto's own herbicides; 3) plants which are substitutes for older products and 4) plants which are in general more resilient, bigger and higher yielding than previous generations.

Although the process is difficult and its potential benefits long term, its implications are enormous, both for innovators and also for consumers. The creation of one new variety with a different genetic structure in the laboratory, would give birth to a whole new species to replace the older varieties which are more susceptible to disease and changes in the environment. The important difference between genetically engineered products and older variety improvements is that while previously the goal of plant breeding was to increase productivity through cross breeding with the variety which appeared to be most resilient, the precision of genetic engineering allows the targeting of specific diseases and climatic variables in developing a higher quality plant, which will not only increase output, but can also be planted in different environments. Quality improvements can also target specific aspects of the plant such as flavour, aroma or taste. Thus the aim of the latter is in improving quality, whereas the aim of the former was to improve productivity ${ }^{145}$.

The new product is also in a position to address the needs and preferences of consumers in that it may remove any inconvenience associated with traditional production processes. In the case of agriculture in particular, prices tend to fluctuate considerably ${ }^{146}$. Erratic weather conditions and a number of other uncertainties and natural and man-made disasters such as famines or floods (which although natural in the sense that they are related to the weather, tend to have a far greater and often disastrous impact in those countries where farming or other human activities have depleted natural vegetation which holds the topsoil together), often prevent developing country suppliers from meeting their supply targets which results in price fluctuations. Annual harvests also vary and the quality of the final product is often not the same from year to year. For those crops especially which serve as raw material inputs for industrial or other purposes, these uncertainties are extended up the chain of production. This appears to have been a major rationale for large multinationals and biotechnology companies to target agricultural products, and especially cash crops. In the words of the US biotechnology firm Calgene:

${ }^{145}$ Of course, there are fears, often quite legitimate, about the release of genetically altered plants and animals into the environment. Nevertheless, this does not detract from the potentials of genetic engineering for detecting and improving resistance to diseases in plants, although it is acknowledged that government regulations concerning field testing and trial should be in place to stop dangerous accidents from occurring. 
"The value of most crops grown for food processing is determined primarily by the crop's processing characteristics such as texture, flavour, colour, protein and carbohydrate content, and shelf life. Food processors have traditionally bought raw materials in commodity markets where all products are essentially undifferentiated. With recombinant DNA technology however, Calgene can provide food processors an opportunity to gain competitive advantage by allowing precise genetic modification to develop proprietary crop varieties with enhanced characteristics which can then be patented to grow with their exclusive use." ${ }^{147}$

Biotechnology research and especially the ability to insert better characteristics into plants in the laboratory and then to replicate the genetically engineered product, would eliminate some of these supply constraints.

For a number of crops, initial biotechnology research came in the form of tissue culture, and attempts through genetic engineering to create superior hybrids which are higher yielding and more resistant to disease. In the case of cocoa, the raw material used to produce chocolate, Africa, especially west Africa, accounts for most of the world's production and export. For the largest African producers, cocoa is an important cash crop, accounting for 90 percent, 60 percent and 40 percent of the exports of the nations of Togo, Ghana and the Côte d'Ivoire respectively ${ }^{148}$. In the early $1980 \mathrm{~s}, 60-80$ percent of the world's international trade in cocoa was controlled by four chocolate producing companies. The tendency toward concentration has continued since and in addition to this, major cocoa producers such as Hershey Foods in the US and Nestle of Switzerland have devoted a considerable proportion of funds for biotechnology R\&D in cocoa and related products.

Tissue culture and genetic engineering can increase the yield of the cocoa bean severalfold. The cultivated cocoa plant is based on a very narrow genetic range which makes it susceptible to disease. Estimates are that between 20 and 30 percent of the world's cocoa output is lost due to disease and pests and it is estimated that while traditional cocoa yields reach a high of about 500 kilogrammes of cocoa beans per hectare, micro propagated high yielding cocoa plants are expected to yield upto 2000 kilogrammes per hectare (Sasson 1990). In fact, countries in the east such as Malaysia and Indonesia have greatly increased yields by using higher yielding tissue culture varieties (see table 5.1).

Genetic engineering has the potential to further increase that yield. This would mean a considerable increase in cocoa production, resulting in lower prices and lower production costs for chocolate producers. This research is still in progress and it is likely that these effects will have a long term impact.

${ }^{147}$ quoted in Juma (1989), p 135 
Table 5.1. Production of Cocoa beans (000 tonnes)

\begin{tabular}{|llll|}
\hline Country & 1982 & 1986 & 1991 \\
Cameroon & 122 & 118 & 951.3 \\
Côte d'Ivoire & 464 & 580 & 790 \\
Ghana & 225 & 219 & 295 \\
Nigeria & 181 & 110 & 150 \\
Brazil & 310.5 & 366.2 & 365 \\
Ecuador & 85 & 105 & 101.3 \\
Indonesia & 16.2 & 40 & 130 \\
Malaysia & 61.8 & 131.2 & 225 \\
Total & 1727 & 1972.2 & 2449.3 \\
\hline
\end{tabular}

Source: FAO Yearbook Various issues (Rome: FAO)

Similarly, genetic engineering is replacing the place of origin of traditional products. For example, a recent decision of the US department of Commerce granted \$1.2 million to a Utah based biotechnology company to develop a substitute for pyrethrum through genetic engineering. Pyrethrins, obtained from the flowers of the pyrethrum plant are a natural bioinsecticide and demand for them has grown manyfold in an increasingly environmentally conscious world. The plant comes largely from East Africa where traditional agricultural technologies were not sufficient to meet demand. Many of the main producers of pyrethrum such as Kenya, expanded production by the introduction of tissue culture and micropropagation to meet expanding demand. The investment made by investors, the scientific community and the farmers alike, in introducing tissue culture may therefore prove to be in vain if a genetically engineered pyrethrum substitute were to be developed which would make large traditional markets like the US self-sufficient in the production of pyrethrum based insecticides.

In the case of pharmaceutical and medical research as well, genetically engineered products which are both substitutes for older products and also entirely new products, or previously non-existent cures for diseases, are appearing on the market. For example Factor VIII, a blood clotting protein is lacking in Haemophiliacs, who are under constant threat of injury, both external and internal, which can lead to bleeding and death. Factor VIII can be genetically engineered which can then be used to treat this condition ${ }^{149}$. Similarly, research using rDNA techniques for a number of incurable diseases, most notably cancer, are at various stages of research or approval from the appropriate health authority. A number of other drugs are providing replacements for patients who lack the biochemical ability to produce or process 
the protein needed by their bodies ${ }^{150}$. One example is the production of human insulin, the first rDNA drug approved in the US, while another is the human growth hormone, which is being used on children with growth retardation tendencies. Thus advanced biotechnology research, both in the agricultural and pharmaceutical sectors, is producing products which will potentially replace a number of low quality products.

\subsection{New Processes Driving Out Old Products and Processes}

For a number of traditional, homogeneous products, not only is the problem one of substitution by a new product, but also of increasing competition between processes. In the case of agriculture, industrial biotechnologies are increasingly driving out agricultural technologies and methods of production. For example, the production of high-value secondary metabolites for drugs developed from medicinal plants and flavours developed from plants, is increasingly replacing traditional drugs and flavourings.

Industrial techniques are pervasive challenges to producers of traditional products, because they not only replace or compete with traditional products, but also produce techniques which can be extended to a number of previously unrelated natural products ${ }^{151}$.

One of the first crops which was affected by industrial biotechnology based products was sugar. Although there was some evidence of starches having sweetening properties since the early 19 th century ${ }^{152}$, the large scale replacement of sugar, especially cane sugar, can be traced back to the 1970s with the development of High Fructose Corn Syrup (HFCS) produced from maize or corn. HFCS, at first an expensive product of modern enzyme technology, has today come close to meeting the entire demand for sweeteners from the soft drinks industry. Its popularity is largely due to its particular characteristics, such as its liquid state at room temperature, making it more convenient for use in industrial processes especially for the soft drinks industry, and also because of the highly protected nature of markets such as the EEC and the USA where it is being used, ensuring sugar prices which are considerably higher than elsewhere in the world and high enough to allow competitive production of HFCS. The prices of HFCS also tend to be more stable than that of sugar since it uses only 10 percent of the total US corn harvest every year ${ }^{153}$. Corn also stores better and for a longer period of time than either sugarcane or sugarbeet, adding further stability to the price since it allows producers of HFCS to hold stocks ${ }^{154}$. The OECD estimates that in 1983 almost two thirds of total sugar consumption in the US was accounted for by liquid sugar ${ }^{155}$.

150 Ibid, p. 76.

151 Junne (1991), p 3.

152

Ibid, $\mathrm{p} 8$.

153

Ibid.

Ibid. see also Ruivenkamp, 1984.

155

OECD (1989), p 86 
Further breakthroughs have also enabled scientists to produce a new generation of sweeteners which are targeted at a more health conscious community. The brand name Nutrasweet is one such product manufactured by Monsanto and has been followed by a number of other competing low-calorie sweeteners. It was estimated that as early as the 1970 s some 20 sweeteners were being used in industrialized countries ${ }^{156}$. Today the number is still higher. While the introduction of alternative sweeteners is not a new phenomenon, and while artificial sweeteners are still in use, the emphasis seems to have moved to natural sweeteners in recent times. The development of Thaumatin, 100,000 times sweeter than sugar, from a fruit found in central and south-west Africa ${ }^{157}$, may soon find its way into the market. The sweetener which is being marketed by the name of Talin is still extremely expensive and therefore not yet a viable threat to other sweeteners. However the search for other similar sweeteners, as well as for reducing the cost of present sweeteners continues.

These developments have brought about considerable changes in the sugar market. Countries such as the Philippines which are highly dependent for their export earnings on the international demand for sugar, have suffered considerably as a result of the collapse of sugar prices. The emergence of HFCS and subsequent sweeteners have intensified efforts to develop newer substitutes with a higher concentration of fructose. As a result of this, along with the increasing success of niche markets such as low calorie products, it is likely that cane sugar producers will have to go through major structural adjustments in the next few years. Thus, the impact on producers of the traditional product, sugar, will be negative, although this will not be the case for product variety. As table 5.2 below summarises, and as described above in the text, the sweetener market has been characterised by an increasing variety of products as an increasing number of substitutes are developed to displace sugar.

Cocoa butter has important characteristics which makes it indispensable for the production of chocolate and account for its distinctive flavour. Biotechnology has brought about two important changes to the pattern of cocoa production. Industrial biotechnology has the potential to displace the use of cocoa altogether in the production of chocolate. Cocoa, because it is labour intensive and grown largely on small holdings, tends to be higher priced than a number of other oilseeds. Production uncertainties and a high degree of susceptibility to disease add to the upward pressures on the market price for cocoa. Chocolate producers have been experimenting with ways to produce cocoa butter substitutes (CBSs) through the use of cheaper oils with qualities similar to that of cocoa. The predominant raw materials used to produce CBSs are Shea, Illip and Sal, grown mainly in Africa in small quantities and because of their relative unimportance as cash crops, low priced.

A number of other oilseeds which are cheaper than cocoa butter, notably palm oil, one of the cheapest edible oils at present, are also being experimented with. The use of CBSs are however restricted in the production of chocolate by international agreements, notably the International Cocoa Agreement and also by a number of countries ${ }^{158}$. So far therefore, their use has been limited, although some countries allow their use in restricted quantities along with cocoa butter. As long as these restrictions continue, the market for cocoa is likely to

156 Panchamukhi and Kumar (1988).

157 Society for International Development (1988).

158 Society for International Development (1988). 
remain relatively protected, although new breakthroughs may result in a relaxing of these restrictions.

Once again, as with the market for sweeteners, the total variety of products in the market for cocoa butter appears to be increasing as a result of biotechnology R\&D. Table 5.2 shows that cocoa butter production could either be increased through secondary biotechnologies or through genetic engineering. Alternatively, the use of other edible oils to produce Cocoa Butter Substitutes, would increase the total variety of Cocoa Butter products available in the market.

Other examples of such displacement abound and will become more common as industrial scale up techniques become more advanced. Vanilla, the flavour extracted from the vanilla pod, used widely across the world with an export value estimated to be about US \$ 100 million at present, has been the subject of much of this research in recent years. Recent reports say that a California based biotechnology company, Escagenetics Corporation has now developed a cost-effective method of producing vanilla extract through an industrial process at a cost of about US $\$ 25$ per pound instead of the US $\$ 200$ per pound cost of natural vanilla. This phytovanilla, whose patent has been applied for, is now in the process of being commercially scaled up and will probably be available in the market soon after ${ }^{159}$. The losers will be the world's producers of natural vanilla, all located in developing countries and those consumers who prefer this product, who will have to pay higher prices as the product increases in price, or will experience lower welfare if the product is entirely substituted away by the biotechnology competitor.

Research on other flavours and essences such as saffron is also taking place, although it is not at as advanced a stage as vanilla. Similarly, as shown in table 5.2 below, attempts to develop industrial substitutes for other products and widely used drugs such as quinine (which is used for treating malaria), will bring enormous benefits for companies which make these breakthroughs. In the case of these products, the impact is not as clear as for the others discussed above. The production of a substitute, especially a high quality substitute, may also drive all older qualities out of the market. This as we shall see in the Part II below is indeed the result in some of the new quality based growth models (see Chapter 6), where the production of each new quality immediately results in the older quality being driven out of the market.

Table 5.2 also shows a particular relationship between the country whose product is displaced, in the cases mentioned above, developing countries, and the country doing the displacing, in these cases industrialized countries. This appears to be an interesting variant on the Grossman and Helpman argument that no innovator targets his/her own innovation. In the case of these products, displacement is north-south, and although there is some targeting of northern products by northern producers, this is not generally the case with respect to southern producers targeting or displacing northern products. 
Table 5.2. Substitution through biotechnology ${ }^{1}$

\begin{tabular}{|c|c|c|c|c|c|}
\hline $\begin{array}{l}\text { Affected } \\
\text { Commodity }\end{array}$ & $\begin{array}{l}\text { Biotechnology } \\
\text { substitute }\end{array}$ & $\begin{array}{l}\text { Company/ } \\
\text { Country }\end{array}$ & Stage & $\begin{array}{l}\text { Market } \\
\text { size }\end{array}$ & $\begin{array}{l}\text { Affected } \\
\text { Country }\end{array}$ \\
\hline UGAR & $\begin{array}{l}\text { 1. HFCS } \\
\text { produced from } \\
\text { starch through } \\
\text { immobilized } \\
\text { enzymes } \\
\text { 2. Krystar: } \\
\text { starch based } \\
\text { sweetener } \\
\text { (crystallized) } \\
\text { 3. Talin } \\
\text { produced from } \\
\text { berries } 10,000 \\
\text { times sweeter } \\
\text { than sugar } \\
\text { 4. Aspartame } \\
\text { low calorie } \\
\text { sweetener, } 200 \\
\text { times sweeter } \\
\text { than sugar }\end{array}$ & $\begin{array}{l}\text { US \& Japan } \\
\text { Tate \& Lyle } \\
\text { Tate \& Lyle, } \\
\text { UK, } \\
\text { Unilever, } \\
\text { UK, Ingene } \\
\text { Monsanto }\end{array}$ & $\begin{array}{l}\text { In market } \\
\text { since } 1978 \\
\text { Developed } \\
\\
\text { Scaleup } \\
\text { stage. In } \\
\text { market in } \\
\text { UK, Austria } \\
\text { Japan } \\
\text { Market } \\
\text { value over } \\
\text { \$1 billion }\end{array}$ & $\begin{array}{l}\$ 14.6 \text { bil } \\
\text { in } 1980 \text {, } \\
\$ 10 \text { bil } \\
\text { in } 1984 \\
\text { same } \\
\\
\\
\$ 14.6 \text { bil } \\
\text { in } 1980 \text {, } \\
\$ 10 \text { bil } \\
\text { in } 1984\end{array}$ & $\begin{array}{l}\text { Philippines, } \\
\text { Caribbean } \\
\text { and African } \\
\text { countries } \\
\text { same } \\
\text { same } \\
\text { same }\end{array}$ \\
\hline COCOA & $\begin{array}{l}\text { 1. CBSs from } \\
\text { low value oils } \\
\text { eg palm oil } \\
\text { 2. Cocoa butter } \\
\text { production } \\
\text { through cell } \\
\text { culture }\end{array}$ & $\begin{array}{l}\text { Univ Tokyo } \\
\text { Ajinomoto } \\
\text { licensed; } \\
\text { patents filed } \\
\text { FujiOil, } \\
\text { Genencor, } \\
\text { CPC Int'l } \\
\text { Unilever UK } \\
\text { Cornell Univ, } \\
\text { Hershey } \\
\text { foods, Nestle }\end{array}$ & $\begin{array}{l}\text { Commercial } \\
\text {-ization } \\
\text { stage }\end{array}$ & $\begin{array}{l}\$ 3.7 \\
\text { billion } \\
\text { Same }\end{array}$ & $\begin{array}{l}\text { Cote } \\
\text { d'Ivoire } \\
\text { Ghana, } \\
\text { Brazil, } \\
\text { Cameroon, } \\
\text { Ecuador, } \\
\text { Granada }\end{array}$ \\
\hline VANILLA & $\begin{array}{l}\text { Production of } \\
\text { phyto vanillin }\end{array}$ & & $\begin{array}{l}\text { Commercial } \\
\text {-ization } \\
\text { likely by } \\
\text { end of } \\
\text { decade }\end{array}$ & $\begin{array}{l}\$ 67 \\
\text { million }\end{array}$ & $\begin{array}{l}\text { Madagascar } \\
\text { Comoros, } \\
\text { Reunion, } \\
\text { Indonesia }\end{array}$ \\
\hline
\end{tabular}


Table 5.2. Continued ${ }^{1}$

\begin{tabular}{|c|c|c|c|c|c|}
\hline $\begin{array}{l}\text { Affected } \\
\text { Commodity }\end{array}$ & $\begin{array}{l}\text { Biotech } \\
\text { Substitute }\end{array}$ & $\begin{array}{l}\text { Company/ } \\
\text { Country }\end{array}$ & Stage & $\begin{array}{l}\text { Market } \\
\text { Size } \\
\end{array}$ & $\begin{array}{l}\text { Affected } \\
\text { Country }\end{array}$ \\
\hline GUM ARABIC & $\begin{array}{l}\text { Production } \\
\text { through } \\
\text { fermentation } \\
\text { of raw sugar }\end{array}$ & $\begin{array}{l}\text { IGI } \\
\text { Biotech, } \\
\text { Companies } \\
\text { in the US }\end{array}$ & In market & $\begin{array}{l}\$ 60 \\
\text { million }\end{array}$ & $\begin{array}{l}\text { Sudan, } \\
\text { Nigeria, } \\
\text { Senegal }\end{array}$ \\
\hline $\begin{array}{l}\text { NATURAL } \\
\text { FATS }\end{array}$ & $\begin{array}{l}\text { 1. Non-calorie } \\
\text { fat substitutes } \\
\text { 2. Microbial } \\
\text { production }\end{array}$ & $\begin{array}{l}\text { Monsanto, } \\
\text { Procter \& } \\
\text { Gamble } \\
\text { Unilever }\end{array}$ & $\begin{array}{l}\text { Commercial } \\
\text {-ization }\end{array}$ & $\begin{array}{l}\$ 11.6 \\
\text { billion } \\
\text { (Third } \\
\text { World } \\
\text { Export) }\end{array}$ & $\begin{array}{l}\text { Latin } \\
\text { America, } \\
\text { Malaysia, } \\
\text { Philippines }\end{array}$ \\
\hline PYRETHRUM & 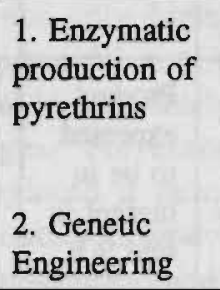 & $\begin{array}{l}\text { Univ of } \\
\text { Minnesota, } \\
\text { Mclaughlin } \\
\text { Gormley } \\
\text { King \& Co }\end{array}$ & $\begin{array}{l}\text { Process } \\
\text { patented }\end{array}$ & $\begin{array}{l}\$ 110 \\
\text { million }\end{array}$ & $\begin{array}{l}\text { Tanzania, } \\
\text { Ecuador, } \\
\text { Kenya }\end{array}$ \\
\hline CINCHONA & $\begin{array}{l}\text { Phyto- } \\
\text { production of } \\
\text { quinine }\end{array}$ & $\begin{array}{l}\text { Plant } \\
\text { Sciences } \\
\text { Ltd UK }\end{array}$ & $\begin{array}{l}\text { Research } \\
\text { stage }\end{array}$ & & Indonesia \\
\hline SAFFRON & $\begin{array}{l}\text { Phyto- } \\
\text { production of } \\
\text { saffron }\end{array}$ & $\begin{array}{l}\text { Univ of } \\
\text { Edinburgh } \\
\text { Albright \& } \\
\text { Wilson, UK } \\
\end{array}$ & $\begin{array}{l}\text { Research } \\
\text { stage }\end{array}$ & & India \\
\hline COFFEE & $\begin{array}{l}\text { Upgrading } \\
\text { poor varieties } \\
\text { of coffee }\end{array}$ & $\begin{array}{l}\text { General } \\
\text { Foods, US, } \\
\text { Nestle, } \\
\text { Swiss }\end{array}$ & $\begin{array}{l}\text { Research } \\
\text { stage }\end{array}$ & $\$ 10$ billion & $\begin{array}{l}\text { Africa, } \\
\text { Latin } \\
\text { America }\end{array}$ \\
\hline SOYABEANS & $\begin{array}{l}\text { rDNA } \\
\text { production of } \\
\text { single cell } \\
\text { proteins from } \\
\text { natural gas/ } \\
\text { biomass for } \\
\text { cattle feed }\end{array}$ & $\begin{array}{l}\text { Hoechst, } \\
\text { FRG; ICI, } \\
\text { UK; }\end{array}$ & $\begin{array}{l}\text { Process } \\
\text { Developed } \\
\text { but not yet } \\
\text { cost } \\
\text { effective }\end{array}$ & $\begin{array}{l}\$ 7.2 \\
\text { billion }\end{array}$ & $\begin{array}{l}\text { Argentina, } \\
\text { Brazil, } \\
\text { Cóte } \\
\text { d'Ivoire, } \\
\text { Senegal }\end{array}$ \\
\hline SAPOTA & $\begin{array}{l}\text { Phyto } \\
\text { production of } \\
\text { chili }\end{array}$ & $\begin{array}{l}\text { Lotte } \\
\text { (Japan) }\end{array}$ & $\begin{array}{l}\text { Expected in } \\
\text { market mid } \\
90 \text { s }\end{array}$ & & $\begin{array}{l}\text { Central } \\
\text { America }\end{array}$ \\
\hline
\end{tabular}


Table 5.2. contd. ${ }^{1}$

\begin{tabular}{|c|c|c|c|c|c|}
\hline $\begin{array}{l}\text { Affected } \\
\text { Commodity }\end{array}$ & $\begin{array}{l}\text { Biotechnology } \\
\text { Substitute }\end{array}$ & $\begin{array}{l}\text { Company/ } \\
\text { Country }\end{array}$ & Stage & $\begin{array}{l}\text { Market } \\
\text { size }\end{array}$ & $\begin{array}{l}\text { Affected } \\
\text { country }\end{array}$ \\
\hline NATURAL FATS & $\begin{array}{l}\text { low calorie fat } \\
\text { substitutes: } \\
\text { Microbial } \\
\text { production of oil }\end{array}$ & $\begin{array}{l}\text { Monsanto, Procter } \\
\text { \& Gamble } \\
\text { respectively } \\
\text { Unilever }\end{array}$ & $\begin{array}{l}\text { Commerc } \\
\text {-ialization } \\
\text { stage }\end{array}$ & $\begin{array}{l}\$ 11.6 \text { bil } \\
\text { (third } \\
\text { world } \\
\text { exports) }\end{array}$ & $\begin{array}{l}\text { Latin } \\
\text { America, } \\
\text { Malaysia, } \\
\text { Philipp. }\end{array}$ \\
\hline $\begin{array}{l}\text { LITHOSPERMUM } \\
\text { (Ko-Shikonin) }\end{array}$ & $\begin{array}{l}\text { Shikonin through } \\
\text { Tissue culture }\end{array}$ & $\begin{array}{l}\text { Mitsuit Petro } \\
\text { chemicals Japan }\end{array}$ & $\begin{array}{l}\text { Commerc } \\
\text {-ialized }\end{array}$ & & $\begin{array}{l}\text { China, Rep } \\
\text { of Korea }\end{array}$ \\
\hline PAPAVER & $\begin{array}{l}\text { Phyto production } \\
\text { of codeine and } \\
\text { opium through } \\
\text { tissue culture }\end{array}$ & & $\begin{array}{l}\text { Process } \\
\text { patented }\end{array}$ & $\begin{array}{l}\$ 20 \\
\text { million }\end{array}$ & Mexico \\
\hline ECHINACEA & $\begin{array}{l}\text { Phyto production } \\
\text { of Echinacea } \\
\text { purpurea } \\
\text { (medicinal } \\
\text { product) }\end{array}$ & $\begin{array}{l}\text { Lomopharm } \\
\text { (Germany) in } \\
\text { collaboration with } \\
\text { German subsidiary } \\
\text { of BAT, UK }\end{array}$ & $\begin{array}{l}\text { Product } \\
\text { expected } \\
\text { to be in } \\
\text { market in } \\
\text { mid } 90 \text { s }\end{array}$ & & Mexico \\
\hline CATHARANTHUS & $\begin{array}{l}\text { Phyto production } \\
\text { of vincristine }\end{array}$ & $\begin{array}{l}\text { Canadian National } \\
\text { Research }\end{array}$ & $\begin{array}{l}\text { Expected } \\
\text { in market } \\
\text { mid } 90 \mathrm{~s}\end{array}$ & $\begin{array}{l}\$ 18-20 \\
\text { million } \\
\text { (US } \\
\text { market) }\end{array}$ & \\
\hline JASMINE & $\begin{array}{l}\text { Phyto production } \\
\text { of Jasmine }\end{array}$ & & $\begin{array}{l}\text { Expected } \\
\text { in market } \\
\text { mid-90s }\end{array}$ & $\begin{array}{l}\$ 0.5 \\
\text { million }\end{array}$ & \\
\hline DIGITALIS & $\begin{array}{l}\text { Phyto production } \\
\text { of digitoxindi- } \\
\text { goxin }\end{array}$ & $\begin{array}{l}\text { University of } \\
\text { Tuebingen, } \\
\text { Boehringer- } \\
\text { Mannheim, } \\
\text { Germany }\end{array}$ & $\begin{array}{l}\text { Scale up } \\
\text { stage }\end{array}$ & $\begin{array}{l}\text { \$20-55 } \\
\text { million } \\
\text { (US } \\
\text { market) }\end{array}$ & \\
\hline RAUWOLFIA & $\begin{array}{l}\text { Phyto production } \\
\text { of Reserpine }\end{array}$ & & $\begin{array}{l}\text { Research } \\
\text { stage }\end{array}$ & $\begin{array}{l}\$ 80 \\
\text { million } \\
\text { (US } \\
\text { market) }\end{array}$ & \\
\hline
\end{tabular}

${ }^{1}$ Many substitutes are in different stages of development. The terminology used in this table uses the following evolution in R\&D: Research is the first stage, followed by Scale up which implies the first steps from the laboratory stage to industrial production, followed finally by commercialization.

Source: Derived mainly from Panchamukhi and Kumar (1988) and RAFI Communique various issues. 
Thus innovation in this case, appears to be leading to a decline in market shares of developing countries, as their traditional products are displaced by substitutes, lending some support to the argument that the developing country (as a whole) share of international trade is declining ${ }^{160}$.

This last point relating to traditional and changing trade relationships between developing and industrialized countries, has important implications for traditional export products and in the case of developing countries, agricultural products. We relate the model on international trade, to this last point, lending interesting implications for north-south trade in traditional and innovation products, and also for future research directions.

To summarize then, in the previous section we have identified two major displacing effects of biotechnology which are likely to have implications for product variety:

\section{(i) Displacement by Increasing Quality}

Techniques to improve yield are now being perfected in many countries to develop crops which are not only higher yielding, but also disease and pest resistant. Genetic engineering is a powerful new technique which will create entirely new species of crops having the potential to completely replace older products that are more susceptible to disease and climatic changes. For example in the case of cocoa, countries in east Asia and Latin America have displaced a number of countries in Africa which still tend to use older techniques and varieties to produce cocoa.

In the pharmaceutical and medical sectors, high quality products are also appearing on the market, although the lag between innovation, approval and completion of testing, is considerable and in comparison, only a few products are available on the market. However, judging from the number of products at various stages through this initial phase of testing (see for example US OTA, 1991 and Ernst and Young, 1992), it is likely that the impact on older generations of products will be large.

\section{(ii) Displacement through New Techniques}

Industrial techniques are increasingly displacing cash crops, especially those which are expensive, or whose supply fluctuates. The benefit to the consumer in this case, is a steady supply and a reduction in costs. High Fructose Corn Syrup for example, was able to cater to the needs of the soft drinks industry and also ensured steady supply by shifting to another crop as an input, namely, corn which was not as perishable as sugar cane and could therefore be stored more easily. In the case of vanilla and pyrethrum, both substances are exported by developing countries, with Madagascar and Kenya respectively, being the largest exporters of these crops. Demand for pyrethrum has increased substantially over the last decade, and the

${ }^{160}$ See for example World Investment Report (United Nations, 1991) and Narula (1993), both of whom have observed that from trade and investment figures it appears that the developing country share has been declining over recent years. 
inability of east African farmers to expand production sufficiently ${ }^{161}$, has meant a consequent increase in price. The new substitute will be substantially cheaper and will also overcome any potential supply problems.

However, while industrial biotechnology and genetic engineering will no doubt displace old products and processes, the implications for variety seem to be somewhat positive. As table 5.2 shows, the number of substitutes which have often been developed, are in fact, larger than the products displaced. Thus in the case of sugar for example, the substitutes developed include over 20 alternative sweetening products. Many of them, directed at specific niche markets such as the low calorie diet market, are also fulfilling certain demands which serve to increase consumer utility. Many of these substitutes are quite widely available, such as saccharin and nutrasweet which serve the low calorie market, and HFCS, which appears to be widely used by the soft drinks industry. Sugar itself, continues to have a market among nonindustrial consumption, such as households, and small-scale confectionary.

Similarly, for cocoa butter, two major kinds of substitutes are being developed at present which could increase the total variety of products available to consumers ${ }^{162}$. Thus in these cases, new innovations would result in increasing variety.

While we have looked at the changes biotechnology introduces into the production side, we finally turn to examine the demand side and what the consequences of increasing quality and productivity are on consumer preferences.

\subsection{Quality, Variety and Consumer Preferences}

It was argued in the previous section that the two kinds of innovations, one quality increasing and the other productivity (price) increasing (reducing) will displace a number of traditional products, as is often the case when a new technology is introduced. From the point of this discussion however, the interesting question is what impact this will have on consumer welfare, and since consumer preferences can be defined in terms of variety and quality, what are the implications of increasing quality and productivity given consumer preferences for variety.

As is apparent from the earlier surveys on the nature of the technology (see Section I) biotechnology has recorded successes in raising the quality of products available in the economy. This is true both of industrialized countries, where especially in medicine, higher quality products are raising consumer utility greatly, and also in developing countries where greater agricultural productivity and the availability of a wide range of diagnostic kits are being offered to consumers. The result is an overall increase in quality, but also in production technologies and the level of knowledge in the economy.

161 See Juma (1989) on the topic of pyrethrum research in Kenya, and also the Biotechnology and Development Monitor (1992), no. 13, for a recent discussion of the situation with respect to the pyrethrum market.

${ }^{162}$ For lovers of chocolate however, this could mean declining quality because the distinctive taste of cocoa butter can often not be replicated sufficiently using substitutes. 
The implications for consumer preferences for variety however differ across sectors and according to circumstances. In agriculture for example, previous experience with the adoption of new high-yielding varieties during the green revolution show a mixed record. Some areas saw a high adoption of the new varieties, resulting sometimes in an increase in monoculture cropping, while in others the higher quality product was disregarded in favour of maintaining greater crop diversity. As discussed briefly in the section on methodologies above, this difference in adoption has in practice, been influenced by the situation of individual farmers and the decison to maintain variety is often reflected in a desire to spread risk. In general, it has been argued that the degree of risk sharing in this manner is most often associated with the smaller, subsistence farmer, whose access to credit is limited, and who stands to lose more if the crop fails (Ziesemer 1987). This was also a pattern associated with the green revolution especially in certain parts of the world. For example, in the Punjab, in India, it was noted that the larger scale farmers had more of a tendency in general, to adopt the higher yielding varieties, whereas a greater crop diversity was found in the fields of small scale farmers (Shiva, 1989).

A number of factors other than risk sharing, such as the need for better irrigation systems which were often accessible only to large scale farmers were also associated with the adoption of high yielding varieties and may also have contributed to the faster diffusion of the green revolution and therefore the spread of monoculture, among large scale farms. Despite this, the importance of spreading risk among farmers is an acknowledged factor in their tendency to plant crops of a more diverse genetic structure. Hayami and Ruttan (1991) dispute the argument that the green revolution tended to favour large scale farmers, although their analysis of adoption of new varieties in thirty villages in Asia, shows that while there was a faster rate of adoption by small scale farmers (in relative or percentage terms), it was the medium sized farms that tended to adopt the new varieties at a higher rate in later years (pp338-339). This appears to support the argument that while the absolute rate of adoption is lower in small scale farms, the relative rate of adoption is lower in large scale farms. In addition, Hayami and Ruttan agree that in cases where the distribution of land was highly skewed, new varieties tended to reinforce this bias ( $p$ 338).

Thus it is likely that for reasons of access to the higher prices associated with the new biotechnology based varieties, and of spreading risk, the adoption of higher quality, to the extent that it results in declining variety, will most probably be more common in areas with large landholdings with a principle agent structure. This is already apparent to some extent in countries such as Malaysia where large landholdings of important cash crops such as rubber and oil palm are being uniformly planted with higher yielding varieties which are more similar in terms of genetic make up. Thus, it is difficult to say what the impact on variety, as a result of consumer preferences, will be in agriculture.

Similarly, with animal biotechnologies, the use of a number of new drugs such as Somatotropin, as mentioned above, may result in a reduction of species variety as higher yielding animals and fish, increasing social welfare and increasingly replace the older, lower yielding varieties.

In the case of the pharmaceutical sector, the implications are less ambiguous. It would be expected that the appearance of higher quality drugs and vaccines would make older products, of a lower quality, redundant. This may not necessarily be the case if social preferences are taken into account. Despite the availability of the new drug, old drugs will continue to be demanded by society because of incomplete substitution between the old and 
new drug. A number of reasons, including allergies to particular medications, a preference for both brand name based and generic varieties ${ }^{163}$, and the presence of different strains of diseases which have to be treated using slightly differentiated medical treatments may ensure that new drugs will not immediately drive out older, competing products. In the longer run when genetically engineered products become more widely available, there will however be more of a tendency for consumers to choose the new product rather than choose for variety. The genetically engineered product, which is a more perfect substitute for the older product will therefore completely displace it ${ }^{164}$.

\section{Conclusions}

Thus, two implications emerge from this chapter, relating biotechnology to the growth and trade models constructed in Chapters 8 and 9 in Part III. Firstly, as discussed above, consumer preferences appear to imply a desire for higher quality, but not necessarily at the expense of variety. Thus, even though quality improvements provide consumers with a more desirable product, this does not necessarily result in all older qualities being rejected immediately, although, this may be the case in the long run and is more likely to happen as genetically engineered products become more acceptable and accessible. In fact, production of higher quality products and products which are cheaper, tends to result in an increase in the total variety of products available in the economy. Thus, the evidence from biotechnology shows that consumers tend to prefer both variety as well as products which are cost reducing or of a higher quality. We have taken the particular example of pharmaceuticals because the evidence here is most clear. Society will always prefer a greater variety of products, including both higher and lower quality products.

Even though we have used this particular example to use in the subsequent growth and trade models, there is also similar evidence from the agricultural sector where industrial biotechnology is adding to the total variety of products available to consumers. The evidence here is however mixed, showing that while in some cases biotechnology adds to product variety, it can also completely displace the older product.

This last result led to the second conclusion we draw from this chapter, namely that biotechnology appears to have an important implication for north-south trade. Of all the products examined, the trend appears to be that biotechnology research done primarily in the north is targeting and displacing products produced in the south. Many of these such as sugar,

${ }^{163}$ Here the production of different varieties of the same products, depends very much upon the type of patent regime present in the country. For example. Indian companies are able to produce and export AZT, the drug used to treat AIDS, because the drug was developed using a different process, than that used by Wellcome, the patent holder for AZT in the United States. Because India does not grant or recognize product patents, this is possible under Indian patent law, but not under US patent law which grants process and product patents. The Indian AZT is being exported to a number of developing countries who would otherwise have to pay a higher price to import the American drug.

164 I am grateful to Dominique Foray, who was a discussant at the Evolutionary Economics Conference in Strasbourg in October 1994 for pointing out this distinction between the long run impact of biotechnology as genetically engineered products become more accessible to consumers. 
vanilla, cocoa are traditional agricultural products. Biotechnology therefore will result in traditional products from developing countries losing value and being driven out of the market. The total share of international trade is therefore declining for developing countries, confirming some of the earlier observations made about trade relations between north and south.

In the next section we examine the manner in which the theoretical literature discusses the implications of innovation for growth and trade. The way in which preferences for variety and quality are modeled in the new growth and trade models are then related to the implications of biotechnology R\&D for quantity, quality and variety, before moving on to the model presented in the final section. The structure of consumer preferences observed in this chapter are used in both models and we also discuss the final conclusion, that of declining share of trade for developing countries, in the model on international trade presented in Chapter 9 below. 


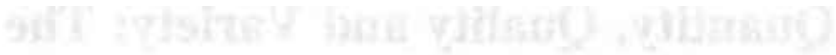




\section{Introduction}

In the previous section, we examined the changing nature of quantity, quality and variety in developing and industrialized countries, as a result of innovation and imitation in biotechnologies. We concluded that both quantity and quality based improvements may have a significant impact on economic growth in biotechnology affected sectors, and also on the variety of products available to consumers. The nature of the impact, i.e., whether it would be variety reducing or variety increasing depends very much on consumer preferences and would be different in different sectors. Thus to recapitulate briefly, in the pharmaceutical sector, biotechnology innovations would mostly have a positive impact on variety, especially in the short run, although as genetically engineered products become more widely available, this variety may be reduced to one as consumers choose the genetically engineered products; in agriculture, this impact was more ambiguous, depending upon the absolute or relative risk averseness of farmers, and increasing returns in the supply of seeds ${ }^{165}$.

In Part II, we continue to examine the impact of innovation upon the changing nature of quantity, quality and variety, but from a theoretical perspective. The literature on technological change has gone through a number of changes, most importantly, in attempting to endogenize rates of technical change and the impact on economic growth. The sources of technological change in these new growth and trade models have come mainly from human capital, learning and investment in R\&D. Many of them model innovation within a sector devoted solely to $R \& D$, while the innovation is commercialized in a separate production sector. The earlier papers however tended to model technological change in an aggregate sense, i.e. without explicitly referring to the microfoundations of market structures. In these models, technological change was introduced often as a separate factor in the production function, either as an exogenous shift parameter as in the early models, or as a variable characterised by increasing returns to scale as in the later growth models. In the two chapters which this section comprises we examine three different aspects of growth models. In chapter 6 which follows immediately, a brief survey of the aggregate production function approach is described, beginning with the early growth models and ending with the more recent "new" growth literature of the 1980 s and 1990 s, which has been built upon the foundations of old growth theory, with a number of notable differences, most importantly of presenting technological change as an endogenous variable and in introducing different sources of technological change in the production function.

This is followed by a discussion of the manner in which the new growth literature is related to market structure. Here the models introduced often describe the process of technological change in the form of new products which are introduced on the market. Innovation and production usually take place in separate sectors and are characterised by differing market structures. We first look at models which describe innovation in terms of the introduction of products which are horizontally differentiated followed by vertical differentiation. The emphasis will be upon examining the implications of these two types of innovations on product variety.

165 On this latter aspect, some of these changes were already discussed in the methodology section of Chapter 1 and will be discussed again in Section III below. 
It will not be the goal of this section, to survey the entire literature on new growth and trade theory. Instead, we emphasise those models and discussions which relate more directly to the methodology described here, i.e., the way in which these models relate technological change to increasing quality and/or variety of products present in the economy. 


\section{Introduction}

The early growth models, including those which first explored the effect of exogenous technological change on the production function, were attempts at explaining the aggregate impact of technical change on economic growth. The empirical analysis carried out by Tinbergen (1942) and Solow (1957) demonstrated that the size of the residual was considerable and growth could not be explained simply by factor accumulation. The early growth models and some more recent ones attempted therefore to explain it within the framework of the aggregate production function. These models do not use explicit microeconomic foundations to explain the contribution of, or production of knowledge in specific production or research sectors. Instead, knowledge or technology (and different models use different sources of technology), is included in the production function as a separate factor of production.

The early literature on technological change, especially Solow (1956), Arrow (1962) and Shell (1967), looked at technological change as an increase in per capita output and the capital labour ratio. These quantity increases improved consumer welfare because of the way in which consumer preferences were modelled, and led to economic growth in all of these variables.

\subsection{Growth Theory and Technological Change}

The early growth models or "old" growth theory placed capital formation at the centre of technological progress in an economy. In the traditional production function, where the basic inputs are labour and capital, capital referring to machinery and similar forms of physical capital, the accumulation of the latter becomes the driving force behind a change in the production function and therefore economic growth.

The foremost contribution to the theory of technological change was made by Robert Solow. In his model which has formed the basis of much of growth theory, Solow (1956, 1957) argued that capital accumulation would cause labour productivity to rise as well, resulting in rising factor productivity, rather than simple capital accumulation being the driving force behind innovation and economic growth. 
The model in its most basic form is as follows: The production function for output $Q(t)$ includes physical capital $K(t)$, and technological change, $A$ embodied in labour $L$, which is fixed.

$$
Q(t)=K^{1-\alpha}[A L]^{\alpha} \quad 0<\alpha<1
$$

Exogenous technical change is defined as an exponential function $A=A_{o} e^{\gamma t}$, where $\gamma$ is the rate of technical change in the economy. Equation (6.1) can be rewritten

$$
Q(t)=K^{1-\alpha} A_{o}^{\alpha}\left[e^{\gamma_{t}} L\right]^{\alpha}
$$

Equilibrium in the goods market is denoted by equality between savings and investment

$$
s Q(t)=I(t) \equiv \dot{K}(t)
$$

and labour supply growth as

$$
L=L_{0} e^{g t}
$$

The system can be solved by taking growth rates of the components of the production function, ie. $A L$ and $K(t)$

$$
\hat{K}=s A_{o}^{\alpha} k^{-\alpha}
$$

where $k$ is defined as capital per effective worker. After normalizing $A_{o}$ to one we can write this as

$$
k(t)=\frac{K(t)}{e^{\gamma t} L}
$$

and

$$
\hat{N}=\gamma+g
$$

From the production function we can solve for the growth rate of capital per efficient labour unit, $k$ 


$$
\hat{k}=\hat{K}-\hat{N} \quad \Rightarrow \hat{k}=s k^{-\alpha}-(\gamma+g)
$$

In the steady state when $\hat{k}=0$, then the relationship between capital and effective labour is steady. If $(\gamma+g)$ is greater than $s k^{-\alpha}$, then the capital to effective labour ratio is falling and vice versa. In this case. the assumption is one of decreasing marginal product of capital.

Thus, economic output and the total capital stock in the economy grow at a steady rate which is equal to the rate of growth of technical progress $\gamma$, and the growth rate of labour, $g$. Any change in factor inputs will result therefore in allocation adjustments and the economy will find itself back in the steady state position.

Fig. 6.1. Dynamics in the Solow Model

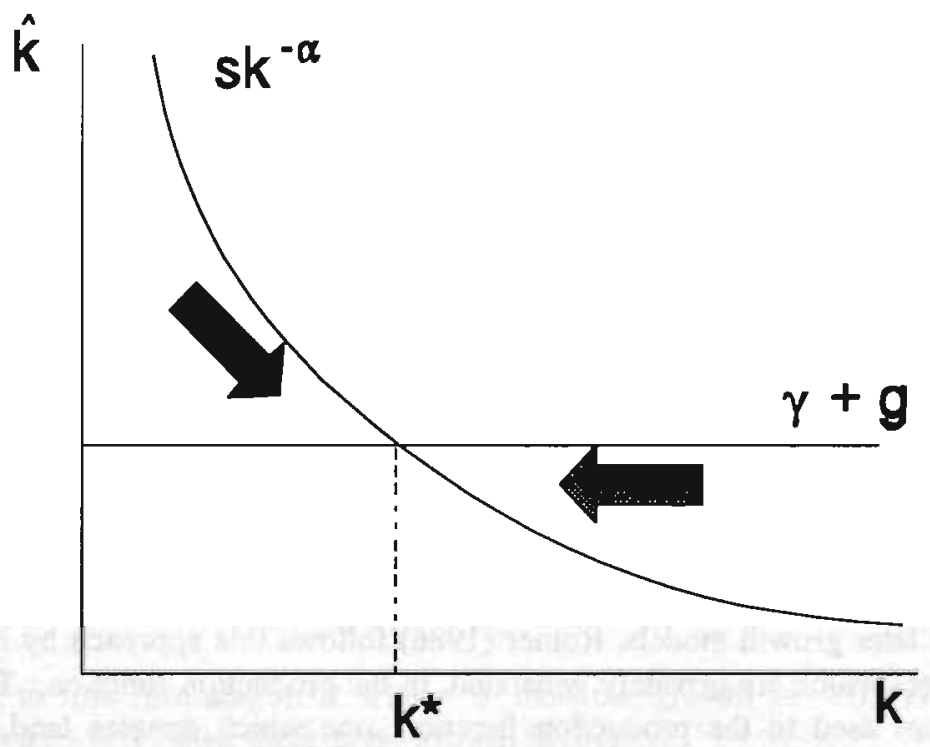

Technical progress in this model and others based on this model, is therefore exogenous and has a constant growth rate of capital per effective labour unit. The resulting increase in total output per input unit, also implies that technical change produces a growth in the total quantity of products produced per input unit.

While the Solow model is explicitly related to increasing output from technical change based on physical capital accumulation, human capital and knowledge have also been used to explain technological change in the early growth model. Shell (1967) looked at technical change based upon public knowledge while Arrow (1962) examined the accumulation of 
knowledge through learning by doing. We now examine these and the growth models which followed them.

\subsection{Endogenous Technical Change}

Thus while technological change in the Solow model was an exogenous variable in the production function, Arrow (1962) and Shell (1967) explicitly referred to technological change in which knowledge or learning is represented by cumulative gross investment, in the case of Arrow (1962) and by resources devoted specifically to inventive activity in Shell (1967).

Arrow's main contribution was in arguing that the role played by knowledge in production is an increasing function of time, i.e., the amount of knowledge available in the economy at time $t$, was directly linked to all cumulative capital investment in the economy before time $t$. This is the direct result of knowledge associated with innovations which cannot be appropriated. Spillovers of this nature have also been explicitly introduced into the production function by Arrow himself, and later by Romer $(1986,1990)$ and Grossman and Helpman (1991a for example). Thus in the model, economic experience measured by cumulative gross investment, determines productivity per worker, and learning results in higher productivity of output.

Shell (1967) describes technical change as being related to explicit investment in inventive activity, with a change in the stock of technical knowledge described by the equation:

$$
\dot{K}=\sigma \alpha(t) Y(t)-\rho K
$$

where $0 \leq \alpha(t) \leq 1$ is the portion of output which is invested in invention and $0 \leq \sigma \leq 1$ is the portion of inventions that can be called successful. Thus, as with Arrow (1962), technical change is attributed to public knowledge and private investment in invention (in the case of Shell), or capital accumulation (as in Arrow).

Among the later growth models, Romer (1986) follows this approach by introducing knowledge spillovers which are privately generated, in the production function. Two sets of factors are therefore used in the production function, one which denotes land, labour or capital, is fixed in supply, while the other, $K$, which denotes knowledge, can be accumulated over time. Increase in production in this model comes from the use of knowledge aggregated over the number of firms in the economy:

$$
K=\sum_{i=1}^{N} k_{i}
$$

where $K$ is aggregate knowledge and $N$ is the number of firms. Thus the aggregate level of knowledge is increasing over the number of firms in the economy. Firms maximize profits taking $K$ as given and although the private marginal product of knowledge is decreasing, the inclusion of aggregate knowledge in the production function, adds to the productivity of private capital and therefore to total output. This spillover is similar to that of Arrow (1962), 
with the exception that in the model by Romer (1986), this externality is due to the action of spillovers on the productivity of private capital. The introduction of the externality moreover implies that a market solution is not optimal, introducing the possibility of government policy to rectify the imbalance.

In Lucas (1988), the components of production, as they enter the production function are physical and human capital, where $K(t)$ is the capital stock and $\dot{K}(t)$ represents capital accumulation. The introduction of human capital as an input in the production function is simply in terms of a measure of productivity, i.e. a general skill level in which a worker with human capital $h(t)$ is as productive as two workers with human capital of $\frac{1}{2} h(t)$ each, similar to the aggregate knowledge defined by Romer (1986), which is included in the production function on the right side of the goods market equilibrium equation

$$
N(t) c(t)+\dot{K}(t)=A K(t)^{\beta}[u(t) h(t) N(t)]^{1-\beta} h_{a}(t)^{\gamma}
$$

where $c(t)$ is consumption, $N(t)$ is labour, $A$ is a general measure of technology in the economy and is constant as in Solow (1956 and 1957 or a spillover if $\gamma>0$ ) and $h_{a}(t)$ is an average measure of human capital in the economy, across all labour classes. Dynamic technological change in the model comes from the rate of change over time of this human capital:

$$
\dot{h}(t)=h(t)^{\delta} G(1-u(t))
$$

where $G$ is increasing with $G(0)=0$. Holding $\delta=1$ and assuming that $G$ is linear, this implies that

$$
\dot{h}(t)=h(t) \sigma[1-u(t)]
$$

According to this formulation if $u(t)=0$ then the growth of $h(t)$ is maximum $(=\sigma)$, whereas if $u(t)=1$, then there is no growth in $h(t)$.

Aggregate economy-wide productivity and total output is therefore the subject of these models which follow the basic Solow (1957) production function approach, although the sources of technological change can be labour or capital augmenting, where technical change can exhibit constant or increasing returns to scale in total factor productivity.

Lucas' (1988) second model is extended to two goods, where production is once again a function of human capital, but where productivity growth is also dependant upon the percentage of the workforce devoted to production. Instead of describing human capital accumulation as withdrawing the labour force from production and into training, such as in the first model, in this model, productivity is defined in terms of leaming by doing and is directly related to the effort devoted to production. 


$$
c_{i}(t)=h_{i}(t) u_{i}(t) N(t), \quad i=1,2
$$

where $c_{i}$ is consumption, $u_{i}(t)$ is the fraction of the workforce devoted to producing good $i$ and where the rate of change in $h(t)$ can be written

$$
\dot{h}_{i}(t)=h_{i}(t) \sigma_{i} u_{i}(t), \quad \sigma_{1}>\sigma_{2}
$$

where the rate of growth of $h_{i}$ can be interpreted here as learning by doing, which increases with the effort $u_{i}(t)$ devoted to production, where by assumption, if $\sigma_{1}>\sigma_{2}$, then good one is the high technology good. Thus in contrast to (6.13), this formulation shows that learning by doing will increase as the amount of effort devoted to production increases. The opposite was the case in the earlier model, where it was the amount of labour withdrawn from the labour force which had a positive impact on technological change.

Preferences are defined by a CES utility function

$$
\begin{gathered}
u\left(c_{1}, c_{2}\right)=\left[\alpha_{1} c_{1}^{-\rho}+\alpha_{2} c_{2}^{-\rho}\right]^{\frac{-1}{\rho}} \\
\alpha_{i} \geq 0, \quad \alpha_{1}+\alpha_{2}=1, \rho>-1, \quad \gamma=\frac{1}{1+\rho}
\end{gathered}
$$

The allocation of production in autarky is determined by the elasticity of substitution, where if gamma is larger than 1, goods are perfect substitutes and the economy will only produce one of the two goods. The opposite is the case, when gamma is less than one, then both goods are produced and the share of each good is determined by the allocation of resources to the production of each good $\delta_{1} u_{1}=\delta_{2} u_{2}$. Determining which good to specialize in, in the case that gamma is greater than one, depends upon the initial conditions and technologies. Thus if the economy produces $c_{1}$ more efficiently at time 1 , then more is produced and the economy becomes better at producing it.

In a situation of free trade (two small countries trading with each others), specialization is determined by relative prices and each country produces according to its initial endowment of human capital; because of the externality created by human capital accumulation, countries accumulate skills and knowledge over time and become better at producing the product in which they have comparative advantage initially and specialization.

Thus technological change in this case, enhances initial comparative advantage, with the good in which the country initially had comparative advantage, being produced in greater quantities as a result of learning in this model.

Technical change is therefore modelled explicitly as a productivity enhancing process. The way in which technical change has been introduced however has been different through the years. Despite this, the earlier models appear to have been mainly concerned with explaining some of the stylised Kaldorian facts about economic growth. Productivity improvements as they have been modelled, mainly through the production function, imply an 
increasing quantity of production in the economy. Even in those models, such as Lucas (1988), where more than one commodity is explicitly introduced into the model, the emphasis is on increased production of those commodities rather than an increasing range of varieties or qualities of products. As utility is only influenced by quantity (by assumption), this is a meaningful approach. However, once variety and quality appear in the utility function, this will have to be changed.

\section{Conclusions}

Thus in this first chapter in Part II, we have introduced some of the basic literature on technological change and economic growth. The main causes of economic growth in these models points to the importance of technological change, variously portrayed as capital accumulation in the Solow $(1956,1957)$ model, as knowledge based, learning by doing in Arrow (1962) and public knowledge in Shell (1967), as knowledge spillovers which are privately generated in Romer (1986), as well as human capital in Lucas (1988).

The production function approach has been used largely to show the importance of introducing scale economies in technical change and economic growth. In these models, economic growth is largely portrayed as increasing output of a particular good. However, a number of recent models have also described technical change in an economy in the form of new products entering the market in each time period.

In the following chapter, we examine two of these approaches that new growth and trade theory has taken, namely, (i) the introduction of new products through technical change which are horizontally differentiated, i.e. are imperfect substitutes for products already in existence; and (ii) the introduction of new products which are quality improvements over older qualities, and are therefore perfect substitutes for the older products. The implications for variety of both types of innovations are quite different and we discuss each in turn, before moving on to the model of endogenous growth and trade, developed in Chapters 8 and 9, and which is based upon some of the models we discuss in Chapter 7 below. 



\section{Variety and Quality in Trade and Growth Models}

\section{Introduction}

In the last chapter we discussed growth models that have taken the production function approach to technical change. An important characteristic of these models was the use of capital or knowledge augmenting technical change combined with knowledge spillovers, that contributed to an increase in the total productivity and therefore in the total quantity of goods produced.

In the 1980s and 1990s, a new group of models emerged, with a slightly different approach to the sources of technological change. The basic premise of these models was that technological change can often be observed, not just as an increase in productivity which can lead to increasing quantity, but also through the appearance of new goods which are (i) imperfect substitutes for one another and are variety increasing; and (ii) perfect substitutes in that they are higher quality products and completely replace older qualities.

For example, in the case of the first, similar products with different brand names, have become widely available in the market and two way trade in like or similar products has also become a common phenomenon. Similarly, in the case of the second kind of technological change, daily observations point to the existence and appearance of products or processes which are of a higher quality than older products. Consumers tend to prefer these higher quality products, rejecting the older qualities from their consumption bundle in the process. Thus technical change can result not only in quantity increases but also in the production of new goods, similar to, or imperfect substitutes for products already in existence.

This is also the case with biotechnology where quantity increases as a result of productivity improvements do occur, but the appearance of new products which are imperfect substitutes for older products are also characteristics of the new biotechnology. For example, the development of new substitutes for older products such as sugar and vanilla, among others, is a common example which has been used in the literature (see Junne, 1991), and although the new products may displace older products to some degree, in general the result, especially in the case of sugar, has been a rising variety of products. In the same way, higher quality products such as vaccines and diagnostic kits for detecting diseases or processes such as bioremediation, to extract metals and other material from wastewaters, may also lead to the rejection of older qualities by consumers. Thus the development of new substitutes for older products is also an example which can be used in biotechnology and lends some substance to the argument of increasing or decreasing variety, the former the result of horizontal innovations, whereas the latter is the result of production of vertical innovations, which push out older qualities.

In this chapter we look at this aspect of technical change, especially in the context of new growth and trade models and relate them to the structure of the growth and trade model which follows. Specifically, we will examine the way in which products enter the market and 
the implications for variety depending upon the manner in which consumer preferences are modelled. Since the earliest models are trade models, we look at these first and then move on to the more dynamic growth models of the late 1980 s and early 1990 s.

\subsection{The Variety Models}

With respect to the horizontal differentiation models, the appearance of new varieties has been discussed in two ways in these models. The first is by modelling new varieties in the production function and the second through consumer preference for variety. We begin by discussing these two approaches and then provide a more detailed survey of the models themselves.

\subsubsection{Horizontal Differentiation in the Production Function}

Increasing variety has been presented in the new growth models by including them explicitly in the production function. Instead of consumers demanding greater variety, in these models, final output is increased through the use of a greater variety of inputs, or intermediate products. Increasing variety appears therefore, not from preferences but in the production function for the final good.

In Ethier (1982), product differentiation is expressed in a variety of intermediate products and the manufacturing sector, which produces under increasing scale economies, has the following production function:

$$
M=n^{1-\alpha}\left[\sum_{i=1}^{n}\left(\frac{x_{i}^{\alpha}}{n}\right)\right]^{\frac{1}{\alpha}}
$$

where $x(i)$ is the quantity of the $i$ th intermediate good, the parameter alpha lies between 0 and 1 and $n$ is the number of intermediate goods used in the manufacturing sector. The production function, indicates higher productivity from increasing variety, depending upon the value of alpha. Lower values of alpha indicate higher productivity from a greater variety of intermediate goods used in this sector. In a static analysis Ethier shows that two way trade in both differentiated and homogeneous sectors follow the basic results of the Heckscher Ohlin theory quite closely, although there is specialization in different varieties of intermediate goods. function

Romer's 1990 paper also uses this concept of increasing variety in the production

$$
Y\left(H_{Y} L, x\right)=H_{Y}^{\alpha} L^{\beta} \sum_{i=1}^{A} x_{i}^{1-\alpha-\beta}
$$

where $H_{y}$ is human capital used in the production of the final good, $Y, L$ is labour, and $x_{i}$ is the $i$ th intermediate product, $x$. Output depends upon increasing variety $A$, of intermediate 
goods. The producing firm has to rent $x(i)$ units of the durable good $i$, which is patented, before he/she can produce the final good $Y . H$ and $L$ are fixed and $K$, which is total capital, grows by the amount of consumption foregone

$$
\dot{K}(t)=Y(t)-C(t)
$$

where $C(t)$ is consumption at time $t$ and the relation between intermediate goods and capital stock is denoted by $K=\mu \sum_{i=1}^{A} x_{i}$ where $\mu$ represents consumption foregone, i.e. the number of units which are invested in the production of the intermediate good.

The aggregate stock of innovations (summed over all individuals as in Romer (1986)) changes according to

$$
\dot{A}=\delta H_{A} A
$$

where $A$ can be seen as knowledge or spillovers from innovative activities (as in the 1986 paper) or as the number of varieties, so as not to get confused with $H_{A}$ which is also knowledge or human capital. These spillovers or the number of varieties increases the productivity of human capital in the research sector. This is an important specification, which has been used by a number of others (see below), and not only implies a growth in proprietary information, but also in the contribution of innovations to knowledge in the economy. Thus, the growth of knowledge is directly proportional to the stock of new varieties $A$, in the economy.

The research sector exhibits increasing returns to scale, which therefore results in an increase in the marginal product of human capital used in research. The externality produced by the growth of varieties in the economy implies a balanced growth equilibrium, in which growth in the economy is dependant upon the productivity of human capital, $\delta H_{A}$ (which is equivalent to the growth rate of $K$ ).

\subsubsection{Horizontal Differentiation Through Preferences}

Most of the new models which have attempted to describe technological change in terms of the appearance of new, horizontally differentiated products, have made use of the "love of variety" approach based on Spence (1976) and Dixit and Stiglitz (1977). The love of variety approach uses consumer preferences to indicate an increasing desire for variety. The basic approach uses a symmetric and concave utility function where the total number of quantities available, are demanded by consumers. This Constant Elasticity of Substitution (CES), utility function is usually defined as 


$$
u\left(C_{1}, C_{2}, \ldots .\right)=\left[\sum_{i=1}^{n} C_{i}^{\alpha}\right]^{\frac{1}{\alpha}}, \quad \alpha=\left(1-\frac{1}{\sigma}\right), \quad \sigma>1
$$

where $\sigma$ is the elasticity of substitution between two varieties and $n$ is the total number of varieties. Restricting elasticity to be larger than one implies that marginal revenue will be positive (or if the elasticity of demand with respect to price is lower than 1, marginal revenue is negative (Helpman and Krugman, 1985), which implies that the utility function can be used in models with imperfect competition.

In addition, to quantity, this function has the property of also valuing variety. The indirect utility function therefore has the following form

$$
u\left(\frac{E_{i}}{n p_{i}}, \ldots, \frac{E_{i}}{n p_{i}}\right)=n^{\frac{\sigma}{(\sigma-1)}} C_{i}
$$

where $E_{i} / n p_{i}$ measures consumption and $n_{i}$ is the number of varieties of product $i$ available where the price $p_{i}$ is the same for all varieties. Then the consumer will prefer to buy all varieties in equal quantities given the budget constraint. The utility elasticity of $n^{\sigma / \sigma-1}>1$ is higher than that of $C_{i}$. Thus the number of varieties, as they increase, increases consumer welfare, because of this form of preferences.

\subsubsection{Trade and Growth and Increasing Variety}

Although the Heckscher Ohlin Samuelson model of international trade has formed the basis of modern trade, its restrictive assumption of perfect competition has caused some degree of uneasiness in using it to explain all international trade patterns. The testing of trade theories (see Leamer, 1984) has been a regular phenomenon in an effort to prove its efficacy with respect to different kinds of trade flows. One particular area has been of special concem and a weakness of the HOS trade model, namely intra-industry trade. Despite all indications pointing to a dominance of this kind of trade, the HOS model with its restrictive assumptions, is largely unable to explain it. Many of the new trade models which have been developed, have been in response to this gap in traditional factor endowment based theory. Intra-industry trade, as its name suggests, is two way trade in like products, and indicates some degree of demand for variety, rather than just quantity, as the previous models have implied. Technical change must therefore take place partly in response to this apparent demand for like products. The group of trade models we discuss in this section therefore, relate to intra-industry trade in horizontally differentiated products.

While the early trade models were mostly static, they were followed by a number of endogenous growth models which discussed the impact of technical change on economic growth within a dynamic framework. These will also be discussed below, especially in relation to the impact of technical change on the variety of products available and demanded by consumers in the economy. 
In a stylized north-south model, Krugman (1979) departed from the older trade and growth models in demonstrating the appearance of new products (which were different from old products) as a result of technical change. The model was based on Vernon's (1966) theory of the product cycle which argued that products are transferred to countries with lower labour costs after a period of being produced in innovating countries. The basic idea and assumptions of the model are simple. Two countries exist, north and south and the only difference is that while the north produces new goods and perhaps old goods as well, the south can only produce old goods.

Consumer preferences are based on (7.5) above. However, in the case of the Krugman (1979) model, $n$ is the number of northern and southern products available to consumers. Similarly, instead of assuming productivity increases in the production function as in the other models, he assumes that technical change occurs entirely in the form of the availability of new products, resulting thus in an increasing variety of products rather than an increasing quantity of the same product.

By assumption, only the north can produce new products, whereas the production of old products depends upon relative wages. In this case, Krugman assumes that $w_{N} / w_{s}>1$, implying that the north is not competitive in producing old goods, resulting in a model with complete specialization. By assuming a rate of innovation and imitation which is proportional to products already in existence, he assumes technical change based on previous knowledge, where the appearance of new products depends upon old products

$$
\begin{gathered}
\dot{n}=i n \\
\dot{n}_{s}=t n_{n}
\end{gathered}
$$

where $n$ denotes the number of products available, dots indicate rates of change over time, $t$ is a parameter, and the subscripts $s$ and $n$ denote south and north respectively. The rate of innovation in the north is therefore proportional to the number of products already in the economy, while the rate of imitation in the south is dependant upon the number of products and a lag which is measured by $1 / t$. Thus the steady state is characterised by constant wages and rates of innovation and imitation.

Although simple in formulation and simplistic in its assumptions, the Krugman model was considerably influential in that it led the way for a whole group of new models which depicted technical change as increasing variety rather than just quantity.

Judd (1985) and Grossman and Helpman (1991d) extend Krugman's initial model to a dynamic framework. In Judd (1985), the problem faced by the country is a trade off between present consumption, or future investment in invention which will increase product variety. The country's utility maximization is then

$$
\begin{aligned}
& \max \int_{0}^{\infty} e^{-\beta t} y^{\alpha} V d t, \quad 0 \leq y \leq e^{\lambda_{t}} V^{-1} \\
& \text { s.t } \quad k \dot{V}=e^{\lambda_{t}}-y V
\end{aligned}
$$


where beta is the rate of time preference, $y(t)$ is the common level of consumption where the interval of goods is described by the set $[0, V(t)]$, and $0<\alpha<1, V$ is an integral measure of the number of goods as before, the elasticity of demand for a good is $(1-\alpha)^{-1}$ and lambda is a parameter describing the constant growth rate of labour, where $\lambda \geq 0$. The symmetric structure implies that at each time consumers will consume each good at the same rate.

Innovation is measured by the equation $y(t)=\left(e^{\lambda t}-k \dot{V}\right) / V$ where $k \dot{V}$ measures the amount of labour allocated to innovation. The optimal rate of innovation is therefore one where the loss of current utility due to investment in innovation, is equal to the gain in next period's utility from increasing variety. This model also demonstrates an interesting property of CES functions which will become relevant in the model developed in Chapters 8 and 9 below, namely that in spite of the presence of monopoly profits from infinite patents as is one of the cases described by Judd here, the equilibrium attained is optimal. This is because the CES utility function, due to its assumption that all monopolies charge the same price, ensures that the marginal rate of substitution is always equal to the marginal rate of transformation and the allocation of consumption will be efficient at any time, given the allocation of labour between production and innovation ${ }^{166}$. Thus unlike a number of new growth and trade models in which the presence of an externality from imperfect competition results in an inefficient allocation of resources, the presence of monopoly profits in this case does not imply that government policy to redistribute resources would be efficient or desirable.

In the case of Grossman and Helpman (1991d), as in Krugman, comparative advantage in the production of new products is assumed to lie with the north, while the south is the imitator. However, unlike Krugman, the wage gap between the two regions cannot be assumed to be constant and two different outcomes may result, depending upon whether the wage gap is narrow or large. The southern firm which has a cost advantage over the north, prices according to the size of this wage gap, although the result is always a movement of production from north to south.

Similarly, in contrast to Krugman (1979), instead of assuming an exogenous rate of innovation and imitation, these rates are endogenously developed in the model. Knowledge spillovers as in Arrow (1962) and Romer (1986), are also included both (i) in the production of new varieties and (ii) in imitation as the south targets a given number of northern products for imitation at any time. In contrast also to the Krugman case, they find that because of increasing returns to scale in production of goods and knowledge, relative wages in the north rise when the relative size of the north increases. However, while steady state growth increases with an increase in the size of the North in the narrow gap case, in the case of the wide wage gap, the opposite is true and an increase in the size of the south increases steady state growth. Moreover, intemational trade is always welfare improving in both cases.

Intermediate product variety and trade is also discussed by Grossman Helpman (1990), in a dynamic analysis of the impact of scale economies on trade and growth. Using the Ethier (1982) production function shown in equation (7.3) above, the main contribution of this model is in describing innovation and production as an interaction between two separate sectors. As with Ethier (1982) also, the specification of the production function ensures that technical efficiency gains are made from an increasing degree of specialization. This comes from the increasing number of varieties (indicated by an increase in $n$ ) of intermediate products which 
go toward the production of the final goud. Thus innovation takes place entirely in the intermediate sector and generates dynamic scale economies in the final product sector. As in Romer (1986) above, private investment in R\&D generates two kinds of products, (i) an innovation for which innovators receive indefinite patents whose benefits are appropriated in the form of oligopoly profits and (ii) knowledge which cannot be appropriated but instead provides increasing returns in the next generation of innovations. The patented innovations thus generated are bought by intermediate producers to increase the number of intermediate varieties produced.

Comparative advantage is measured by the relative productivities of the $R \& D$ and intermediate sectors in each country where if $b_{i} \equiv\left(a_{L n i}\right) /\left(a_{L X}\right)^{\alpha} \quad$ measures relative labour coefficients of the R\&D and differentiated sectors in country $i$, then country 1 will have comparative advantage in R\&D if $b_{1}<b_{2}$.

The results show slower growth in variety and in the world, if relative demand for the final product of the country with comparative advantage in $R \& D$ increases. This is because resources are moved out of the sector with comparative advantage, into the sector with a comparative disadvantage. Thus rather than the very special Krugman (1979) conclusion that economic growth is always increased through trade. in this model Grossman and Helpman conclude that the assumption of different relative productivities changes this result substantially.

In their earlier model (1989), also on trade in horizontally differentiated products. Grossman and Helpman use a love of variety utility function

$$
u=\left[\int_{0}^{n} c_{x}(i)^{\alpha x} d i\right]^{s_{1}} c_{y}^{1-s_{x}}, \quad \alpha, s_{x} \varepsilon(0.1)
$$

which exhibits consumer preferences for increasing variety as in Krugman. $c_{x}(i)$ is consumption of differentiated good $i, c_{y}$ is consumption of the homogeneous good, and $n$ is the number of available varieties. In production, constant returns to scale are assumed, with human capital and unskilled labour the two factor inputs. The assumption of different relative endowments along with the production technologies specified, ensures that the north produces and exports differentiated goods and imports the traditional good.

In this model, as in their later model (1991d) described above, newly invented products do not displace older products. There are two major difference with the later model: (i) while the 1991d model assumes differences in technologies, in 1989a they assume differences in endowments and (ii) the 1991d paper includes knowledge, and blueprints, in the sense of Romer (1990). The results however for variety are basically the same, where the number of products is increasing and variety offered to the consumer is also increasing. In trade, based on different relative endowments of skilled and unskilled labour, the result is that there is no more R\&D in the steady state and all resources are devoted to production.

In Grossman and Helpman (1991a, Ch. 3), production and innovation are introduced usually as separate sectors following Judd (1985). Inventors are granted patents of an indefinite duration although free entry and constant returns to scale drive profits down. 


$$
Y=\left[\int_{0}^{n} x(j)^{\beta} d j\right]^{\frac{1}{\beta}}
$$

where as in Ethier (1982), $x(j)$ is quantity of the intermediate good $i$, and as in the SpenceDixit-Stiglitz formulation, the elasticity of substitution between any two products is $\sigma=1 /(1-\beta)>1$. The production function above, exhibits constant returns to scale in quantities, given $n$. The elasticity of production of $n, 1 / \beta$, is higher than that of $x$.

In a second formulation, $R \& D$ activities are characterised by increasing returns to scale as a result of knowledge spillovers and new products produced by the R\&D sector have the following technology

$$
\dot{n}=\frac{L_{n} K_{n}}{a}
$$

where the rate of innovation $n$ is proportional to the productivity, $\frac{K_{n}}{a}$ of aggregate labour employed in the R\&D sector, $L_{n}$ (the previous verbal formulation had been in (7.11) with $K_{n}(t) \equiv 1$ except in the previous case in equation (7.4), where $\dot{A}$ and $A$ were used instead of $\dot{n}$ and $K_{n}$ ). This production technology for innovation is a differential equation describing the evolution of the number of varieties. This is similar to the equation used by Judd in (7.8), where $\dot{V}=\frac{e^{\lambda t}-y V}{k}$ describes the evolution of innovation in time without spillovers, while the exogenous formulation of Krugman in (7.7), $\dot{n}=i n$, describes the rate of innovation in the north.

In the case of knowledge spillovers in $R \& D$, the cost of producing new varieties falls as knowledge accumulation rises. This provides the incentive for investment in the manufacturing firm. The increasing stock of knowledge increases the incentive to do R\&D. However, because of the resource constraint, any shift in resources from production to R\&D implies an increase in R\&D at the cost of production. This in turn implies that the value of the R\&D firm rises. Thus the combined effect of investment in R\&D and in manufacturing as the cost of product development falls, implies that in the steady state, resources are devoted to both R\&D and production and the growth rate of new varieties is constant.

Thus, in these models of increasing variety through horizonal innovation, two general observations can be made: (i) firstly, the specification of consumer utility and production functions usually imply increasing utility or increasing production of variety. Horizontal innovation of products which are imperfect substitutes for older products add to the total variety of products available in the market; and (ii) trade usually leads to specialization in different varieties of products and both countries trade in horizontally differentiated products. Comparative advantage arises, either from an assumption of different relative factor endowments as in (Grossman and Helpman, 1989) or through different technologies as in (Krugman 1979, Ethier 1982 and Grossman and Helpman (1991d)). 
Thus the general characteristics of these models, is that innovation produces new goods or factors which are horizontally differentiated. Their impact on variety is increasing, because they are imperfect substitutes for older products.

In the following section, we discuss another group of models in which product innovation is not horizontal, i.e. increasing variety, but vertical, i.e. increasing quality.

\subsection{Trade and Growth in Higher Quality Products}

Two types of models are identified here. In the first, the results of quality improvements are constant or changing ranges of product variety, while in the second, creative destruction results in only one product, the highest quality product, being available in the market. Thus in the latter, quality destroys variety, whereas in the former, this may or may not be the case, depending upon the model specifications.

In contrast to the Krugman paper, which examined the emergence of new products based on a horizontal differentiation framework, Flam and Helpman (1987) developed a trade model in which exogenous innovation is vertical, i.e., it introduces new products of a higher quality, into the economy in a comparative statics manner.

The two country, one factor model is based on trade in two commodities, one differentiated and the other homogeneous. Comparative advantage arises from differences in relative labour productivities and the North has comparative advantage in new products. Unit labour inputs for the differentiated product, are defined, where $z$ is the quality index of the differentiated product, as:

$$
\begin{aligned}
& a(z)=\frac{e^{\gamma z}}{A} \\
& a^{*}(z)=\frac{e^{\gamma z}}{A^{*}}, \gamma, \gamma>0
\end{aligned}
$$

where $a(z) / a^{*}(z)$ is declining in $\mathrm{z}$ (an asterisk indicates the foreign country, in this case south), $A$ is a productivity measure, and the north has comparative advantage in high quality products if $\gamma^{*}>\gamma$. .

The specification of the utility function

$$
u(y, z)=y e^{\alpha z}, \quad \alpha>0
$$

where $y$ is the homogeneous good, and $z$ the quality index of the differentiated product, one unit of which is consumed, ensures that the relationship between consumer income and the consumption of a greater quantity of the homogeneous product, as well as a higher quality of the differentiated product, is positive. The specification also implies that there is an income class $I_{d}$ corresponding to labour class $h_{d}$. where $h$ is a measure of human capital, or skills, at which the consumer is indifferent between consuming good $z$ from the north or from the 
south. They introduce an income distribution for a continuum of individuals who populate both regions, and belong to different income classes, as described above.

Assuming that only the south produces homogeneous goods, whereas both regions produce the differentiated good, the question to examine is the range of $z$ products that are consumed by both regions in equilibrium. The assumption of northern comparative advantage in high quality goods implies that in the central case, the north exports high quality products and imports low quality and homogeneous products from the south. The presence of different income classes however, is what determines the range of products consumed by both regions and in equilibrium, they calculate the maximum and minimum quality of commodities consumed and produced by each region, based upon income distribution and demand.

Comparative statics show that the range of products thus consumed, changes when there is a shift in the initial parameter specifications. For example, an increase in the southern productivity parameter, $A^{*}$, has a negative impact on relative northern wage and the northern income class, $h_{d}$, switches consumption to foreign products. This is because the price of southern products has fallen and because northern production and northern wages decline. However, the decline in northern wages is not big enough to make them equal to southem wages and some northern consumers belonging to this income class shift demand to southern goods. Thus the range of products produced in the north declines while those produced in the south rise. The opposite happens in the case of a rise in northern productivity, where northern consumers demand higher quality goods and because of their expanded income, the northem range expands to include higher quality goods as well as a larger number of lower qualities than before, while the southern range contracts. The entire range of commodities (from the maximum quality consumed in the north, to the lowest quality consumed in the south), however, remains the same. This is because a constant proportion is spent on differentiated goods by each income class, which is exogenously fixed.

While the Flam and Helpman (1987) model shows that the result of quality improvements is a constant range of products consumed and present in the market as older varieties are pushed out, the models by Segerstrom et.al. (1990), Grossman and Helpman (1991b and c) and Aghion and Howitt (1992), have a different implication for variety.

Segerstrom et.al. (1990), assume two countries with labour endowments which are fixed over time and only workers in the north are capable of doing R\&D. The result of each $R \& D$ race is an innovation which provides the firm with a monopoly. There are three groups of products present in the economy at each time, old goods, present innovations and innovations still to come. Within each group however, goods are perfect substitutes, with a Cobb Douglas utility function. Thus each time a new product $n+1$ becomes available, consumers, given the choice of goods $x_{1}$ and $\alpha x_{n+1}$ which, if are equally priced, would choose the new good $\alpha x_{n+1}$. Thus new goods substitute perfectly for old products and when both are priced equally, the new product makes the old one obsolete.

Quality based improvements in intermediate products are introduced by Aghion and Howitt (1992), in the production function. Innovation takes place through R\&D according to a poisson process and is independent of all previous innovations. Each innovation gives the innovator an economy wide monopoly over a new intermediate product from the patent which lasts forever, although the monopoly lasts only until the next innovation. Each subsequent innovation raises productivity by a constant parameter, although the cumulative nature of innovation implies that productivity in each period increases by $A_{t}=A_{0} \gamma^{\prime}$ where $A_{0}$ is the 
initial value of $A$ and $\gamma>1$ indicates the productivity increase each period. Thus at each point in time the economy has a higher $A_{t}$. The assumption of monopoly in the intermediate goods sector is made to ensure that producers cover the costs of buying the patent from the innovators. The idea of Schumpeter's creative destruction is thus incorporated in the model as each new innovation destroys the previous innovator's monopoly, while raising economywide productivity.

The allocation of labour between manufacturing and R\&D shows a negative dependency of current research on future research. The prospects of losing monopoly from next period's $R \& D$ because an anticipation of higher investment in $R \& D$ will increase wages and therefore reduce profits this period, and a rising rate of creative destruction in the next period, therefore discourages $R \& D$ this period.

In equilibrium, $R \& D$ decisions this period therefore have to take into account all costs and benefits, including the costs or benefits of next period. The result of creative destruction therefore is the appearance of a new quality of intermediate products and an economy-wide increase in productivity. However, the destruction of this period's monopoly rent by next period's monopolist results in one variant being available in the economy in each period. Thus, the result of higher quality is a destruction of the older variety and the presence in each period of only one variety, the highest quality.

Based on the Aghion and Howitt (1992) approach, Grossman and Helpman (1991c), include consumer preferences for higher quality products specifically in the utility function

$$
U(t)=\int_{0}^{\mathrm{I}}\left[\sum_{j} q_{j}(\omega) d_{j t}(\omega)\right] d \omega
$$

where $d_{j t}(\omega)$ denotes the quantity of consumption of quality $j$ of product $\omega$ at time $t$. The result of $R \& D$ activity is the production of both blueprints which are appropriable and of knowledge which cannot be patented and spills over through the production function for the next innovation. Production is based upon a single factor, labour and is characterised by oligopoly. Each product $\omega$ can be improved with quality $j$ being denoted by $q_{j}(\omega)=\lambda^{j}$ where lambda, the quality "jump" is the same for each $\omega$. This is similar to the Aghion and Howitt formulation of productivity increasing according to $A_{t}=A_{0} \gamma^{\prime}$ where $A_{0}$ is the initial value of $A$ and $\gamma>1$ indicates the productivity increase each period. The consumer therefore prefers at each time, the highest quality, with the lowest quality adjusted price. This as we shall see, is the highest quality, or the newest innovation.

The innovator of the newest quality charges a price which, adjusted for quality, is lower than that charged by the nearest quality: because of the assumption of free entry, producers price at marginal cost, which is the wage rate adjusted for the quality of the product. The price of the highest quality therefore is also equivalent to marginal cost adjusted for quality. However, because of the higher quality, the innovator is always one step (equivalent to lambda) ahead of the nearest rival and the limit price of each new innovation is 


$$
p=\lambda w
$$

where lambda is the size of the quality improvement. The leader captures the entire market by pricing below the price of the nearest rival product (which is equal to marginal cost), and because of the lower price, is able to capture the entire market. Thus all previous producers, who price at marginal cost, are pushed out of the market, leaving only the highest quality product in the market.

On the demand side, due to preferences, the consumer will prefer a higher quality product with the lowest quality adjusted price. This will always be the newest product.

Since licensing of patented innovations is not possible in this model, all manufacturing takes place by the innovator and the incentive to invest in R\&D is a flow of profits until the next innovation occurs. Innovation occurs with probability $1 d t$ at time $d t$. The size of the technology "jumps" up the ladder remain constant and as in Aghion and Howitt (1992), with each innovation the level becomes larger. The assumption of monopoly profits ensures that while inventors never target their own good for improvement, once the improvement is made, some inventors move toward improving the improved product. Preferences on the other hand, as described above, indicate that consumers will only choose the highest quality, adjusted for price. Both these conditions, imply that only one variety, the highest quality, will remain in the market and will be consumed.

In an extension to a two country case, with three firms, Grossman and Helpman (1991c) show creative destruction in a trade model. They assume that the north is better at doing R\&D than the south. Each jump up the ladder is exogenously given as $\lambda>1$. The market structure consists of a northern leader who innovates and prices at its marginal cost, equivalent to northern wage adjusted for the quality improvement; a northern firm which competes with both northern and southern firm and maximises profits by setting a quality adjusted price equal to or below the southern firm's marginal cost of production which is southern wage; and finally a southern firm which imitates, prices at a quality adjusted rate above its marginal cost. Innovation and imitation technologies require $a_{D L} l$ and $a_{D F} l$ units of labour for a leader and for a follower respectively.

In the steady state, rates of imitation and innovation are constant. Each product is improved stochastically and although the presence of three firms implies that the product can be improved upon or copied in the steady state, there is a constant process of quality improvement. As in (1991b), preferences in the utility function imply that consumers want the highest quality (price adjusted).

Northern innovators improve on southem products and because labour productivity is higher in the north (i.e. $a_{D L}<a_{D F}$ ), the higher quality product has a cost advantage and all production of the new good moves to the north. Because the northern innovator is able to price at lambda times the marginal cost of production of the nearest competitor (who is always one step below on the ladder), and because consumers demand the highest quality, the innovator is able to monopolise 100 percent of the market. This shift in monopoly profits from southern to northern firm, or vice versa, or from a northern firm to the newest innovator, ensures that all earlier monopolies (either in the north or in the south) are wiped out and only one variety is left in the economy, that of the highest quality. 
This aspect of both the Grossman and Helpman (1991b and c) and Aghion and Howitt (1992) models implies that the equilibrium growth rate is not the optimal growth rate, because of the presence of monopolies and the business stealing effect where the innovator destroys the producer surplus of the previous monopolist and Grossman and Helpman (1991b) suggest the use of a tax or a subsidy on R\&D outlays to ensure optimum growth in R\&D investment and consumption.

Thus, in contrast to the Flam and Helpman (1987) model where a whole range of qualities remains in the market in each time period, in the Segerstrom et.al. (1990), Aghion and Howitt (1992) and Grossman and Helpman (1991b and c) models, only one variety, the newest or highest quality (whether it has just been invented or whether it has been imitated), remains.

In somewhat different approaches, Stokey $(1988,1991)$ and Young $(1991,1993)$ demonstrate that quality improvements can have a different impact on variety than some of the models discussed above. In Stokey (1988) and Young (1991), an improvement in product quality results in higher quality characteristics. A range of characteristics are present in the labour force, which in turn reflect the range of qualities produced

$$
q_{t}(z)=\int_{z}^{\infty} x_{t}(s) d s, \quad z \geq 0
$$

where good $s$ provides one unit of the characteristic $z \varepsilon[0, s], x_{t}$ is the quantity of goods and the production function is such that $q_{t}(z)$ defines the allocation of characteristics $z$ where $z \varepsilon R_{+}$defining the set of characteristics and $s \varepsilon R_{+}$defining the set of potentially producible goods. In this case therefore, higher quality is considered more desirable because it contains higher quality characteristics. The utility function in Stokey (1988) also indicates a preference for higher quality

$$
U(q)=\int_{0}^{\infty} u(q(z)) d z
$$

where once again, $z$ indicates characteristics and $q_{t}(z)$ indicates the allocation of characteristics. Learning by doing is characterised by spillovers across goods. Thus, the production function is characterised by an increasing allocation of characteristics, implying that higher quality goods enter and replace lower quality goods.

In Young (1991), consumer preferences indicate a strong preference for variety although consumers prefer goods with lower prices. For prices which are too high, consumption of those goods is zero. Thus there exists some limit price, below which the consumer demands all qualities, and above which the consumer demands zero qualities. In Stokey (1988), this is defined as consumption in some range $\left[A_{t}, B_{t}\right]$, while consumption below and above this range is zero. This can be derived from the utility maximization problem of a consumer. given the preferences in equation (7.18) above 


$$
\begin{gathered}
\max _{x \varepsilon X} \int_{0}^{\infty} u\left(\int_{0}^{\infty} x(s) d s\right) d z \\
\text { s.t. } \int_{0}^{\infty} p(s, k) x(s) d s-y \leq 0, \quad x(s) \geq 0, \text { all } s
\end{gathered}
$$

which gives the following solution from (7.18) and (7.19) above

$$
x(s) \quad\left|\begin{array}{cc}
=0 & s \varepsilon(0, A) \\
>0 & s \varepsilon[A, B] \\
=0 & s \varepsilon(B, \infty)
\end{array}\right|
$$

where the lower boundary $A$, is determined by the unit cost function and the upper bound, depends on preferences, labour allocation and the unit cost function.

In the case of Young (1991), there is a similar limit good $M$, such that for all goods $x$, for which unit cost requirements $a(x, t) \geq a(M, t)$, consumption is zero due to high prices. Learning by doing from cumulated labour is described as

$$
\frac{d T(t)}{d t}=\int_{\pi(t)}^{\infty} L(s, t) d s
$$

where $T(t)$ is the current level of knowledge, $L(s, t)$ is labour allocated to production of good $s$ at time $t$ and learning is bounded in that the amount of labour required to produce each good $s$, cannot fall below a certain level. Thus if $a(s, t)=\bar{a}(s)$ then there is no more leaming, while if $a(s, t)>\bar{a}(s)$, then the result of leaming by doing is higher productivity for those goods.

$T$ therefore is the dividing point with $s \leq T(t)$ goods having no more learning while $s \geq T(t)$ have continued learning by doing. Because both unit costs are determined by the movement of $T$ from (7.21) above, the total range of production is symmetric around $T$. In equilibrium as learning increases $T(t)$ grows, and learning in older products ceases, while newer products are produced.

However, preferences in the 1991 paper by Young, indicates a preference for cheaper goods but also for variety. The first implies that consumers prefer to consume goods in which leaming by doing is taking place, while the second indicates their preference for goods in which learning has been exhausted. Thus a range of goods on both sides of $T$ will be consumed. Technical change ensures that $T$ continues to increase according to (7.23) above, with learning by doing exhausted in goods in the lower range. As $T$ increases, goods in which learning by doing takes place become cheaper, allowing consumers to consume more of those goods. However, the range of goods in which learning by doing is no longer taking place is also falling as a result of rising learning by doing in other products. The equal division of labour between the two sectors however, also implies that the range of products in which learning by doing is no longer taking place declines less than the range of products in which learning by doing is taking place increases. Thus in this model, both the quantity 
and the total range of variety consumed will increase because of lower unit costs of production in the learning by doing sector.

In the 1993 paper by Young, an explicit innovation activity is included, as in Grossman and Helpman (1989), where new goods are invented and patented by private agents at the rate

$$
\dot{N}(t)=\frac{L_{R}}{a_{R}}
$$

where $a_{R}$ is unit labour cost and there is free entry in R\&D, implying perfect competition. The equation which describes learning is somewhat different from that in the 1991 paper

$$
\dot{T}(t)=\int_{T(t)}^{N(t)} \psi L(s, t) d s
$$

where $\psi$ is the rate at which learning takes place. Consumer preferences as in the previous paper imply a desire for increasing quality, given prices and the budget constraint, and also for variety. The difference with the previous paper is that the size of the range on either side of $T$ is determined by $N-T$ because the upper bound in (7.23) above is now $N$. If the gap between innovation and learning is increasing, goods below $T$ will be substituted away by newer goods above $T$, and total variety measured by $\tau(=T-Z)+\mu(=N-T)$, where $Z$ and $N$ are the bottom and upper limits respectively of the range of goods consumed, increases. $Z$ defines the good for which unit costs of production are too high, and the consumer does not consume goods more expensive than $Z$. If $N-T>\mu^{*}$ (where $\mu^{*}$ is some critical value), the newest goods do not enter the consumer's consumption bundle as their costs are too high.

In steady state equilibrium, there is a constant range of goods $N-T$, implying that $\dot{N}=\dot{T}$ since $\dot{R}=\rho$, the latter because of the assumption of free entry into invention, which determines the interest rate as a function of the profits of the most advanced firm and the rate of change of the value of the firm ${ }^{167}$. Two types of steady state equilibria are examined. In the first instance, the no growth case shows that firms will invest in invention activities only if the cost of invention is lower than or equal to the aggregate size of the market, or if the rate of time preference in the steady state (also equal to the rate of interest in the steady state), is high enough to enable firms to borrow. The case discussed above where $N-T>\mu^{\circ}$, produces the same result as in the static case, with newly invented goods not being consumed because of high prices.

In the case of the second type of equilibrium $\mu^{*}>N-T>0$, steady state growth is positive and lies in between the two extremes discussed above. In this case, the growth rate in the economy once again depends upon the aggregate size of the market, interest rates and the cost of invention. The economy is characterised by rising invention, indicating an increasing number of higher quality varieties consumed, as older varieties drop out and newer varieties enter the consumption bundle, until the rate of invention exceeds the rate of learning sufficiently to reach $\mu^{*}$. Then new goods are no longer consumed, and the number of 
varieties consumed declines as labour is moved out of lower quality goods into innovation activities. Thus, while the 1991 paper by Young shows increasing variety, in Young (1993) the range of products in the market remains constant in each period.

This analysis in Young (1991), and especially the later paper (1993), is quite similar to the dynamics of innovation and substitution in the model we develop in Chapter 8 and 9 below. While in Young (especially 1993), the dynamics are described by the equations describing innovation and learning-by-doing externalities ( $\dot{N}$ and $\dot{T}$ respectively), in our case the range of varieties present in the economy changes in the steady state according to the relative forces of higher quality being preferred and planned leaming decreasing fixed costs. These dynamics are elaborated upon further in Chapters 8 and 9 below.

\section{Conclusions}

Thus the description of previous models of increasing variety and increasing quality, point to a few generalized conclusions and implications for variety:

1. In the first group of models, innovation is horizontal, i.e. new products which are invented are imperfect substitutes for old varieties and therefore are not expected to displace older varieties. The reason for older varieties staying within the market, despite the appearance of new products, lies mainly in the manner in which consumer preferences are modeled. The love of variety utility function implies that a constant elasticity of substitution between products ensures that given a certain budget constraint, consumers will prefer to consume the same quantities of all varieties available in the market. Thus, old varieties will continue to be demanded despite newer varieties available in the market.

Another method by which these models have presented increasing variety, is by including a love of variety approach in the production function. Thus innovation takes place through the production of a greater variety of intermediate products, which are used to produce the final good. By indicating a love of variety in the production function for the final good, these models show an increasing range of horizontally differentiated intermediate varieties in the market. Thus in general, in these models, the specification of a love of variety, constant elasticity of substitution function, ensures that older varieties do not drop out, and instead add to the total variety of products available in the market.

2. In contrast, the impact of increasing quality on variety is somewhat different. Here, there are two types of models which were analysed.

In the first group of models, for example Grossman and Helpman (1991a Ch 4, 1991b and c) and Aghion and Howitt (1992), the invention of higher quality products, always results in the rejection of the old variety from the market, leaving only the highest quality available. The reason for this is Schumpeterian creative destruction, with the presence of monopoly in each new innovation wiping out the monopoly profits earned by the previous innovation. Consumer utility in this case is maximised by consuming the highest quality, and therefore, the older product is therefore driven out of the market, and the newest producer appropriates all monopoly profits. Thus in models which have this structure, there is only one variety, the highest quality, present in the market at each moment in time. 
For the second group of models, the introduction of different groups of individuals with different levels of human capital creates preferences which are not the same for all qualities. Thus in the Flam and Helpman (1987) model for example, different classes of individuals with different incomes, results in demand for different groups of products having different qualities. At each moment in time therefore, there is always a range of different quality products available in the market because of consumer demand. Variety in this static model therefore always remains constant but greater than one. Only the range of products produced in each region changes if there is a change in the relative productivities of countries.

In the Stokey $(1988,1991)$ and Young $(1991$ and 1993) models however, there are rich dynamics which show a range of goods with different qualities. Young's models (1991 and 1993), are particularly interesting and particularly relevant because they present possible situations in which the range of qualities available in the economy, may be actually increasing (1991), rather than remaining one as in Aghion and Howitt (1992) or in the Grossman and Helpman models, or remaining constant as in Flam and Helpman (1987) and Young (1993).

These implications for increasing quality and variety are especially important for the model developed in chapters 8 and 9 below, where the result of quality improvements is shown to present both increasing as well as decreasing variety in the economy, in a dynamic analysis. As discussed in greater detail in these chapters, this is largely because of the combined approach used, that of introducing higher qualities through an R\&D and production sector with or without learning, and of consumer preferences which reflect a love of variety approach, combined with preferences for increasing quality. 



\section{Part III}

\section{Quality and Variety: Modelling Endogenous Growth and Trade}

"Science is a differential equation. Religion is a boundary condition"...A. Turing 



\section{Introduction}

In Part I and Part II above, we first presented developments in biotechnology, followed by a theoretical section. The latter discussed the manner in which new growth and trade models treat issues of increasing variety and increasing quality, as opposed to just quantity. The first Part showed that innovation in biotechnology also presents both the prospect of increasing variety and increasing quality. This was especially evident from Chapter 5 , where the empirical impact of quality and productivity innovations were discussed in relation to consumer preferences and increasing and decreasing variety in the economy.

Part III develops and discusses a closed economy model of endogenous growth based on increasing quality and changing variety and an open economy model describing trade between two regions which we call north and south.

From Chapters 3 and 4 above, where the patterns of biotechnology R\&D were examined in industrialized and developing countries respectively, we have identified the basic institutional and market structures of biotechnology R\&D. In general, there appear to be two broad sectors which carry out different aspects of biotechnology related activities: (i) a research sector, that was initiated in the public domain, but which is increasingly characterised by private, profit maximizing agents and with free entry by other researchers and companies. This is especially evident from the emergence of the New Biotechnology Firm in industrialized Countries and private/public linkages for research; and (ii) a sector which is devoted to commercializing biotechnology, again dominated by the private sector, initially characterised by large firms in many countries, who can provide up front financing for scaleup and product development, and possess forward and backward linkages to resources and markets, which have often been weaknesses of the smaller, specialized firms.

Similarly, in Chapter 5 we examined the innovation process itself, and the impact of innovation on the total variety of products available at each time in the economy. Chapters 8 and 9 which follow, develop a model of endogenous growth and international trade, based on the new growth and trade literature discussed in Part II and using the general trends in modern biotechnology R\&D identified thus far.

The model discussed in these chapters contains some elements from the theoretical literature on horizontal and vertical product differentiation discussed above, and is inspired by observations about biotechnology discussed in Part I above. In Chapter 7 above it was shown that three types of results have been obtained from new growth and trade models: (i) the use of a love of variety utility function results in an ever increasing variety of products as new products never make old products redundant; (ii) the ideal variety preferences result in new products always making an old product redundant, i.e. there is complete displacement of older products and the remaining product is always the newest product; and finally (iii) a number of new models have also shown results which lie in between these two extremes, i.e., a constant or increasing range of varieties remains in the economy, with each new innovation resulting in the displacement of one or more older products, depending upon the model specifications.

Chapter 5 above however, shows that the impact of biotechnology is in reality a combination of increases in quality, with increases or decreases in variety as a result of 
innovation and of consumer preferences. The models presented in the following two chapters are therefore broader than the models surveyed in the previous chapters and in fact may be applicable to a wide range of sectors and technologies. In this respect, the innovation in both the closed and open economy models presented here, is that they are not technology or industry specific but in fact more general than the new growth and trade models and therefore make a new contribution to the recent literature on growth and trade.

It is shown that instead of just one of these cases, all three become special cases in the models in chapters 8 and 9. depending upon fixed costs in the differentiated sector. We show that variety can increase as in Young (1991), remain constant (for a considerable period of time), as in Young (1993), and eventually decline as in Grossman and Helpman (1991b and c). This is followed by a chapter summarising the results of the model and drawing policy conclusions for biotechnology and growth. 


\section{A Closed Economy Model of Horizontal and Vertical Product Differentiation}

"This is so perfectly general that no particular application of it is possible"...G. Polya

\section{Introduction}

Technological change and especially the use of scientific knowledge to upgrade products and processes have become an important source of economic growth, both in the theoretical as well as in the empirical literature in recent years.

As previous chapters in Part I have shown, the success of biotechnology both in industrialized and in developing countries has often depended on the combined effort of basic scientific research, institutional and government support as well as the presence of a private sector which is able to commercialize the results of R\&D. Biotechnology can lead to two types of innovations: firstly by improving the structure of products which are already in use, through altering their genetic structure; and secondly, by developing products which are novel and are not presently in existence. In both cases we argue that biotechnology brings about quality improvements along a vertical quality ladder similar to that described by Grossman and Helpman (1991b and c), Aghion and Howitt (1992) and Flam and Helpman (1987). However, we have also seen that society's utility function should value variety as well as quality.

In the following two chapters, a model of endogenous growth and trade, based on biotechnology, with some elements that are common to some of the new growth models such as Flam and Helpman (1987) and Young (1991), is developed. With respect to empirical observations, we relate the structure of the model to biotechnology, especially in the pharmaceutical sector. In this sector, biotechnologies have provided researchers with techniques with which they can understand better the relationships between chemical structure and biological activity. This understanding is crucial for the development of new pharmaceutical products, both for improving on present drugs and also for developing new cures. In addition biotechnology results in a better understanding of diseases, allowing new research to be targeted to more specific problems. According to the US OTA, there are two basic approaches to using biotechnology in this sector: firstly to develop human proteins which were previously non-existent, such as human growth hormone using rDNA techniques, and secondly to design synthetic molecules which can then be used to examine the workings of the disease thereby enabling the use of the technology in designing drugs which interact in the disease process. The first biotechnology based drug, recombinant human insulin developed in 1982 was one such protein which was either not available or only in small quantities before the biotechnology product became available. Human growth hormone was another such 
protein as are some of the cancer related drugs such as Tissue plasminogen activator (tPA) which dissolves blood clots and is known to reduce the incidence of heart attacks. Epogen, the best selling biotechnology drug so far, has been used in dialysis related anaemia and a number of other drugs have been developed for treating different strains of hepatitis, as well as AIDS related illnesses.

Similarly in developing countries, although they still lag considerably behind industrialized countries in terms of technological capabilities, new techniques such as monoclonal antibodies are being used to develop diagnostic kits for detecting common regional diseases. The disease prevention programme has also received a considerable boost in many countries as new vaccines to combat some of the more common diseases in these countries are reaching various advanced stages of $R \& D$ and will become available shortly.

Society during each time period will demand a variety of biotechnology based products, of different qualities. This is because for a number of reasons peculiar to biology and medicine we argue that society will continue to demand a variety of products of different qualities, even though the highest quality is available for the same (quality adjusted) price. For example, in pharmaceuticals, a country will continue to demand a variety of medicines for reasons such as allergies to particular medicines, or different strains of the same disease, which only react to vaccines, or treatments which contain a slightly different mix of the same basic compounds. Similarly with ag-bio products, different circumstances such as soil or climatic conditions, would require somewhat different compositions of products which basically perform the same function, such as insecticides or pesticides. Thus social welfare is increased by variety.

Accordingly, this paper departs from earlier analyses, in the introduction of love of variety preferences combined with quality, or vertical differentiation. We introduce a social utility function, in which society prefers to consume both higher quality products, and also maintain a range of varieties at each point in time. We assume two sectors, one which does $R \& D$ and produces the innovation, and the second which uses the innovation to produce higher quality products. New products in the differentiated sector may replace old products as with previous models such as Aghion and Howitt (1992) and Grossman and Helpman (1991a). However, like the model by Flam and Helpman (1987), this model finds that in many cases, instead of all previous qualities being replaced by the newest quality, each new variety joins a range of older varieties in the market. Consumers prefer both variety and quality, and hence, there are a range of varieties demanded and consumed. The case of only one variety being present in the market at each time as in the Grossman and Helpman quality ladders models, is therefore a specialized result of this analysis.

There are two additional observations about variety which are made by this model: In Flam and Helpman 1987, the analysis of variety is static and a variation in the growth rates of different variables results in a constant range of products, with the highest qualities always replacing the same number of old variants. In this paper, we show in a dynamic analysis that the range may be constant, but can also increase or decrease. We find a case in which all older varieties which were previously dropped from the consumption bundle are reselected. This love of (complete range of) variety is also a special case of the model. We present the exact time patterns as simulations in the final sections of this chapter.

Thus the model adds to the literature in three ways: first, because the model describes all three cases, it is in fact a much broader and general model which contains the individual cases described in previous growth and trade models; second, by combining both love-of and 
ideal-variety preferences, we move a step closer to the real choices of consumers, and third, by presenting a range of products being present at each moment in time, we also present a situation, where at each point in time, consumers choose different qualities, and where the appearance of new innovations only gradually results in older varieties being pushed out of the market or in some cases, not at all. Thus the increasing range of Young (1991), the decreasing range of Grossman and Helpman (1991) and the constant range of Young (1993), are all special cases of this model, although only temporarily with respect to the latter.

The structure of this chapter is as follows: In Section 8.1 we present the model. Section 8.2 looks at equilibrium dynamics under the assumption of perfect capital markets, while Section 8.3 looks at the special case of no capital markets. Finally in section 8.4 we present the results of simulations which show a range of dynamics with respect to quality and variety and which is followed by a concluding section.

\subsection{The model}

We present a closed economy model of innovation and quality improvements. The economy is endowed with one factor, namely labour, $N$ with quality $H$. There are two sectors, one which does research and the other produces differentiated products. Innovation takes place in the R\&D sector, which produces innovations. The innovations become an input into the commercial sector, resulting in the production of goods with higher quality. Thus in each period, innovations in the R\&D sector result in quality improvements in the differentiated sector, treated as quality weights, as described in Flam and Helpman (1987), given to quantities in a love-of-variety utility function.

Following from the discussion in the previous chapter on demand, we concentrate here on society's demand rather than that of individual consumers. The utility function specified here therefore relates to society's utility function and budget. The intertemporal social utility function we specify has the following form:

$$
U=\int_{1}^{\infty} e^{-\rho(\tau-1)}[\log u] d \tau
$$

where rho is the subjective discount rate and the subutility function $u$, is of the Spence-DixitStiglitz type (see Helpman and Krugman, 1985, pp.118-120):

$$
u=\left[\int_{\varepsilon^{-}}^{n}\left(q_{z} e^{\alpha z}\right)^{\theta} d z\right]^{\beta}, \begin{gathered}
z \varepsilon\left[z^{-}, n\right] \\
0<\theta<1 \\
\beta>1 \\
\alpha \geq 0
\end{gathered}
$$

where $q_{z}$ is the quantity of quality $z$ demanded, while $z^{-}$is the lowest and $n$ the highest quality demanded by consumers. The parameter $\theta$ represents society's constant demand elasticity for quantity and as in the love of variety models discussed above in Chapter 6 , we 
specify theta to lie between 0 and 1 . However, in contrast to the love of variety utility functions before, the specification here includes a quality weight. In the exponential function, more importance is given to quality by society, the greater the size of alpha, while choice is independent of quality if $\alpha=0$ (see Flam and Helpman 1987 for further discussion on this specification).

As is the case with this specification from Spence-Dixit and Stiglitz, we assume that $n$, or the number of varieties demanded in each period can be infinitely large. This ensures that as $n$ grows, utility increases.

A society with this utility specification maximises its utility, subject to the budget constraint

$$
\int_{t}^{\infty} e^{-R(\tau-t)}\left(\int_{z^{-}}^{n} p_{z} q_{z} d z-E\right) d \tau-W(t) \leq 0
$$

where $R(\tau)$ is the rate of cumulative interest from time $t$ to time $\tau, p_{z}$ is price of quality $z$ and $E$ is the consumer's labour income in each period.

We specify the Lagrangean,

$$
L=\left[\int_{t}^{\infty} e^{-p(\tau-t)} \log u[.] d \tau\right]+\lambda(t)\left[\int_{1}^{\infty} e^{-R(\tau-t)}\left(E-\int_{z^{-}}^{n} p_{z} q_{z} d z\right) d \tau+W(t)\right] .
$$

where $\log u$ is the subutility function from equation (8.2) and the time index of $p_{2}, q_{2}$ and $n, z^{-}$and $E$ has been ignored as before. The first order conditions from this problem are (8.3) with equality and

$$
\frac{e^{-\rho(\tau-t)}}{u[.]}\left[\beta[.]^{\beta-1} \theta\left(q_{z} e^{\alpha z}\right)^{\theta-1}\right] e^{\alpha z}-\lambda e^{-R(\tau-r)} p_{z} \leq 0
$$

Given the inequality in (8.5) above, $\frac{\partial L}{\partial q_{z}} q_{z}=0$

In the case that (8.5) above holds with equality, it generates the following price, quantity relationship

$$
\frac{p_{i}}{p_{j}}=\frac{\left(q_{i} e^{\alpha i}\right)^{\theta-1} e^{\alpha i}}{\left(q_{j} e^{\alpha j}\right)^{\theta-1} e^{\alpha j}}
$$

and from this, we can calculate the demand elasticity for differentiated goods, 


$$
\frac{\partial p_{i}}{\partial q_{i}} \cdot \frac{q_{i}}{p_{i}}=\frac{(\theta-1)\left(q_{i} e^{\alpha i}\right)^{\theta-2} \cdot\left(e^{\alpha i}\right)^{2} \cdot q_{i} p_{j}}{\left(q_{j} e^{\alpha j}\right)^{\theta-1} \cdot e^{\alpha j} \cdot p_{i}}=\theta-1
$$

This result is identical to the one obtained from the Spence-Dixit-Stiglitz function without quality weights. The solution to the intertemporal utility maximization problem can be calculated by multiplying $q_{z}$ to equation (8.5) and integrating over $z$

$$
\frac{e^{-\rho(\tau-t)}}{u} \beta[.]^{\beta-1} \theta \int_{z^{-}}^{n}\left(q_{z} e^{\alpha z}\right)^{\beta}=\lambda e^{-R(\tau-t)} \int_{z^{-}}^{n} q_{z} p_{z} d z
$$

and the resulting equation after cancellation becomes

$$
\beta e^{-\rho(\tau-t)} \theta=\lambda(t) e^{-R(\tau-t)} \int_{z^{-}}^{n} p_{z} q_{z} d z
$$

In growth rates this yields the rate of change in expenditures equalling the difference between the rates of interest and of time preference.

In the case of no capital markets, equation (8.9) reduces to

$$
\beta e^{-p(\tau-t)} \theta=\lambda(t) e^{-R(\tau-t)} E
$$

Which can be written in growth rates as

$$
\hat{E}=\hat{N}=\dot{R}-\rho
$$

where we take $w H$ to be equal to 1 . Taking the growth rate of $N=\varepsilon$, we write

$$
\dot{R}=\varepsilon+\rho
$$

Next we turn to supply. We begin by specifying the structure of production in the differentiated sector first, and then do the same for the R\&D sector. We assume only one factor of production, labour $N$, which is allocated between the two sectors, and has human capital of $H$.

Producers in this sector licence the blueprint produced by the innovator in the R\&D sector, and produce higher quality products. The production function is assumed to be

$$
q_{z}=z F^{2}\left(H \cdot N^{z}\right)
$$


where $q_{z}$ is quantity of quality $z$ and $z$ is an index of varieties, $z \varepsilon[0, n]$ for which blueprints are produced by the R\&D sector and which are licensed by the producer in the differentiated sector. Because we assume that

$$
F_{z}^{\prime}\left(H . N^{z}\right)=1
$$

equation (8.13) can be written

$$
q_{z}=z H \cdot N^{z}
$$

By licensing blueprint $z$ from the R\&D sector, the producer in the differentiated sector becomes a monopolist because of his impact on price according to (8.7). The monopolist minimizes production costs

$$
C_{z}\left(q_{z}, w, H\right)=w \cdot H \cdot N^{z}+\lambda^{z}\left(q_{z}-z \cdot H N^{z}\right)
$$

where $w$ is wage per efficient labour unit and $C_{z}($.$) is total variable cost. The producers' first$ order condition for cost minimization with respect to $N^{z}$ is

$$
w \cdot H-\lambda^{z} z H=0
$$

which can be rewritten

$$
\begin{aligned}
& C_{z}^{\prime}\left(q_{z}, w, H\right)=\lambda^{z}=\frac{w \cdot H}{z H} \\
& C_{z}^{\prime}\left(q_{z}, w, H\right)=\lambda^{z}=\frac{w}{z}
\end{aligned}
$$

which is the marginal cost of the monopolist.

The producer eams instantaneous profits

$$
\pi_{z}=\left[q_{z} p_{z}\left(q_{z}\right)-C_{z}\left(q_{z}\right)-b_{z}\right]
$$

where $b_{z}$ is the cost of licensing $z$ from the R\&D sector and is included in the cost because the innovation is assumed to be licensed in each period from the innovator in the R\&D sector. This yields the following first order condition 


$$
p_{z}+q_{z} p_{z}^{\prime}\left(q_{z}\right)-C_{z}^{\prime}\left(q_{z}\right)=0
$$

which means that marginal revenue equals marginal cost which is the monopolist's optimal pricing condition. From the first order conditions for consumer demand we have determined the price elasticity of demand and from (8.21), we can calculate the marginal revenue of the monopolist:

$$
C_{z}^{\prime}\left(q_{z}\right)=p_{z}\left(1+\frac{p_{z}^{\prime}}{p_{z}} \cdot q_{z}\right)=p_{z} \theta
$$

implying that

$$
C=C^{\prime} q_{z}=p_{z} \theta q_{z}
$$

and from equation (8.19)

$$
p_{z}=\frac{w}{\theta z}
$$

Thus, (8.23) for the cost function and (8.24) for price in (8.20) yield the monopolist's profits

$$
\pi_{z}=q_{z} w\left[\frac{1-\theta}{\theta Z}\right]-b_{z}=0
$$

Profits have to be zero because under the assumption of free entry into the differentiated sector, each potential producer offers all profits when a blueprint is auctioned off (see Romer, 1990).

The R\&D firm is characterised by innovators who are granted infinitely lived patents for their innovations. The production function of the research sector is assumed to be

$$
\dot{n}=n^{\delta} F^{R}\left(H . N^{R}\right)
$$

where $n$ is the flow of innovations and $n$ is a measure of cumulated learning, from each innovation. Delta measures the elasticity of learning. If $\delta=1$, the specification corresponds to that of Shell (1967) and if $\delta=0$, there is no learning as in Phelps (1966). As with the differentiated sector, assuming linear technologies in labour means that equation (8.26) can be rewritten 


$$
\dot{n}=n^{\delta} H N^{R}
$$

Each innovation is patented by its innovator and licensed out to the producer of a differentiated good. The producer maximizes the sum of discounted cash flows over time from $t$ to infinity subject to the production function (8.27)

$$
L=\operatorname{Max}_{N^{R}} \int_{t}^{\infty} e^{-R(\tau-t)}\left[\int_{0}^{n} b_{z} d z-w H N^{R}+\dot{W}-\dot{R} W\right] d \tau+\lambda\left[n^{\delta} H N^{R}-\dot{n}\right]
$$

where $w$ is wage and $b_{z}$ is the licensing charge for innovation $z ; \dot{W}$ are savings received from and $\dot{R} W$ are savings paid to households. Define the current value Hamiltonian for the R\&D sector

$$
\mathrm{H}=\int_{z^{-}}^{n} b_{z} d z-w H N^{R}+\dot{W}-\dot{R} W+\lambda n^{\delta} H N^{R}
$$

which yields

$$
\frac{\partial \mathrm{H}}{\partial N^{R}}=-w \cdot H+\lambda n^{\delta} H \leq 0, \frac{\partial \mathrm{H}}{\partial N^{R}} \cdot N^{R}=0
$$

and an equation of motion for lambda

$$
\dot{\lambda}=\dot{R} \lambda-\frac{\partial \mathrm{H}}{\partial n}=\dot{R} \lambda-b_{n}-\lambda \delta n^{\delta-1} H N^{R}
$$

implying

$$
\hat{\lambda}=\dot{R}-\frac{b_{n}}{\lambda}-\delta n^{\delta-1} H N^{R}
$$

The future impact of $n$ on $n$ is taken fully into account. Here we differ from Grossman and Helpman where $n^{\delta}$ is a public factor.

From equation (8.30) 


$$
\lambda \leq \frac{w H}{n^{8} H}
$$

Inserting equation (8.33) in (8.31), this yields

$$
\lambda=\dot{R} \frac{w}{n^{\delta}}-b_{n}-\frac{w H N^{R} \delta n^{\delta-1}}{n^{\delta}}
$$

If we take $w$ as the numeraire, equation (8.34) can be rewritten

$$
\dot{\lambda}=\frac{\dot{R}}{n^{\delta} A^{R}}-b_{n}-\frac{H N^{R} \delta}{n}
$$

From equation (8.33) we can calculate the derivative of lambda with respect to time and take growth rates

$$
\lambda=-\lambda \frac{n \delta}{n} \quad \text { or } \hat{\lambda}=-\hat{n} \delta
$$

Combining this with equation (8.32) we get

$$
-\hat{n} \delta=\dot{R}-b_{n} n^{\delta}-H N^{R} \delta n^{\delta-1}
$$

which can be rearranged by multiplying with $n$

$$
n \delta=b_{n} n^{\delta+1}-\dot{R} n+H N^{R} \delta n^{\delta}
$$

and inserting from the production function (8.27) we solve

$$
\dot{R}=b_{n} n^{\delta}=\frac{b_{n} n}{H N^{R}} \Rightarrow b_{n}=\frac{\dot{R}}{n^{\delta}}
$$

The licensing fee for the most recent variant is therefore equal to the rate of interest, corrected for productivity in R\&D or the value of new patents per efficient labour hour in R\&D equals the rate of interest. $b_{n}$ determined in this way, one can solve for $q_{n}$ according to (8.25) as a function of $\dot{R}$ and $n$.

Thus to briefly describe the basic elements of the model thus far, the economy is characterised by an R\&D sector which produces a flow $n$ of innovations based on labour $N^{R}$, with human capital $H$ and cumulated learning $n^{\delta}, 0 \leq \delta \leq 1$. Each innovation is granted 
an infinite patent and the producer has to pay the innovator $b_{z}$ for licensing each innovation $z$. Access to the innovation grants the producer a monopoly over the production of that quality and the price of the new good is equivalent to the monopolist's marginal revenue or cost divided by theta. Reinsertion of (8.25) into the cash flow function of the R\&D firm yields

$$
\pi^{R D}=\int_{z^{-}}^{n} \frac{q_{z} w(1-\theta)}{z \theta} d z-w H N^{R}+\int_{1}^{\infty} \dot{W}-\dot{R} W
$$

Using (8.15), this becomes

$$
\int_{z^{-}}^{n} \frac{z H N^{z} w(1-\theta)}{z \theta} d z-w H N^{R}+\int_{t}^{\infty} \dot{W}-\dot{R} W
$$

which after cancellation yields discounted cash flow

$$
H w\left[\left(\frac{1-\theta}{\theta}\right)_{z^{-}}^{n} N^{z} d z-N^{R}\right] e^{-R(\tau-t)}+\left[\int_{t}^{\infty} \dot{W}-\dot{R} W\right] e^{-R(\tau-t)}
$$

Carrying out the integration over new loans, $\dot{W}$ and interest cost $\dot{R} W$ yields:

$$
e^{-R(\tau-t)} \int_{1}^{\tau}(\dot{W}-\dot{R} W) d \tau \Rightarrow \int_{1}^{\tau}\left[W e^{-R(\tau-t)}-\dot{R} W e^{-R(\tau-t)}\right] d \tau
$$

which from partial integration can be solved

$$
\left[e^{-R(\tau-1)} W\right]_{t}^{\tau}-\int_{t}^{\infty}-\dot{R} e^{R(\tau-\tau)} W d \tau-\int_{1}^{\infty} \dot{R} W e^{-R(\tau-t)} d \tau
$$

and after cancellation

$$
e^{-R(\tau-t)} W(\tau)-W(t)=-W(t) \quad \text { if } \lim _{\mathrm{T} \rightarrow \infty} e^{-\mathbb{R}(\tau-1)} W(\tau)=0
$$

The discounted sum of interest payments in excess of new loans has to equal the initial value of wealth lent to the R\&D firm. In short, total profits have to cover initial losses. The limit condition must hold because the budget flow constraint of the household can also be written as 


$$
\dot{W}=\dot{R} W+w H N-\int_{z^{-}}^{n} p_{z} q_{z} d z
$$

For this to equal (8.3), we must have

$$
\int_{i}^{\infty} \dot{W}-\dot{R} W d \tau=\int_{i}^{\infty}\left(E-\int_{z^{-}}^{n} p_{z} q_{z}\right) d \tau=-W(t)
$$

Having completed the basic specification of the production and consumption sectors, we now move on to calculate the labour market allocation between the two production sectors. The special case of no capital markets is examined in section 8.3 below.

\subsection{Dynamics with Perfect Capital Markets}

In this section, we examine the case where consumers save and invest and innovators can borrow on a perfect capital market for their innovation costs. Before we move on to an examination of steady state dynamics, labour market allocation has to be determined. Substituting values for $p_{z}$ and $q_{z}$ from the zero profit condition in the differentiated sector into (8.9), we calculate

$$
e^{-p(\tau-t)} \beta \theta=\lambda(t) e^{-R(\tau-t)} \int_{z^{-}}^{n} \frac{1}{\theta z} z H N^{z}
$$

which can be written

$$
e^{-\rho(\tau-t)} \beta \theta=\lambda(t) e^{-R(\tau-t)} \frac{1}{\theta} \int_{\vdots}^{n} H N^{z}
$$

Insert from the labour market equilibrium

$$
e^{-p(\tau-t)} \beta \theta=\lambda(t) e^{-R(\tau-r)} \frac{1}{\theta} H\left(N-N^{R}\right)
$$

Differentiating with respect to time

$$
-\rho e^{-\rho(\tau-t)} \beta \theta=\lambda(-\dot{R}) e^{-R(\tau-s)}\left(N-N^{R}\right) \frac{H}{\theta}+\lambda e^{-R(\tau-t)}\left(-\dot{N}^{R}\right) \frac{H}{\theta}
$$




$$
\begin{gathered}
-\rho=-\dot{R}-\frac{\dot{N}^{R}}{N-N^{R}} \\
\dot{N}^{R}=(\rho-\dot{R})\left(N-N^{R}\right)
\end{gathered}
$$

Thus in the steady state, either $\rho=\dot{R}$ or $N=N^{R}$. However, the latter would imply that all the labour in the economy is allocated to the R\&D sector and there would be no production of the differentiated good. Consumer utility hence would not be maximized. Thus this cannot be an equilibrium and we therefore take the first as a solution for the steady state. If $\rho>\dot{R}$, implying that $\dot{N}^{R}>0$, until $N^{R}=N$; this cannot be an equilibrium as explained before. If $\rho<\dot{R}$, implying that $\dot{N}^{R}<0$, until $N^{R}=0$; there would be no more innovation and we therefore will not discuss this case. There is no reason why the economy should approach the steady state slowly, and therefore $\dot{R}=\rho$ from the beginning as in Grossman and Helpman (1991c).

We can now calculate the labour allocation between the two sectors, under the assumption of perfect capital markets. Substitute for $b_{z}$ from the zero profit condition of the differentiated product producer, into the profit function of the R\&D sector ${ }^{168}$

$$
\int_{1}^{\infty} e^{-R(\tau-t)}\left[\int_{z^{-}}^{n} w H N^{=} \frac{1-\theta}{\theta}-w H N^{R}\right] d \tau-W_{t}=0
$$

where $W_{t}$ is initial wealth which the consumer uses to lend to the R\&D sector. Substitute from the labour market equilibrium condition to write

$$
\int_{i}^{\infty} e^{-R(\tau-t)}\left[w H \frac{1-\theta}{\theta}\left(N-N^{R}\right)-w H N^{R}\right] d \tau-W_{t}=0
$$

168 Since we assume that the R\&D firm negotiates all licensing contracts to the differentiated sector in period $t$, and $n$ is private knowledge, a problem of time inconsistency may be caused if the innovator reneges on any contracts in the future. If this does happen, then we cannot assume zero profits in the long run as the innovator becomes a monopolist since he/she has higher productivity from learning, $n$, than a potential late entrant who has to begin from a lower level of learning (see Grossman and Helpman 1991a, Chs. 8 and 11). To ensure zero profits, we assume either that there is a legal framework such as an antitrust law which prevents monopoly profits and ensures that the innovator honours all contracts signed in period $t$, or we assume 100 percent tax on profits, which removes the incentive to have monopoly profits. 
which after setting $w=H=1$, can be rewritten

$$
\int_{1}^{\infty} e^{-R(\tau-t)}\left[\left(\frac{1-\theta}{\theta}\right) N-\frac{1}{\theta} N^{R}\right] d \tau=W_{1}
$$

to obtain the steady state allocation of labour in R\&D where $N^{R}$ has to be constant and $\dot{R}=\rho$. Taking the term in brackets before the integral and carrying out the integration yields

$$
N^{R}=(1-\theta) N-\theta W_{t} \rho
$$

The richer the society is therefore, the less labour it will put into research in equilibrium. If we take the special case of no initial wealth, then the allocation of labour in both sectors in the steady state is

$$
\begin{aligned}
& N^{R}=(1-\theta) N \\
& \int_{z^{-}}^{n} N^{z} d z=\theta N
\end{aligned}
$$

From (8.12) we have the solution for $\dot{R}$ which we insert in (8.39) for the case of no population growth, to solve for $b_{n}$ which in the steady state is

$$
b_{n}=\frac{\rho}{n^{\delta}}
$$

We can calculate the growth rate of $b_{z}$ before moving on to analyzing the rate of change in $z^{-}$. From equation (8.6), the solution for prices, (8.24), and the zero profit condition of the firm (8.25), we get the following relationship between $b_{i}$ and $b_{j}$ where $i$ and $j$ are variants selected by the household

$$
\frac{b_{i}}{b_{j}}=\left[\frac{j}{i}\right]^{\theta} \cdot\left[\frac{e^{\alpha j}}{e^{\alpha i}}\right]^{\theta}
$$

and

$$
\frac{b_{i}}{b_{j}}=\left[\frac{j e^{\alpha j}}{i e^{\alpha i}}\right]^{\theta}
$$


Hence $b_{i}$ and $b_{j}$ grow at the same rate, as do $q_{n}$ and $q_{z}$. From equations (8.25), (8.60) and (8.15), it follows that

$$
\hat{b}_{n}=\hat{q}_{n}=\hat{b}_{z}=\hat{q}_{z}=\hat{N}^{z}=-\delta \hat{n}
$$

and we can write

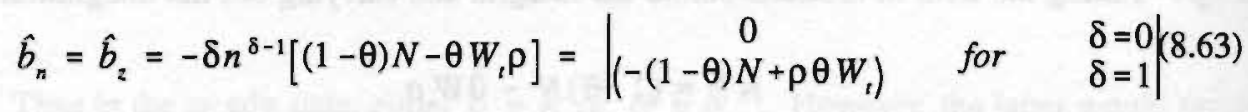

Thus in the case of Shellian learning effects, the value of the license $b_{n}$ is negatively related to the learning or spillover effect and the growth rate of $b_{z}$ and $b_{n}$ is constant, and negatively related to the growth rate of innovations. If learning is Phelpsian, then $b_{n}$ is only dependant on the rate of time preference and the growth rate is zero. This is because since we have already established the growth rate of $n$, we can conclude from this that as $t$ goes to infinity, $b_{n}$ approaches but never exactly reaches zero in the case of learning. If $0<\delta<1, \hat{n}$ approaches zero in the long run and $\lim _{n \rightarrow \infty} \hat{b}_{z}=0$

Licensing fees do not fall over time if there is no learning, i.e., $\delta=0$. With learning, the lower the rate of time preference and initial wealth, the quicker they fall. Next we calculate the change in $z^{-}$. We begin by equating the wealth terms in the consumer's budget constraint and the zero profit condition of the R\&D sector

$$
\int_{i}^{\infty} e^{-R(\tau-t)}\left[E-\int_{z^{-}}^{n} p_{z} q_{z} d z\right] d \tau=\int_{t}^{\infty}\left[-\int_{z^{-}}^{n} b_{z} d z+w H N^{R}\right] e^{-R(\tau-t)}
$$

Taking the derivative with respect to time $t$, we find that the households' excess of labour income over expenditure has to equal the excess of labour cost over revenue in the R\&D firm.

$$
E-\int_{z^{-}}^{n} p_{z} q_{z} d z=-\int_{z^{-}}^{n} b_{z} d z+w H N^{R}
$$

We substitute from (8.24) for $p_{z}$ and $q_{z}$ from the zero profit condition of the differentiated sector producer, (8.25)

$$
E-\int_{z^{-}}^{n} \frac{1}{\theta z}\left(\frac{\theta z}{1-\theta}\right) b_{z} d z=-\int_{z^{-}}^{n} b_{z} d z+w H N^{R *}
$$

with $N^{R *}$ from (8.56). Using $w=H=1$, this can be written 


$$
E-\frac{1}{1-\theta} \int_{z^{-}}^{n} b_{z} d z=-\int_{z^{-}}^{n} b_{z} d z+N^{R}
$$

Alternatively, inserting (8.24) for $p_{z}$ and (8.15) for $q_{z}$ in (8.65), we write

$$
\begin{aligned}
& E-\int_{z^{-}}^{n} \frac{N^{z}}{\theta}=-\int_{z^{-}}^{n} b_{z} d z+N^{R \cdot} \\
& E=\int_{z^{-}}^{n} \frac{N^{z}}{\theta}-\int_{z^{-}}^{n} b_{z} d z+N^{R *}
\end{aligned}
$$

Inserting from the labour market equilibrium

$$
E=\frac{1}{\theta}\left(N-N^{R}\right)-\frac{1}{1-\theta} \int_{z^{-}}^{n} b_{z} d z+N^{R *}
$$

and from (8.56)

$$
E=\frac{1}{\theta}\left(\theta N+\rho \theta W_{t}\right)-\frac{1}{1-\theta} \int_{z^{-}}^{n} b_{z} d z+N^{R^{*}}
$$

Differentiate this with respect to time $\tau$, for given initial wealth $W_{1}$, constant $N$ and $H$ equal to one as before,

$$
\dot{E}=\left[\frac{1}{1-\theta} \int_{z^{-}}^{n} \dot{b}_{z} d z+\left(b_{n} \dot{n}-b_{z} \cdot \dot{z}^{-}\right)\right]
$$

The last equation will also be obtained in the no capital market case because $W$, is constant above. Besides its impact on $N^{R}$ and therefore $n$, it is clear that $W_{1}>0$ has an impact on the initial value of $z^{-}$when calculated from (8.71), because $E, \dot{n}$ and $b_{z}$ have already been solved for, where $E=w H N ; \dot{n}=n^{\delta}\left[(1-\theta) N-\rho \theta W_{t}\right]$ and $b_{z}$ from (8.63) and (8.59).

Next we define the analogous equation for the no capital market case. From that we go on to consider the dynamics of $z^{-}$. This will allow for the conclusion that our model contains the possibilities for (i) a constant range of variety as in the Flam and Helpman (1987) and the Young (1993) models for very long time periods; (ii) an increasing range of variety as in the Young (1991) model and (iii) a decreasing range of variety converging to the one variety case as in Grossman and Helpman (1991b and c) models. 


\subsection{The Special Case of No Capital Markets}

If we assume no capital markets, initial wealth $W_{t}=0$ and no savings or interest, and a regulation of monopoly that ensures zero profits each period, the costs of innovation must be exactly equal to the revenues from licensing to the production sector, implying that

$$
\int_{z^{-}}^{n} b_{z} d z-w H N^{R}=0
$$

We use this condition along with the zero profit condition in the differentiated sector, to calculate the allocation of labour in each sector. Taking the zero profit condition in the differentiated sector, equation (8.25), substituting for $q_{z}$ from equation (8.15) and inserting we obtain

$$
b_{z}=z H N z\left[\frac{1-\theta}{\theta Z}\right]
$$

implying that

$$
b_{z}=H N^{z}\left[\frac{1-\theta}{\theta}\right]
$$

Equation (8.75) can be inserted into the zero profit condition of the R\&D sector, setting equation (8.28), to zero

$$
\int_{z^{-}}^{n} b_{z} d z=\int_{z^{-}}^{n} H N^{z} d z\left[\frac{1-\theta}{\theta}\right]=H \cdot N^{R}
$$

which can be rewritten as

$$
H \int_{z^{-}}^{n} N^{z} d z\left[\frac{1-\theta}{\theta}\right]=H . N^{R}
$$

and

$$
\frac{N^{R}}{\int_{z^{-}}^{n} N^{z} d z}=\left[\frac{1-\theta}{\theta}\right]
$$


Inserting the second equation from (8.76) into the labour market equilibrium equation

$$
N=N^{R}+\int_{z^{-}}^{n} N^{z} d z
$$

we obtain the resource allocation

$$
N=\frac{1-\theta}{\theta} \int_{z^{-}}^{n} N^{z} d z+\int_{z^{-}}^{n} N^{z} d z \quad \Rightarrow \int_{z^{-}}^{n} N^{z} d z=\theta N
$$

or

$$
N=\frac{\theta}{1-\theta} N^{R}+N^{R} \quad \Rightarrow N^{R}=(1-\theta) N
$$

This could have been obtained directly from (8.57) for $W_{t}=0$.

Thus, having calculated the labour allocation between the two sectors, we can now move on to the dynamics of the system in equilibrium. The economy we have just described is characterised by a constant share of labour in innovation, whose growth rate is described by the production function of the $R \& D$ sector and can be shown as

$$
\grave{n}=n^{\delta} H N^{R} \text { or } \dot{n}=n^{\delta} N(1-\theta)
$$

assuming that $H=1$, the next step is to calculate the rate of change of $z^{-}$. In equation (8.3) for the no capital market case, income equals expenditure each period. We insert values of $p_{z}$ and $q_{z}$ from (8.24) and the zero profit condition (8.25), in the differentiated sector

$$
E=\int_{z}^{n} \frac{1}{\theta z} b=\left(\frac{\theta z}{1-\theta}\right) d z
$$

which can be rewritten

$$
E=\frac{1}{1-\theta} \int_{z^{2}}^{n} b_{z} d z
$$

By definition $H N \equiv E$

Again, we assume that $H, N$ and $E$ are constant. Inserting this into equation (8.84) and taking the derivative with respect to time $t$, 


$$
0=\dot{E}=\frac{1}{1-\theta}\left[\int_{z^{-}}^{n} \dot{b}_{z} d z+\left(b_{n} \dot{n}-b_{z^{-}} \cdot \dot{z}^{-}\right)\right]
$$

Multiplying and dividing by $b_{z}$ yields

$$
0=\frac{1}{1-\theta}\left[\int_{z^{-}}^{n} \hat{b}_{z} b_{z} d z+\left(b_{n} \dot{n}-b_{z^{-}} \dot{z}^{-}\right)\right]
$$

From (8.60) and (8.61) above, we established the relative relationship between $b_{i}$ and $b_{j}$. From this we also concluded that the growth rate of $b_{z}$ is independent of $z$. We can therefore rewrite equation (8.86) taking the growth rate of $b_{z}$ before the integral

$$
0=\frac{1}{1-\theta}\left[\hat{b}_{z} \int_{z^{-}}^{n} b_{z} d z-\left(b_{n} \dot{n}-b_{z} \cdot \dot{z}^{-}\right)\right]
$$

Inserting values for $b_{n}$ from (8.59) above, and the time derivative of $n$ from the production function, (8.27), and (8.76) for $\int_{z^{-}}^{n} b_{z} d z$ and (8.81) for $N^{R}$

$$
0=\frac{\hat{b}_{z} H(1-\theta) N}{1-\theta}+\left[\left(\frac{\rho}{n^{\delta}}\right) \frac{H(1-\theta) N n^{\delta}}{(1-\theta)}-\frac{b_{z} \dot{z}^{-}}{(1-\theta)}\right]
$$

which, after cancellation can be rewritten

$$
0=\hat{b}_{z} H N+\left[\rho \frac{H(1-\theta) N}{(1-\theta)}-\frac{b_{z} \cdot \dot{z}^{-}}{(1-\theta)}\right]
$$

Solving for $b_{z} \dot{z}^{-}$yields

$$
b_{z} \dot{z}^{-}=H N(1-\theta)\left[\hat{b}_{z}+\rho\right]
$$

From which we can calculate $i^{-}$ 


$$
\dot{z}^{-}=\frac{H N(1-\theta)\left[\hat{b}_{z}+\rho\right]}{b_{z^{-}}}
$$

By substituting in (8.61) we can calculate the value of $b_{z}$ as a function of $b_{n}$ and write

$$
\dot{z}^{-}=\frac{H N\left[\hat{b}_{z}(1-\theta)+\rho(1-\theta)\right]}{b_{n}\left[\frac{n e^{\alpha_{n}}}{z^{-} e^{\alpha_{z}}}\right]^{\frac{\theta}{\theta-1}}}
$$

From (8.59) we rewrite

$$
\dot{z}^{-}=\frac{H N[-\delta \hat{n}(1-\theta)+\rho(1-\theta)]}{\frac{\rho}{n^{\delta}}\left[\frac{n e^{\alpha n}}{z^{-} e^{\alpha z^{-}}}\right]^{\theta-1}}
$$

The dynamics of $n$ and $\hat{n}$ are described in (8.27) and (8.63) above. Thus we can write the general equation for $z^{-}$and $n$ as

$$
\begin{aligned}
\dot{n} & =n^{\delta}(1-\theta) N \\
\dot{z}^{-} & =\frac{[-\delta \hat{n}+\rho](1-\theta)}{\frac{\rho}{n^{\delta}}\left[\frac{n e^{\alpha n}}{z^{-} e^{\alpha z^{-}}}\right]^{\theta-1}}
\end{aligned}
$$

if $z^{-}<n$ and $z^{-}=n$ otherwise. If $z^{-}=n$, only the most recent variant remains in the market. This qualification will be dropped henceforth. The sign of $\dot{z}^{-}$depends on $\rho-\delta \hat{n} . \rho$ determines the level of $b_{n}, \delta \hat{n}$ determines the speed of the decline in $b_{z}, q_{z}$ and $N^{z}$. If the decline in these variables is strong (weak) enough in relation to the level of $\rho$ or $b_{n}$, there will be (no) room for a decrease in $z^{-}$and (no) reselection of variety.

Next, since we want to examine both the cases of perfect learning as in Shell and no learning as in Phelps, we examine the specific solution for equation (8.95) in each case.

\subsubsection{The Case of Delta $=1$ (Shell)}

The growth rate of $b_{z}$ has been calculated from (8.63) above. Using the case of delta $=1$, we insert in (8.94) and write 


$$
\dot{z}^{-}=\frac{H N[-(1-\theta) N(1-\theta)+\rho(1-\theta)]}{\frac{\rho}{n}\left[\frac{n e^{\alpha \mu}}{z^{-} e^{\alpha z}}\right]^{\theta-1}}
$$

From which, putting $N=1$,

$$
\begin{aligned}
& \dot{z}^{-}=n \frac{-(1-\theta)^{2}+\rho(1-\theta)}{\rho}\left[\frac{n}{z^{-}} e^{\alpha\left(n-z^{-}\right)}\right]^{\hat{\theta}-\theta} \\
& \dot{z}^{-}=\frac{n[\rho-(1-\theta)](1-\theta)}{\rho}\left[\left(\frac{n}{z^{-}}\right) e^{\alpha(n-z)}\right]^{\theta-\theta}
\end{aligned}
$$

\subsubsection{Delta $=0$ (No Learning as in Phelps)}

If we assume no learning, ie. delta $=0$, then we have the following result for the change in $z^{-}$, where the only differences lie in the calculation of $b_{n}$ and the growth rate of $b_{z}$. The value of $b_{n}$ equals $\rho$ because delta is equal to 0 . We can therefore rewrite equation (8.94)

$$
\dot{z}^{-}=(1-\theta)\left[\left(\frac{n}{z^{-}}\right) e^{\left(x\left(n-z^{-}\right)\right.}\right]^{\frac{\theta}{1-\theta}}
$$

Thus we have two variants of the differential equation (8.94), describing the dynamics of the re-emergence and displacement of old products. In the Shellian case of strong learning (delta $=1$ ), new products enter and old products are displaced according to

$$
\begin{gathered}
\dot{n}=n(1-\theta) N \\
\dot{z}^{-}=n \frac{[\rho-(1-\theta)](1-\theta)}{\rho}\left[\left(\frac{n}{z^{-}}\right) e^{\alpha\left(n-z^{-}\right)}\right]^{\frac{\theta}{1-\theta}}
\end{gathered}
$$

in the case of no learning as in Phelps, delta $=0$ and the two differential equations which describe the range of varieties available in the economy at each time can be written

$$
\begin{gathered}
\dot{n}=(1-\theta) \\
\dot{z}^{-}=(1-\theta)\left[\left(\frac{n}{z^{-}}\right) e^{\alpha\left(n-z^{-}\right)}\right]^{\theta}
\end{gathered}
$$

Thus while in the first case, strong learning effects, as expected, have a positive influence on the rate of innovation, they also have an impact on the rate by which older products are dropped or reselected from the consumption bundle (i) via the $n$ term in (8.99) 
and (ii) via the $-\delta \hat{n}$ term in (8.94) which becomes $(1-\theta)$ in the Shellian case in (8.99). This is due to two reasons: firstly, the budget constraint ensures that older products are dropped as the value of new products consumed increases. As the latter rate increases due to learning, the faster is the rate of rejection of older products due to the budget constraint. Secondly, with (no) learning, the fixed cost of producers, $b_{z}$, are (not) decreasing. Therefore the equilibrium quantity produced, according to (8.25), is (not) decreasing. The consumer buys (the same amount of) less of each good, and has (no) more room in the budget for old varieties. In sum, given the price of each variety $z$, as a fixed mark up over marginal costs, the room for variety is determined by the number and quantity of the varieties. Besides learning, the level of fixed costs $\rho$, matters as well. If it is high, relative to its rate of decline $-\delta \hat{n}$, varieties will be selected away by consumers.

In more formal terms, if $\rho-\delta \hat{n}>0, \dot{z}^{-}$is increasing, contributing to decreasing variety. In the case that $\rho-\delta \hat{n}<0, \dot{z}^{-}$is increasing negatively, implying increasing variety, as older varieties are reselected. Whereas $\rho-\delta \hat{n}$ determines the sign of $\dot{z}^{-}$, the exponential term from the quality weights in preferences determines the speed of the development.

The second case of no learning is more straightforward, with both innovation and replacement being driven by the demand elasticity theta, and in addition, quality preferences. No leaming implies that the fixed cost stays constant and since consumers have a fixed budget, old varieties are rejected in favour of new varieties which enter the consumer's consumption bundle.

\subsection{Simulations for the No Capital Market Case}

In order to study the dynamic system, we ran simulations using different parameter values and combinations thereof. Before the simulations could be run however, the initial values of both upper and lower bounds of the integral, i.e. $n$ and $z^{-}$had to be established. With respect to the first, different initial values can be chosen by assumption. However, for the latter, initial values had to be calculated for each corresponding initial value used for $n$. The details of the calculations for initial values for $z^{-}$are to be found in appendix $\Pi$ at the end of the thesis. In this section instead, we present some of the more interesting results of these simulations, especially as they relate to the earlier discussions on biotechnology and innovation. The rest of the figures can be found in appendix III below. We describe first the case of strong learning effects as in Shell and then the case of delta $=0$.

\subsubsection{The Case of Strong Learning Effects}

Two separate trends are recorded in the case of strong private learning effects. In the simulations, three different initial values of $n$ were used, 2, 4 and 8 . The results from the first set of simulations revealed that for higher values of $\alpha$ and for higher values of $n$, the two differential equations go out of bounds very quickly. Thus the base values used were 0.83 for $\theta$ and 0.1 and 0.2 for $\alpha$. The initial value for $z^{-}$was calculated according to appendix II which can be found at the end of this Chapter. 
Figure 8.1. Learning (delta $=1$ )

alpha $=0.1$, theta $=0.83$, mo $=0.03$

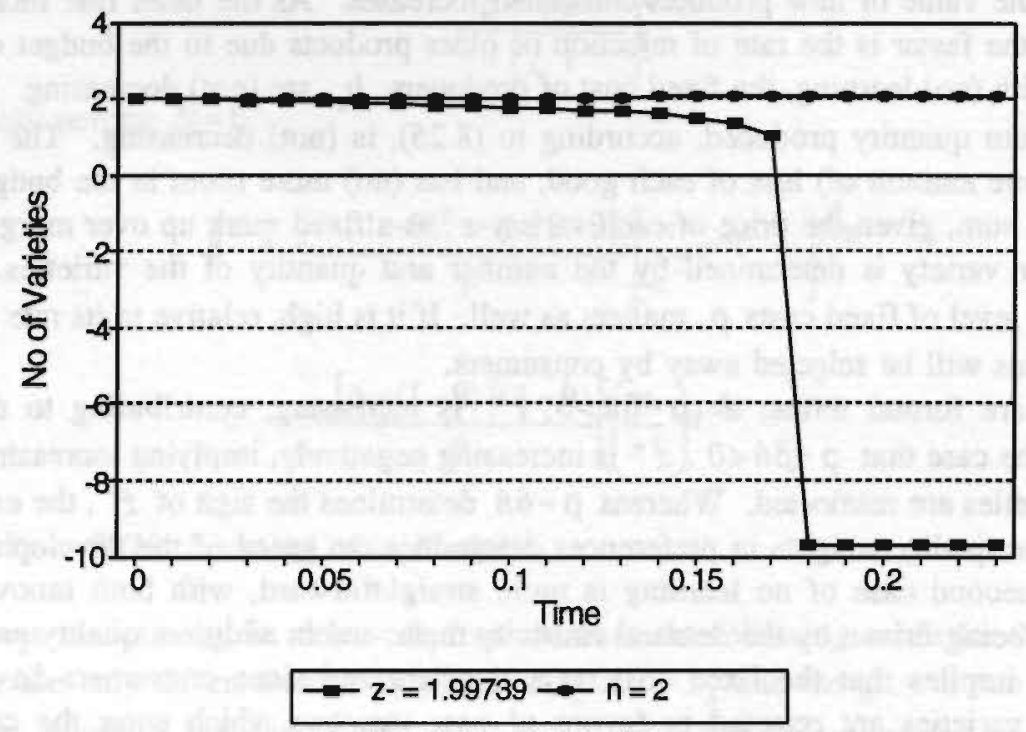

The value for the rate of time preference $\rho$, was varied. In the first instance low values were used for this parameter, ranging from 3 percent to 10 percent ${ }^{169}$. In all the figures below (also see appendix III below), the legends at the bottom of each graph, indicate initial values for $z^{-}$and for $n$.

In the case of low values of the rate of time preference, i.e when $\rho-\delta \hat{n}<0, \dot{z}^{-}$is moving negatively, that is, the total variety of products is increasing and consumers are reselecting older products, which had previously been rejected by them. Figures 8.1. and 8.2. show results for $n$ equal to 2 and for low values of $\rho$ set to 0.03 and 0.04 . In both cases, variety increases as the differential equation for $z^{-}$moves negatively and for $n$ positively. The reason for old products re-entering the consumers choice bundle is due to declining fixed costs $b_{z}$, which from the differentiated producer's zero profit condition implies that the equilibrium quantity produced is also falling, which enables the consumer to spend a greater portion of the budget on a greater variety of products. The exponential term in the equation for $\dot{z}^{-}$reinforces this negative movement. Higher $\rho$ implies a higher price for $b_{z}$, and therefore a higher equilibrium value for $q_{z}$; the result is less variety when taking into account differences in scale of the axes in each case.

169 The range of values used for theta have been estimated using different models, to range between 0.83 to 0.9; see for example Gasiorek, Smith and Venables (1991) quoted in Abraham (1994). The range of values estimated for time preference appear in general to lie between 1 and 4 percent (see Trostel, 1993, 335). 
Figure 8.2. Learning (delta $=1$ )

alpha $=0.1$, theta $=0.83$, tho $=0.04$

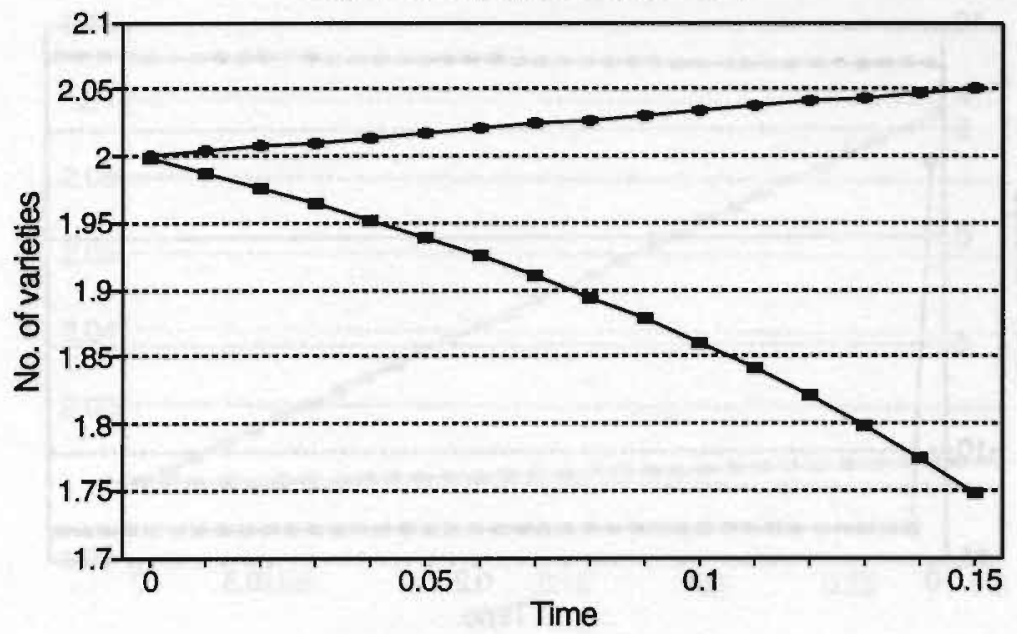

$\rightarrow z=1.99804-n=2$

Figure 8.3. Learning (delta $=1$ )

alpha $=0.1$, theta $=0.83$, mo $=0.03$

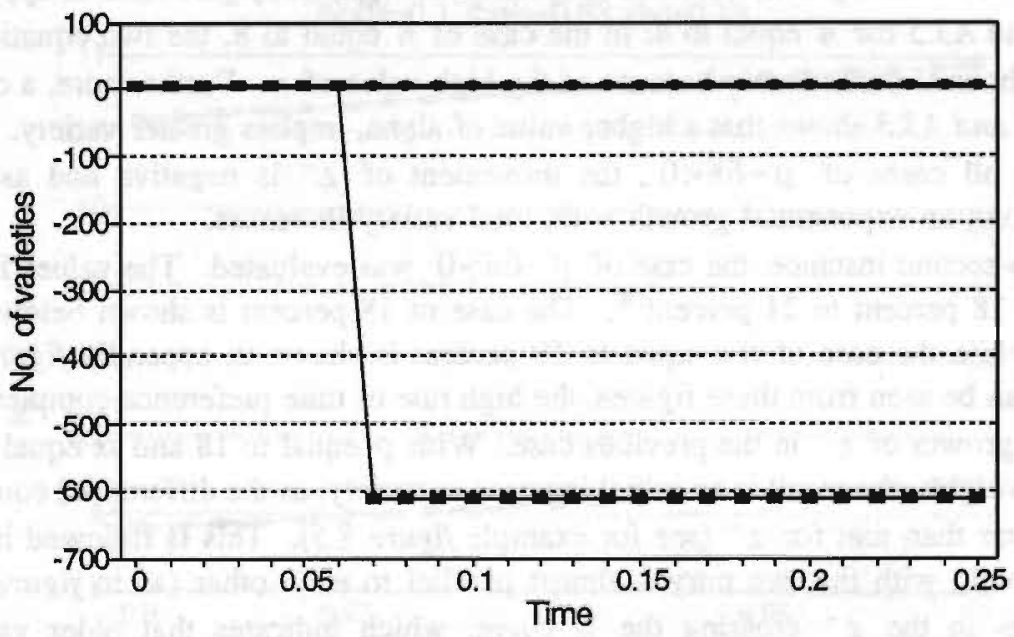

$\rightarrow-z-=3.84089 \multimap n=4$

For different initial values for $n$, the initial value of $z^{-}$varies. In general, the greater the initial value of $n$, implying lower initial values of fixed costs and equilibrium output $q_{z}$, the greater the variety and difference between initial values for $n$ and for $z^{-}$and the faster the negative movement of $\dot{z}^{-}$. This can be seen from figures 8.3 and 8.4 (see also figure 8.1, where $n=2$ ). 


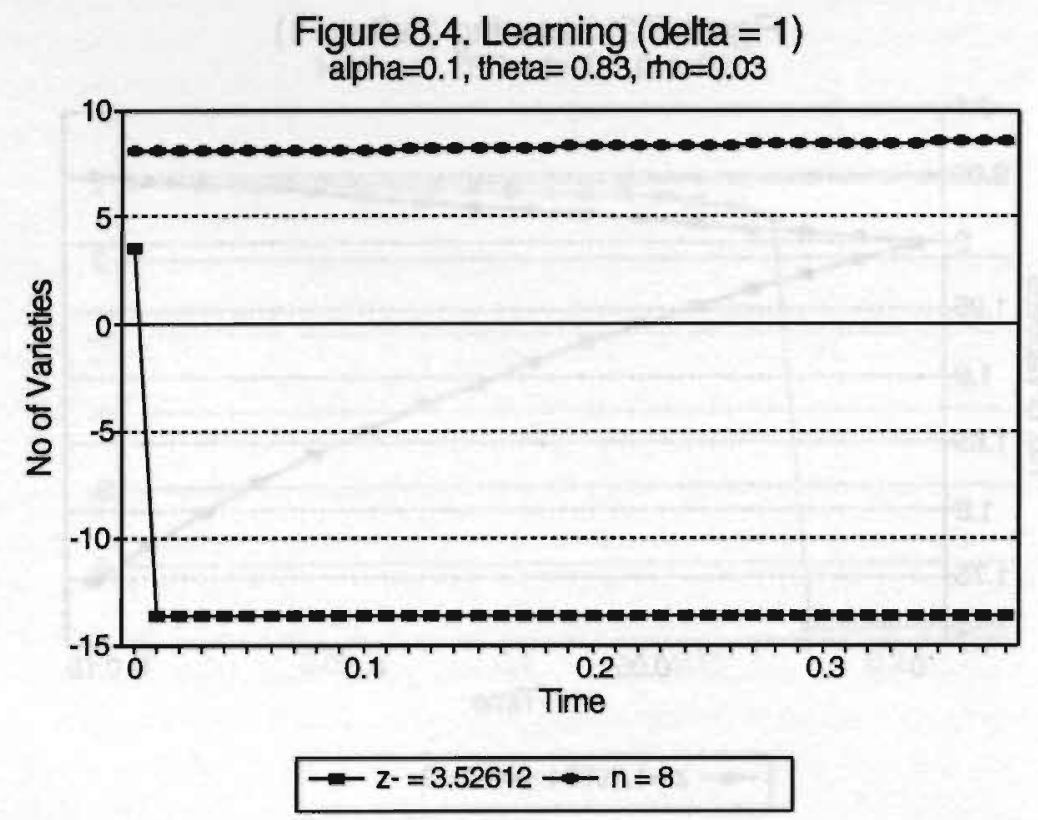

For values of $n$ where alpha is 0.2 , a similar pattern emerges (see figure A3.3 in appendix for $n$ equal to 2 and $A 3.5$ for $n$ equal to 4 ; in the case of $n$ equal to 8, the two equations appear to go out of bounds immediately because of the high value of $n$. Furthermore, a comparison of figure 8.1 and $A 3.3$ shows that a higher value of alpha, implies greater variety. In general therefore, in all cases of $\rho-\delta \hat{n}<0$, the movement of $\dot{z}^{-}$is negative and as $n$ moves positively along an exponential growth path, total variety increases.

In the second instance, the case of $\rho-\delta \hat{n}>0$ was evaluated. The values for $\rho$ used, ranged from 18 percent to 21 percent ${ }^{170}$. The case of 18 percent is shown below in figures 8.5 to 8.8 , while the case of rho equal to 19 percent is shown in appendix figures $A 3.8$ to A3.11. As can be seen from these figures, the high rate of time preference completely offsets the negative growth of $z^{-}$in the previous case. With $\rho$ equal to 18 and $\alpha$ equal to 0.1 , i.e. low quality weights, the result is an initial increase in variety, as the differential equation for $n$ increases faster than that for $z^{-}$(see for example figure 8.5). This is followed by a period of equal growth, with the two curves almost parallel to each other (as in figure 8.6), and finally results in the $\dot{z}^{-}$crossing the $\dot{n}$ curve, which indicates that older varieties are eventually driven out by innovations (figures 8.7 and 8.8 ). The reason for this change from an increase to a decline in variety, is a higher rate of time preference, implying that fixed costs $b_{z}$ and the equilibrium quantity of $z$ are initially high and therefore variety is low.

170 This value of time preference, i.e. $>17 \%$ may seem rather large. However, if we use the estimates of the growth rate of innovation, derived from patent data in chapter 3, (which ranged from 10.27 in the US and 10.71 in Europe), then the rate of time preference used here does not seem to be as large as at first. 
Figure 8.5. Learning (delta $=1$ )

alpha $=0.1$, theta $=0.83$, mo $=0.18$

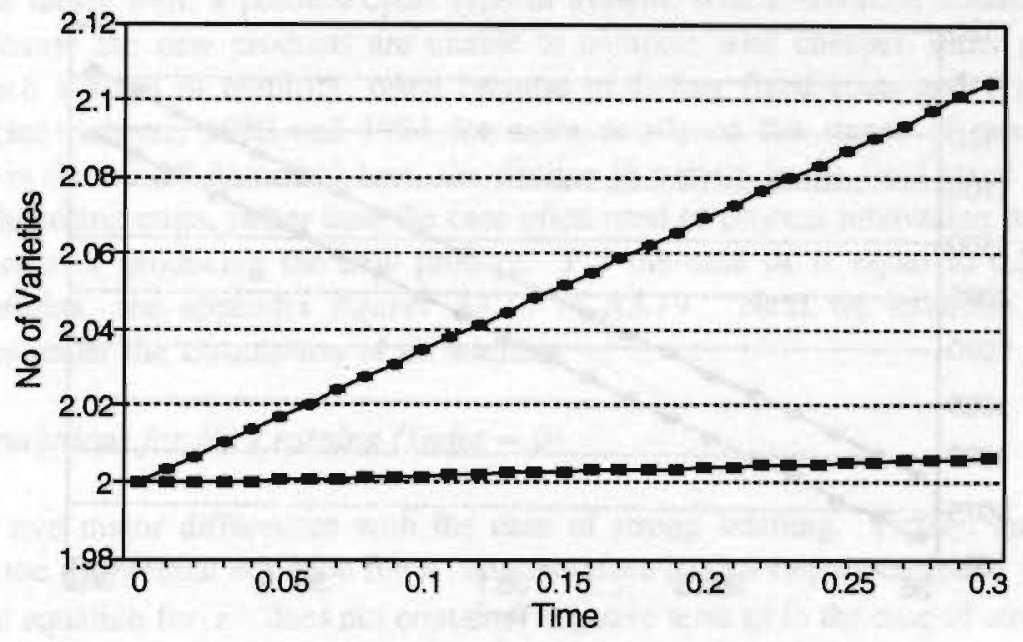

$\rightarrow z-=1.99956 \rightarrow n=2$

Figure 8.6. Learning (delta $=1$ ) alpha $=0.1$, theta $=0.83$, rho $=0.18$

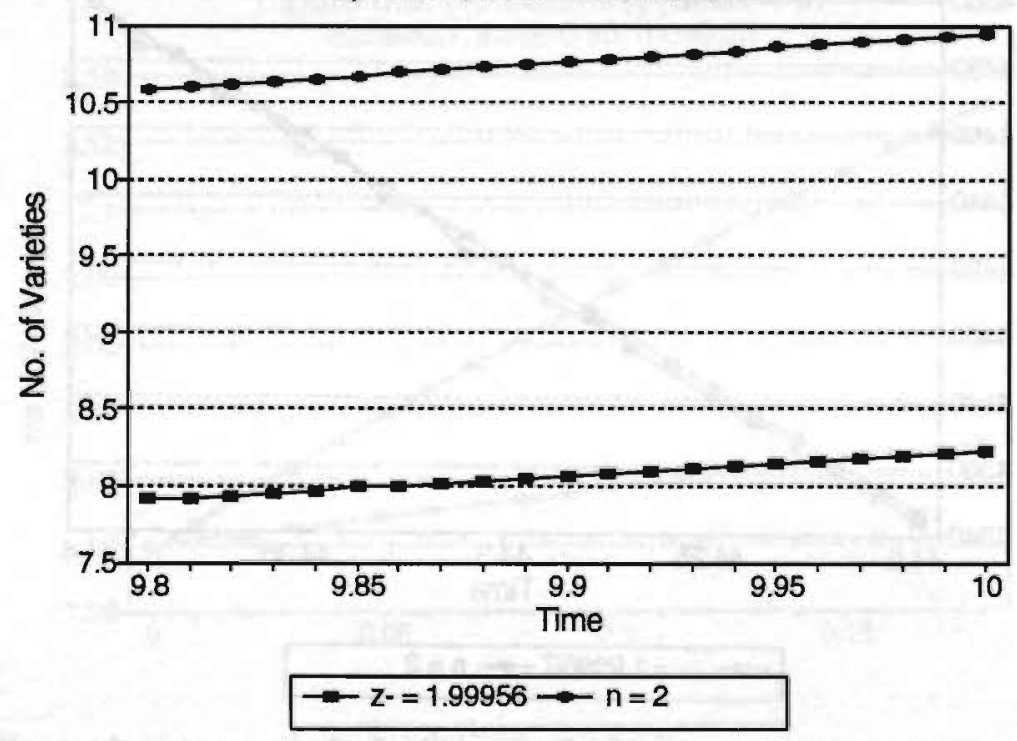

However, the exponential impact of quality finally comes through, crowding out variety through quality. The case where rho equals 0.18 and $n$ equals 4 , are shown in appendix figures A3.12 to $A 3.15$ and $A 3.16$ to $A 3.19$ for $n$ equal to 8 . A higher initial value for $n$ implies greater variety in the beginning because the $b_{z}$ values are lower as are those for $q_{z}$, thus leaving more room for variety. 
Figure 8.7. Learning (delta $=1$ )

alpha $=0.1$, theta $=0.83$, tho $=0.18$
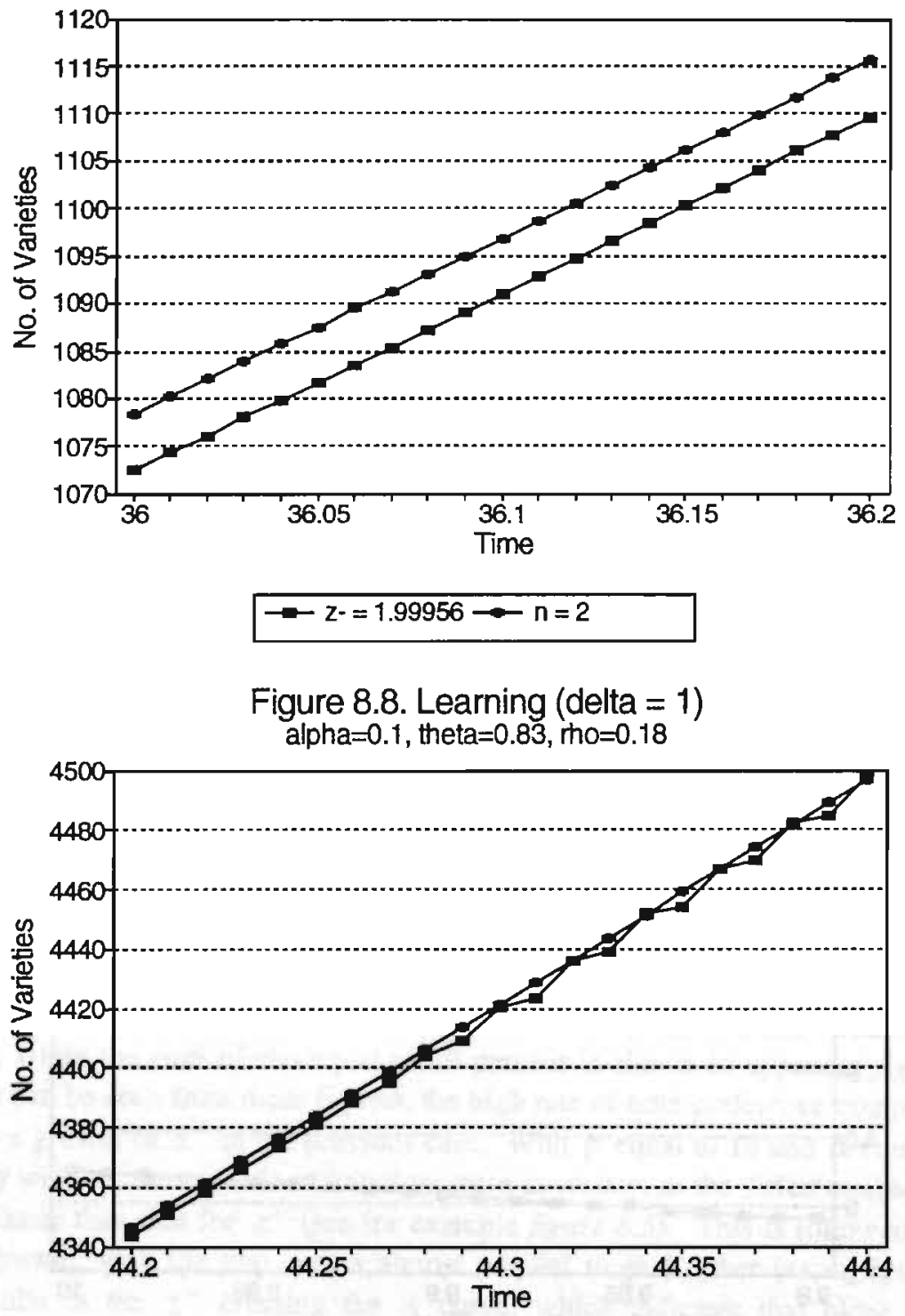

$\rightarrow-z-=1.99956 \multimap n=2$

This last result, with new variants driving out the old, is what we see in the quality ladders model of Grossman and Helpman (1991b and c) and Aghion and Howitt (1992), where the emergence of a new variety, immediately results in the older variety being driven out due to the presence of monopoly profits from the innovation, which destroys the monopoly position of the older product. 
In this model therefore, this type of creative destruction does appear to be present, but comes at a rather late stage (usually between periods 30 and 40). Instead this case appears to describe rather well, a product cycle type of system, with innovation initially increasing variety because the new products are unable to compete with cheaper, older products and finally reach a stage of maturity, often because of falling fixed costs and drive out older products (see Scherer, 1980 and 1984 for more details on the stages of product cycles). However, in the model described here, the decline in variety in the final stage is caused by declining licensing costs, rather than the case often used of process innovation which reduces the fixed cost of producing the new product. For the case of $\alpha$ equal to 0.2 , i.e. higher quality weights, see appendix figures A3.16 to A3.19. Next we examine the case of simulations under the assumption of no learning.

\subsubsection{Simulations for No Learning (Delta $=0$ )}

There are two major differences with the case of strong learning. Firstly, learning is not present in the differential equation for $n$, and therefore has no impact on it and secondly, the differential equation for $z^{-}$does not contain a negative term as in the case of strong learning, implying that fixed costs and equilibrium output are not driven down. Thus we can rule out any negative movement in the differential equation for $z^{-}$.

Figure 8.9. No Learning (delta $=0$ )

alpha $=0.1$, theta $=0.83$, rho $=0.03$

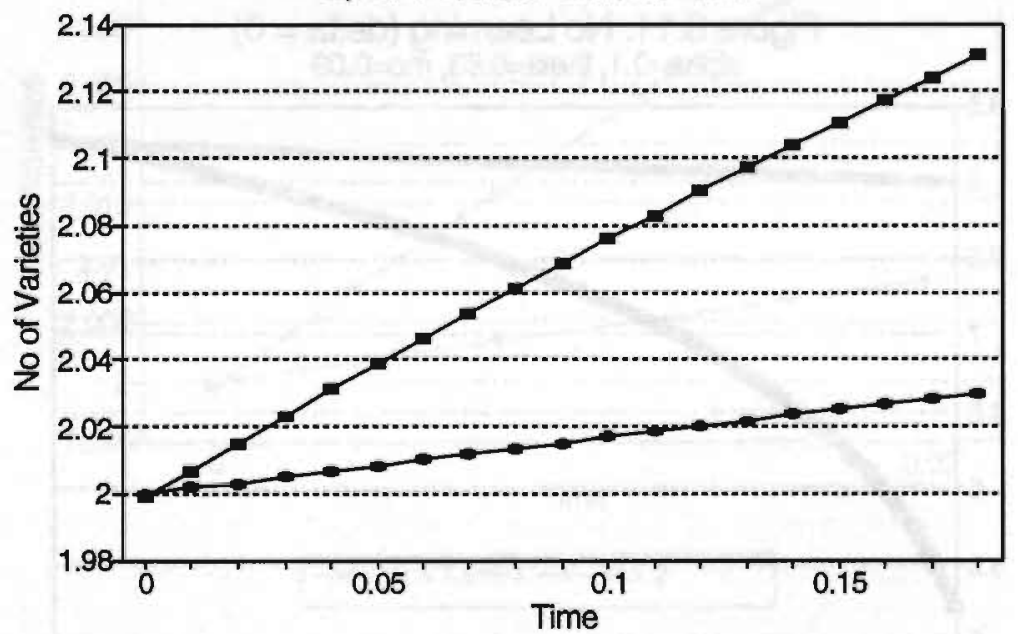

$\rightarrow-z^{-}=1.99869 \rightarrow n=2$ 
Figure 8.10. No Learning (delta $=0$ ) alpha $=0.1$, theta $=0.83$, ho $=0.03$

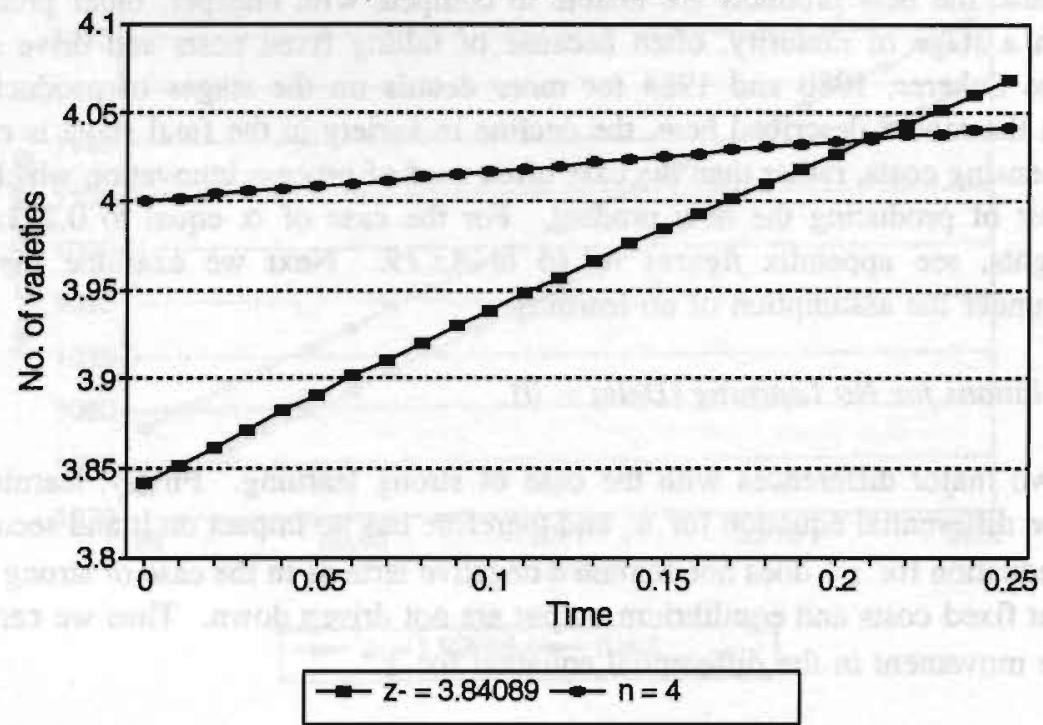

Figure 8.11. No Learning $($ delta $=0$ ) alpha $=0.1$, theta $=0.83$, ho $=0.03$

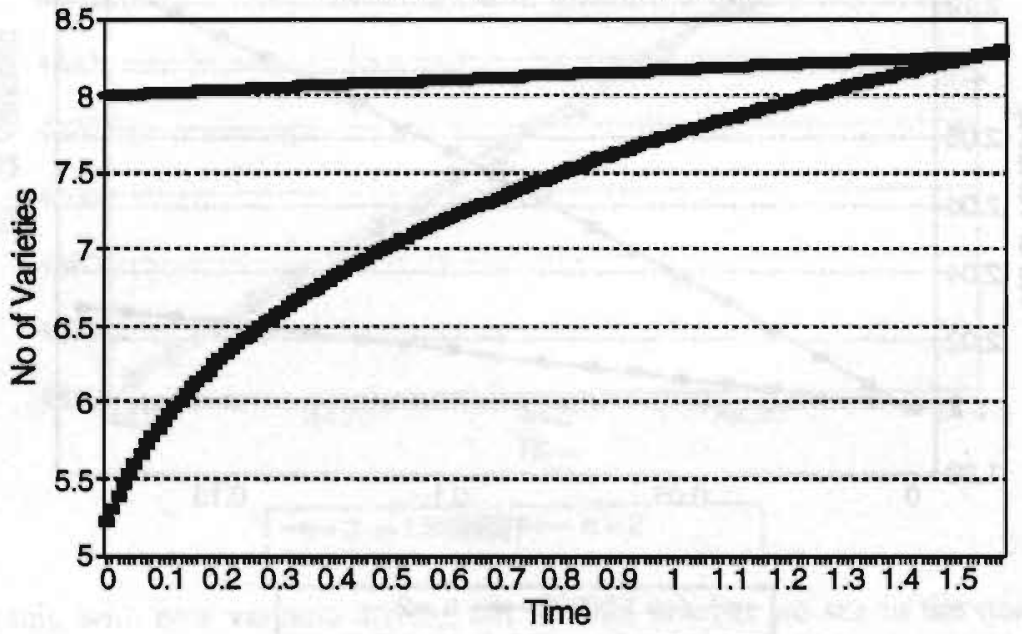

$\leadsto-z-=5.21802 \multimap n=8$ 
As in the case of learning, the initial values used for $n$ were 2,4 and $8,0.83$ for $\theta$ and 0.1 and 0.2 for $\alpha$. The rate of time preference $\rho$, was varied as before. However, since $\rho$ does not occur in either differential equation and only changes the initial value for $z^{-}$, the changes in $z^{-}$are not significant. We therefore only report on the lower values of time preference rates used. The general result for all values of $n, z^{-}$and $\alpha$ used, (figures 8.11, 8.12 and 8.13 below and also see figures $A 3.2$ and $A 3.4, A 3.6$ and $A 3.7$ in appendix), is that there is convergence in the rates of change of both differential equations, i.e., there is creative destruction in the sense of Grossman and Helpman (1991 b and c) and Aghion and Howitt (1992), and only one variety, that is, the highest quality is left on the market.

The use of different initial values of $n$, as in the case of strong learning effects, changes the time at which new varieties drive out older ones, where successively higher values of $n$ are associated with later time periods of new varieties crowding out old ones (see figures $8.9,8.10$ and 8.11 for $n$ values of 2,4 and 8 respectively). This is because households can afford relatively lower values of $z^{-}$if $n$ is higher initially, making the initial difference between $n$ and $z^{-}$greater. See also the case of $n$ equal to 2 and 4 when rho is 0.1 , in figures 8.12 and 8.13 respectively.

Figure 8.12. No Learning (delta $=0$ )

alpha $=0.1$, theta $=0.83$, mo $=0.1$

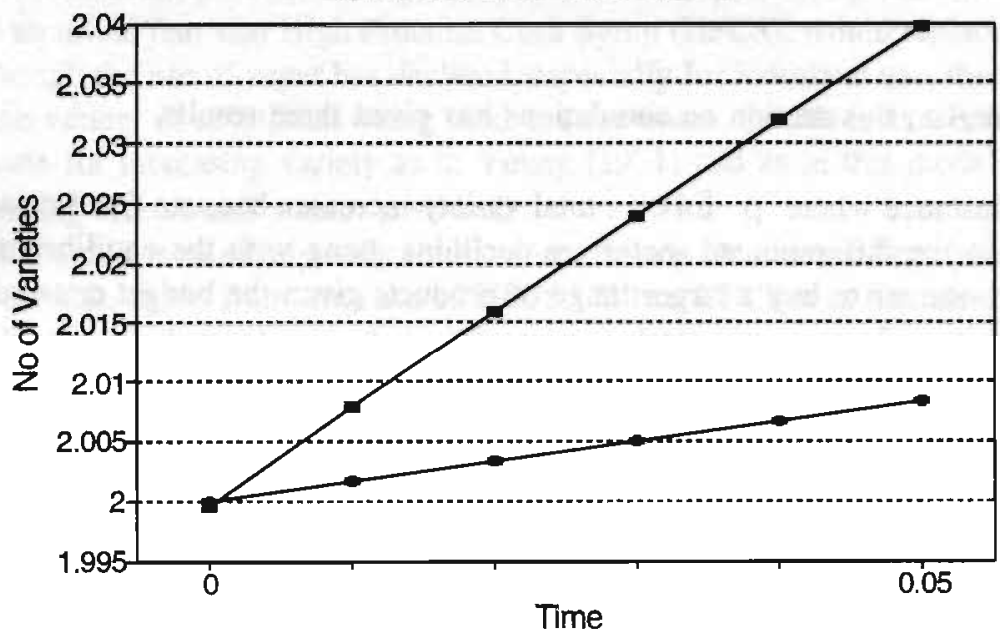

$\rightarrow-z-=1.9961 \multimap n=2$ 


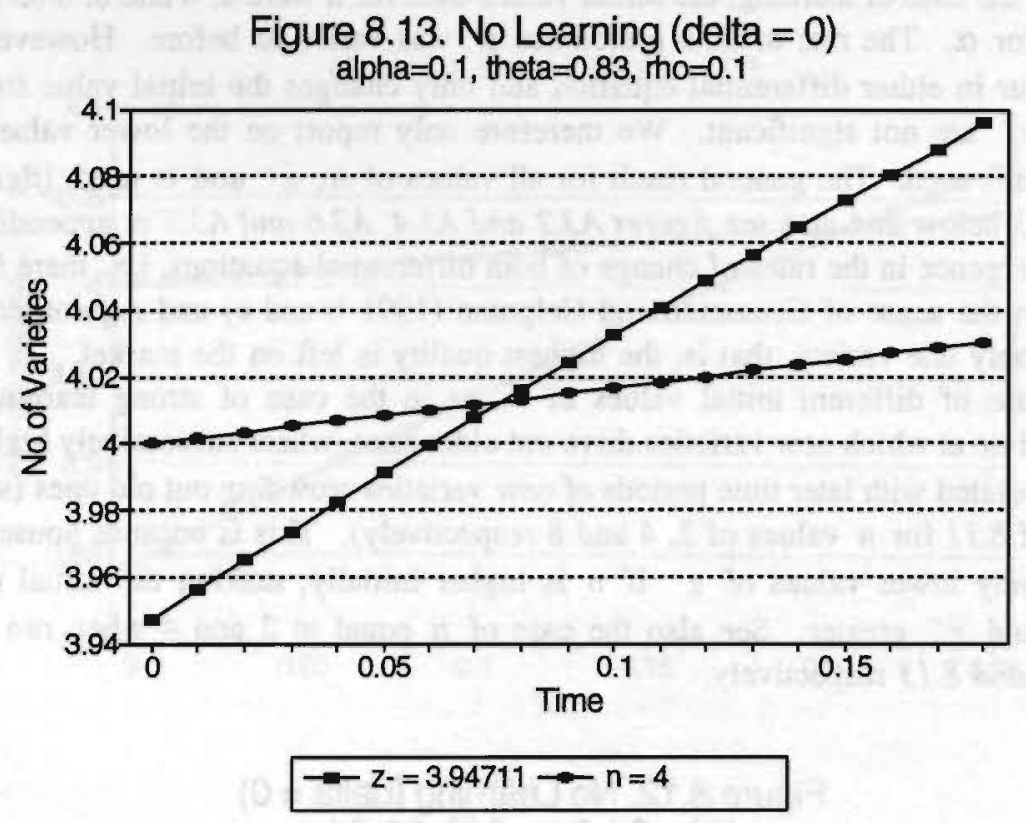

Thus, to summarize, this section on simulations has given three results.

1. In the first instance where $\rho-\delta \hat{n}<0$, total variety increases because fixed costs faced by the producers in the differentiated sector are declining along with the equilibrium quantity, allowing the consumer to buy a larger range of products given the budget constraint.

2. In the second case, with $\rho-\delta \hat{n}>0$, fixed costs are decreasing but high, as is the equilibrium quantity produced. Consumers therefore buy higher quality products, with lower qualities dropping out and variety declines. This case resembles descriptive accounts of the product cycle as new products go through different stages associated with declining costs. eventually driving out old products.

3. In the third case of no learning, the result is one of new products almost immediately driving out older products. Here, because the fixed costs and equilibrium output levels are constant, consumers, given their budget constraints are unable to buy a larger variety of products, and given preferences for quality, older products are dropped in favour of new products of a higher quality. The contrast provided by cases 1 and 3 , when similar values of rho are used can also be seen from figures A3.1 to A3.4 in the appendix below. 


\section{Conclusions}

In this chapter, we have presented a closed economy growth model based on an R\&D sector which innovates and licenses its patented innovations to a production sector which produces differentiated products. Only one factor of production is present and we have examined both the cases of perfect and no capital markets.

The results of the simulations used to examine the dynamics of the system, presented a number of interesting implications for variety, showing in specific, that depending upon the values of certain parameters, the system had a wide range of implications for variety, ranging from the creative destruction result of previous models such as Aghion and Howitt (1990) and Grossman and Helpman, where only one variety is present, to the constant range of Flam and Helpman (1987) and Young (1993) for long time periods, although not for the steady state, and to increasing variety, such as in Young (1991).

This range of results also has interesting parallels with the previous chapter describing the impact of quality improvements through biotechnology, upon older products, and traditional technologies. For example, in the case of genetic engineering, there is a case to be made for creative destruction as in Grossman and Helpman, with a new product completely displacing an old product from the consumer demand function. However, in a number of cases, old products are increasingly facing competition, not from just one product, but from a number of different products and processes. For example, in the case of sugar, although there was an initial fear that High Fructose Corn Syrup (HFCS), would replace sugar over the years, although the use of sugar has declined, especially for industrial use, there has also been a rise in the variety of substitutes being used as sweeteners. In this instance, therefore, a case can be made for increasing variety as in Young (1991) and as in this model, in the case of strong learning effects and where $\rho-\delta \hat{n}<0$.

Although it is relatively early to draw conclusions about a product cycle, there is some evidence for this, again from the case of HFCS. When HFCS was first developed, its costs were too high for industrial use. A combination of declining costs of production and higher internal prices especially in the EC, have ensured that HFCS is now the most widely used substitute for sugar and although it has not succeeded in completely displacing sugar, this is probably due to the fact that the two are imperfect substitutes for each other. A more recent sweetener such as thaumatin which is used in crystallized form such as sugar, may pose a more strong challenge, although due to its high cost of production, this is only likely in the distant future. For some cases however such as vanilla, as was seen from Chapter 5 above, substitutes are considerably cheaper, implying a faster rate of substitution than was the case with sugar. This may also be an indication of the long term development of biotechnology in general. At present we find that second generation biotechnologies which are often imperfect substitutes, tend to dominate, as the genetically engineered products are still costly for most consumers. Thus, variety in the short run will increase. However, it is likely, that when genetically engineered products become cheaper and more widely accessible to consumers, they will tend to displace older products completely. Thus, the result will be increasing variety in the short run which is gradually reduced to a single variety as genetically engineered products become more widely available. 
Finally, the reselection of older products one can argue, is also taking place in conjunction with new technologies. For example, biotechnologies are making it increasingly possible to reselect traditional products, whether through conservation of traditional products, or the use of tissue culture and micropropagation techniques to multiply traditional agricultural products. The example of the neem tree, a tree with astringent properties which is widely used across the Indian subcontinent by indigenous medicine, can be used to illustrate this, where patents are now being granted to traditional products and compounds developed from the properties of the tree, which is likely to increase their consumption by a larger group of consumers, as the products become more widely marketed.

Thus the model presents interesting dynamics with respect to innovation and substitution of products driven by quality weights and the dynamics of variable and fixed costs. In the next chapter, we examine these dynamics in the context of intemational trade and economic growth. The extensions will be particularly relevant to some of the displacement problems between northern and southern products, which we have described above. 
"When the community passes from peaceable savagery to a predatory phase of life, the conditions of emulation change. The opportunity and the incentive to emulation increase greatly in scope and urgency"...T. Veblen

\section{Introduction}

In the previous chapter, we examined technological change within a closed economy with two sectors and one factor of production. The results as we saw show a constant rate of innovation and economic growth, combined with differing rates of growth in product variety, depending upon consumer preferences for quality or for variety. In this section we consider trade between two countries.

We begin with an integrated trade equilibrium where it is assumed that factors of production can move between the two economies and then move on to examining the trade equilibrium, where the two countries or regions consider only trade in goods and factor movement is not allowed. We assume in the first instance that only the north innovates ${ }^{171}$, i.e. has an R\&D sector, while both countries produce different sets of differentiated products. Since we assume that technologies of production are the same in both countries, the ability of a country to do R\&D implies a greater knowledge. Thus, the north produces higher quality differentiated products while the south produces lower quality differentiated products. Unlike a number of previous models (such as is the case of the quality models of Grossman and Helpman), we assume that international patents are enforceable, that is, countries cannot imitate, but have to pay royalties for the use of any patented innovations. Thus, the differentiated sector in both countries has to pay for any innovation produced by the R\&D sector. We also assume that no innovation is licensed out to any two producers, ensuring thereby that the range of products produced by producers in the south is always different from that produced in the north.

Of the few recent models which have examined innovation and imitation in the presence of international patents, the one by Helpman (1993) is most relevant to the analysis here. Helpman (1993) interprets stricter intellectual property rights in a two country model based on Krugman (1979) as a reduced rate of imitation. Thus, the only impact is that the developing region is able to imitate at a reduced rate. The result, as is to be expected intuitively, is an improvement in the terms of trade of the northern country because the fraction of goods produced in the north increases. Presumably, this implies that with perfect

171 Grossman and Helpman (1991a, Ch.8) also rule out southern innovation and argue that this can be done in a number of ways: firstly by assuming that southern producers require more labour to invent the same product as the north, they would have endowed the north with comparative advantage in innovation; secondly they could have assumed that $n_{N}>n_{s}$, (as in this chapter), ensuring that the knowledge gap would enable the north to maintain its lead in the long run; and finally, by assuming that the north has skilled labour while southern labour is unskilled, would again ensure that the south would produce low quality goods. 
enforcement of intellectual property protection, the rate of imitation would be close to zero. However, the possibility of licensing is not addressed, should this be the case.

Within the framework of the models we discussed earlier however, such as the Grossman and Helpman (1991a and b) models, which use a sectoral analysis to discuss innovation and imitation, patents are in general ruled out when discussing trade, and the south always imitates products from the north rather than licensing them. Thus these models tend to ignore the enforcement of intellectual property rights across national boundaries in order to emphasise imitation. In our approach instead, both intellectual property rights are recognized across national borders and we allow for licensing where licensing becomes a fixed cost in the producer's production function.

Licensing across countries is however discussed briefly in Grossman and Helpman (1991a, Ch 7), in terms of a lump sum payment for a patent from the innovating firm to the licensee. In the case of horizontally differentiated products, the licensing firm in these circumstances will only license if its costs of paying for the license equals the present value of profits from entering into duopolistic competition with the innovator. In their case this only occurs if there is a manufacturing cost difference between the two countries, which ensures that the licensee could make monopoly profits which are higher than the profits it could make on its own. This would ensure that the licensor would not compete with the licensee and therefore the latter would divert all monopoly profits from the former, because factor prices would be equalized as a result of the transfer of technology.

In the case of vertically differentiated products, because innovations are no longer imperfect substitutes for older products such as is the case with horizontally differentiated innovations, there is no longer competition with like goods. The innovator is now competing with manufacturers of older products. There are two trade equilibria which emerge in this case: in the first, there is no enforcement of non-competition clauses, such that if the patent is licensed but the innovator also continues to produce the product, there is no licensing in equilibrium. This is because if the new product is more costly to produce and the innovating country has comparative advantage in the production of the innovation, then if there is competition between the two countries, the innovating country would earn all the profits in the Bertrand equilibrium. In the the second case where the innovating country agrees to make the licensor the exclusive producer of the innovation, as in the model presented in this chapter, there is an equilibrium which allows licensing to be profitable. However, in contrast to the model presented below, licencing in the Grossman and Helpman case only takes place if the cost of production in both countries is the same. Innovators will license their innovations because competition to improve products targets only the newest generation of products. Thus competition is most intense among innovators in the technologically advanced region. The rationale for granting a license to a producer in the non-innovating region is to ensure that a longer period of monopoly profits can be sustained for that innovation. This would not be possible, if the innovation was produced by the innovating firm because of competition to develop the new generation of innovations ${ }^{172}$.

172 Grossman and Helpman (1991a, pp 200-205). This point is also made with reference to the result they get in many of their papers, that once innovation takes place, the race to develop the next generation of products begins and the innovated product becomes the new target for quality improvements (see also Grossman and Helpman 1991b and c). 
In this chapter imitation by the south is completely ruled out and the south can only produce goods by licensing the technology from the northem innovator. Unlike Grossman and Helpman (1991a, Ch 7), we do not rule out licensing by northern firms of new innovations. However, we do rule out any competition with regards to the same innovation, i.e. the innovation is only licensed out to one producer. Thus each patent is licensed to only one producer and the product to which that patent belongs is only produced by that licensor.

\subsection{The Integrated Equilibrium}

The structure of production and resource endowment is assumed to be the same as in the previous chapter, except now the countries are indexed $N$ and $S$ (for north and south respectively). We assume that while only the north can do R\&D (i.e. it has a comparative advantage in $R \& D$ ), both regions produce and export the differentiated good, $z$. The structure followed in this chapter is the same as in Chapter 8 above, beginning with demand and then moving on to describe the differentiated and R\&D sectors.

Consumer preferences and utility are described in the same manner as in the closed economy, i.e. intertemporal utility is denoted by

$$
U=\int_{1}^{\infty} e^{-p(\tau-t)}[\log u] d \tau
$$

where rho is the subjective discount rate and the subutility function $u$ is

$$
u=\left[\int_{z_{i}^{-}}^{n}\left(q_{z_{i}} e^{\alpha z}\right)^{\theta} d z\right]^{\beta}, \begin{gathered}
z \varepsilon\left[z^{-}, n\right] \\
0<\theta<1 \\
\beta>1 \\
\alpha \geq 0
\end{gathered} \quad i=N, S
$$

where $q_{z}$ is the quantity of quality $z$ demanded, while $z^{-}$is the lowest and $n$ is the highest quality demanded by consumers. The parameter $\theta$ represents society's constant demand elasticity for quantity. Utility is maximized with respect to the budget constraint by consumers in the north and in the south, where $R(\tau)$ is the rate of cumulative interest from time $t$ to time $\tau, p_{z}$ is price of quality $z, E$ is consumer income in each period and wealth is assumed to be zero because its impact has been discussed in the previous chapter.

Thus the budget constraint for each region can be written

$$
\int_{t}^{\infty} e^{-R(t-\tau)}\left[\int_{z^{-}}^{n} p_{z} q_{z_{N}} d z-E_{N}\right] d \tau \leq 0
$$


and similarly for the south

$$
\int_{i}^{\infty} e^{-R(t-\tau)}\left[\int_{z_{j}^{*}}^{n} p_{z} q_{z_{s}} d z-E_{S}\right] d \tau \leq 0
$$

where subscripts denote regions north and south and $E_{N}$ and $E_{S}$ is national income for the north and south respectively. The Lagrangean can now be written

$$
L=\left[\int_{t}^{\infty} e^{-\rho(t-\tau)} \log u[.] d \tau\right]+\lambda(t)\left[\int_{t}^{\infty} e^{-R(t-\tau)}\left(E_{N}-\int_{z_{i}^{-}}^{n} p_{z} q_{z_{\alpha}} d z\right)\right] d \tau
$$

and similarly for the south

$$
L=\left[\int_{t}^{\infty} e^{-p(t-\tau)} \log u[.] d \tau\right]+\lambda(t)\left[\int_{t}^{\infty} e^{-R(t-\tau)}\left(E_{S}-\int_{\xi}^{n} p_{z} q_{z_{s}} d z\right)\right] d \tau
$$

from which the first order conditions are equation (9.3) and

$$
\frac{e^{-\rho(t-\tau)}}{u}\left[\beta[.]^{\beta-1} \theta\left(q_{z_{\psi}} e^{\alpha z}\right)^{\theta-1}\right] e^{\alpha z}-\lambda e^{-R(t-\tau)} p_{z} \leq 0
$$

for the north and equation (9.4) and

$$
\frac{e^{-\rho(t-\tau)}}{u}\left[\beta[.]^{\beta-1} \theta\left(q_{z_{s}} e^{\alpha z}\right)^{\theta-1}\right] e^{\alpha z}-\lambda e^{-R(t-\tau)} p_{z} \leq 0
$$

for the south, and if (9.7) and (9.8) above hold with equality, we can calculate the price elasticity of demand for differentiated goods as before

$$
\frac{p_{i}}{p_{j}}=\frac{\left(q_{i_{\mu}} e^{\alpha i}\right)^{\theta-1} e^{\alpha i}}{\left(q_{j_{\mu}} e^{\alpha j}\right)^{\theta-1} e^{\alpha j}}
$$

and 


$$
\frac{p_{i}}{p_{j}}=\frac{\left(q_{i_{s}} e^{\alpha_{i}}\right)^{\theta-1} e^{\alpha_{i}}}{\left(q_{j_{s}} e^{\alpha_{j}}\right)^{\theta-1} e^{\alpha_{j}}}
$$

As relative prices, $\theta$ and quality weights are the same in both countries, relative quantities demanded must also be the same. From (9.9) and (9.10) we can calculate northem and southern elasticity of demand respectively

$$
\frac{\partial p_{i}}{\partial q_{i_{N}}} \cdot \frac{q_{i_{w}}}{p_{i}}=\frac{(\theta-1)\left(q_{i_{\mu}} e^{\alpha i}\right)^{\theta-2} \cdot\left(e^{\alpha i}\right)^{2} \cdot q_{i_{N}} p_{j}}{\left(q_{j_{N}} e^{\alpha j}\right)^{\theta-1} \cdot e^{\alpha j} \cdot p_{i}}=\theta-1
$$

and

$$
\frac{\partial p_{i}}{\partial q_{i_{s}}} \cdot \frac{q_{i_{s}}}{p_{i}}=\frac{(\theta-1)\left(q_{i_{s}} e^{\alpha i}\right)^{\theta-2} \cdot\left(e^{\alpha i}\right)^{2} \cdot q_{i_{s}} p_{j}}{\left(q_{j_{s}} e^{\alpha j}\right)^{\theta-1} \cdot e^{\alpha j} \cdot p_{i}}=\theta-1
$$

Thus because we assume that preferences are the same in both regions and that the structure of the utility function is the same, we obtain the same result for elasticity of demand for $z$ goods. The solution to the intertemporal utility maximization problem can be calculated by multiplying $q_{z}$ to equation (9.7) and (9.8) and integrating over $z$

$$
\frac{e^{-\rho(\tau-t)}}{u} \beta[.]^{\beta-1} \theta \int_{z_{N}^{-}}^{n_{\mu}}\left(q_{z_{\mu}} e^{\alpha z}\right)^{\theta}=\lambda(t) e^{-R(\tau-t)} \int_{z_{\mu}^{-}}^{n} p_{z} q_{z_{\mu}} d z
$$

and

$$
\frac{e^{-\rho(\tau-t)}}{u} \beta[\cdot]^{\beta-1} \theta \int_{z_{j}^{-}}^{n_{s}}\left(q_{z_{s}} e^{\alpha z}\right)^{\theta}=\lambda(t) e^{-R(\tau-t)} \int_{z_{z}^{-}}^{n} p_{z} q_{z_{s}} d z
$$

Expenditures in both countries grow at the rate of interest minus the rate of time preference. In the case of no capital markets that rate is zero if incomes are constant.

We now move to the differentiated sector, where it is assumed that both regions have the ability to produce differentiated products. We assume only one factor of production, labour $N$, which is allocated between the two sectors, and has human capital of $H$. As before, we assume that producers of differentiated products license innovations from the R\&D sector, and become monopolists by virtue of being the sole users of the new patent. International patents are enforced, ensuring that southern producers cannot imitate or pirate 
an innovation, but have to license it from the northern innovator just as northern producers of the differentiated good do. Thus both north and south license innovations and produce differentiated goods. We also impose the condition that once the innovation is licensed to one producer, it cannot be licensed to another. Thus each differentiated producer, produces different differentiated products.

The production function in both countries is the same as before

$$
q_{z_{i}}=z_{i} F_{i}{ }^{z}\left(H_{i} N_{i}^{z}\right), \quad i=N, S
$$

and because we assume linear technologies in production as before, this can be written:

$$
q_{z_{i}}=z_{i} H_{i} N_{i}^{z}
$$

The monopolist minimizes production costs

$$
C_{z_{i}}\left(q_{z_{i}}, w_{i}, H_{i}\right)=w_{i} H_{i} N_{i}^{z}+\lambda^{z}\left(q_{z_{i}}-z_{i} H_{i} N_{i}^{z}\right)
$$

where $w_{i}$ is wage per efficient labour unit and $C_{z}($.$) is total variable cost.$

The producers' first order condition for cost minimization with respect to $N_{i}^{z}$ is

$$
w_{i} H_{i}-\lambda z z_{i} H_{i}=0
$$

which can be rewritten

$$
\begin{gathered}
C_{z_{i}}^{\prime}\left(q_{z}, w_{i}, H_{i}\right)=\lambda^{z}=\frac{w_{i} H_{i}}{z_{i} H_{i}} \\
C_{z_{i}}^{\prime}\left(q_{z}, w_{i}, H_{i}\right)=\lambda^{z}=\frac{w_{i}}{z_{i}}
\end{gathered}
$$

which is the marginal cost of the monopolist.

Because we have assumed that differentiated producers become monopolists by licensing $z_{i}$ from the R\&D sector, the profit function of the monopolist can be written

$$
\pi_{z_{i}}=\left[q_{z} p_{\varepsilon_{1}}\left(q_{z_{i}}\right)-C_{\xi}\left(q_{z}\right)-b_{z_{i}}\right]
$$


Optimization with respect to $q_{z}$ yields the following first order condition

$$
p_{z_{i}}+q_{z_{i}} p_{z_{i}}^{\prime}\left(q_{z_{i}}\right)-C_{z_{i}}^{\prime}\left(q_{z_{i}}\right)=0
$$

which means that marginal revenue equals marginal cost which is the monopolist's optimal pricing condition. From the first order conditions for consumer demand we have determined the price elasticity of demand and from (9.22), we can calculate the marginal revenue of the monopolist

$$
C_{z_{i}}^{\prime}\left(q_{z_{i}}\right)=p_{z_{i}}\left(1+\frac{p_{z_{i}}^{\prime}}{p_{z_{i}}} \cdot q_{z_{i}}\right)=p_{z_{i}} \theta
$$

implying that

$$
C_{i}=C_{i}^{\prime} q_{z_{i}}=p_{z_{i}} \theta q_{z_{i}}
$$

and from equation (9.20)

$$
p_{z_{i}}=\frac{w_{i}}{\theta z_{i}}
$$

Thus, (9.25) and (9.16) in (9.21) yield the monopolist's profits

$$
\pi_{z_{i}}=q_{z_{i}} w_{i}\left[\frac{1-\theta}{\theta z_{i}}\right]-b_{z_{i}}=0
$$

The assumption is again that profits have to be zero because free entry into this sector enables each potential producer to offer all profits when a blueprint is auctioned off (see Romer, 1990). Equation (9.26) can be written as

$$
b_{z_{i}}=w_{i} z_{i} H_{i} N_{i}^{z}\left(\frac{1-\theta}{\theta z_{i}}\right) \quad i=N, S
$$

Cancellation of $z_{i}$ and integration over northern and southern ranges of $z$ yields 


$$
\int_{z^{-}}^{n} b_{z^{-}} d z=\frac{1-\theta}{\theta} \int_{z^{-}}^{n} w_{i} H_{i} N_{i}^{2} d z \quad i=N, S
$$

R\&D, we assume can only be done by the northern region, i.e. as in Grossman and Helpman (1991a, Ch 8), we assume that the north has comparative advantage in R\&D and innovation activities. The R\&D sector therefore has the same structure and allocation of resources and the price structure of each new innovation is therefore the same as before. Since R\&D is only done by the north, we drop all country subscripts, except to indicate northern and southern wages and incomes, in this section. As before, the production function of the research sector is

$$
\dot{n}=n^{\delta} F^{R}\left(H_{N} N_{N}^{R}\right)
$$

where $\dot{n}$ is the flow of innovations and $n$ is a measure of learning from each innovation. Delta measures the elasticity of these spillovers where if delta $=1$, we have perfect learning as in Shell (1967) and if delta $=0$, there is no learning as in Phelps (1966). The assumption of linear technologies in labour means that equation (9.29) can be rewritten

$$
\dot{n}=n^{\delta} H_{N} N_{N}^{R}
$$

Each innovation is patented by its innovator and licensed out to the producer of a differentiated good. We assume free entry in this sector and the producer maximizes the sum of profits over time from zero to infinity

$$
L=\operatorname{Max}_{N^{R}} \int_{t}^{\infty} e^{-R(\tau-t)}\left[\int_{z^{-}}^{n} b_{z} d z-w_{N} H_{N} N_{N}^{R}\right] d \tau+\lambda\left[n^{8} H_{N} N_{N}^{R}-\dot{n}\right]
$$

where $w_{N}$ is wage and $b_{z}$ is the licensing charge for innovation $z$, subject to the production function (9.30)

From the current value Hamiltonian for the R\&D sector

$$
\mathrm{H}=\left[\int_{z^{-}}^{n} b_{z} d z-w_{N} H_{N} N_{N}^{R}\right]+\lambda n^{\delta} H_{N} N_{N}^{R}
$$

we obtain 


$$
\frac{\partial \mathrm{H}}{\partial N^{R}}=-w_{N} H_{N}+\lambda n^{\delta} H_{N} \leq 0, \frac{\partial \mathrm{H}}{\partial N_{N}^{R}} N^{R}=0
$$

and an equation of motion for lambda

$$
\begin{gathered}
\dot{\lambda}=\dot{R} \lambda-\frac{\partial \mathrm{H}}{\partial n}=\dot{R} \lambda-b_{n}-\lambda \delta n^{\delta-1} H_{N} N_{N}^{R} \\
\Rightarrow \hat{\lambda}=\dot{R}-\frac{b_{n}}{\lambda}-\delta n^{\delta-1} H_{N} N_{N}^{R}
\end{gathered}
$$

From equation (9.33)

$$
\lambda \leq \frac{w_{N} H_{N}}{n^{\delta} H_{N}}
$$

Inserting equation (9.36) in (9.34), and using $w_{N}$ as the numeraire, this yields

$$
\dot{\lambda}=\frac{\dot{R}}{n^{\delta}}-b_{n}-\frac{H_{N} N_{N}^{R} \delta}{n}
$$

From equation (9.36) we can calculate the derivative of lambda with respect to time and take growth rates

$$
\dot{\lambda}=-\lambda \frac{\dot{n} \delta}{n} \quad \text { or } \hat{\lambda}=-\hat{n} \delta
$$

Combining this with equation (9.35) we get

$$
-\hat{n} \delta=\dot{R}-b_{n} n^{\delta}-H N^{R} \delta n^{\delta-1}
$$

which after multiplying by $n$ can be written

$$
\dot{n} \delta=b_{n} n^{\delta+1}-\dot{R} n+H N_{N}^{R} \delta n^{\delta}
$$

and inserting from the production function (9.30) we solve 


$$
\dot{R}=b_{n} n^{\delta}
$$

Thus the fixed cost (or the cost of licensing the innovation from the innovator) depends positively upon the rate of interest but negatively upon the learning parameter and $n$.

\subsubsection{Labour Allocation}

Another major change from the previous chapter is the presence of a larger labour force in the integrated equilibrium, and although the south devotes all its labour force to the production of differentiated products, specialization is not necessarily the case with the north. The next step therefore is to calculate the allocation of labour in the two sectors in the north. For this we take the new zero profit condition in the R\&D sector, which can now be written

$$
\left[\int_{z_{i}^{*}}^{n_{N}} b_{z_{N}} d z+\int_{z_{s}^{-}}^{n_{s}} b_{z_{s}} d z-w_{N} H_{N} N_{N}^{R}\right]=0
$$

where the two extremes of each integral denote the range of products produced in the north $(\mathrm{N})$ and in the south (S) (which can be assumed to be continuous in an integrated equilibrium), we insert (9.28) to write

$$
\left[\frac{1-\theta}{\theta} \int_{z_{N}^{-}}^{n_{N}} w_{N} H_{N} N_{N}^{z} d z+\frac{1-\theta}{\theta} \int_{z_{s}^{-}}^{n_{s}} w_{S} H_{S} N_{S}^{z} d z-w_{N} H_{N} N_{N}^{R}\right]=0
$$

which can be rewritten

$$
\frac{1-\theta}{\theta} \int_{z, i}^{n_{N}} w_{N} H_{N} N_{N}^{z} d z+\frac{1-\theta}{\theta} E_{S}=w_{N} H_{N} N_{N}^{R}
$$

where $E_{s}$ is southern income since the south does no R\&D and therefore allocates all its labour to the production of the differentiated good. From the labour market equilibrium in the north where $N_{N}=\int_{z=}^{n_{N}} N^{2} d z+N^{R}$, we write

$$
\frac{1-\theta}{\theta} \int_{z=}^{n_{N}} w_{N} H_{N} N_{N}^{z} d z+\frac{1-\theta}{\theta} E_{S}=w_{N} H_{N}\left(N_{N}-\int_{z_{N}^{-}}^{n_{N}} N_{N}^{z} d z\right)
$$




$$
\left(\frac{1-\theta}{\theta}+1\right) \int_{z \bar{N}^{-}}^{n_{N}} w_{N} H_{N} N_{N}^{z} d z+\frac{1-\theta}{\theta} E_{S}=w_{N} H_{N} N_{N}
$$

from which we obtain

$$
\begin{gathered}
\frac{1}{\theta} \int_{z-i}^{n_{N}} w_{N} H_{N} N_{N}^{z} d z=w_{N} H_{N} H_{N}-\frac{1-\theta}{\theta} E_{S} \\
\Rightarrow \int_{z_{N}^{-}}^{n_{N}} w_{N} H_{N} N_{N}^{z} d z=\theta w_{N} H_{N} N_{N}-(1-\theta) E_{S}
\end{gathered}
$$

Once again, from the labour market equilibrium in the north, we can replace the LHS of this equation to write

$$
w_{N} H_{N}\left(N_{N}-N_{N}^{R}\right)=\theta w_{N} H_{N} N_{N}-(1-\theta) E_{S}
$$

which can be written

$$
\begin{gathered}
w_{N} H_{N} N_{N}-\theta w_{N} H_{N} N_{N}+(1-\theta) E_{S}=w_{N} H_{N} N_{N}^{R} \\
\Rightarrow(1-\theta) w_{N} H_{N} N_{N}+(1-\theta) E_{S}=w_{N} H_{N} N_{N}^{R}
\end{gathered}
$$

Taking northern and southern income together as $E_{w}$, we obtain the allocation of total labour in the integrated equilibrium to northern $R \& D$.

$$
(1-\theta) E_{W}=w_{N} H_{N} N_{N}^{R}
$$

and if $w_{N}$ and $H_{N}$ are set equal to one, then equation (9.52) can be written

$$
(1-\theta) E_{W}=N_{N}^{R}
$$

Thus a constant rate $(1-\theta)$, of world labour is allocated to the R\&D sector in the north in the integrated equilibrium. From this allocation, we can now calculate the trade equilibrium. Taking the two extremes of factor price equalization, i.e. 
$\frac{w_{s}}{w_{N}}=1$

and if all labour in the north were allocated only to $R \& D$, i.e. perfect specialization:

$$
N_{N}^{R}=N_{N}
$$

we can draw

Figure 9.1. Labour and Income Constraints

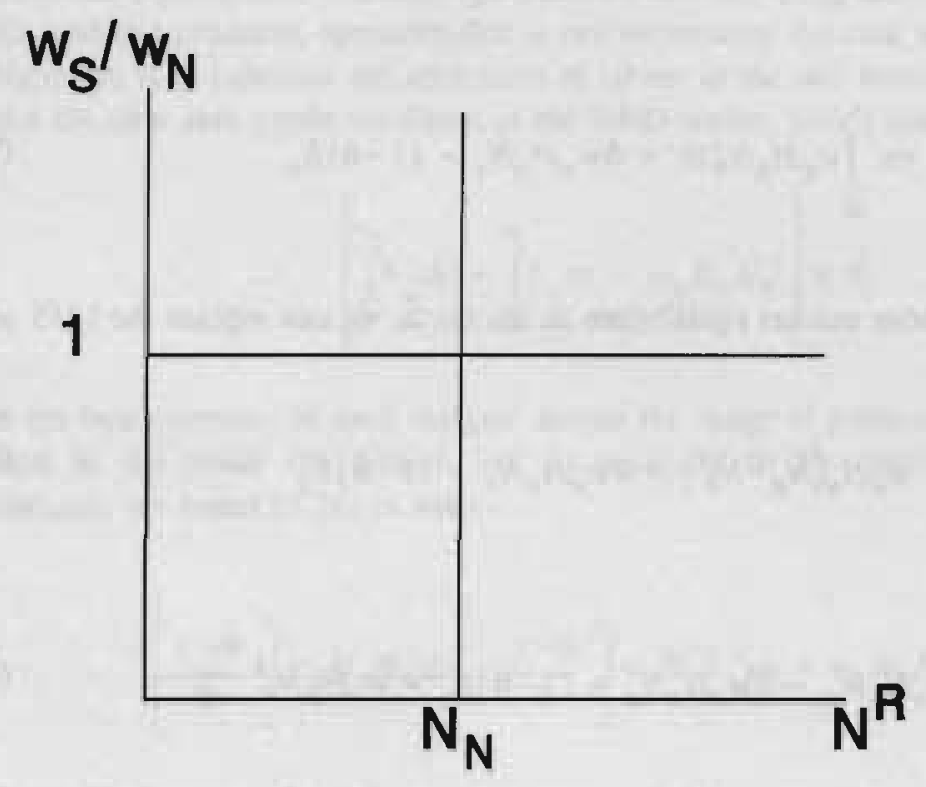

and inserting the labour allocation from the integrated equilibrium gives the three equilibria shown in figure 9.2. below which can be derived from equation (9.51) where $E_{N}=w_{N} N_{N}$ and $E_{S}=w_{S} N_{S}$

$$
(1-\theta)\left[w_{N} H_{N} N_{N}+w_{S} H_{s} N_{s}\right]=w_{N} H_{N} N_{N}^{R}
$$

Dividing both sides by $w_{N}$ we write

$$
(1-\theta)\left[H_{N} N_{N}+\frac{w_{s} H_{s} N_{s}}{w_{N}}\right]=N_{N}^{R} H_{N}
$$




$$
\frac{w_{S}}{w_{N}}=\left[\frac{N_{N}^{R}}{(1-\theta) N_{S}}-\frac{N_{N}}{N_{S}}\right] \frac{H_{N}}{H_{S}}
$$

(9.56) is the positively sloped equation drawn in figure 9.2 below. Putting $N^{R}=N_{N}$ equation (9.56) can be written

$$
\frac{w_{s}}{w_{N}}=\frac{\theta N_{N}}{(1-\theta) N_{s}} \frac{H_{N}}{H_{S}}
$$

Figure 9.2. The Trade and Integrated Equilibria

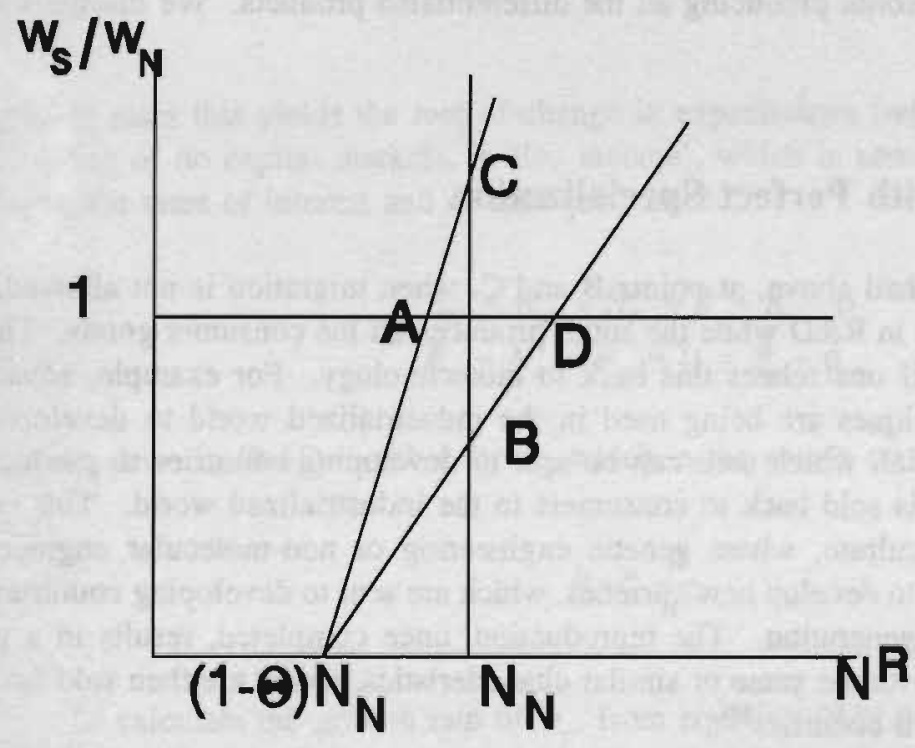

There are four equilibria in this case, A, B, C and D. At point A and D, there is factor price equalization in an integrated equilibrium. In $A$, north does both R\&D and production. In $D$, north hires labour from the south to do only $R \& D$. Without labour migration, there are only trading equilibria at points $\mathrm{B}$ and $\mathrm{C}$. At point $\mathrm{B}$ there is complete specialization, with north doing all the R\&D and the south producing all the differentiated products. The equilibrium at point $\mathrm{B}$ will be discussed in more detail in the next section.

Equilibrium $\mathrm{C}$ is a special situation, where by looking at the graph one sees that at point $C w_{S} / w_{N}>1$, implying that southern income is higher than northern. In this case, the 
south is becoming richer by producing the differentiated good, rather than through innovation, which is an interesting result because it is contrary to all growth theoretic and policy arguments in favour of investment in R\&D to enable a country to encourage innovation and welfare.

Equilibrium $\mathrm{C}$ may be of interest when considering a narrow wage gap. It is rather implausible, intuitively, that in the north-south context that has been discussed in this model, that the south will have higher wages relative to the north. However, in the case of northnorth trade, i.e. where there is comparatively less of an income difference between the two regions, this may be a possible conclusion. For example, a country may become more rich by allocating resources to a sector where it has strong demand than in a sector such as R\&D. Within the framework of this model then, the north would invest in R\&D whereas, the sector in the country with higher relative wages may become richer by investing in production rather than in R\&D. Thus the equilibrium wage levels in this case may be demand determined in the sense that $\frac{\theta}{1-\theta}$ may be higher than relative labour supply, $N_{S} H_{S} / N_{N} H_{N}$ in (9.57).

The integrated equilibria at $\mathrm{A}$ and $\mathrm{D}$ are analogous to the closed economy case, since labour migration is allowed in these cases. Thus, the most interesting case is the equilibrium at point B where migration does not occur and there is perfect specialization with the north doing only R\&D and the south producing all the differentiated products. We discuss this in the next section.

\subsection{Equilibrium with Perfect Specialization}

Thus, as we have established above, at points $\mathrm{B}$ and $\mathrm{C}$, when migration is not allowed, the north perfectly specializes in $R \& D$ while the south produces all the consumer goods. This is not an unlikely situation if one relates this back to biotechnology. For example, advanced genetic engineering techniques are being used in the industrialized world to develop new products or genetic material, which then can be sent to developing countries to produce or reproduce, which in turn is sold back to consumers in the industrialized world. This is the case for instance in agriculture, where genetic engineering or non-molecular engineering techniques are being used to develop new varieties, which are sent to developing countries for reproduction and mass regeneration. The reproduction, once completed, results in a great many plants or plantlets with the same or similar characteristics, which are then sold back to consumers in industrialized countries ${ }^{173}$.

To take this one step further, and to bring it in line with the model described here, southern producers would be able to license new products which are patented in the north to produce and export these products back. This would be the case if the protection of

173 The reason for this particular pattern of trade which is taking place between a number of countries (this particular example is from an Indian firm which specializes primarily in tissue culture, but whose techniques increasingly revolve around these activities), appears to be primarily related to lower wages and lower marginal costs of production. The scientific knowledge and capability required for such activities however are also important and this has important policy considerations for capability building which we will expand upon below. 
intellectual property rights is complete and enforced, as is assumed in the model. However, though this is not at present the case, there is considerable evidence which points to a strengthening of intellectual property rights and this may become reality in the near future. Here a word of caution is perhaps appropriate, since it is not clear from the evidence we have, that the innovations are only licensed to a producer in the south, and not to other competitors in the north as well.

As in the case of the closed model, we calculate the fixed cost and its growth rate. The first order conditions from consumer optimization (9.13) and (9.14), can be written as

$$
\frac{e^{-\rho(\tau-t)}}{u} \beta[.]^{\beta-1} \theta \int_{z_{s}^{-}}^{n}\left(q_{z_{i}} e^{\alpha z}\right)^{\theta}=\lambda e^{-R(\tau-t)} \int_{z_{i}^{-}}^{n} p_{z_{i}} q_{z} d z \quad i=N, S
$$

which after cancellation can be written

$$
\beta e^{-\rho(\tau-t)} \theta=\lambda(t) e^{-R(\tau-t)} \int_{z^{-}}^{n} p_{z_{1}} q_{z} d z \quad i=N, S
$$

In growth rates this yields the rate of change in expenditures (which in this case, under the assumption of no capital markets, is also income), which is zero, and equals the difference between the rates of interest and of time preference:

$$
\begin{aligned}
& \hat{E}_{N}=\hat{w}_{N}+\hat{N}_{N}=0=\dot{R}-\rho \\
& \hat{E}_{s}=\hat{N}_{s}+\hat{w}_{s}=0=\dot{R}-\rho
\end{aligned}
$$

We insert these in (9.41) to solve for $b_{n}$ which in the steady state is

$$
b_{n}=\frac{\rho}{n^{5}}
$$

To calculate the growth rate of $b_{z}$, from equation (9.9) or (9.10) and the zero profit condition of the firm (9.26), we calculate the relationship between $b_{i}$ and $b_{j}$ where $i$ and $j$ are variants selected by the household. From equation (9.9) and (9.10) above, the relationship between relative quantities of the two variants which are consumed in both countries, is the same for both regions. Thus inserting relative quantities from (9.26) and relative prices from $(9.25)$ into $(9.9)$ or $(9.10)$ yields 


$$
\frac{b_{i}}{b_{j}}=\left[\frac{j}{i}\right]^{\theta-1} \cdot\left[\frac{e^{\alpha j}}{e^{\alpha i}}\right]^{\theta}
$$

and

$$
\frac{b_{i}}{b_{j}}=\left[\frac{j e^{\alpha j}}{i e^{\alpha i}}\right]^{\theta}
$$

Hence, we conclude that $b_{i}$ and $b_{j}$ grow at equal rates because of $(9.26)$ and at the same rate as $q_{n}$ and $q_{z}$ because of (9.16), at the same rate as $N_{z}$. We conclude that

$$
\hat{b}_{n}=\hat{q}_{n}=\hat{b}_{z}=\hat{q}_{z}=\hat{N}_{N}
$$

where

$$
\hat{b}_{n}=\hat{b}_{z}=-\delta n^{\delta-1} N_{N}=\left|\begin{array}{ccc}
0 & \text { for } & \delta=0 \\
-N_{N} & \delta=1
\end{array}\right|
$$

This result is similar to that obtained in the closed economy model under the assumption of no capital markets and strong learning effects. The major difference between the closed and open economy models is in the amount of labour allocated to production. In the case of the closed economy model, $(1-\theta) N$ was allocated to the R\&D sector, whereas in the open economy case, this is $N_{N}$. The absolute size of labour allocated to R\&D is therefore greater in the trade equilibrium with complete specialization, than in the closed economy case. This implies that the rate of innovation will be faster but lower (higher) than in the integrated equilibrium, if the economy is in equilibrium $B$ (C) because the corresponding integrated equilibria is $\mathrm{D}(\mathrm{A})$ with $w_{s} / w_{N}<(>) 0$.

What remains now, is to describe the two differential equations which determine variety in the economy. From (9.57) we can calculate

$$
(1-\theta) w_{s} N_{s}=\theta w_{N} N_{N}
$$

implying that

$$
w_{s} N_{s}=\theta E_{w}
$$

and since labour allocation in the south is 


$$
\int_{z^{-}}^{n} w_{s} H N^{z} d z=w_{s} N_{s}=\theta E_{w}
$$

From prices and the zero profit condition in the differentiated sector $(9.28)$ we calculate

$$
\theta E_{W}=\left(\frac{\theta}{1-\theta}\right)_{z}^{n} \int_{z} b_{z} d z
$$

Inserting equation (9.67) into (9.68) and differentiating with respect to time yields

$$
\frac{1}{\theta}\left(\dot{w}_{s} N_{s}+w_{s} \dot{N}_{s}\right)=\dot{E}_{W}=\frac{1}{1-\theta}\left[\int_{z^{-}}^{n} \dot{b}_{z} d z+\left(b_{n} \dot{n}-b_{z} \dot{z}^{-}\right)\right]
$$

Dividing both sides by $\frac{1}{\theta} w_{s} N_{s}$

$$
\hat{w}_{s}+\hat{N}_{s}=\frac{\theta \dot{E}_{w}}{w_{s} N_{s}}=\frac{\theta}{(1-\theta) w_{s} N_{s}}\left[\int_{z^{-}}^{n} \dot{b}_{z} d z+\left(b_{n} \hat{n}-b_{z^{-}} \dot{z}^{-}\right)\right]
$$

Dividing and multiplying by $b_{z}$

$$
\hat{w}_{s}+\hat{N}_{s}=\frac{\theta \dot{E}_{W}}{w_{s} N_{s}}=\frac{\theta}{(1-\theta) w_{s} N_{s}}\left[\hat{b}_{z} \int_{z^{-}}^{n} b_{z} d z+\left(b_{n} \dot{n}-b_{z}-\dot{z}^{-}\right)\right]
$$

because of (9.63), $\hat{b}_{z}$ is constant and can therefore be taken before the integral. From equations (9.28) above, we insert for $\int_{z^{-}}^{n} b_{z} d z$ and write

$$
\hat{w}_{s}+\hat{N}_{s}=\frac{\theta \dot{E}_{W}}{w_{s} N_{s}}=\left(\frac{\theta}{1-\theta}\right) \frac{1}{w_{s} N_{s}}\left[\hat{b}_{z} N_{s} w_{s}\left(\frac{1-\theta}{\theta}\right) d z+b_{n} \dot{n}-b_{z} \dot{z}^{-}\right]
$$

Since the growth rates of southern wages and labour are assumed to be zero, we can now solve for $\dot{z}^{-}$ 


$$
\begin{aligned}
b_{z} \dot{z}^{-}=\left(\frac{1-\theta}{\theta}\right) w_{s} N_{s} \hat{b}_{z}+b_{n} \dot{n} \\
\Rightarrow \dot{z}^{-}=\frac{\left(\frac{1-\theta}{\theta}\right) w_{s} N_{s} \hat{b}_{z}+b_{n} \dot{n}}{b_{z^{-}}}
\end{aligned}
$$

In equation (9.75), we insert values for $\hat{b}_{z}=-\hat{n} \delta=-\delta n^{\delta-} N_{N}$ from (9.65) and we use $i$ equal to $z^{-}$and $j$ equal to $n$ in (9.62) to replace $b_{z^{-}}$. and we insert $b_{n}=\rho / n^{\delta}$ from (9.61) above and use (9.57):

$$
\dot{z}^{-}=\frac{w_{N} N_{N}(-\delta \hat{n})+\rho N_{N}}{\frac{\rho}{n^{\delta}}\left[\left(\frac{n}{z^{-}}\right) e^{\alpha\left(n-z^{\prime}\right)}\right]^{\frac{\theta}{\theta-1}}}=N_{N}(\rho-\delta \hat{n})\left[\frac{n}{z^{-}} e^{\alpha}\left(n-z^{-}\right)\right]^{\frac{\theta}{1-\theta}}
$$

This is the general equation for $z^{-}$. As in the case of the closed economy, we now have two differential equations, one in $n$ which describes the change in new products and the other in $z^{-}$ which describes the change in old products:

$$
\begin{gathered}
\dot{n}=n^{\delta} N_{N} \\
\dot{z}^{-}=N_{N}(\rho-\delta \hat{n})\left[\frac{n}{z^{-}} e^{\alpha(n-z)}\right]^{\theta}
\end{gathered}
$$

A comparison of these two differential equations shows that learning has a positive influence on both. However, the size of northern labour also has an influence on the differential equation for older varieties.

If the net effect on $\dot{z}^{-}$is stronger in the negative term i.e., $\rho<\delta \hat{n}$, then, as in the closed economy case, the movement of the differential equation will be negative, implying that old products are reselected and variety is growing. This is because the fixed cost is falling (and its level rho, is small), and since $\hat{b}_{z}=\hat{q}_{z}$, this implies that the quantity of goods produced in equilibrium is also declining and consumers can spend more of their budgets on consuming variety. The opposite will hold in the case of $\rho>\delta \hat{n}$ and if rho is large with the result that variety will decline or may remain constant for some period, as in the last Chapter, before declining. Thus the net result is the same as in the closed economy case except that the rate of innovation and of older varieties dropping out or being added, is faster because $N_{N}$ in (9.77) was $(1-\theta) N_{N}$ in the closed economy case.

In previous trade models such as Grossman and Helpman (1991c), an increase in the resource base results in an increase in innovation, as more resources can be devoted to R\&D. Since the size of the resource base in the north determines the rate of innovation in this case, 
the model here also has the same result. However, the impact on total variety depends upon the rate of time preference and the growth rate of new varieties.

We can now look at the impact of greater innovation on the terms of trade. We describe the terms of trade in terms of relative prices, i.e.,

$$
\frac{b_{n}}{p_{z}}=\frac{\rho / n^{\delta}}{w_{s} / \theta z}=\frac{\rho}{n^{\delta}} \cdot \frac{N_{s}(1-\theta) z}{w_{N} N_{N}}
$$

which implies that an increase in innovation in the case of learning, would drive the terms of trade of the north down and an increase in the size of the south will drive the terms of trade of the north up. If we set $N_{N}$ equal to 1 , then an increase in the rate of time preference $\rho$, will also imply an improvement in northern terms of trade. A rise in $\theta$, i.e. the constant elasticity of demand for quantity, will result in a decline in the northern terms of trade. In the case of learning, an increase in the parameter delta, will result in a decline in northern terms of trade for any given $n$.

The movement of the $\dot{z}^{-}$curve can therefore be either negative if $\rho-N_{N}<0$, and positive if $\rho-N_{N}>0$ as in the case of the simulation results obtained from the case of no capital markets and spillovers in the closed economy model. Thus variety can either increase, remain constant or decrease, depending upon the size of the rate of time preference.

In the case of $\rho-\delta \hat{n}>0$ where the total amount of variety first increases, and eventually declines after some time, the implications for southern products, especially traditional products (here represented by the differential equation in $z^{-}$), is that their share is increasing or remains constant for a period of time, before these products are completely driven out of the market by new varieties. This would therefore lend support to the earlier observation made in Chapter 5 above, that developing countries are losing market share as a result of their traditional products being driven out of the market by biotechnology R\&D in industrialized countries, which targets traditional products. The examples used included sugar, vanilla and cocoa among others.

In the case of no learning also, the size of the north drives both differential equations. As in the case of the closed economy model in Chapter 8 above, here too, both equations will move positively. However, it is unclear from the information contained in these equations, what the speed of the movement will be. Thus, it is difficult to say whether the number of varieties will increase, remain constant or decline. On the basis of experience from the previous chapter, we would guess that the exponential term will drive $z^{-}$quickly towards $n$. The implications once again for developing countries would be negative, especially for producers of traditional products. If innovation completely drives out traditional products, as appears to be the case with no learning in innovation, the share of developing country traditional products in international trade would again decline. Thus the dynamics of the model lend strong support to the idea put forth by empirical studies, that the developing country share of international trade is declining.

To summarize then, there are four equilibria, two integrated and two perfect specialization possibilities without migration. In the equilibrium discussed above, there is complete specialization with the north doing all the R\&D and the south producing the entire range of differentiated products. Innovation in this case is higher $\left(n N_{N}\right.$ in the case of 
learning), than in the closed economy case, because all labour is now devoted to innovation in the north rather than a percentage $((1-\theta))$, of it. The relationship between the innovation rate and the rate of rejection or reselection of old varieties is therefore similar to the closed economy model.

However, referring back to figure 9.2 above, the integrated equilibrium $\mathrm{D}$, appears to have large gains from trade. From this equilibrium it is evident that if resources could be moved between countries, the resources devoted to innovation would be greater than $N_{N}$, $\left((1-\theta) E_{w}\right.$ from equation 9.53 above), and the rate of innovation would be even higher in an integrated equilibrium than in the trade equilibrium, implying also that consumers would be able to buy higher qualities and the southern wage would equal the northern wage, even though the south is technologically backward.

\section{Conclusions}

In the last two chapters, we have developed a closed economy model of endogenous growth and an open economy growth model in this Chapter, based largely on the sectoral framework developed in the new growth models, which show interesting similarities and dissimilarities with previous models of the same genre.

Thus the closed economy growth model is characterised by regulated monopoly in innovation, and monopolistic competition in the production sector due to producers licensing innovations from the R\&D sector. Innovation takes place in the form of higher quality products. Products are patented indefinitely by innovators and then licensed out. The assumption of free entry in the initial periods, together with a legal framework or regulation in the R\&D sector ensures that there are no monopoly profits. However, each product is only licensed to one producer, giving that producer monopoly rights over its production.

The main contribution of this model is in the use of a utility function which combines both quality improvements as well as consumer preferences for variety in a very simple manner. This is perhaps a more realistic approach, given what is observed from industrial and agricultural biotechnology sectors; secondly, the model also produces a variety of results, ranging from the case of perfect or creative destruction, seen in the quality ladders models of Grossman and Helpman (1991a Ch4, and 1991b and c) and Aghion and Howitt (1992), and the result obtained by Flam and Helpman (1987) and by Young (1993) of a constant range, to that of an increasing range as discussed by Young (1991).

In the trade model, we extend this analysis further to explain international trade between two regions, one less technologically advanced than the other. We rule out imitation by the less technologically advanced region (called south), because of strict enforcement of intellectual property rights, arguing that this appears to be the general trend in the real world at present. Extending the closed economy model in this manner, results in complete specialization, with the north, which has a comparative advantage in R\&D because it is technologically more advanced, doing all the $R \& D$, while the south licenses innovations from the north and supplies both national and international markets with the differentiated product.

Although the dynamics with respect to quality and variety remain the same as in the closed economy case under the assumption of no capital markets, the trade model shows interesting results from interactions between north and south in terms of rates of innovation. 
For example, an increase in the rate of innovation, increases the range of new patents transferred to the south. An increase in the rate of innovation however, will lower northern terms of trade. A decline in the north's terms of trade however, will also imply a lower fixed cost of production for southern producers. If learning effects are present, and if $\rho<-\delta \hat{n}$, then variety will increase, while if $\rho>-\delta \hat{n}$, then variety can temporarily either increase, decrease or stay constant.

Another important conclusion we drew relates to the share of developing country exports in international trade. Although in the model, developing countries are the only producers of differentiated products, we found that both under conditions of learning $(\rho-\delta \hat{n}>0)$, and no learning in innovation, developing countries will lose market share in traditional products. This supports the earlier observation made that R\&D by biotechnology companies in industrialized countries appears to be targeting and displacing traditional products which are produced in developing countries, resulting in a decline in their market share.

Thus the model in general demonstrates a number of possible outcomes for quality and variety and has interesting implications with regard to the impact of innovation on economic welfare in an integrated equilibrium.

In the next chapter which is also the concluding chapter, we draw some policy conclusions and summarise the results as they relate to economic growth and development especially with respect to biotechnology. The framework chosen of quantity, quality and variety will serve as a background as with the rest of the thesis until now. 

"The selling and buying are over. All the dues on both sides have been gathered in, and it is time for me to go home....Do not fear, I have still something left"....R. Tagore

"Genes are the primary policy makers; brains are the executives"...R. Powers

\section{Introduction}

This thesis was presented in three broad Parts to examine the nature of innovation and industrial and agricultural production in biotechnology and to formally present some of these observations in an endogenous growth and trade model, which was developed within the differentiated product framework of the new growth and trade literature.

Part I examined patterns of innovation, institutional structures and production in biotechnology based industries, both in industrialized and in developing countries. In Part II, we examined the basic characteristics of the new growth and trade literature and its relation to innovation, and economic growth, culminating in the development of a growth and trade model in Part III. The common theme within which context each section was placed, was that of the impact of quality and productivity improving product innovations through biotechnology, on the total variety of products available in the economy. In this final chapter, we continue to work within this framework to summarise and draw some policy conclusions from the observations made above.

The main objective of the thesis was to examine the patterns of innovation, production and economic growth which are characterised by biotechnology, and to draw some parallels and contrasts between the experiences of industrialized and developing countries. In section 1 below, an attempt is made to synthesize some of the observations as they relate to technological and organisational structures, and how the direction and intensity of innovation relates to these in turn. The identification of patterns of innovation is crucial to describing the interactions between different agents in the economy, and how those interactions contribute to technological change.

The second section examines the structure of recent models of growth and trade which together with observations about patterns of innovation in biotechnology, provided the framework within which to develop the economic model presented in chapters 8 and 9. Finally, we return to the three themes of quantity, quality and variety and draw some tentative policy conclusions with respect to the future development of biotechnology, both in industrialized and in developing countries.

\subsection{Some Stylised Facts about the Nature of Biotechnology R\&D}

In Part I, the question of patterns of innovation and the general institutional and organisational structure of biotechnology was addressed. Although specialisation across countries tends to 
be different, with biotechnology playing an important role in the pharmaceutical sector in many industrialized countries whereas it is more predominant in agriculture in developing countries, there are a number of similarities in research and production structures and frameworks.

The R\&D structure in general appears to be dominated by two types of institutions or firms: (i) Firstly, basic research tends to be carried out largely in the public domain, by public sector institutions and universities, and although this is changing in many industrialized countries, modern biotechnology in the 1960s and especially 1970s owes its origins to basic research breakthroughs made at universities in Europe and in the USA.

These institutions however, tend to be weak at performing more applied R\&D of a downstream nature, for a number of reasons, the most important of which are perhaps a lack of knowledge about market structures and marketing techniques and the incentive structure which is different in academic institutions and in private sector firms.

Downstream research and development, for these reasons then tends to be dominated by the private sector, both in industrialized and increasingly in developing countries, although the absence of capital markets in the latter has made downstream development all the more difficult, even for the private sector.

(ii) The second sector therefore tends to be mostly dominated by private companies, although again, in developing countries this is less the case. The applied research done by these private agents is more suited to particular market needs and niches than the broad framework within which generic research is done by universities. The proximity to the market and the presence of marketing and management skills is another reason for the greater success of the private sector in developing products for commercialization. The problems of small biotechnology companies demonstrated very well the need for these techniques. These companies have now tried to overcome these constraints by forming marketing and distribution alliances with a number of suppliers in different countries. There is also increasing evidence that there may be a tendency toward concentration as biotechnology, especially industrial biotechnology, tends to become better established. Although the evidence is relatively sketchy thus far ${ }^{174}$ (and more research on this subject may reveal more definite trends), if this were indeed the case, it would point toward a structure dominated by imperfectly competitive markets.

174 The entry of a large number of multinationals along with a decline in the number of small firms in the 1980 s and early 1990 s for example led many to conclude that this was a general trend toward concentration. Evidence of this however, is mixed, especially since by 1994, more and more small companies had become emerging and raising money through the stock market. In a number of cases also where there have been mergers or takeovers between large and small companies, the degree of control has been limited. For example, the most famous takeover, that of Genentech by Hoffman LaRoche has not led to Genentech being subsumed by LaRoche. Instead, Genentech remains relatively autonomous and has continued to be one of the more successful and competitive biotechnology companies. On the other hand, it is also clear that there is a rising degree of multinational investment in biotechnology and as product approval becomes more rapid by the government, investment in biotechnology by these companies is likely to increase. The initial cost of investing in biotechnology is also prohibitively high, and except for those countries where venture capital is available, most notably the US, (in Europe for example, the absence of a venture capital market has resulted in domination by the large companies), the biotechnology industry will tend to be dominated by multinationals who can afford the investment. 
Although these two sectors can be identified as separate entities, their interdependence is also strong. The dependence of the second sector on the first is evident in that without the initial innovations made through basic research, such as the discovery of the double helix structure of DNA by Watson and Crick in 1963 or the discovery of Monoclonal Antibodies and the gene splicing technique developed by Cohen and Boyer in the 1970s, applied research leading to commercial biotechnology would not be possible. The first sector however has also become dependant upon the second to provide research grants and in the American environment, to develop the new biotechnology firms.

The high initial costs for investing in biotechnology have been emphasized in the presence of imperfect capital markets. In many countries the lack of funding through the capital market infrastructure has been a barrier to the entry of small investors. Yet, it was the small investors who initially formed a bridge between basic and applied research. This is most evident in the case of the USA, where commercial biotechnology appears to have had a head start because of the presence of a venture capital market which was willing to fund the small biotechnology companies. A number of other countries in Europe, most notably the UK, have also tried to develop their venture capital markets to encourage the development of specialised companies, but with relatively less success than in the USA.

Evidence of bridging activities by these small companies can also be found in their links to the publicly funded research sector. The founding members of the first biotechnology firm, Genentech for example, were Robert Swanson, a venture capitalist and Herbert Boyer, a University of California Professor, who had along with Stanley Cohen demonstrated the rDNA splicing technique a few years earlier. Despite forming the company however, Boyer continued to maintain his position at the University and especially during the early years, when patents were not being granted to genetic engineering, Genentech's research team and facilities consisted of Boyer and two researchers, who used the facilities of the University ${ }^{175}$. Thus, even after the venture capital company had been formed, the linkages with the University remained strong.

Thus the structure of innovation in biotechnology in both industrialized and also to an increasing degree in developing countries, tends to exhibit a structure in which the public sector tends to dominate the early stages of $R \& D$, but increasingly innovation through patenting is taking place in the private domain. The formation of small biotechnology companies and the growing evidence of strategic marketing and research alliances, demonstrates the dominance of the private sector in production.

\subsection{Quantity, Quality and Variety: The Evidence Thus Far}

The framework used throughout the thesis was that of the impact of quality and quantity on variety. The framework was developed as a result of observations from modern biotechnology, where productivity improvements, i.e. an increase in quantity, vertical and horizontal improvements have had a direct impact on the total variety of products available in the economy. A number of examples have been used to demonstrate this, and because of the pervasive nature of biotechnology, it appears that it can both increase as well as decrease

175 See McKelvey (1994), Chapter 5. 
total variety either through productivity or quality improvements or through the production of an alternative product or process which adds to the total amount of variety in the economy.

The treatment of quantity, quality and variety in new growth and trade models which was examined in Part II above, showed also a number of alternative approaches and structures. In contrast to orthodox growth theory, "new" growth and trade models, especially since the 1980s differ in that they treat innovation in the form of the production of new differentiated products, rather than an increase in the quantity of existing products. One group of models looked at horizontal product innovation, i.e. the production of new goods which are simply substitutes for already existing products. Variety is usually modelled in the utility function, with the love of variety approach emphasizing consumer preferences for variety. In these models, because the new goods are imperfect substitutes for the old goods, it is implied by the specification of utility, that they do not displace the old goods at all. Thus the result often is an infinitely increasing variety of goods (given the budget constraint), all of which are imperfect substitutes for each other.

The second group of models, look specifically at quality improvements. In these models it is argued that innovation is not only horizontal, i.e. adding to the variety of products, but much of the world's innovations come in the form of quality improvements upon older products. Thus innovation is often vertical and this is modelled specifically in the utility or the production functions. Consumer preferences in turn are often modelled as desiring the highest quality adjusted for price. In these models, the result almost always is creative destruction, with the highest quality improvement always driving out any older variety because each innovation gives the innovator a nationwide or worldwide monopoly over that product. At the same time, each new innovation, because of its monopoly, drives out any previous monopolist by destroying his/her monopoly. Thus creative destruction always results in just one variety, usually the newest quality in the market.

There are however, a number of exceptions to these models and we have looked at a number of relevant examples. Here innovation is the result either of learning by doing or of human capital used as an input. They are distinct from the other quality models described above, because instead of just one variety present at all times, these models present a number of products of different qualities present in the economy at all times. The models by Young are especially interesting because the results show an increasing range of variety (1991) and a constant range of varieties in the 1993 paper.

The drawback of all these models is that they provide only single selection profiles with respect to the impact of innovation through increasing quality on older products and therefore the total amount of variety in the economy. Instead, what was needed from the viewpoint of biotechnology, was a formulation which would be able to express many of these options, depending upon cost dynamics and consumer preferences for quality and variety. The model described in chapters 8 and 9 provides an example of how this can be achieved. Instead of just one variety being present in the economy at each time, or instead of a constant or increasing range of varieties being present, alternatively, the model developed above provides a number of scenarios in which each of these situations is a special result, at least for some time periods. Through simulations we found conditions under which variety can either remain constant for a long period of time, or increase over time, or eventually collapse to just one variety as in the models of Aghion and Howitt and Grossman and Helpman described above. Thus, the model provides rich dynamics and a number of implications for the future development of industrial or agricultural biotechnology. 


\subsection{Policy Implications and Suggestions for Future Research}

An additional interesting feature of the model, especially for future research, is that of perfectly exploited learning opportunities over time. Thus each generation of producers benefits from sufficiently strong learning as in the case of (delta $=1$ ). The perfectly intertemporal exploitation implies that there is no underinvestment in R\&D and that a government subsidy to $R \& D$ should not encourage innovators to invest more because the rate of innovation is already at an optimal level, in the presence of such imperfections. The assumption of perfect learning mimics the fact that private knowledge of this nature has most likely also been an important source of technical change in modern biotechnology. In industrialized countries, this is most evident from the pharmaceutical sector where the most modern techniques are being used and evolving most rapidly. The presence of learning by doing would imply that those firms which are innovators today, would continue to innovate in the following periods, because of an accumulation of private knowledge. However, policy conclusions may change with every imperfection or sector added to the model. Allowing for monopoly profits in the R\&D sector may lead to underinvestment in this sector. This will be explored in future research.

Although patent data at present is insufficient to really measure the extent of such cumulative learning and innovation, figures 10.1 and 10.2 below, show some preliminary data for the five largest innovators among the specialized biotechnology companies. Despite a considerable amount of fluctuation, especially for patent applications (figure 10.1), the trend appears to be non-decreasing. Tables 10.1 and 10.2 in the text below give a numerical idea of this increasing trend. The figures on total patents granted to this group of biotechnology innovators is even more clear, as table 10.2 and figure 10.2 show. Thus, although incomplete, the figures and graphs below, give a rough confirmation of the important role played by learning for successive innovations.

Table 10.1. Patent Applications by NBTFs 1980-1991

\begin{tabular}{|l|l|l|l|l|l|l|l|l|l|}
\hline Company & 1981 & 1983 & 1984 & 1985 & 1987 & 1988 & 1989 & 1990 & 1991 \\
\hline Genentech & 9 & 13 & 25 & 21 & 16 & 22 & 17 & 18 & 20 \\
\hline Chiron & 0 & 2 & 15 & 17 & 6 & 23 & 15 & 20 & 27 \\
\hline Alza & 10 & 0 & 1 & 3 & 17 & 11 & 19 & 17 & 22 \\
\hline Celltech & 2 & 6 & 12 & 8 & 7 & 14 & 9 & 14 & 11 \\
\hline Amgen & 0 & 10 & 13 & 0 & 3 & 10 & 9 & 12 & 10 \\
\hline Total & 21 & 31 & 66 & 49 & 49 & 80 & 69 & 81 & 90 \\
\hline
\end{tabular}


Table 10.2. Patents Granted to NBTFs

1982-1991

\begin{tabular}{|l|l|l|l|l|l|l|l|l|l|}
\hline Company & 1983 & 1984 & 1985 & 1986 & 1987 & 1988 & 1989 & 1990 & 1991 \\
\hline Genentech & 0 & 0 & 0 & 0 & 4 & 3 & 13 & 6 & 9 \\
\hline Chiron & 0 & 0 & 0 & 0 & 0 & 2 & 2 & 5 & 11 \\
\hline Alza & 1 & 2 & 3 & 0 & 2 & 1 & 1 & 1 & 12 \\
\hline Celltech & 0 & 0 & 3 & 0 & 2 & 3 & 3 & 5 & 4 \\
\hline Amgen & 0 & 0 & 0 & 0 & 1 & 0 & 1 & 8 & 5 \\
\hline Total & 1 & 2 & 6 & 0 & 9 & 9 & 20 & 25 & 41 \\
\hline
\end{tabular}

Source: Compiled from European Patent Statistics (EPO, Munich, 1993)

A calculation of growth rates of patenting activities by these firms was also somewhat enlightening with regard to learning. The equation estimated was of the log linear form: $\ln \hat{n}=(\delta-1) \ln n+\ln N^{R^{*}}$ where $N^{R^{*}}$ is constant. Thus if delta is 1 there is perfect learning, the first term on the RHS should be zero, implying a constant slope equal to zero. If delta less than 1, i.e., there is weak learning, this slope should be declining, since the first term on the RHS is negative.

The results (tables 10.3 and 10.4 below) show that for all the companies, the slope for patents granted is negative, whereas for patent applications is positive, implying weak learning from the former set of statistics, and strong learning from the latter set.

The second set of statistics, that is, patent applications, may in fact be a better measure of learning, since they imply private knowledge gained from previous innovations, which is being used to generate the next set of innovations which are deemed patentable. The second reason is that of the lag associated with screening and granting of patents. The knowledge gained by the innovation when it is applied for may therefore be more useful for the company's future research activities, rather than when the patent is granted or rejected two years later. The low R squares obtained from the data on patents granted also indicates that these may not be good at explaining growth rates. This is also evident from the graphs presented in figures 10.6 to 10.10 , characterised by strong fluctuations in contrast to the figures on applications, which with the exception of Amgen (figure 10.5), show generally steady trends. Given the restrictive nature of the data set, it may be useful not only to obtain a longer time series but also to include employment statistics in the regressions. This may add to the explanatory value of the equations, since the value of $N^{R *}$ has been assumed to be constant thus far. In the case of patents granted, including employment statistics may not only raise the $\mathrm{R}$ squared, but also may change the constants, which are negative, another indication of the weakness of the data on patents granted. 
Table 10.3. Results from Log Linear Regressions: Patent Applications

\begin{tabular}{|l|l|l|l|l|}
\hline Company & Constant & Slope & R squared & DF \\
\hline Genentech & -0.31136 & 0.47976 & 0.989 & 9 \\
\hline Chiron & -0.102 & 0.3935 & 0.89 & 9 \\
\hline Alza & -0.027 & 0.365 & 0.96 & 9 \\
\hline Celltech & -0.419 & 0.533 & 0.84 & 9 \\
\hline Amgen & -0.002 & 0.357 & 0.998 & 9 \\
\hline
\end{tabular}

Table 10.4. Results from Log Linear Regressions: Patents Granted

\begin{tabular}{|l|l|l|l|l|}
\hline Company & Constant & Slope & R Squared & DF \\
\hline Genentech & -0.302 & -0.183 & 0.055 & 7 \\
\hline Chiron & -0.011 & -0.166 & 0.36 & 7 \\
\hline Alza & 0.025 & -0.117 & 0.67 & 7 \\
\hline Celltech & -0.194 & -1.15 & 0.51 & 7 \\
\hline Amgen & $8.717 \mathrm{E}-17$ & -2.15 & 1 & 7 \\
\hline
\end{tabular}

The relationship between $\ln \hat{n}$ and $\ln n$ is also summarized in figures 10.1 to 10.5 for patent applications (relating to the figures in tables 10.1 and 10.3 above), and in figures 10.6 to 10.10 for patents granted (relating to tables 10.2 and 10.4 above).

The figures show that especially in the case of applications for patents, (figures 10.1 to 10.5 above), the trend toward stability is much higher than in the case of patents granted. In the case of patents granted, the relationship between $\ln \hat{n}$ and $\ln n$ shows a more mixed record. Here the fluctuations are quite large, showing periods of no change followed by periods of rapid decline or rapid increases. As mentioned above, with respect to the regressions, these figures are probably less reliable than those on patent applications. This may also be due to the relatively small number of data points, presenting large fluctuations in the graphs.

Thus, as mentioned earlier, it would be instructive to obtain a larger time series, along with data on employment, in order to obtain anything conclusive about patterns of innovation and learning for these firms. 
Figure 10.1. Applications: Genentech

(1981-1991)

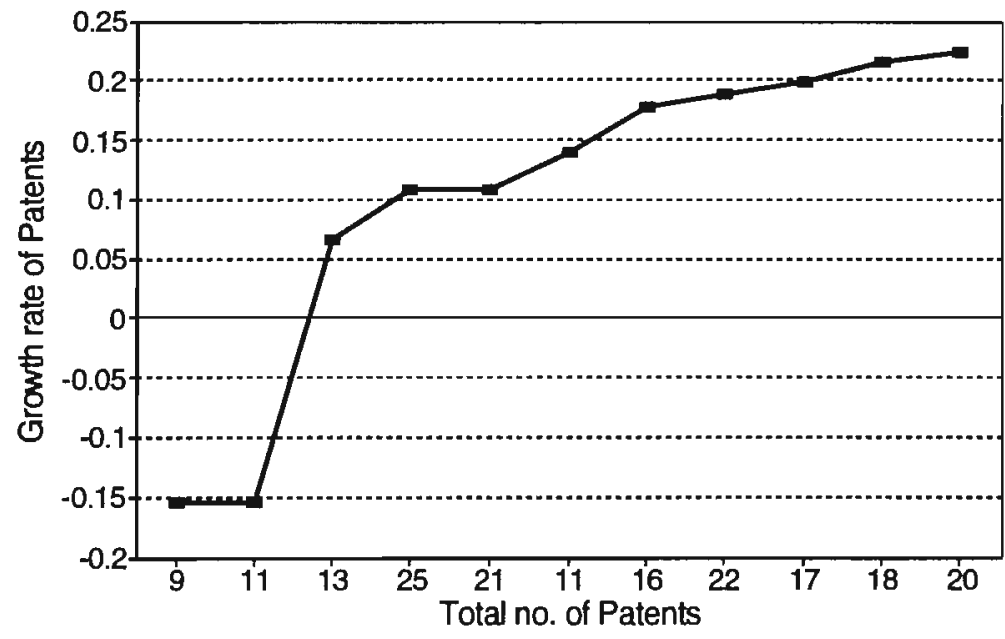

$\rightarrow$ Applications

Figure 10.2. Applications: Chiron (1981-1991)

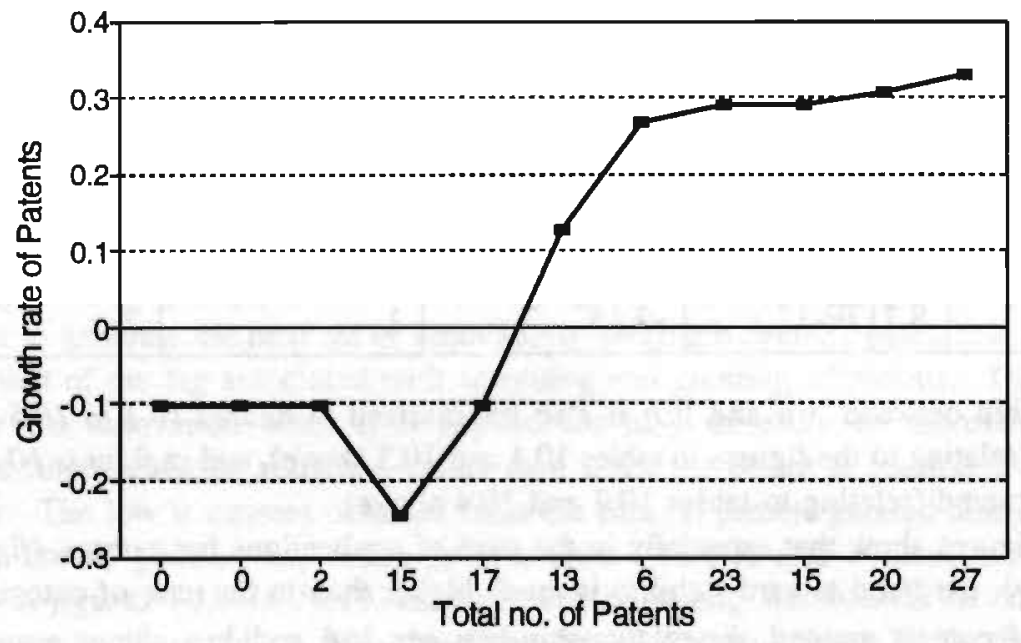

$\rightarrow$ Applications

In developing countries similarly, many of the simpler techniques which are being used for agriculture, are based on green revolution technologies from the 1970s. Many of these products and techniques were developed in institutions in developing countries, such as the National Agricultural Research Centres which were established during this period in many countries. 
Figure 10.3. Applications: Alza

(1981-1991)

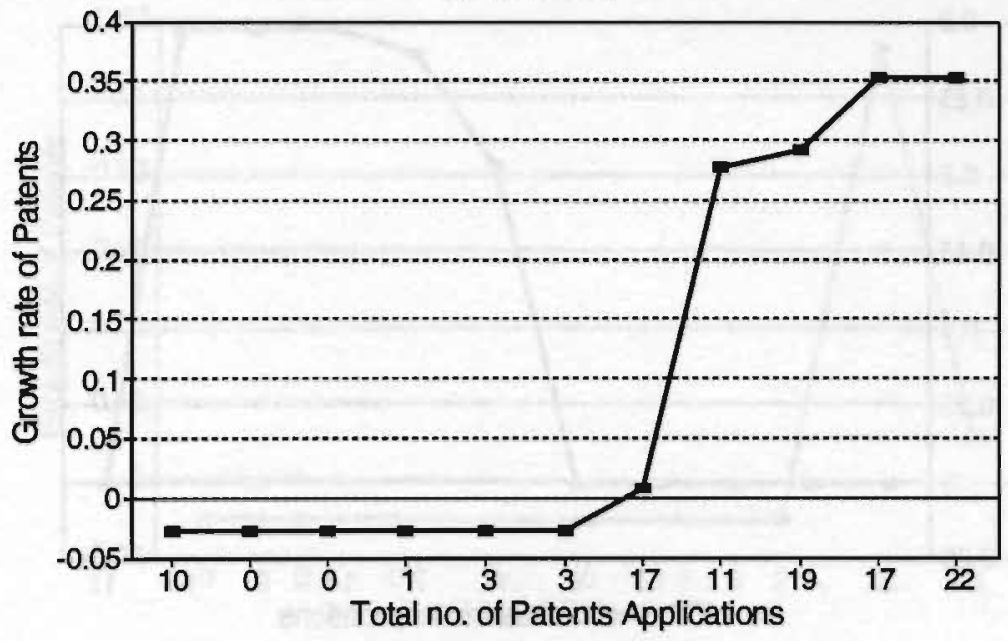

Applications

Figure 10.4. Applications: Celltech (1981-1991)

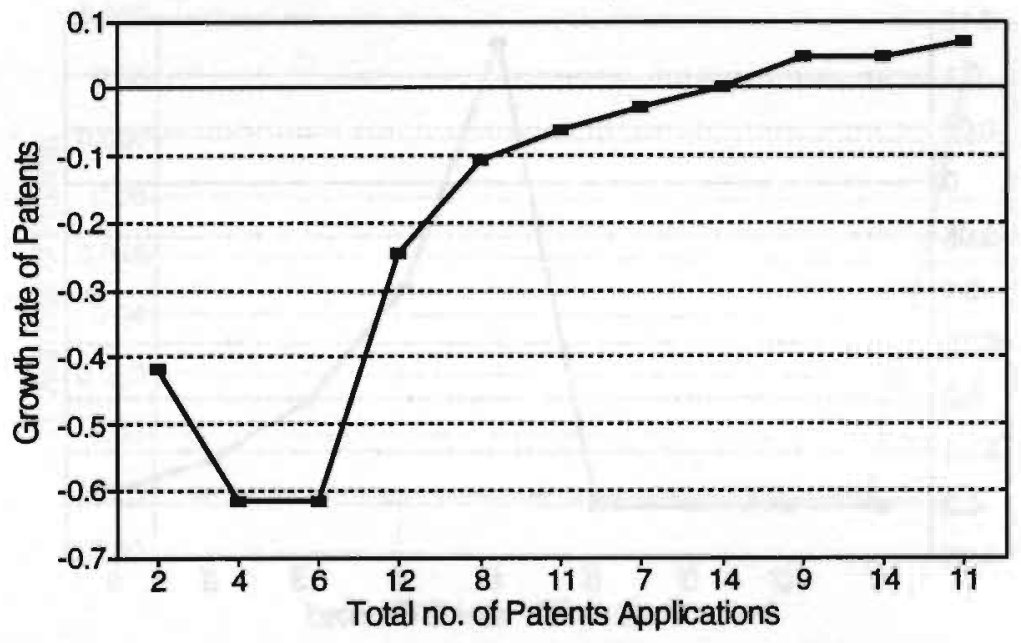

\section{- Applications}

Today's biotechnologies are being developed largely through the use of knowledge gained during the period of the green revolution, as is evident from dependence upon the R\&D infrastructure developed during this period, as well as the relationship between the simpler technologies in use in many developing countries today and their precursors from the green revolution. 
Figure 10.5. Applications: Amgen

(1981-1991)

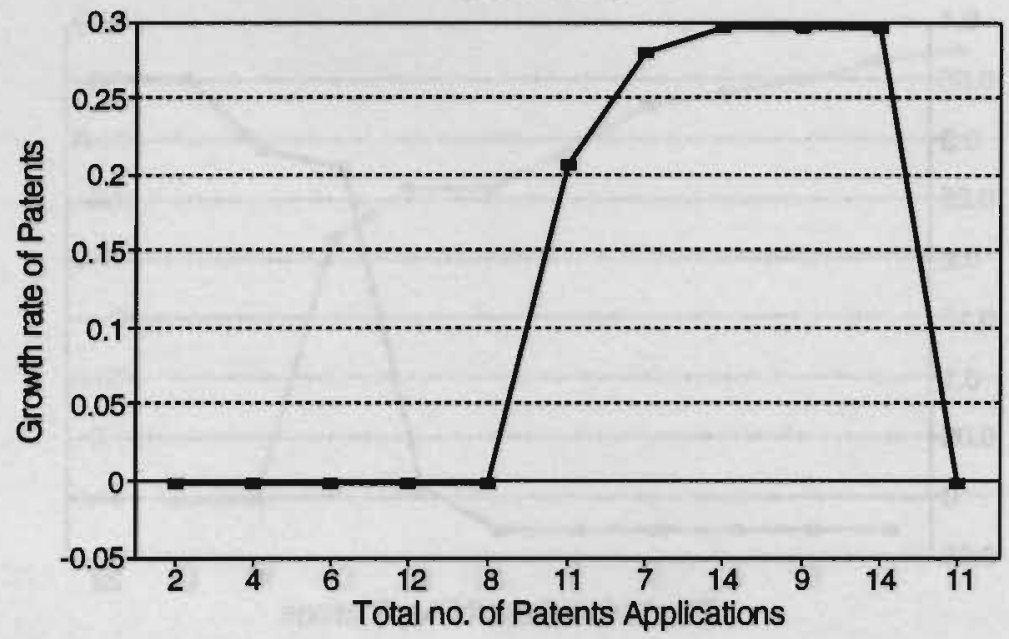

Applications

Figure 10.6. Patents Granted: Genentech

(1983-1991)

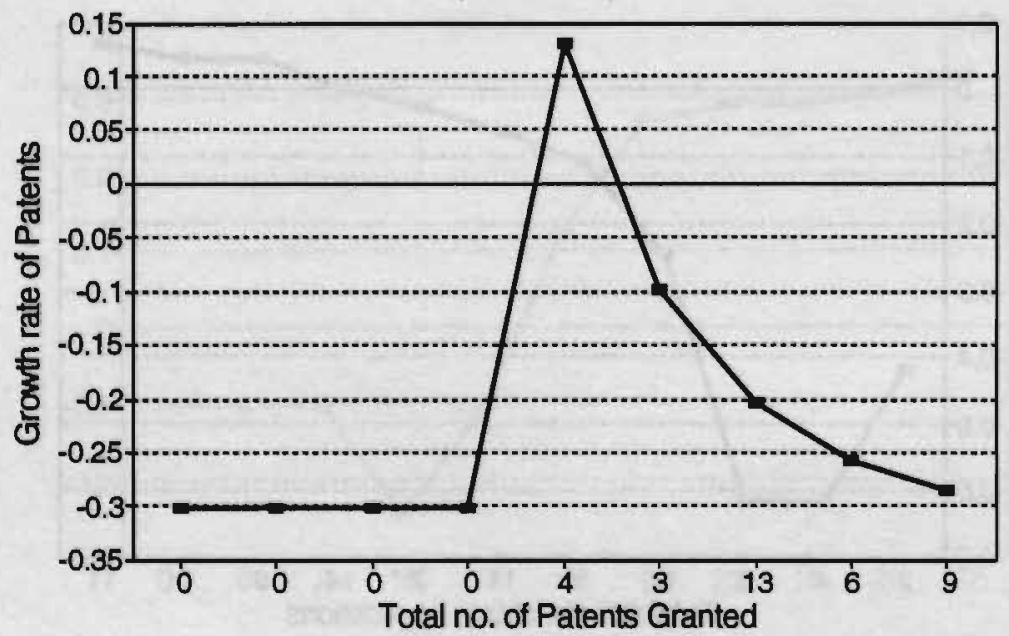

- Granted

Thus, learning has also contributed to the development of some of the breeding techniques present today in many developing countries and providing $R \& D$ subsidies to firms would encourage them to invest in these activities and to increase the rate of innovation. Whether or not this is optimal depends of course, on the precise way of modelling. 
Figure 10.7. Patents Granted: Chiron

(1983-1991)

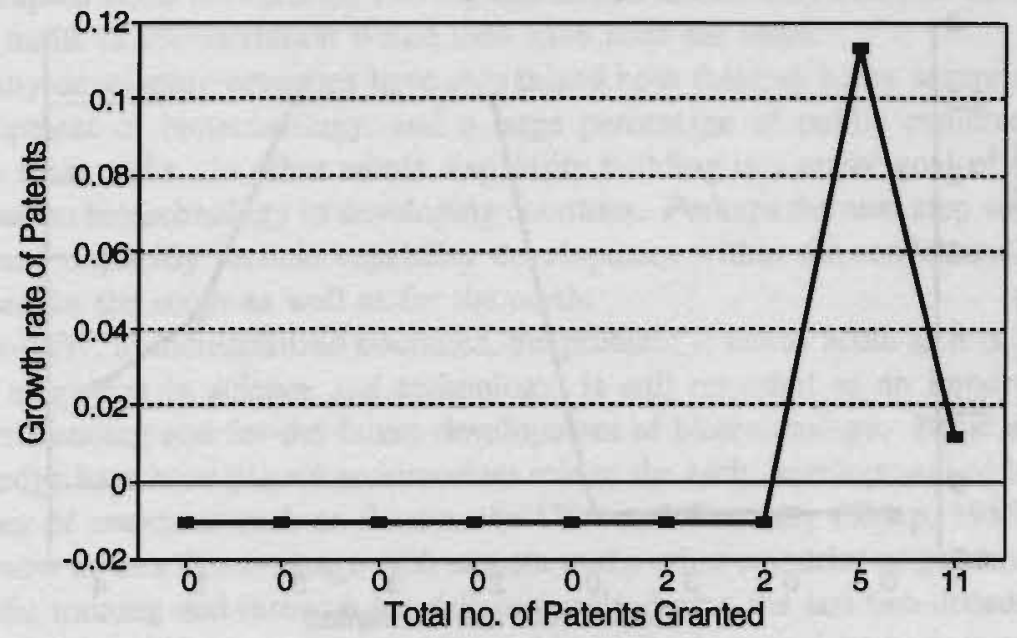

- Granted

Figure 10.8. Patents Granted: Alza (1983-1991)

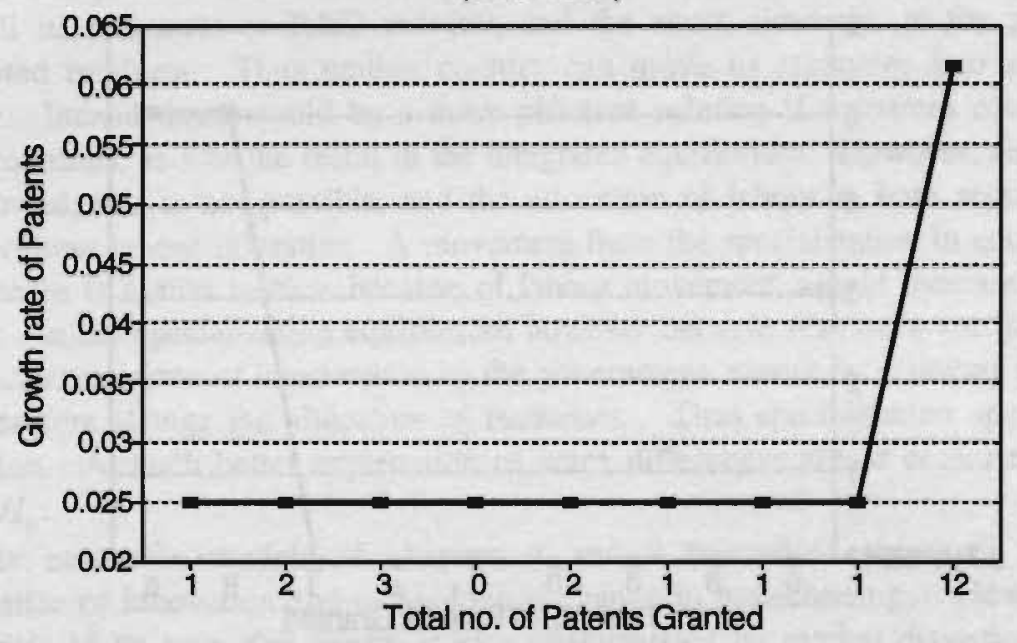

\section{- Granted}

Knowledge accumulation therefore is an area that the government can play a major role in to encourage rates of innovation and economic growth. This is a conclusion reached also from Chapters 3 and 4 where biotechnology policies in industrialized and developing countries were examined, at least with respect to efficient public institutions. The survey, although brief, on developing countries in chapter 3 above, has identified a number of constraints and also a number of examples of success. 


\section{Figure 10.9. Patents Granted: Celltech}

(1983-1991)

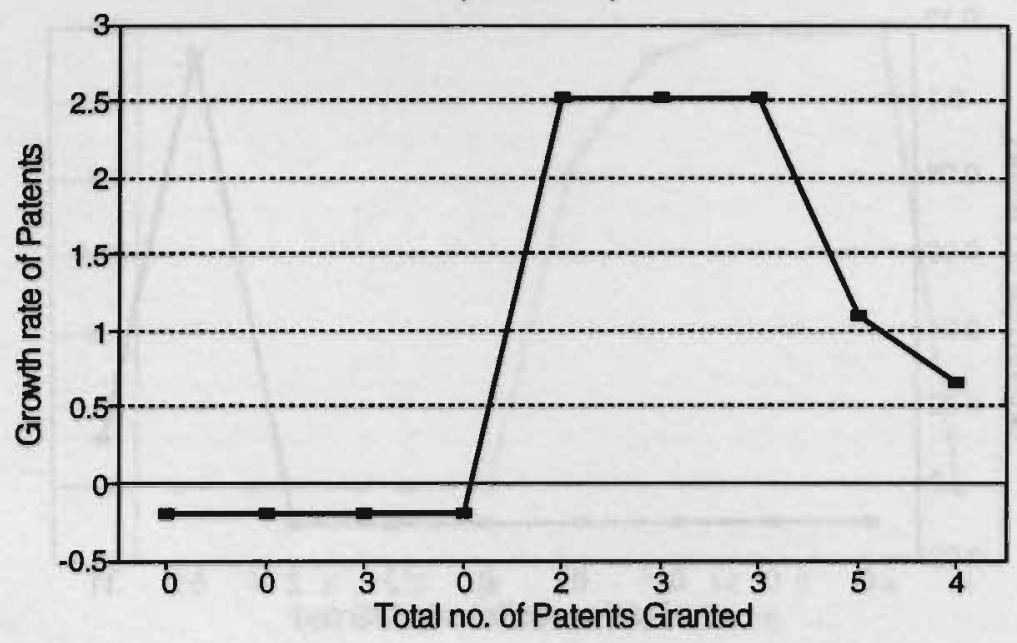

- Granted

Figure 10.10. Patents Granted: Amgen

(1983-1991)

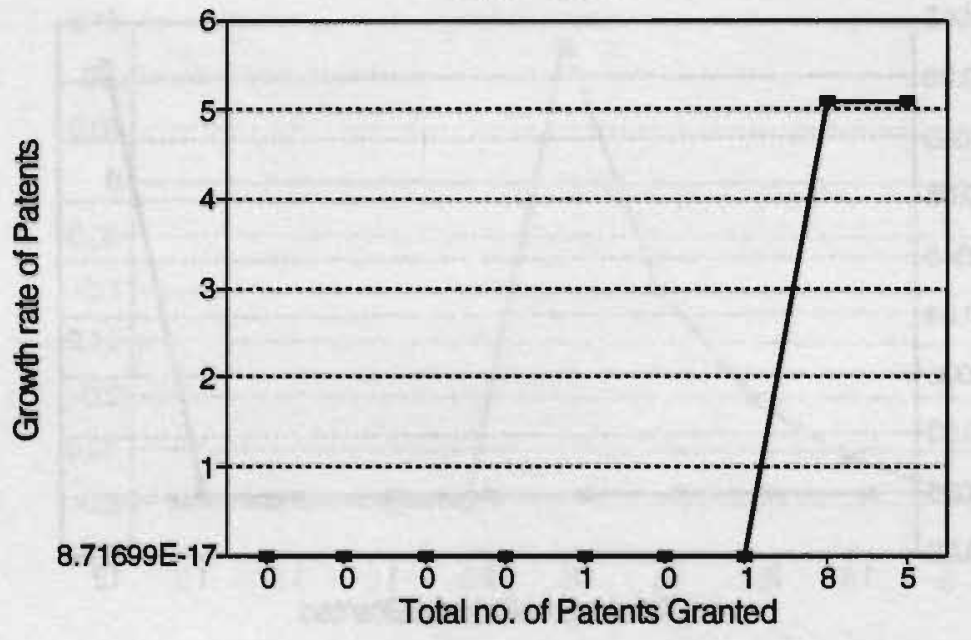

- Granted

Needless to say, the situation is different from country to country, and depends greatly on economic environments and institutional structures. Nevertheless, a number of broad requirements can be identified based on some of these observations. Firstly, the need for a strong science base is fairly obvious due to the scientific nature of biotechnology. A trained group of skilled scientists and researchers to contribute to the basic as well as applied research 
sectors also appears to be a basic requirement. Although this was not addressed explicitly in the model, technology gaps between north and south could have been attributed to differences in human capital skills between the two regions as this affects only absolute advantages. The results, in terms of specialization would then have been the same.

Many developing countries have recognized both these as being severe constraints to the development of biotechnology, and a large percentage of public resources have been devoted to these tasks. In other words, capability building is a major goal of most national programmes on biotechnology in developing countries. Perhaps the next step would therefore be to try and explicitly include capability development within the model and examine the implications for the south as well as for the north.

Similarly, in industrialized countries, the problem is not as acute as it is in developing countries, education in science and technology, is still regarded as an important target of government funding and for the future development of biotechnology. Basic education and the knowledge base have played an important role in the early development of biotechnology in a number of countries such as Britain, the USA and Germany (Sharp, 1985). Britain in fact, may now be at a disadvantage with respect to the other countries as government funding for scientific training and research has fallen sharply during the last two decades.

Having identified the characteristics of biotechnology and its impact on quality and variety and therefore on consumer welfare, the next question to examine is that of any policy recommendations that can be made to address some of the distortions caused by market failures.

With respect to trade, the result of complete specialization implies that the north devotes all its resources to $R \& D$ research and the south similarly, to the production of differentiated products. Thus neither country can move its resources into another sector efficiently. Indeed there would be a more efficient solution if resources could be moved between countries, as was the result in the integrated equilibrium. However, since migration is not allowed, this is not possible, and the allocation of labour in both sectors cannot be changed without labour migration. A movement from the specialization in equilibrium $B$ to $\mathrm{D}$ where there is higher welfare because of labour movement, would increase international efficiency. In the specialization equilibrium however because resources are fully employed in each sector, any form of intervention by the government, except for allowing for migration, cannot therefore change the allocation of resources. Thus specialization appears to be an exaggeration. A much better explanation of wage differences across countries is from the ratio $H_{N} / H_{s}$.

The economic models of chapters 8 and 9 formalised some of the structural characteristics of innovation and technological change in biotechnology. However, as with other models of its type, this model is also characterised by market distortions due to the presence of externalities and monopolistic features. The result of these distortions is usually that the optimal rate of innovation, economic growth and welfare is not the same as that provided in the market equilibrium. Policy measures are therefore recommended to try and offset these market failures and to try and internalise externalities. In this section, we look at any policy conclusions that can be drawn from the implications of the model for economic growth and trade.

With respect to the closed economy model, the presence of two distortions in the model may contribute to non-optimality and therefore could merit policy interventions. The 
differentiated sector, as modelled above, is characterised by imperfect competition with monopoly profits providing the incentive to producers. Similarly, in the R\&D sector, the presence of externalities which accrue to consumers from increasing variety are not reflected in pricing. Thus, governments which wish to encourage innovation, may be inclined to subsidize research, inducing greater investment in R\&D. However, Judd (1985) and Grossman and Helpman (1991a, Ch.8) have shown that the symmetric nature of the CES utility function ensures that the rate of innovation in this case, is optimal, regardless of the presence of monopolistic structures. Grossman and Helpman (1991a Ch.8) show that this is because the opposing distortions caused by monopoly in production and externalities from innovation, are equal to each other and therefore cancel each other out. Thus in this case, the ideal policy would be no policy intervention.

The use of a non-CES utility function however, as Judd (1985) has shown, can indeed lead to under or over production of innovations, and perhaps may be useful for further research on models which examine the impact on variety of increasing quality innovations.

Finally, while the new growth and trade models with differentiated goods, tend to break down innovation and production into different sectors, there is no public investment, a notable and influential factor we see in the development of biotechnology. The literature treating public investment, notably Shell (1967), Barro (1990), Sorenson (1993), Ziesemer (1990 and 93) ${ }^{176}$, doesn't extend to differentiated goods. A possible area of further research may therefore be to extend the analysis in the models described in Chapters 8 and 9 above, to public investment and imperfect capital markets. This may also result in more conclusive policy implications than can be inferred from this model.

\section{4 .}

\section{Conclusions and Linkages to Future Research}

The research in this thesis has focused on identifying the basic structure and interactions in biotechnology based industries in developing and industrialized countries, and the manner in which innovation occurs in both.

Although a relatively young technology modern biotechnology has made rapid strides in the last two decades. The thesis has attempted to identify the major players and to measure rates of technological change which can be attributed to biotechnological innovations. The underlying economic and institutional structure has also played an important role in encouraging or discouraging biotechnology research in various countries. The survey in Chapters 3 and 4 found that although patterns of technological change and areas of specialisation have varied quite greatly between countries, there are a number of basic similarities in terms of financial and institutional requirements and linkages. The model which followed in Chapters 8 and 9 was based on these non-financial and private linkages and demonstrated a number of important relationships between the accumulation of knowledge through learning and innovation and of consumer choice and impacts on changing quality and variety.

An interesting conclusion which has important implications for the changing role of developing countries in international trade, is that product selection in this model may have

176 See Ziesemer (1993) for a survey of public factors in endogenous growth models. 
an impact on their share of intemational trade. Empirical evidence from recent trade related impacts of new biotechnology on traditional products shows that developing country exports, especially of traditional products such as sugar and cocoa are being increasingly eroded by the development of biotechnology based substitutes. In so far as these traditional products are agricultural, as is the case with a large number of products exported by developing countries, this also has an impact on land value. If the case is that older varieties are rejected by consumers, this will imply a lower share of developing country products in international trade, and also a lower value of land as the price of those products fall. In the case of a reselection of older varieties, the value of land will increase as will the share of developing country exports in international trade. The introduction of land into the model as well as a more in depth analysis of trade related impacts of biotechnology, especially on developing countries, would perhaps yield interesting results as to the interplay between these variables.

The policy recommendations which arose from empirical observations relate largely to financing and encouraging investment in public knowledge accumulation. When allowing for profit, they may turn out to be also relevant in the private sector as viewed from the perspective of the model. The need for this is perhaps most evident in developing countries where the research base which was so crucial to the development of modern biotechnology in industrialized countries, is often missing altogether or deficient. The need for a strong research base to support downstream product development is also evident. For example, without the important innovations of the 1970 s and $1980 \mathrm{~s}$, it is unlikely that modern biotechnology would have developed as rapidly. Linkages between generic or basic research which is often publicly funded and carried out at public facilities, and applied research which is most often dominated by the private sector and strongly biased toward product development and commercialization, are also crucial. All these are basic requirements of perhaps any modern technology, and more so for biotechnology which is strongly science based and therefore dependant upon a strong research sector.

Rapid changes in the nature of the technology and also of the structure within which it operates, make the need for in-depth examinations of these changes imperative if one is to understand the nature of innovation in biotechnology. A related area of research which is exciting is that of the changing market structure in industrial biotechnology. The importance of strategic alliances and the rise and fall of the small biotechnology firm are hotly debated topics in the industry today. It is not as yet clear whether there is an increase in one or the other, nor if one is more important at different stages than the other. The model allows for constant or decreasing firm size. Moreover, when variety (in)decreases, the number of firms (in)decreases as well. The market share of the top firms then (de)increases.

Many small companies are also involved in strategic alliances (see the work done by Hagedoorn here), whereas others prefer to merge with larger companies. This area of research was briefly alluded to in Chapters 3 and 4 above, when discussing the development of biotechnology in industrialized countries. However, it was difficult to go into further detail given data constraints. A future area of research, especially as the data become available, could therefore be an examination of innovation under different market structures and especially the resurgence of the small firm after a period of emphasis on the large company.

A second area of research which may lead to some insights on capability building, especially in developing countries, would be to study the phenomena of science parks and regions of scientific capability, perhaps an emulation of Silicon Valley in California during the development of microelectronics. The regions offer scientific expertise and a number of 
examples exist, especially in industrializing countries (such as Korea where a large science park has just been completed in Taejon, and India, where Bangalore has become a scientific centre in recent years), where the capabilities exist, which are flourishing because of their relatively lower labour costs and scientific expertise. The phenomena would be interesting to study because of its possible parallels with the development of similar areas of technological and scientific capability in other parts of the world. It would also have interesting implications for capability building and learning, especially the role of the latter in developing technological and scientific capability. 
Appendices 


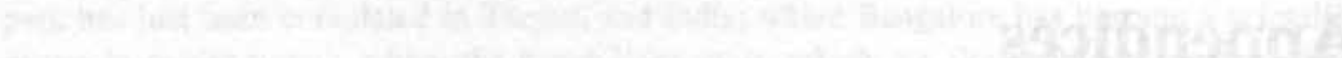
10 


\section{Companies for which Patent Data collected}

\section{a) Pharmaceutical Companies}

Company

Bristol Myers

Merck

Smithkline Beecham

Abbott Labs

American Home Products

Glaxo Holdings

Pfizer

Warner Lambert

Lilly

Schering Plough

Upjohn

Wellcome

Marion Merrill Dow

Syntex
Annual Sales \$ million (1993)

$11,413.000$

$10,498.200$

$9,246.000$

$8,407.843$

$8,304.851$

$7,987.000$

$7,477.700$

$5,793.700$

$4,452.400$

$4,341.300$

$3,653.364$

$3,034.113$

2.818 .000

$2,123.000$

Source: Bio/Technology, Vol. 12, July 1994 


\section{b) New Biotechnology Companies}

Company

Amgen

Genentech

Genzyme

Chiron

Alza

Biogen

Immunex

Genetics Institute

Centocor

Gensia

Athena Neurosciences

Medimmune

Synergen

Applied Microbiology

ISIS

Cytogen

Affymax

Agouron

Liposome Co.

Immune Response

US Bioscience

ICOS

Sphinx

Immunomedics
Annual Sales \$ million (1993)

$1,373.842$

608.189

270.371

239.796

219.831

136.418

122.866

102.041

70.930

29.016

18.631

15.079

13.180

12.327

10.654

10.354

9.826

8.266

5.418

4.768

4.427

3.941

3.455

3.049

Source: Bio/Technology, Vol. 12, July 1994 


\section{c) Chemical Companies}

$\begin{array}{ll}\text { Company } & \text { Annual Sales \$ million (1992) } \\ \text { Hoechst } & 28,310,000 \\ \text { BASF } & 27,480,000 \\ \text { Bayer } & 25,430,000 \\ \text { Du Pont } & 21,730,000 \\ \text { Dow Chemical } & 18,300,000 \\ \text { Ciba Geigy } & 15,100,000 \\ \text { Rhône Poulenc } & 14,781,158 \\ \text { ICI } & 12,700,000 \\ \text { Johnson and Johnson } & 12,477,000 \\ \text { Atochem } & 10,850,000 \\ \text { Exxon } & 10,650,000 \\ \text { Akso } & 9,260,000 \\ \text { Shell } & 8,490,000 \\ \text { Monsanto } & 7,800,000 \\ \text { Solvay } & 7,650,000 \\ \text { Sumitomo Chemicals } & 7,480,000\end{array}$

Source: Bio/Technology Vol. 11, no. 7 (1993) 


\section{Appendix II}

\section{Calculating the initial value of $z$ :}

\section{The Case of No Capital Markets}

In order to carry out the simulations for the growth rates of $n$ and $z^{-}$, the initial value of $z^{-}$ had to be calculated, given the initial value of $n$. We look here only at the no capital market case, for which simulations were carried out.

From $n_{(0)}$ and from equation (8.59) in Chapter 8 or (9.61) from Chapter 9 above, we get

$$
b_{n_{m}}=\frac{\rho}{n_{(0)}^{\delta}}
$$

As in Chapter 8, we can calculate the relative values of $b_{z}$ and $b_{n_{\mathrm{g}}}$ from equations (8.60) and (8.61)

$$
b_{z}=b_{n_{\mathrm{m}}}\left[\frac{n_{(0)} e^{\alpha n_{n_{\mathrm{m}}}}}{z e^{\alpha z}}\right]^{\theta}
$$

In the case of no capital markets, income equals expenditure in each period. From equation (8.24) and from the zero profit condition in the differentiated sector (8.25) for $p_{z}$ and $q_{z}$ into the budget constraint to obtain

$$
E=\frac{1}{1-\theta} \int_{z^{-}}^{n} b_{z} d z
$$

as in equation (8.84).

Substituting for $b_{z}$ from equation (A2.2) into equation (A2.3) we write

$$
E=\frac{1}{1-\theta} \int_{z^{-}}^{n_{\theta}} b_{n_{\mathrm{e}}}\left[\frac{n_{(0)} e^{\alpha n_{(0)}}}{z e^{\alpha z}}\right]^{\theta-1} d z
$$

which can be rewritten 


$$
E=\frac{1}{1-\theta} b_{n_{m}}\left(n_{(0)} e^{\left.\alpha n_{\rho}\right)}\right)^{\frac{\theta}{\theta-1}} \int_{z^{-}}^{n_{m}} z^{\frac{\theta}{1-\theta}} e^{\alpha \frac{\theta}{1-\theta} z} d z
$$

since the initial value of $n_{(0)}$ is exogenous. From this we can find the initial value of $z^{-}$.

We define

$$
t=\alpha\left[\frac{\theta}{1-\theta}\right] z
$$

From which the two extremes of the integral can be defined accordingly:

$$
\begin{aligned}
& \tilde{n}_{(0)}=\left[\frac{\alpha \theta}{1-\theta}\right] n_{(0)} \\
& \tilde{z}^{-}=\left[\frac{\alpha \theta}{1-\theta}\right] z^{-}
\end{aligned}
$$

From (A2.6) we can write

$$
z=t\left[\frac{1-\theta}{\alpha \theta}\right] \Rightarrow \frac{d z}{d t}=\left[\frac{1-\theta}{\alpha \theta}\right]
$$

and $d t=d z\left[\frac{\alpha \theta}{1-\theta}\right]$

Inserting (A2.8) into equation (A2.4) yields

$$
E=\frac{1}{1-\theta} b_{n_{\infty}}\left(n_{(0)} e^{\alpha n_{\infty}}\right)^{\frac{\theta}{\theta-1}} \int_{\varepsilon^{-}}^{\tilde{n}_{\text {m }}}\left[\frac{1-\theta}{\alpha \theta}\right]^{\frac{\theta}{1-\theta}} t^{\frac{\theta}{T-\theta}} e^{\prime}\left(\frac{\alpha \theta}{1-\theta}\right) d t
$$

Taking the constant term $\left(\frac{1-\theta}{\alpha \theta}\right)$ before the integral equation (A2.9) can be rewritten as:

$$
E=\frac{1}{1-\theta} b_{n_{(S)}}\left(n_{(0)} e^{\alpha n_{(\rho)}}\right)^{\frac{\theta}{\theta-1}}\left(\frac{1-\theta}{\alpha \theta}\right)^{\frac{\theta}{1-\theta}} \int_{\tau^{-}}^{\hbar_{n_{0}}} t^{\frac{\theta}{1-\theta}} e^{t}\left(\frac{\alpha \theta}{1-\theta}\right) d t
$$


We define $p$ as any integer value. Inserting $p=\frac{\theta}{1-\theta}$ into equation (A2.10) we write

$$
E=(p+1) b_{n_{m}}\left(n_{(0)} e^{\alpha n_{(j)}}\right)^{-p}\left[\frac{1}{\alpha p}\right]^{p} \int_{\xi-}^{\tilde{n}_{\infty}} t^{p} e^{t}\left(\frac{\alpha \theta}{1-\theta}\right) d t
$$

The initial value for $z^{-}$was then calculated from equation (A2.11) using the mathematical computer programme, Mathematica. This was calculated in three steps. Fist, the integral was calculated using the rule of partial integration. Mathematica's calculations yield a series as the solution to the partial integration. The second step was to express this series in terms of the two extremes of the integral, where according to equation (A2.7) above, the values of $\tilde{n}_{(0)}$ and $\tilde{z}^{-}$were reconverted into $n_{(0)}$ and $z^{-}$respectively. The final step was to calculate the term before the integral and multiply it to the expanded series. The value of $b_{n_{\mathrm{m}}}$ was calculated in terms of values for $\rho$ and $n^{\delta}$ depending upon the two cases of Shellian learning or of Phelpsian learning; alpha was initially varied between 0.1 and 0.5 , but later only 0.1 and 0.2 were used, as the use of higher values of alpha tends to make the simulations go out of bounds; the initial values of $n$ used were 2, 4, and 8; and finally, $p$ was varied between 5 and 19 (implying values of theta between 0.83 and 0.94 ). The initial value of $E$ was normalized to be equal to one.

Given all the values in this manner, mathematica then solves for the only missing value, $z^{-}$. 


\section{Appendix III}

\section{Simulations from No Capital Market Case}

I. Learning and No Learning where $\rho<-\delta \hat{n}$

Figure A3.1. Learning (delta $=1$ )

alpha $=0.1$, theta $=0.83$, rho $=0.04$

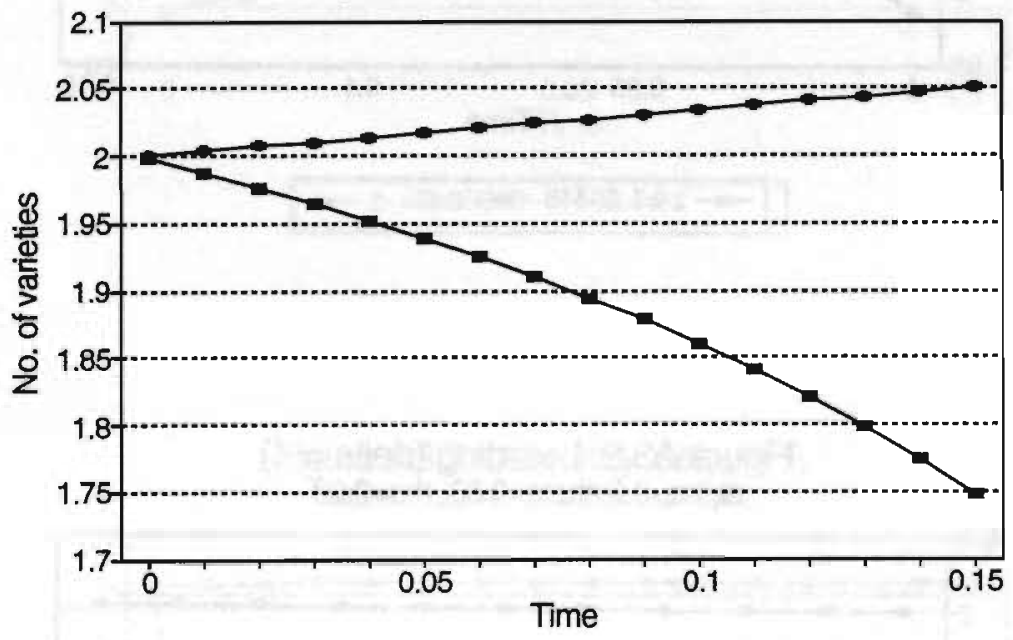

$\rightarrow-z=1.99804 \rightarrow n=2$ 
Figure A3.2. No Learning (delta $=0$ )

alpha $=0.1$, theta $=0.83$, ho $=0.04$

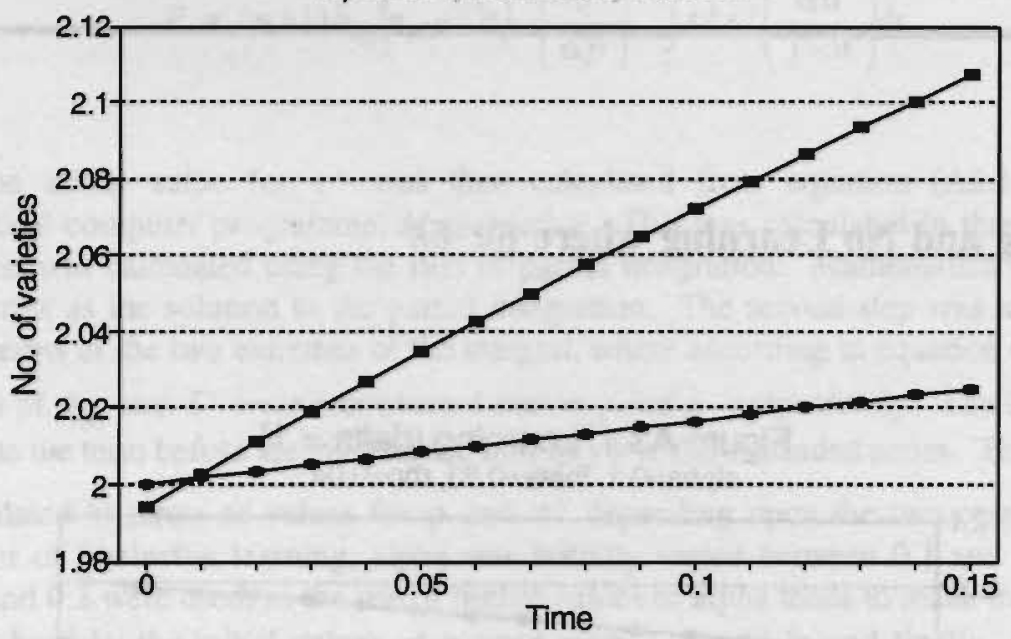

$\because-z-=1.99416 \multimap n=2$

Figure A3.3. Learning (delta $=1$ )

alpha $=0.2$, theta $=0.83, \mathrm{ho}=0.03$

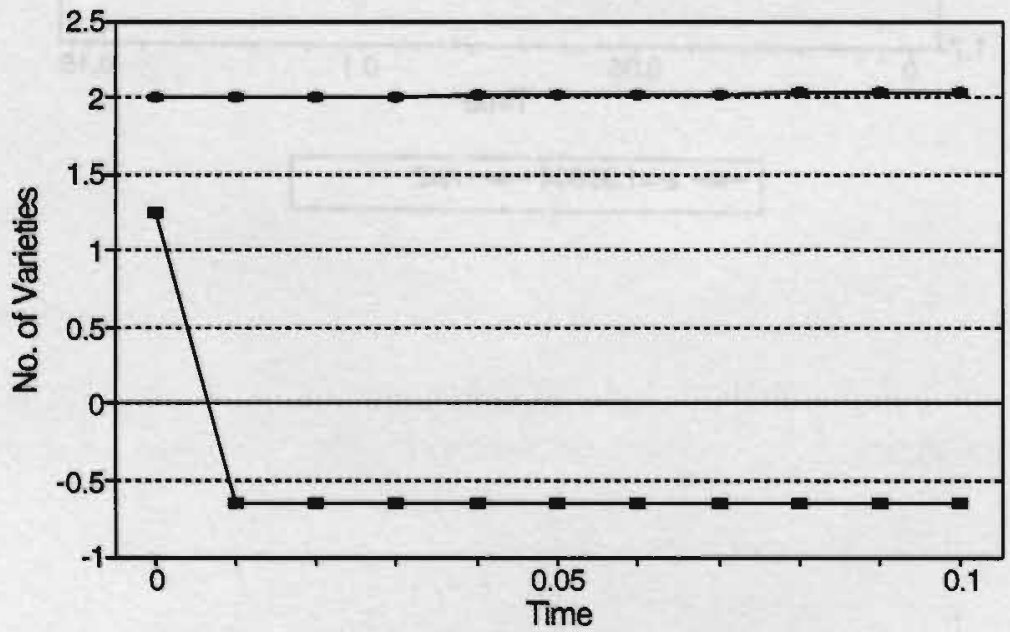

$\rightarrow-z^{-}=1.24525 \multimap n=2$ 
Figure A3.4. No Learning (delta $=0$ ) alpha $=0.2$, theta $=0.83$, rho $=0.03$

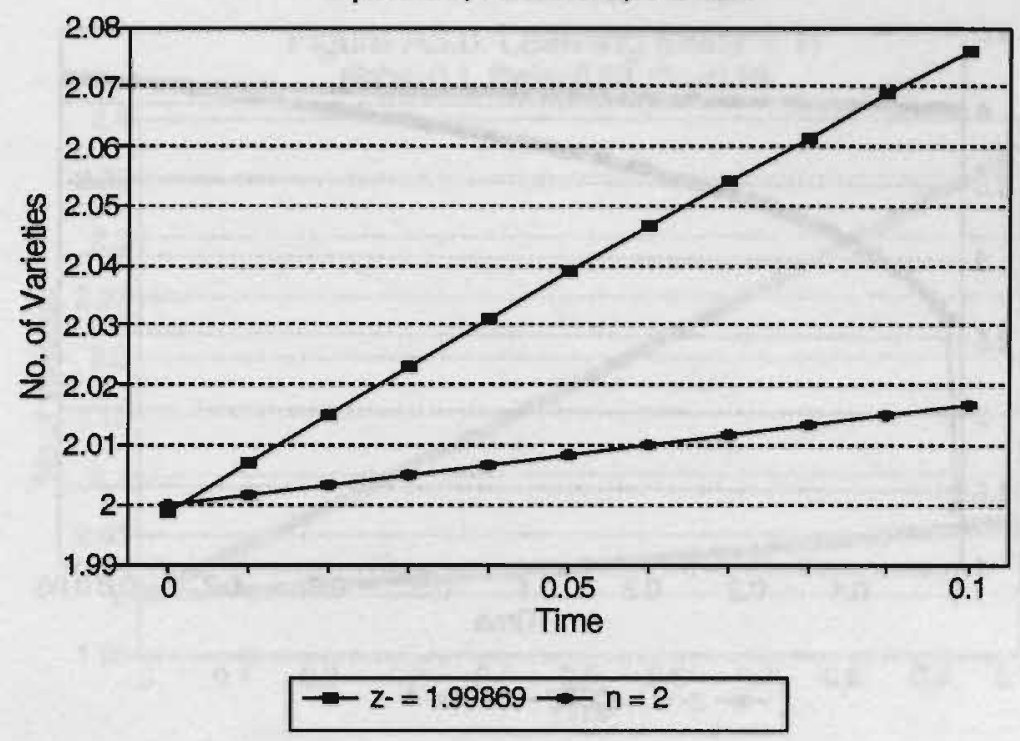

Figure A3.5. Learning (delta $=1$ )

alpha $=0.2$, theta $=0.83$, mo $=0.03$

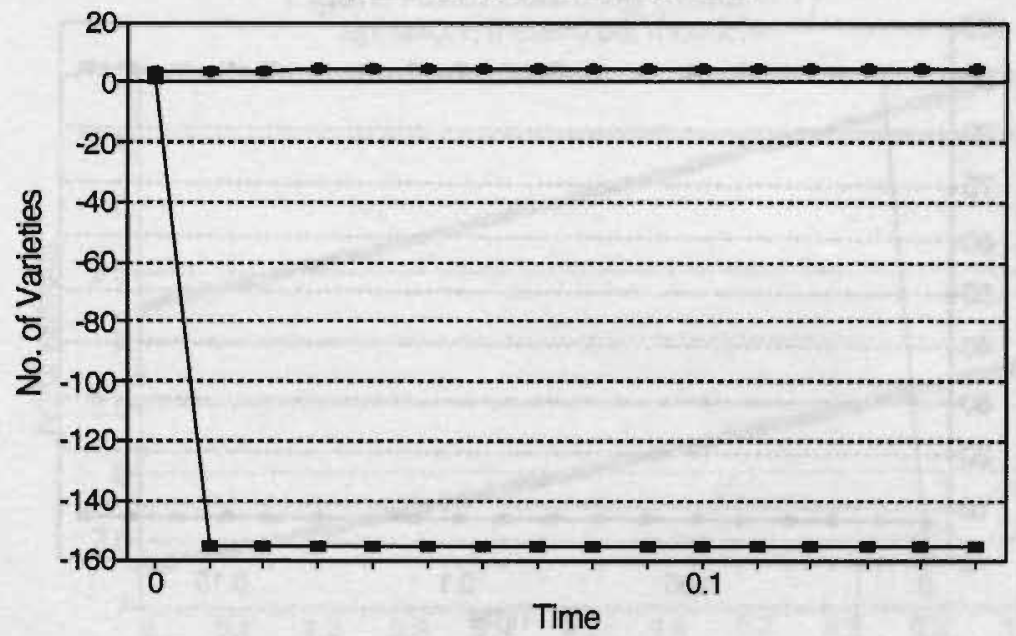

$\rightarrow-z^{*}=1.2205 \multimap n=4$ 
Figure A3.6. No Learning (delta $=0$ )

alpha $=0.2$, theta $=0.83$, rho $=0.03$

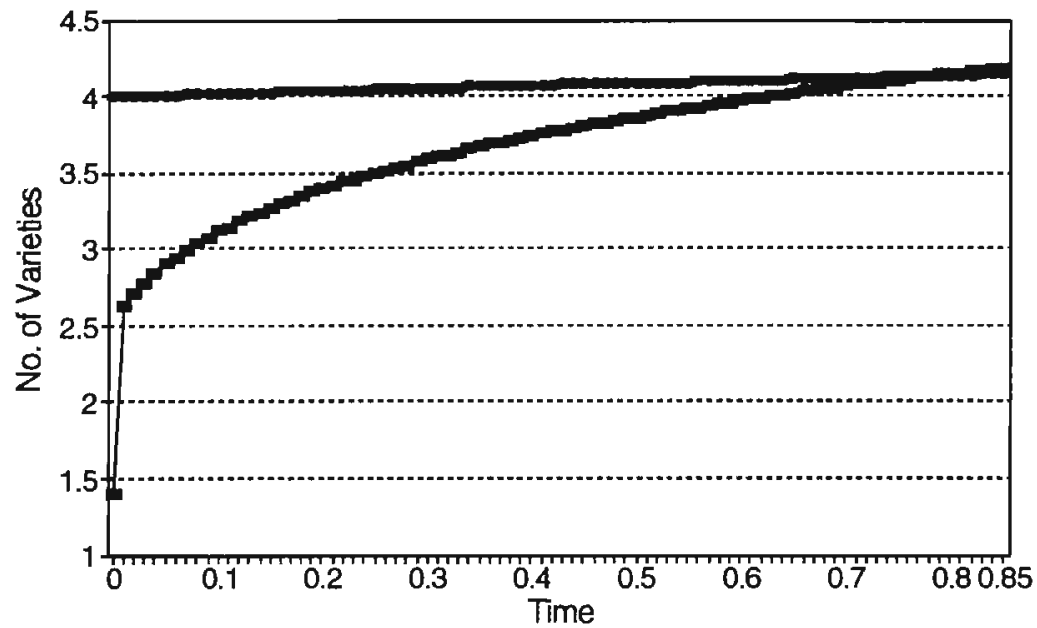

$\multimap-z^{-}=1.40672 \multimap n=4$

Figure A3.7. No Learning (delta $=0$ ) alpha $=0.2$, theta $=0.83$, mo $=0.03$

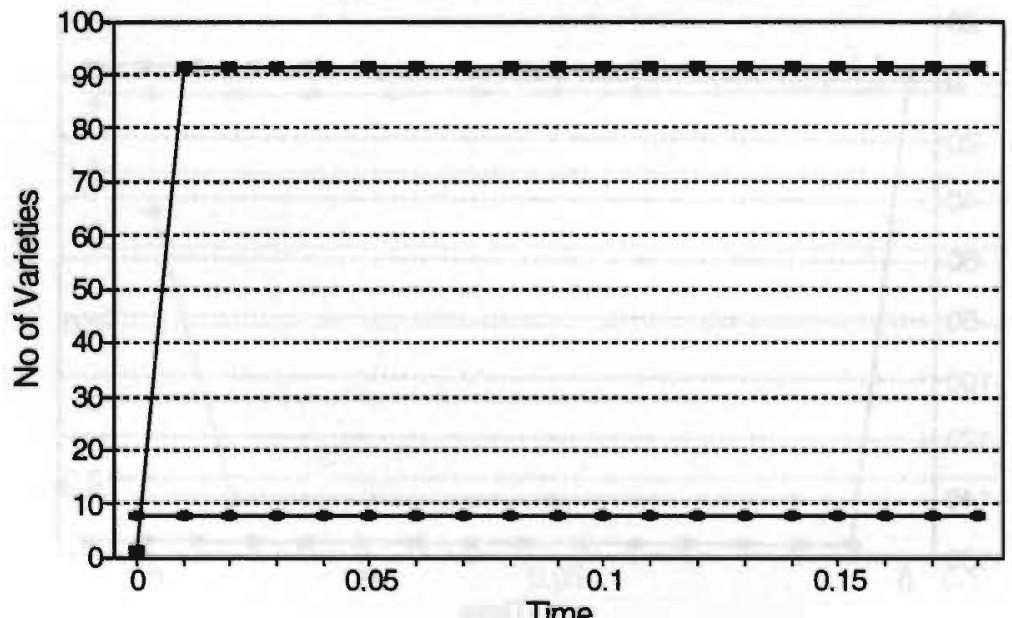

Time

$-z-=1.41431 \multimap n=8$ 


\section{II: Learning for $\rho>-\delta \hat{n}$}

Case 1: rho $=0.19$

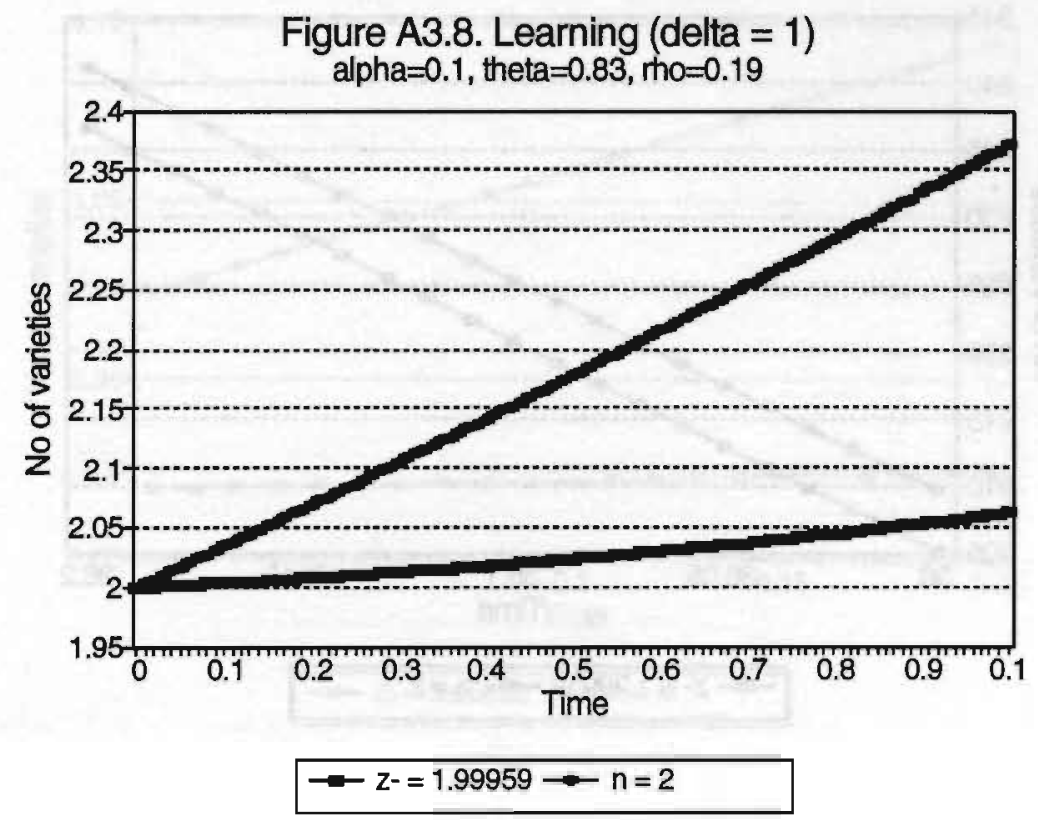

Figure A3.9. Learning (delta $=1$ )

alpha $=0.1$, theta $=0.83$, mo $=0.19$

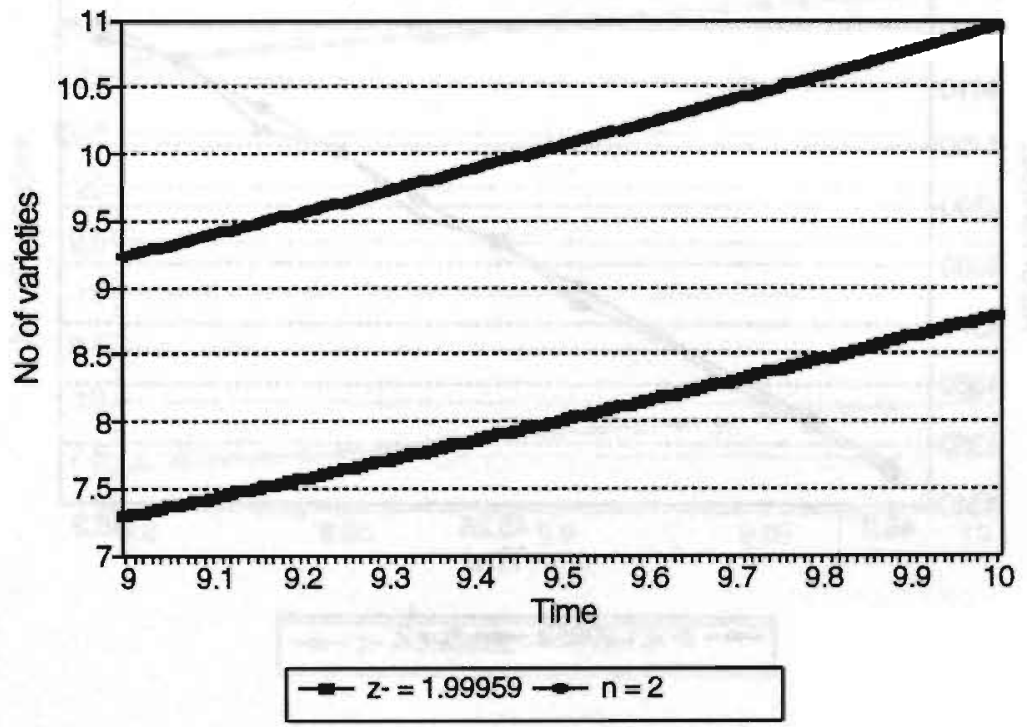


Figure A3.10. Leaming (delta = 1) alpha $=0.1$, theta $=0.83$, tho $=0.19$

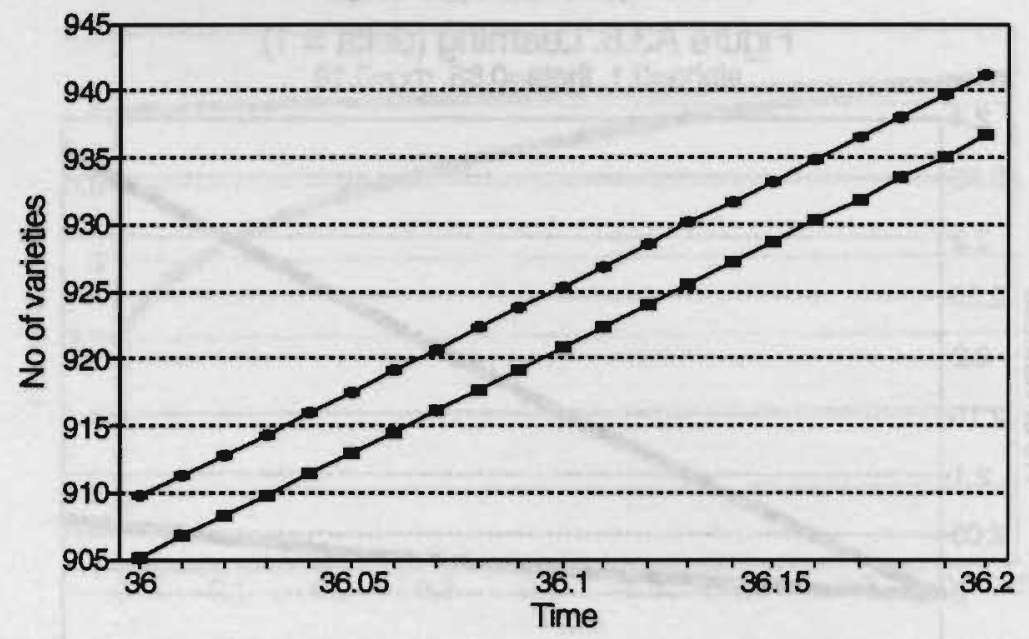

$\because z-=1.99959 \multimap n=2$

Figure A3.11. Leaming (delta = 1)

alpha $=0.1$, theta $=0.83$, roo $=0.19$

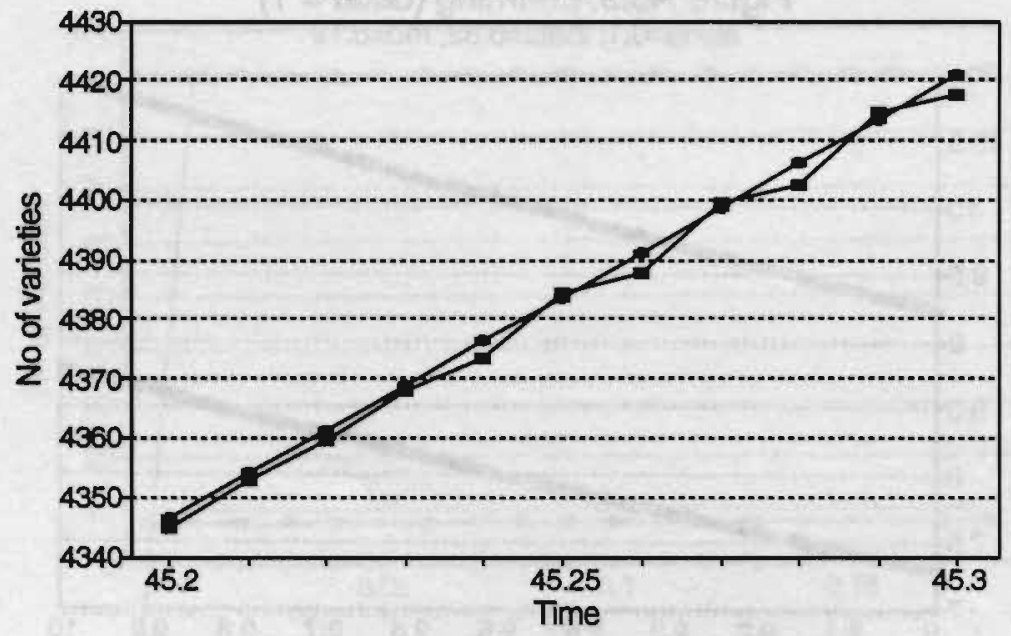

$-z=1.99959-n=2$ 
Case 2: $r h o=0.18$ and $n=4$

Figure A3.12. Leaming (delta $=1$ ) alpha $=0.1$, theta $=0.83$, rho $=0.18$

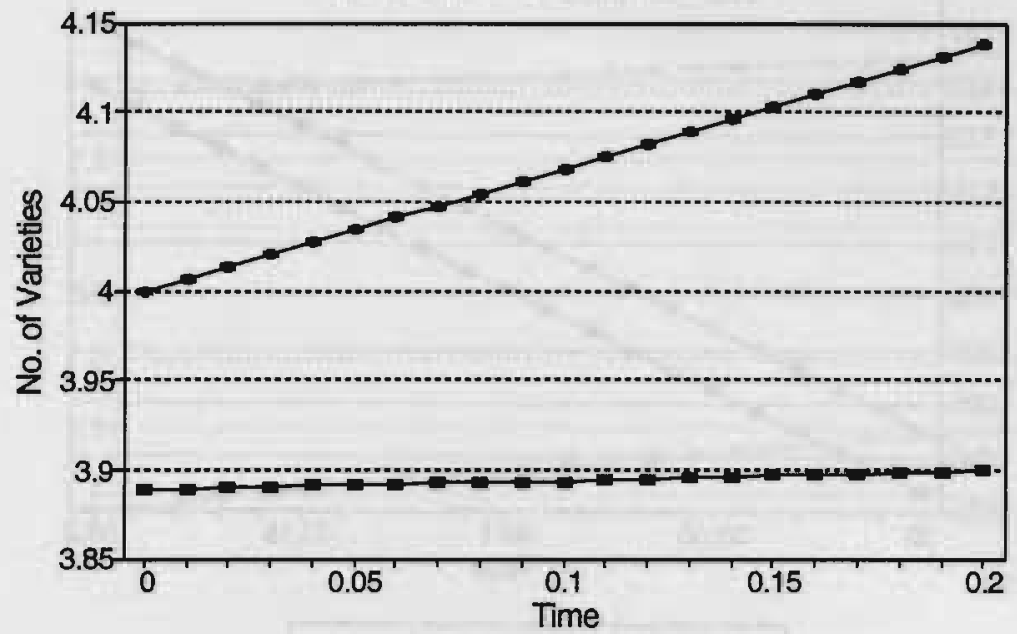

$-z-=3.88882 \multimap n=4$

Figure A3.13. Leaming $($ delta $=1)$

alpha $=0.1$, theta $=0.83$, mo $=0.18$

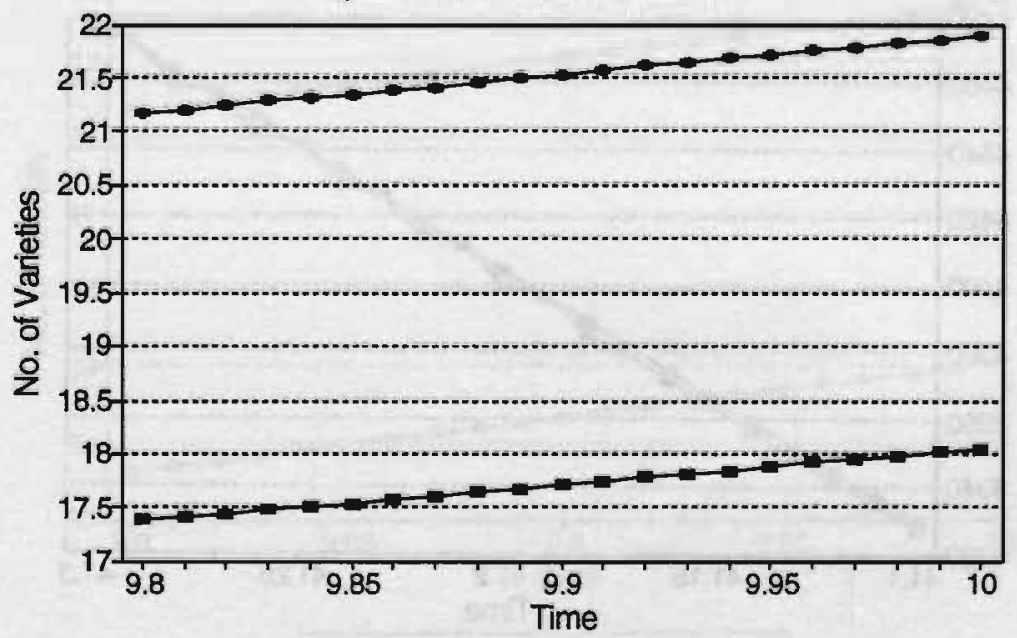

$\because-z^{-}=3.88882 \multimap n=4$ 
Figure A3.14. Leaming (delta $=1$ )

alpha $=0.1$, theta $=0.83, \mathrm{mo}=0.18$

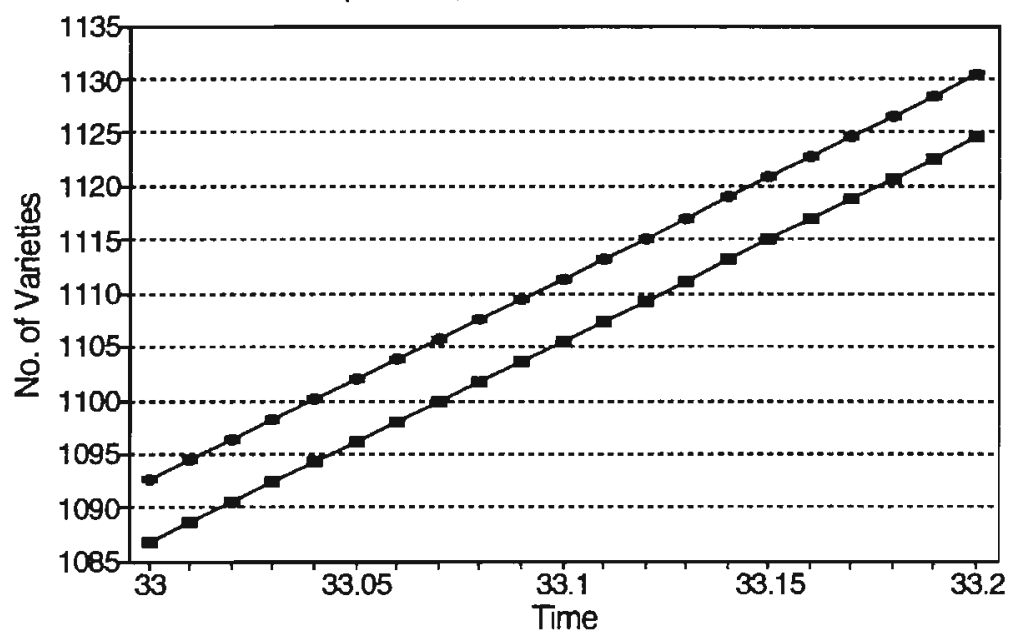

$\because-z-=3.88882 \multimap n=4$

Figure A3.15. Leaming (delta $=1$ ) alpha $=0.1$, theta $=0.83$, rho $=0.18$

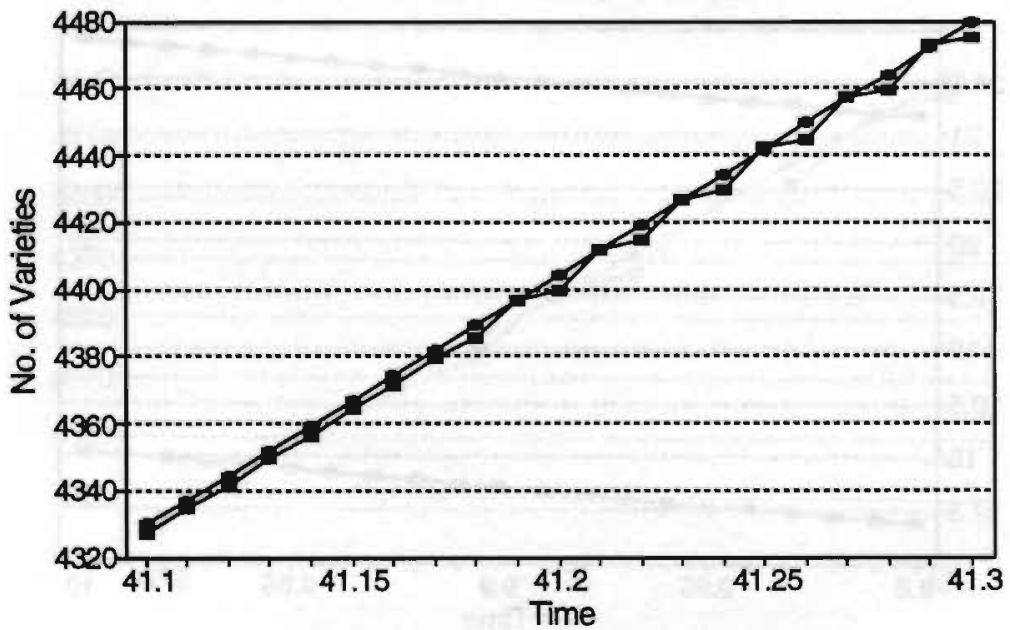

$\rightarrow-z-=3.88882 \rightarrow n=4$ 
Case 3: $r h o=0.18, n=8$

Figure A3.16. Leaming (delta $=1$ ) alpha $=0.1$, theta $=0.83$, rho $=0.18$

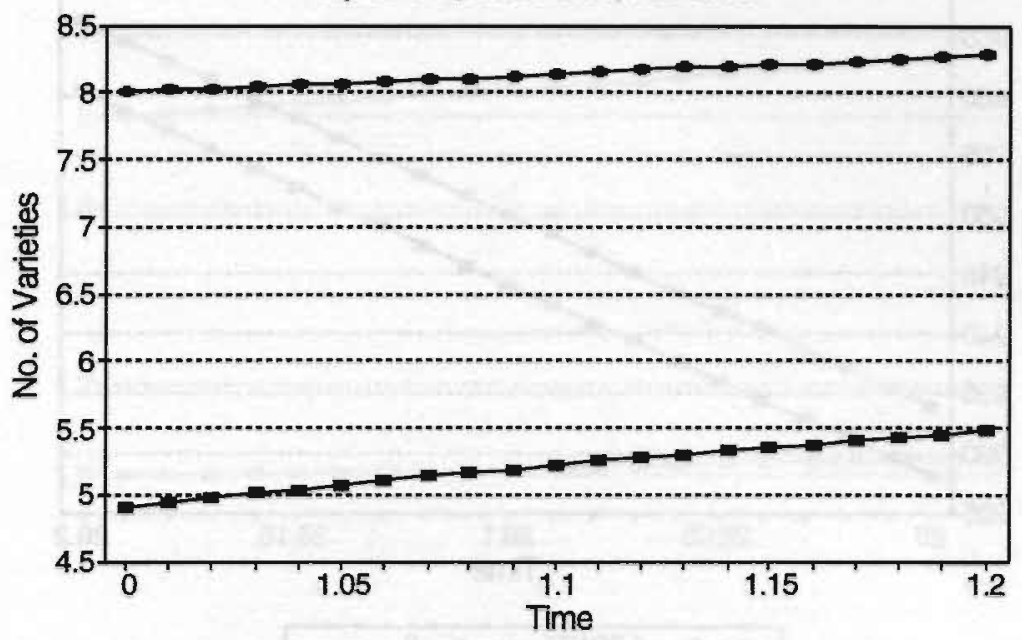

$\because-z-=4.90107 \rightarrow n=8$

Figure A3.17. Learning (delta $=1$ ) alpha $=0.1$, theta $=0.83$, rho $=0.18$

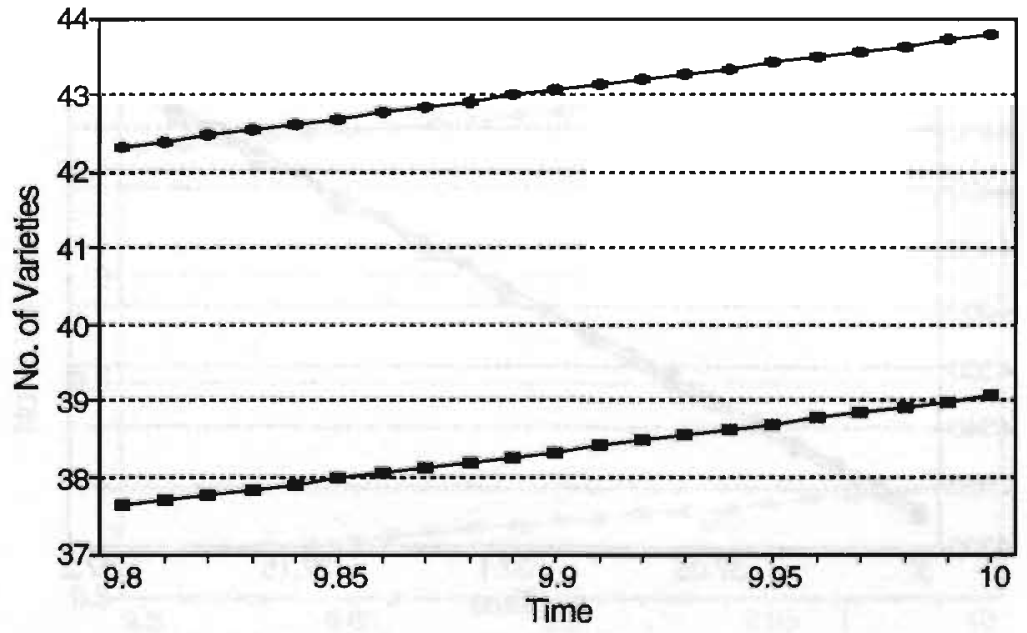

$\multimap-z==4.90107 \multimap n=8$ 
Figure A3.18. Leaming (delta $=1)$

alpha $=0.1$, theta $=0.83$, rho $=0.18$

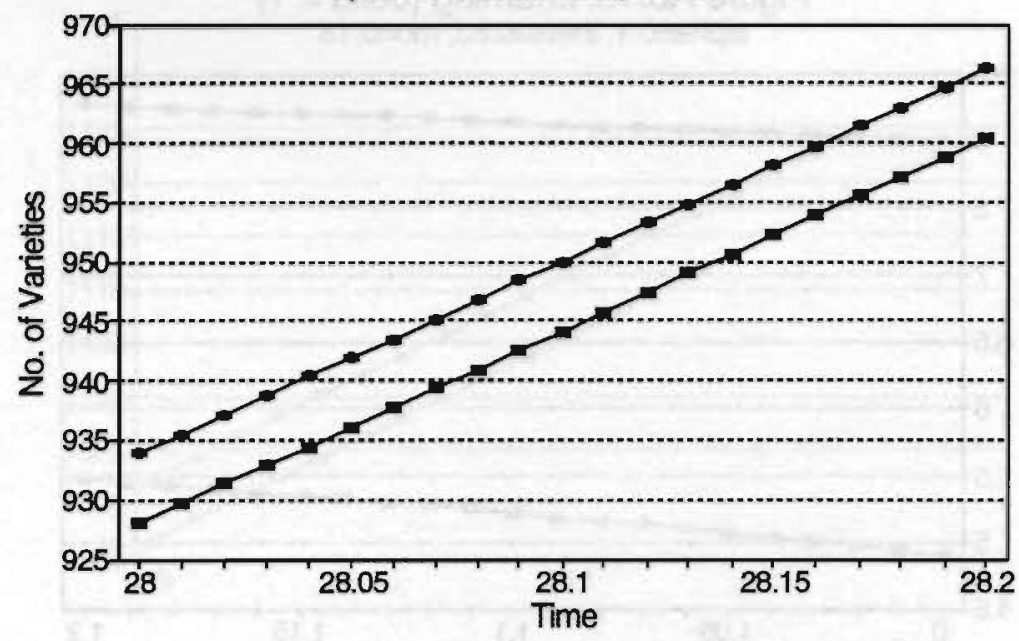

$\rightarrow-z-=4.90107 \rightarrow n=8$

Figure A3.19. Leaming (delta $=1$ )

alpha $=0.1$, theta $=0.83$, mo $=0.18$

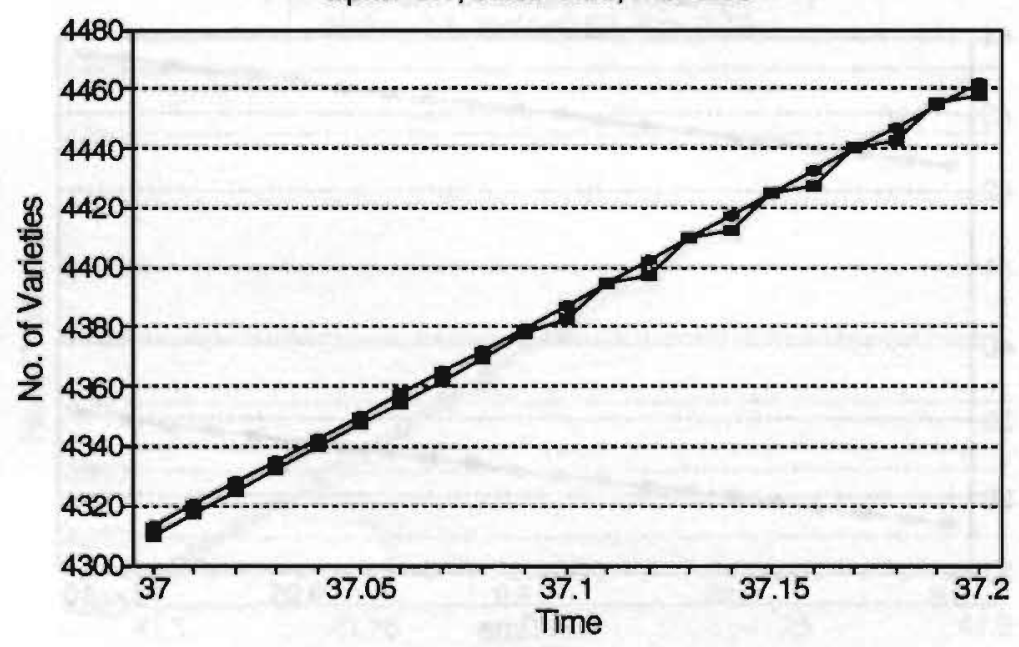

$\rightarrow-z-=4.90107 \multimap n=8$ 
Case 4: rho $=0.18$, alpha $=0.2, n=2$

Figure A3.20. Leaming (delta $=1$ ) alpha $=0.2$, theta $=0.83$, $h o=0.18$

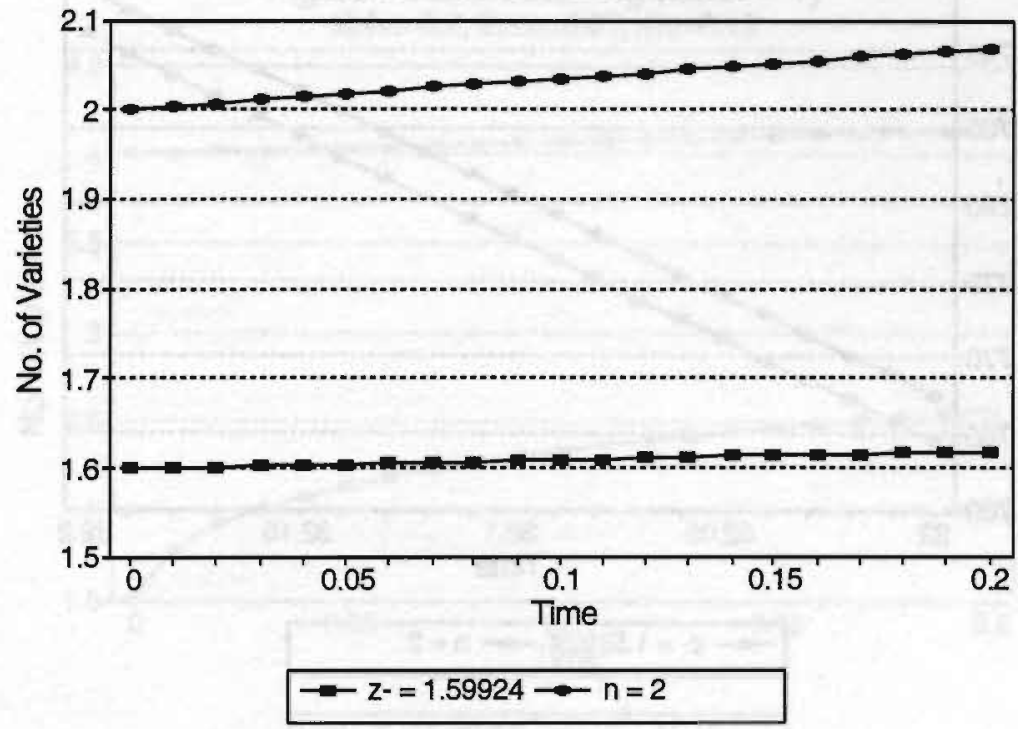

Figure A3.21. Leaming (delta $=1$ )

alpha $=0.2$, theta $=0.83$, rho $=0.18$

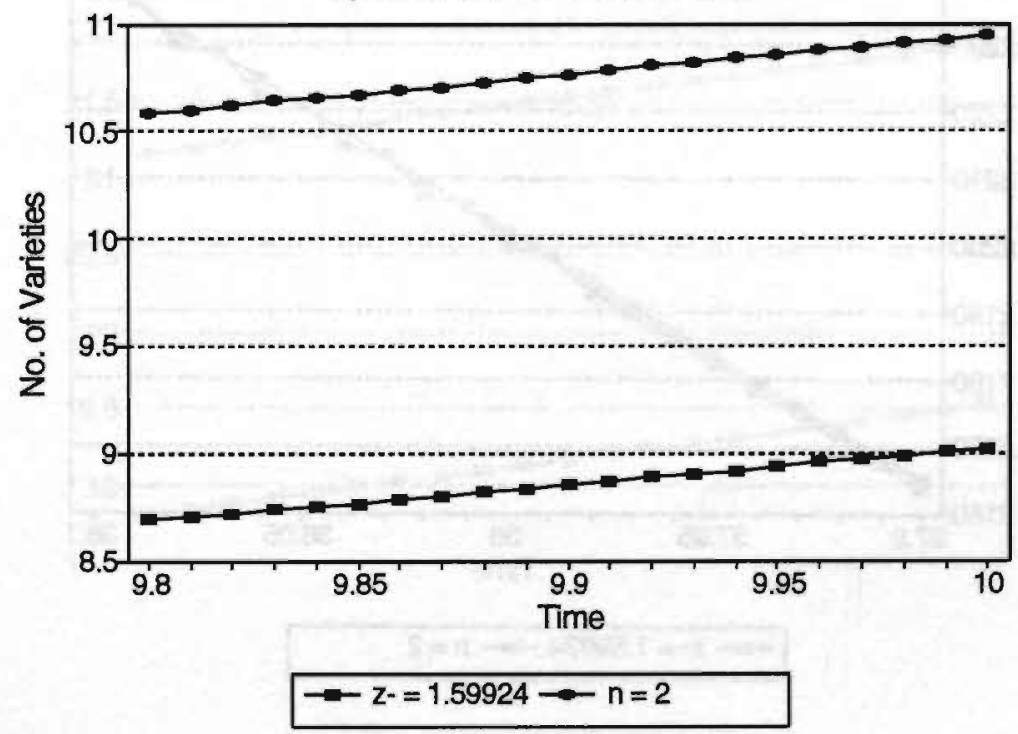


Figure 3.22. Learning $($ delta $=1)$ alpha $=0.2$, theta $=0.83$, rho $=0.18$

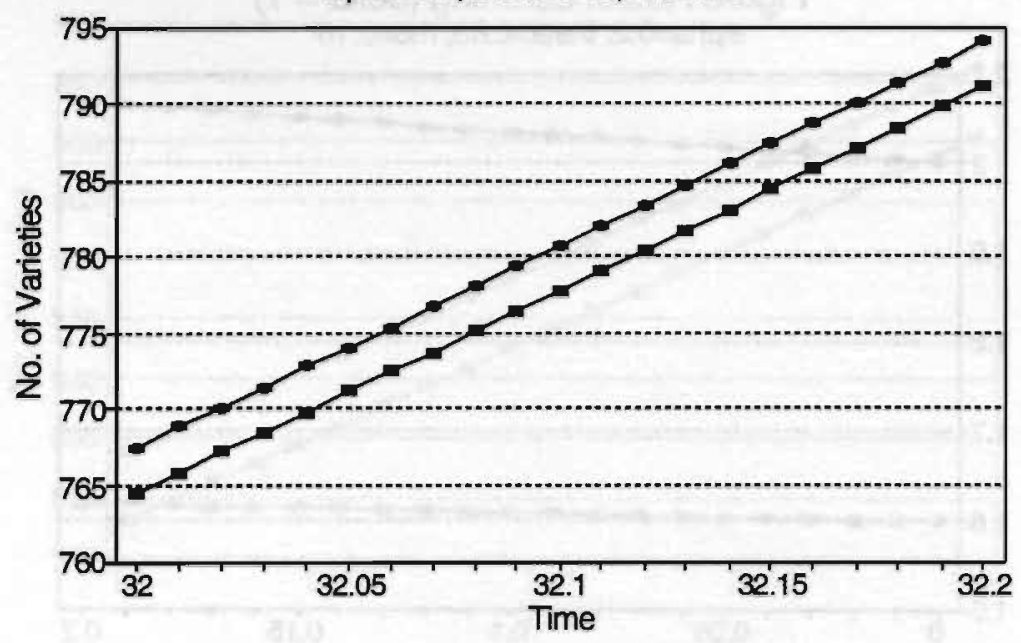

$\because-z-=1.59924 \longrightarrow n=2$

Figure A3.23. Learning (delta $=1$ ) alpha $=0.2$, theta $=0.83$, $m o=0.18$

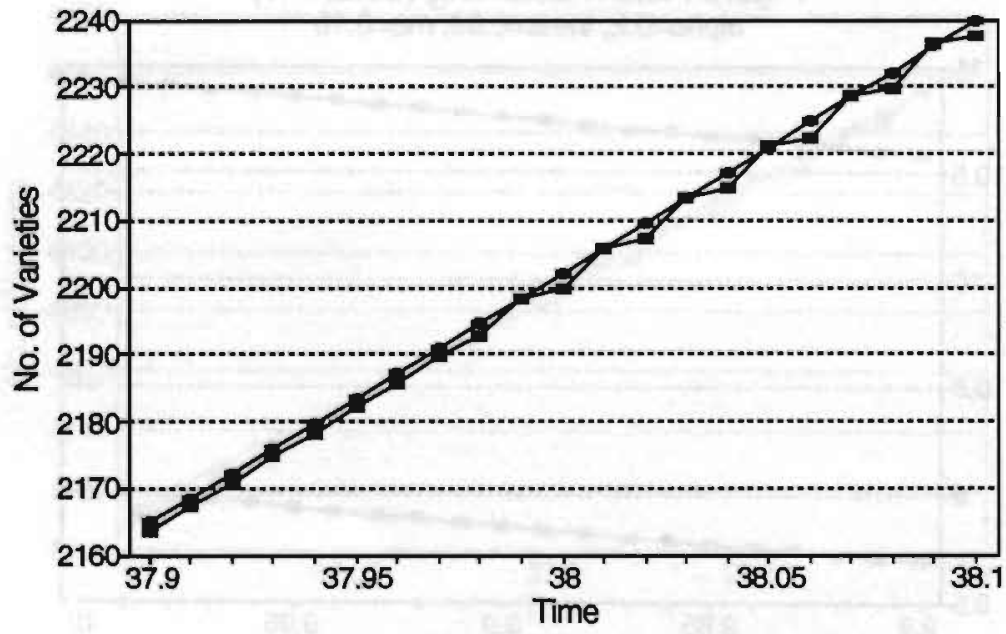

$\because-z=1.59924 \multimap n=2$ 
Case 5: $r h o=0.18$, alpha $=0.2, n=4$

Figure $A 3.24$. Learning (delta $=1$ )

alpha $=0.2$, theta $=0.83$, rho $=0.18$

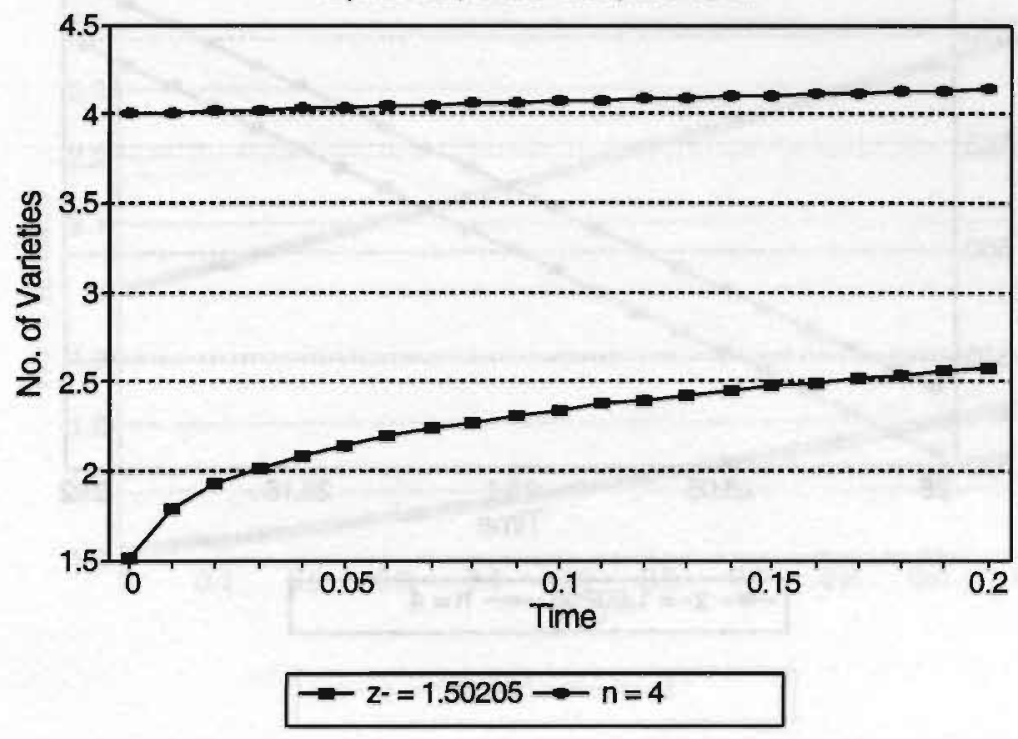

Figure A3.25. Leaming (delta $=1)$

alpha $=0.2$, theta $=0.83, \mathrm{mo}=0.18$

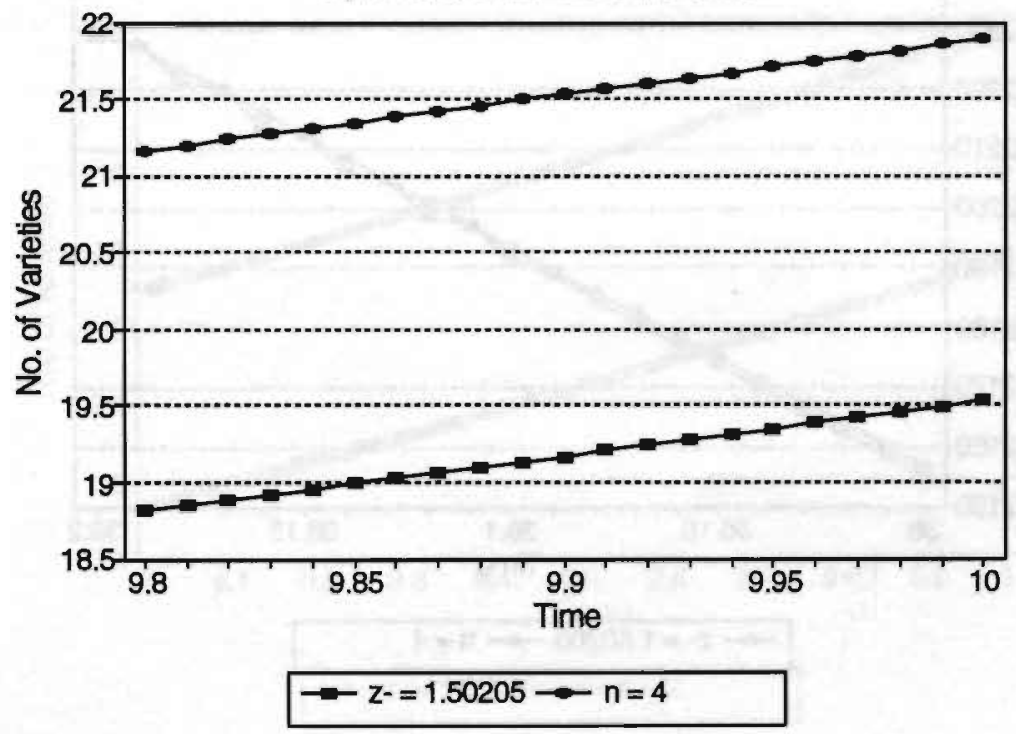


Figure A3.26. Learning (delta $=1$ )

alpha $=0.2$, theta $=0.83$, mo $=0.18$

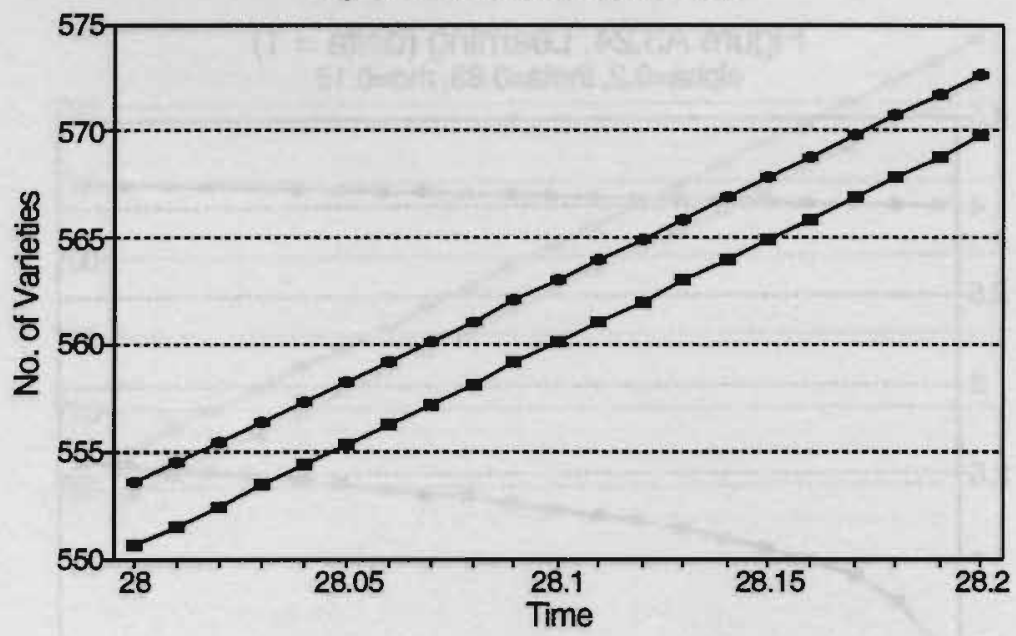

$\rightarrow-z-=1.50205 \multimap n=4$

Figure A3.27. Leaming (delta $=1$ )

alpha $=0.2$, theta $=0.83$, $h 0=0.18$

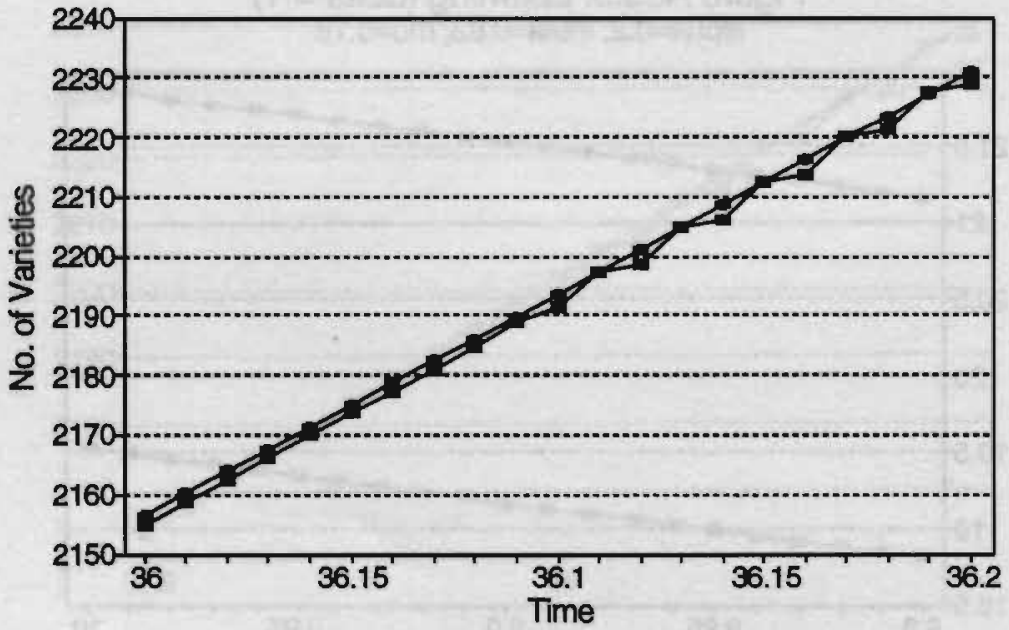

$\because-z^{*}=1.50205 \multimap n=4$ 
Case 6: rho $=0.19$, alpha $=0.2, n=2$

Figure A3.28. Learning (delta $=1$ )

alpha $=0.2$, theta $=0.83$, ho $=0.19$

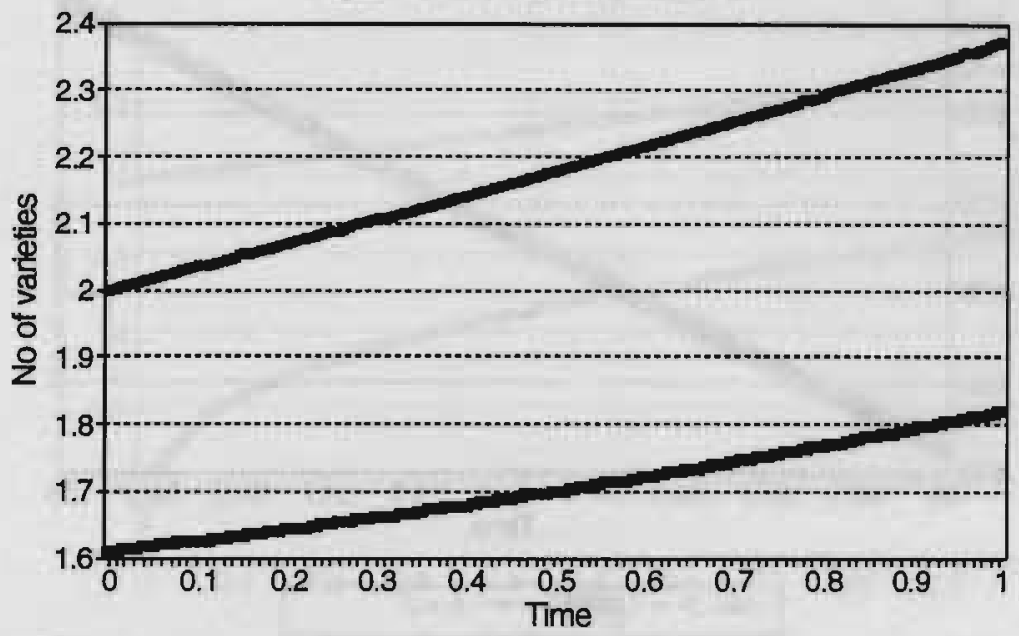

$\rightarrow z-=1.60955 \rightarrow n=2$

Figure A3.29. Leaming (delta $=1$ )

alpha $=0.2$, theta $=0.83$, rho $=0.19$

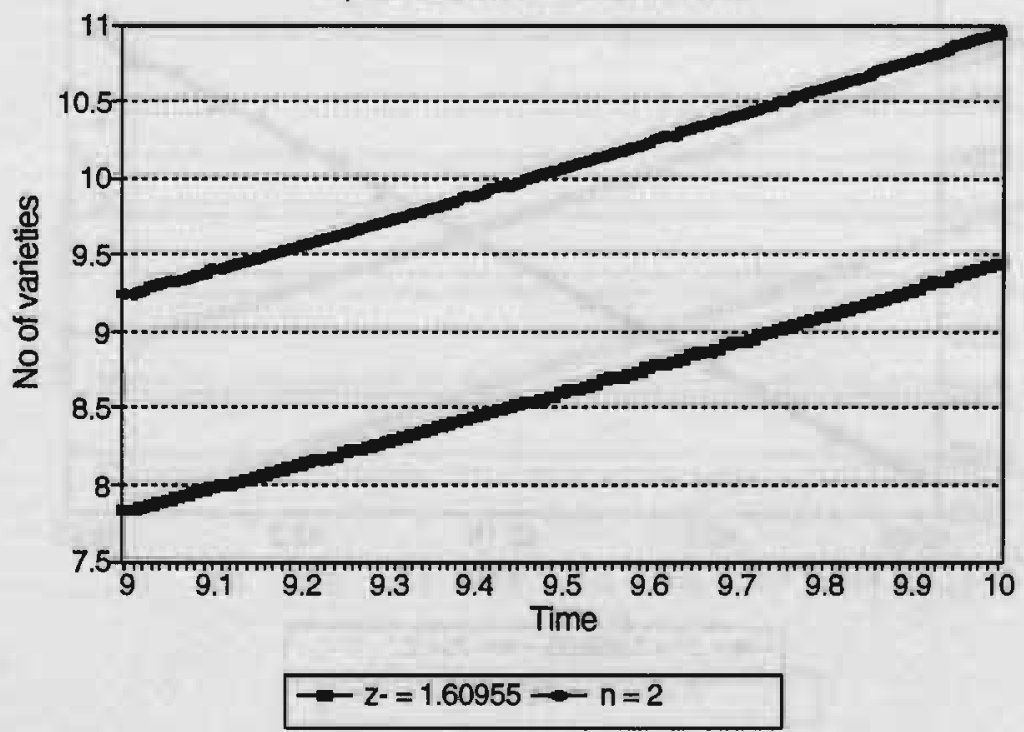


Figure A3.30. Learning (delta $=1$ )

alpha $=0.2$, theta $=0.83$, mo $=0.19$

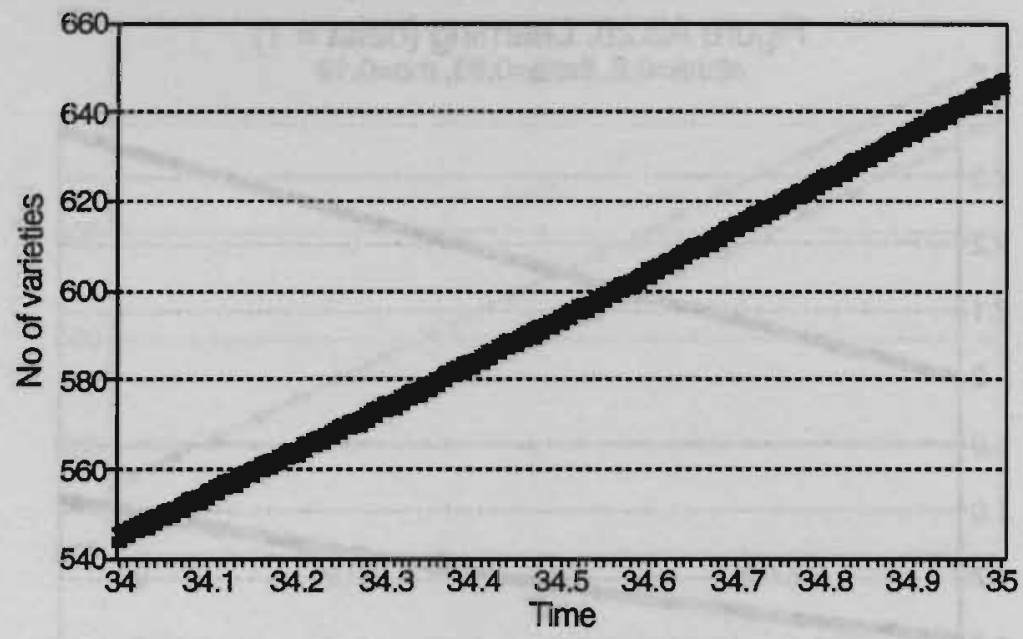

$-z-=1.60955 \rightarrow n=2$

Figure A3.31. Leaming (delta $=1$ )

alpha $=0.2$, theta $=0.83$, tho $=0.19$

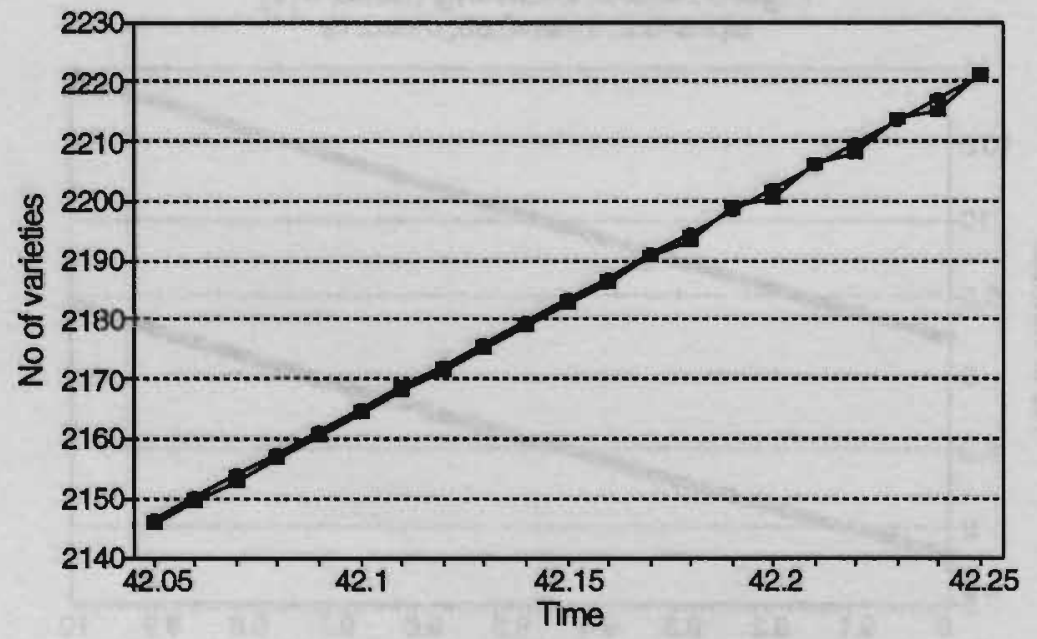

$\because-z \cdot=1.60955 \rightarrow n=2$ 
Case 7: rho $=0.19$, alpha $=0.2, n=4$

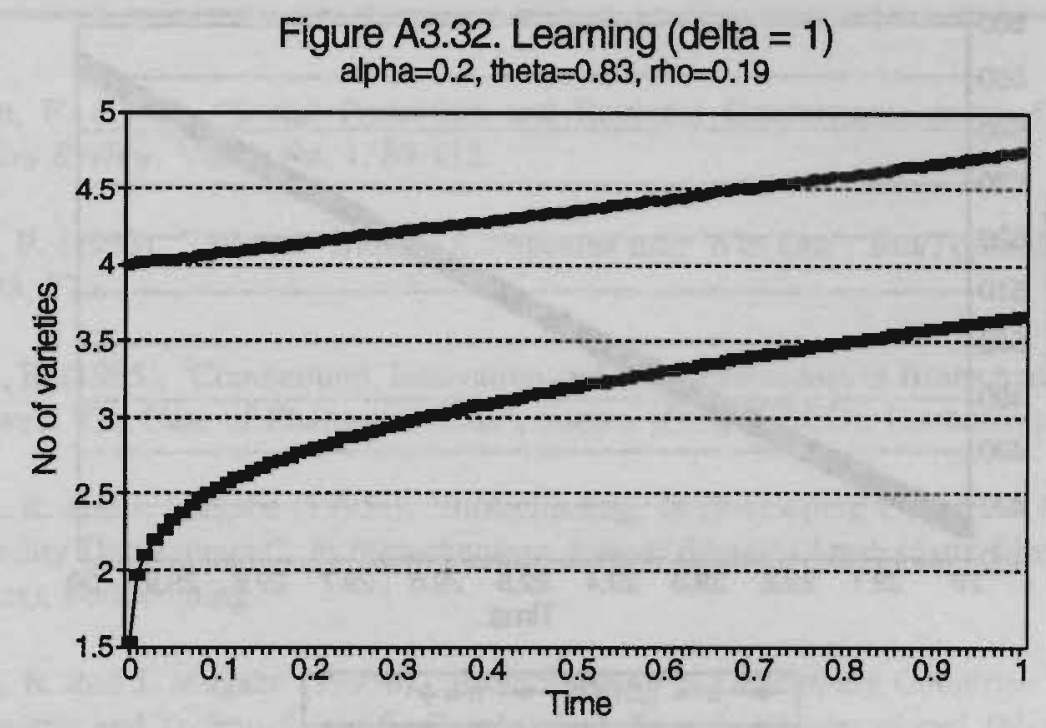

$-z^{-}=1.51525 \rightarrow n=4$

Figure A3.33. Leaming (delta $=1$ )

alpha $=0.2$, theta $=0.83$, mo $=0.19$

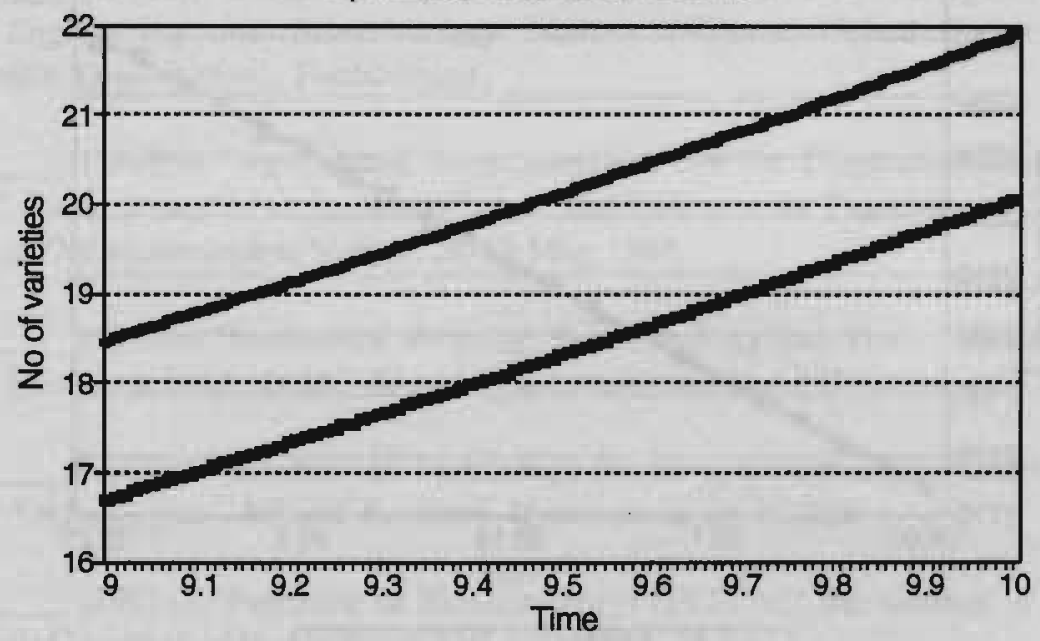

$\rightarrow z \cdot=1.51525 \rightarrow n=4$ 
Figure A3.34. Leaming (delta $=1$ ) alpha $=0.2$, theta $=0.83$, rho $=0.19$

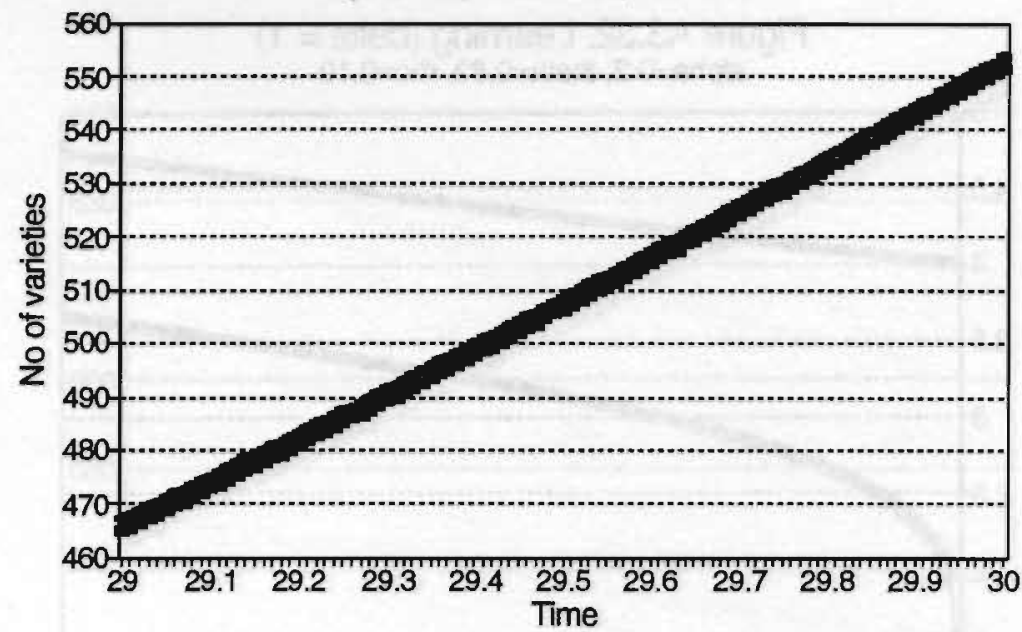

$\rightarrow-z=1.51525 \longrightarrow n=4$

Figure A3.35. Leaming (delta $=1$ )

alpha $=0.2$, theta $=0.83$, $r h o=0.19$

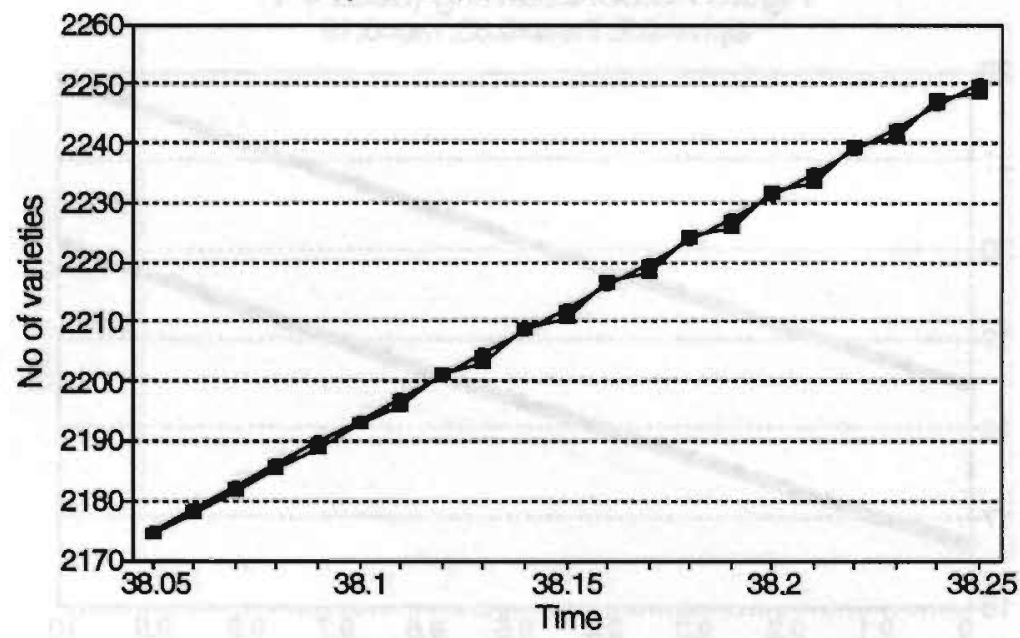

$\rightarrow-z-=1.51525 \rightarrow n=4$ 


\section{References}

Abraham, F. (1994), "Social Protection and Regional Convergence in an EMU", Open Economies Review, Vol.5, No. 1, 89-112.

Abrams, P. (1993), "'Virtual' Biotech Companies may Win Out", Bio/Technology, vol. 11, July $1993,775$.

Acharya, R. (1995), "Competition, Innovation and Competitiveness in Biotechnology in India and Taiwan: The Case of Pharmaceuticals", mimeo (Paris: OECD), Forthcoming.

Acharya, R. and J. Mugabe (1995a), "Biotechnology in Developing Countries: Critical Issue of Capability Development", in Biotechnology Annual Review (Amsterdam: Elsevier Science Publishers), Forthcoming.

Acharya, R. and J. Mugabe (1995b), "Biotechnology in Developing Countries: Institutional Arrangements and Techno-Scientific Capabilities", Biopolicy International, (Nairobi, Kenya: African Centre for Technology Studies), Forthcoming.

Acharya, R. (1994), "Biodiversity Prospecting: Prospects for Private Sector Participation in the Asia-Pacific", paper presented at the Regional Conference on Biodiversity Conservation, organized by the Asian Development Bank, Manila 6-8 June 1994.

(1993a), "Biotechnology in South Asia: Issues of Technological Capability", Genetic Engineering and Biotechnology Monitor (Vienna: United Nations Industrial Development Organisation), Forthcoming.

(1993b), "Agricultural Biotechnologies and the Displacement of Traditional Products", Paper presented at the Workshop on Innovation in the Traditional Sectors and the Survival of Old technologies, Venice, 28-29 May 1993.

(1992a), "Intellectual Property, Biotechnology and Trade: The Impact of the Uruguay Round on Biodiversity" Biopolicy International, No. 4 (Nairobi: ACTS Press).

(1992b), "Science and Technology for Development: Industrializing Countries and New Technologies", MERIT Research Memoranda, no. 92-008.

(1991a), "Patenting of Biotechnology: GATT and the Erosion of the World's Biodiversity" Journal of World Trade Vol. 25, No. 6, 71-88.

(1991b), "Biotechnology and Minerals: The Case of Copper", Biotechnology

and Development Monitor (Amsterdam), no 6, March, 17-18. 
paper presented at the IFIAS International Symposium on Biotechnology and International Trade, Maastricht, 20-22 June.

Acharya, R. and R. Spencer (1990b), "Biotechnology and the Mining Industry: The Bacterial Connection", IFIAS Biopolicy Series, No 3.

Acs, Z.J. and D.B. Audretsch (1989), "Patents as a Measure of Innovative Activity", Kyklos, Vol. 42, Fasc. 2, 171-180.

Aghion, P. and P. Howitt (1992), "A Model of Growth Through Creative Destruction", Econometrica, Vol. 60, No. 2, 323-351.

Arrow, K. (1962), "The Economic Implications of Learning by Doing", Review of Economic Studies, no. 29, 155-173.

Balassa, B. (1981), The Newly Industrializing Countries in the World Economy (New York: Pergamon Press).

Bardhan, P.K. (1977), "Variations in Forms of Tenancy in a Peasant Economy," Journal of Development Economics, 4, June, 105-18.

Barro, R.J. (1990), "Govermment Spending in a Simple Model of Endogenous Growth", Journal of Political Economy, Vol. 98, October, S103-S125.

Barton, J. and W.E. Siebeck (1992), "Intellectual Property Issues for the International Agricultural Research Centres: What Are the Options?" Issues in Agriculture Series, No. 4, (Washington D.C.: World Bank).

Barton, J. and E. Christensen (1988), "Diversity Compensation Systems: Ways to Compensate Developing Nations for Providing Genetic Materials", in Seeds and Sovereignty: The Use and Control of Plant Genetic Resources (ed) Jack R. Kloppenburg (London: Duke University Press).

Bent, S., R. Schwaab, D. Conlin and D. Jeffery (1987), Intellectual Property Rights in Biotechnology Worldwide (London: Macmillan Press).

Beranek, W. and G. Ranis (eds)(1978), Science, Technology and Economic Development: A Historical and Comparative Study, (New York: Praeger Publishers).

Bhaduri, A. (1973), "A Study in Agricultural Backwardness Under Semi-Feudalism," Economic Journal, Vol. 83, No. 329, 120-137.

Bhagwati, J.N. (1964), "The Pure Theory of International Trade: A Survey", Economic Journal, vol 74, 1-84. 
Bhagwati, J.N. and T.N. Srinivasan (1978), Foreign Trade Regimes and Economic Development: India (New York: National Bureau of Economic Research).

Bienefeld, M. (1984), "International Constraints and Opportunities" in Fransman, M. and K. King (eds, 1984), 161-174.

Biotech Consortium India Limited (BCIL)(1993), Directory of Biotechnology Industries and Institutions in India (New Delhi: BCIL).

Bio/Technology, Various Issues (1993 and 1994).

Brander, J. (1986), "Rationales for Strategic Trade and Industrial Policy" in Krugman (ed), 23-46.

Brenner, C. (1992), "Biotechnology and the Changing Public/Private Sector Balance: Developments in Rice and Cocoa", OECD Development Centre Technical Papers No. 72 (Paris: OECD).

Chandrasekhar (1993), "Role of Biotech Consortium India Ltd in the Commercialization of Biotechnology Products/Processes---Status Paper," Paper presented at the Workshop on the Commercialisation of Biotechnologies in Agriculture and Aquaculture at IIM, Ahmedabad, 23-24 April.

Chenery, H. and T.N. Srinivasan (eds) (1989), Handbook of Development Economics: Volumes I and II, (Amsterdam: North Holland).

Cherian, A. (1986), "Cardamom Plantation Industry in India", in Srivastava, H.C., B. Vatsya and K.K.G. Menon (eds.), Plantation Crops: Opportunities and Constraints, Vol. I (New Delhi: Oxford and IBH Publishing Co., Hindustan Lever Research Foundation).

Chin, J. and G. Grossman (1988), "Intellectual Property Rights and North-South Trade", Discussion Papers in Economics, no. 143, Princeton University, Princeton, New Jersey.

Choi, H.S. (1988), "Direction for Technological Self-Reliance: Korean Approaches", Technological Forecasting and Social Change, 33, 23-32.

Cimoli, M. (1990), "Innovation, Endogenous Comparative Advantages and Long-Run Growth" mimeo, September.

Cimoli, M. and L. Soete (1988), "A Generalized Technology Gap Model", Working paper no. 8808 Departimento di Scienze Economiche, Universita degli Studi di Venezia.

Clark, N. and C. Juma (1991), Biotechnology for Sustainable Development: Policy Options for Developing Countries, IFIAS and ACTS (Nairobi, Kenya: African Centre for Technology Studies). 
(1987). Long Run Economics: An Evolutionary Approach to Economic Growth, (London: Pinter Publishers).

Cole, S. (1979), "North-south Income Distribution and Terms of Trade in a Model of Innovation and Transfer of Technology". Science Policy Research Unit, University of Sussex. Brighton, UK.

Conroy, R. (1990), "Domestic and Foreign Technology---Factors Influencing Assimilation and Diffusion Capabilities" in T. Leuenberger (ed).

Cooper C. (1994), Technology and Innovation in the International Economy (London: Edward Elgar, UNU Press).

(1991), "Are Innovation Studies on Industrialized Economies Relevant to Technology Policy in Developing Countries?", UNU/INTECH Working Paper, No. 3, June. (1973)(ed), Science, Technology and Production in Underdeveloped Countries: An Introduction, (London: Frank Cass).

Daly, P. (1985), Biotechnology Business: A Strategic Analysis. (London: Frances Pinter).

Dasgupta, P. (1988), "Patents, Priority and Imitation", Economic Journal, Vol 98. March.

David, P (1991), "Technology, Resource Endowments, Property Rights and Trade: An Open Developing Country's Viewpoint". Centre for Economic Policy Research, Publication no. 278. December.

Denison, E.F. (1967). Why Growth Rates Differ, (Washington DC.: Brookings Institute).

Desai, A. (ed) (1988), Technology Absorption in Indian Industry, (New Delhi: Wiley Eastern Limited).

Desai, A. (1984), "Achievements and Limitations of India's Technological Capability", in M. Fransman (ed), 245-261.

Development Centre for Biotechnology (1994), Biotechnology Information Service Report (Taipei, Taiwan: Development Centre for Biotechnology).

van Dijk, T. (1994), "The Limits of Patent Protection: Essays on the Economics of Intellectual Property Rights", (University of Limburg: Unpublished PhD Dissertation).

Dixit, A. and Stiglitz, J. (1977), "Monopolistic Competition and Optimum Product Diversity," American Economic Review, Vol. 67, 1120-1171.

Dollar, D. (1986), "Technological Innovation, Capital Mobility and the Product Cycle in 
North-South Trade" American Economic Review.

Dore, R. (1984), "Technological Self-Reliance: Sturdy Ideal or Self-serving Rhetoric", in Fransman, M. and K. King (eds, 1984), 65-80.

Dosi, G., K. Pavitt and L. Soete (1990), The Economics of Technical Change and International Trade, (Hemel Hempstead: Harvester Wheatsheaf).

Dosi, G. et.al. (1988), eds., Technical Change and Economic Theory, (London: Pinter Publishers).

Duysters, G. and J. Hagedoorn (1992), "Convergence and Divergence in the International Information Technology Industry", paper prepared for the MERIT Conference on Convergence and Divergence in Economic Growth and Technical Change, Theme III, "Internationalisation of Corporate Technology Strategies", Maastricht, The Netherlands, December 10-12, 1992.

Eisemon, T.O. (1984), "Insular and Open Strategies for Enhancing Scientific and Technological Capacities: Indian Educational Expansion and Its Implications for African Countries", in Fransman, M. and K. King (eds, 1984), 263-278.

Emst and Young (1993), Biotech 94: Long-Term Value, Short-Term Hurdles, Ernst and Young's Eighth Annual Report on the Biotech Industry (San Francisco: Ernst and Young).

Ernst and Young (1992), Biotech 93: Accelerating Commercialization, Ernst and Young's Seventh Annual Report on the Biotech Industry, (San Francisco: Emst and Young).

Ethier, W. (1982), "National and International Returns to Scale in the Modern Theory of International Trade," American Economic Review, Vol. 72, 389-405.

Evenson, R.E. (1993), "The Study of Technology in Economic Development: Lessons from Agriculture for Industry", Keynote address delivered to the first UNU/INTECH Conference, in Maastricht, the Netherlands, June 21-23.

Fagerberg, J. (1988), "Why Growth Rates Differ", in Dosi et.al., 432-457.

Flam, H. and E. Helpman (1987), "Vertical Product Differentiation and North-South Trade", American Economic Review, Vol 77, No 5, 810-822.

Flegel, T. W., G. Tharun and Y. Yuthavong (eds)(1990), Biotechnology for Small Industries in Developing Countries: Proceedings of an International Symposium on Application of Biotechnology for Small Industries Development in Developing Countries, Bangkok, Thailand, 21-24 September 1988.

Fox, B. (1991), "An International Charter for Inventors?" New Scientist, 19 January. 
Fransman, M. (1991), "Biotechnology: Generation, Diffusion and Policy", United Nations University Institute of New Technologies (UNU/NTECH) Working Paper no. 1.

Fransman, M. (1986), Technology and Economic Development, (Brighton: Wheatsheaf Books).

Fransman, M. (1984), "Technological Capability in the Third World: An Overview and Introduction to some of the Issues Raised in this Book", in Fransman, M. and K. King (eds, 1984), 3-30.

Fransman, M. and K. King (eds)(1984), Technological Capability in the Third World, (London: Macmillan).

Freeman, C. (1988), "Technology Gaps, International Trade and the Problems of Smaller and Less-Developed Economies", in Small Countries Facing the Technological Revolution, (eds) Christopher Freeman and Bengt-Ake Lundvall (London: Pinter Publishers), 67-110.

Freeman, C. (1987), Technology Policy and Economic Performance: Lessons from Japan, (London: Frances Pinter).

Freeman, C. (1982), Economics of Industrial Innovation, (Second edition), (London: Frances Pinter).

Freeman, C. (1963), "The Plastics Industry: A Comparative Study of Research and Innovation", Economic Review, No. 26, 22-62.

GATT (1994) Final Act of the Uruguay Round in Marrakesh on 15th April 1994 (New Delhi: Vidhi Publishing).

GATT Secretariat (1990), Communication from Argentina, Brazil, Chile, China, Colombia, Cuba, Egypt, India, Nigeria, Pakistan, Peru, Tanzania, Uruguay and Zimbabwe to the Negotiating Group on Trade-Related Aspects of Intellectual Property Rights, including Trade in Counterfeit Goods, 14 May 1990 (Geneva: GATT).

Ghosh, A.K. and A. Saith (1976), "Indebtedness, Tenancy and the Adoption of New Technology in Semi-Feudal Agriculture," World Development, Vol. 8, April, 291-298.

Grain (1990), "Genes for Sustainable Development: Towards a Global Convention on the Conservation and Sustainable Utilization of Biological Diversity," November.

Greenaway, D. (1991), "New Trade Theories and Developing Countries" in V.N. Balasubramanyam and S. Lall (eds), Current Issues in Development Economics, (London: Macmillan Education Ltd), 156-170.

Griliches, Z. (1990), "Patent Statistics as Economic Indicators: A Survey", Joumal of Economic Literature, Vol. 28, December, 1661-1707. 
Griliches, Z. (ed)(1984), $R \& D$ Patents and Productivity, (Chicago: University of Chicago Press).

Griliches, Z. (1979), "Issues in Assessing the Contribution of R\&D to Productivity Growth", Bell Journal of Economics, No 10, Spring.

Grossman, G. and E. Helpman (1991a), Innovation and Growth in the Global Economy (Cambridge, Ma.: MIT Press).

Journal of Economics, Vol. 106, 557-86.

(1991b), "Quality Ladders and Product Cycles," Quarterly (1991c), "Quality Ladders in the Theory of Growth" Review of Economic Studies, no. 58, 43-61.

(1991d), "Endogenous Product Cycles", The Economic Journal, No. 101 (September), 1214-1229.

(1991e), "Trade, Knowledge Spillovers and Growth", European Economic Review, 35 (Papers and Proceedings).

(1991f), "Growth and Welfare in a Small Open Economy", in E. Helpman and A. Razin (eds.), International Trade and Trade Policy (Cambridge: MIT Press).

American Economic Review, Vol. 80, 796-815.

(1990), "Comparative Advantage and Long-Run Growth", (1989), "Product Development and International Trade", Journal of Political Economy, Vol 97, No 6, 1261-1283.

Halos, S.C. (1989), "Biotechnology Trends: A Threat to Philippine Agriculture?" World Employment Programme Research Working Paper, no. 193 (Geneva: International Labour Office).

Han, Moon H. (1990), "Present Status of R\&D Endeavour of Genetic Engineering and Biotechnology in Korea", in Proceedings of an International Conference on Biotechnology held in Kyungju, Korea, 22-25 April 1990, 12-17.

Hayami, Y. and V.W. Ruttan (1991), Agricultural Development: An International Perspective, (Baltimore: Johns Hopkins University Press).

Helpman, E. (1993), "Innovation, Imitation and Intellectual Property Rights", Econometrica, 61(6), 1247-1280.

Helpman, E. and P.R. Krugman (1989), Trade Policy and Market Structure, (Cambridge, Ma.: 


\section{MГT Press).}

Helpman, E. and P. Krugman (1985), Market Structure and Foreign Trade: Increasing Returns, Imperfect Competition and the International Economy (Cambridge: MIT Press).

Hillebrand, W. (1990), "The Newly Industrializing Economies as Models for Establishing a Highly Competitive Industrial Base--What Lessons to Learn?" in Kulessa (ed).

Hoselitz, B.F. (ed) (1960), Theories of Economic Growth, (New York: The Free Press)

Johnson, C. (1982), MITI and the Japanese Miracle: The Growth of Industrial Policy, 19251975, (Stanford: Stanford University Press).

Johnson, H.G. (1975), Technology and Economic Interdependence, (London: Macmillan Press for the Trade Policy Research Centre).

Johnston, J. (1984), Econometric Methods, 3rd edition, (New York: McGraw Hill).

Jones, R.W. (ed) (1986), International Trade: Surveys of Theory and Policy, Selections from the Handbook of International Economics, (Amsterdam: Elsevier Science Publishers).

Judd, K. (1985), "On the Performance of Patents", Econometrica, Vol. 53, no.3, pp 567-585.

Juma, C. (1989a), Biological Diversity and Innovation: Conserving and Utilizing Genetic Resources in Kenya, (Nairobi, Kenya: ACTS Press).

Juma, C. (1989b), The Gene Hunters: Biotechnology and the Scramble for Seeds, (London: Zed Books)

Juma, C. and J. B. Ojwang (1989) eds. Innovation and Sovereignty: The Patent Debate in African Development (Nairobi, Kenya: ACTS Research Series, No 2).

Junne, G. (1995), "The Impact of Biotechnology on International Commodity Trade", in E.J. DaSilva, C. Ratledge and A. Sasson (eds), Microbial Technology: Economic and Social Aspects, (Cambridge: Cambridge University Press, forthcoming).

Junne, G. and K. van den Doel (1986), "Product Substitution through Biotechnology: Impact on the Third World, Trends in Biotechnology, Vol. 4, no. 4 April 1986, 88-90.

Junne, G. J. Komen and F. Tomei (1989), "Dematerialization of Production: Impact on Raw Material Exports of Developing Countries", Third World Quarterly, Vol. 11, No. 2, April 1989.

Kaplinsky, R. (1988), "Industrial and Intellectual Property Rights in the Uruguay Round and Beyond", (Brighton: Institute of Development Studies, University of Sussex). 
Kaplinsky, R. (1984), "Trade in Technology: Who, What, Where and When?" in Fransman, M. and K. King (eds, 1984), pp 139-160.

Kloppenburg, J. (1988), "The Genetic Resources Controversy", in The Biotechnology Revolution and the Third World: Challenges and Policy Options, (eds) N Kumar and V Panchamukhi, (New Delhi: Research and Information System for the Non-Aligned and Other Developing Countries).

Kenney, M. (1986), Biotechnology: The University-Industrial Complex, (New Haven: Yale University Press).

Kidd, G. and J. Dvorak (1994), "Agracetus' Cotton Patent Draws Opposition", Bio/Technology Vol. 12, July, 659.

Kierzkowski, H. (ed)(1984), Monopolistic Competition and International Trade, (Oxford: Clarendon Press).

Kim, Linsu and C. Dahlman (1992), "Technology Policy for Industrialization: An Integrative Framework and Korea's Experience", Research Policy, 21, 437-452.

King, K. (1984), "Science, Technology and Education in the Development of Indigenous Technological Capability", in Fransman, M. and K. King (eds, 1984), 31-64.

King, R.G. and S. Rebelo (1990), "Public Policy and Economic Growth: Developing Neoclassical Implications", NBER Working Paper no. 3338.

Klausmeier, W.H., P. Hall, C. Chase-Lansdale and R. Parra (1990), "Emerging Biotechnology Enterprises in Southeast Asia: Prospects and Challenges" in Flegel, Tharun and Yuthavong (eds), 179-184.

Komen, J. and G. Persley (1993), "Agricultural Biotechnology in Developing Countries: A Cross-Country Review", ISNAR Research Report, no. 2 (The Hague: ISNAR)

Krueger, A.O. (1986), "Trade Policies in Developing Countries" in Jones (ed), pp 131-181.

Krueger, A.O. (1978), Foreign Trade Regimes and Economic Development: Liberalization Attempts and Consequences, (New York: NBER).

Krugman, P.R. (1989), "New Trade Theory and the Less Developed Countries", in Calvo, G., R. Findlay, P. Kopuri and J.B. de Macedo (eds), Debt, Stabilization and Development (Oxford: Blackwell for WIDER), 347-365.

Krugman, P.R. (ed)(1986), Strategic Trade Policy and the International Economics, (Cambridge, Ma.: MIT Press). 
Krugman, P.R. (1979), "A Model of Innovation, Technology Transfer and the World Distribution of Income", Journal of Political Economy, (87), 2, 253-266.

Kulessa, M. (ed)(1990), The Newly Industrializing Economies of Asia, (Berlin, Heidelberg: Springer-Verlag).

Kumar, N. (1990), "Biotechnology and Substitution of Third World Exports", presentation at plenary session 4 of the Regional Seminar on Biotechnology, Manila, December 3-6.

Kumar, P.V.S. and U. Menon (1992), "Report on Baseline Survey Evaluation Studies on Tissue Culture Cardamom", mimeo (New Delhi: NISTADS).

Laffont, J-J. and J. Tirole (1993), A Theory of Incentives in Procurement and Regulation (Cambridge: MIT Press).

Lall, S. asst by G. Wignaraja (1989), National Capabilities to Master Technological Change: A First Look at Selected Developing Countries, (Paris: OECD Development Centre, June).

Lall, S. (1985), Multinationals, Technology and Exports: Selected Papers (London: Macmillan Press).

Lall, S. (1984a), "India's Technological Capacity: Effects of Trade, Industrial, Science and Technology Policies", in M. Fransman and K. King (eds) 1984.

Lall, S. (1984b), "Exports of Technology by Newly-Industrializing Countries: An Overview", World Development, Vol. 12, No. 5/6, 471-480.

Lall, S. (1982), "The Emergence of the Third World Multinationals: Indian Joint Ventures Overseas", World Development, Vol 10, 127-46.

Lall, S. (1982), "Technological Learning in the Third World: Some Implications of Technology Exports" in F. Stewart and J. James (eds), 157-179

Lall, S. (1976), "The Patent System and the Transfer of Technology to Less Developed Countries", Journal of World Trade Law.

Lavakare, P.J. and J.G. Waardenburg (1989), Science Policies in International Perspective: The Experience of India and the Netherlands, (London: Pinter Publishers).

Leamer, E. (1984), Sources of International Comparative Advantage: Theory and Evidence, (Cambridge, Ma.: MIT Press).

Lee, K. (1989), "Generation of Political Will and Political Action for Biotechnology R\&D in Korea: Implications for Korean and Asian Agriculture", paper presented at the regional seminar on Public Policy Implications of Biotechnology for Asian Agriculture, 6-8 March 
1989, New Delhi, India.

Letiche, J.M. (1960), "Adam Smith and David Ricardo on Economic Growth", in B. F. Hoselitz (ed).

Leuenberger, T. (ed)(1990), From Technology Transfer to Technology Management in China, (Berlin Heidelberg: Springer Verlag).

Lowe, P., T. Marsden and S. Whatmore (eds) (1990), Technological Change and the Rural Environment, (London: David Fulton Publishers Ltd).

Lucas, R. (1988), "On the Mechanics of Economic Development", Journal of Monetary Economics, no. 22, 3-42.

Marstrand, P. (1981), "Patterns of Change in Biotechnology", Occasional Paper Series no. 15, (Brighton: Science Policy Research Unit, University of Sussex).

McKelvey, M. (1994), Evolutionary Innovation: Early Industrial Uses of Genetic Engineering, Phd Thesis, Department of Technology and Social Change, Linköpings University, Sweden.

Menasveta, P. (1990), "The Present Status of Aquaculture in Thailand and the Potential Uses of Biotechnology to Increase Coastal Aquaculture Production" in Flegel, Tharun and Yuthavong (eds), 55-63.

Mestel, R. (1994), "Rich Pickings for Cotton's Pioneers", New Scientist, 19 February, 13-14.

Mooney, P.R. (1979), Seeds of the Earth: A Private or Public Resource?, (Ottawa: Canadian Council for International Cooperation).

Mugabe, J. (1994), Technological Capability for Environmental Management: The Case of Biodiversity Conservation in Kenya, Unpublished PhD Thesis, (Amsterdam: University of Amsterdam).

Narula, R. (1993), An Examination of the Evolution and Interdependence of Foreign Direct Investment and Economic Structure: The Case of the Industrialized Countries, Unpublished $\mathrm{PhD}$ Dissertation (New Jersey: Rutgers University).

National Centre for Genetic Engineering and Biotechnology (NCGEB) (1991), Annual Report (Bangkok: NCGEB).

National Science Council (1993), Indicators of Science and Technology: Republic of China, (Taipei: National Science Council).

Nelson, R.R. and S.G. Winter (1982), An Evolutionary Theory of Economic Change (Cambridge, Ma.: Harvard University Press). 
Nelson, R.R. and S.G. Winter (1977), "In Search of Useful Theory of Innovation", Research Policy, no. 6, 36-76.

Newberry, D.M.G. (1975), "Tenurial Obstacles to Innovation", Journal of Development Studies, July, 263-277.

O'Brien, P. (1974), "Developing Countries and the Patent System: An Economic Appraisal", World Development, Vol. 2, No. 9, September.

OECD (1993a), Traditional Crop Breeding Practices: An Historical Review to Serve as a Baseline for Assessing the Role of Modern Biotechnology, (Paris: OECD).

OECD (1993b), Safety Considerations for Biotechnology Scale-Up of Crop Plants, (Paris: OECD).

OECD (1993c), Field Releases of Transgenic Plants 1986-1992: An Analysis (Paris: OECD).

OECD (1989), Biotechnology: Economic and Wider Impacts (Paris: OECD).

OECD (1985), Biotechnology and Patent Protection: An International Review, by F.K. Beier, R.S. Crespi and J. Straus (Paris: Organization for Economic Cooperation and Development).

OECD (1982), Biotechnology: International Trends and Perspectives by A.T. Bull, G. Holt and M.D. Lilly, (Paris: Organization for Economic Cooperation and Development).

Okimoto, D. (1982) (ed.), Japan's Economy: Coping With Change in the International Environment, (Denver, Co.: Westview Press).

Orsenigo, L. (1989), The Emergence of Biotechnology: Institutions and Markets in Industrial Innovations, (London: Pinter Publishers).

Pack, H. and L.E. Westphal (1986), "Industrial Strategy and Technological Change: Theory versus Reality", Joumal of Development Economics, 22, 87-128.

Padolina, W.G. (1991), "Biotechnology Action Plan" mimeograph, University of the Philippines, Los Baños, Philippines.

Pakes, A. and Z. Griliches (1984), "Patents and R\&D at the Firm Level: A First Look," in Griliches (ed)(1984), 55-72.

Panchamukhi, V.R. and N. Kumar (1988), "Impact of Biotechnology Revolution on Commodity Exports of Developing Countries," (New Delhi: Research and Information System (RIS) for the Non-Aligned and Other Developing Countries).

Patel, P. and K. Pavitt (1987), "Is Western Europe Losing the Technology Race?", Research 
Policy, vol. 16.

Pecorino, P. (1994), "The Growth Rate Effects of Tax Reform", Oxford Economic Papers, forthcoming.

Perez, C. (1988), "New Technologies and Development", in Freeman and Lundvall (eds), 8597.

Perez, C. and L. Soete (1988), "Catching Up in Technology: Entry Barriers and Windows" in Dosi et.al., 458-479.

Persley, G. J. (ed)(1990), Agricultural Biotechnology: Opportunities for International Development, (Wallingford, Oxfordshire: CAB International).

Posner, M. (1961), "International Trade and Technical Change", Oxford Economic Papers, Vol 13, 323-341.

Rahman, A. (ed)(1990), Science and Technology in India, Pakistan, Bangladesh and Sri Lanka, (London: Longman Group).

Reddy, A.S.P and J. Sigurdson (1994), "Strategic Location of R\&D and Emerging Patterns of Globalization: The Case of Astra Research Centre in India", Research Policy Institute, University of Lund, Sweden.

Reid W., S.A. Laird, C.A. Meyer, R. Gámes, A. Sittenfeld, D.H. Janzen, M.A. Gollin and C. Juma (1993), Biodiversity Prospecting: Using Genetic Resources for Sustainable Development, (Washington DC.: World Resources Institute, Instituto Nacional de Biodiversidad, Rainforest Alliance and the African Centre for Technology Studies).

Reinganum, J. (1981), "On the Diffusion of New Technology: A Game Theoretic Approach", Review of Economic Studies, Vol. 48.

Republic of China (1993), Indicators of Science and Technology: Republic of China (Taiwan: Republic of China).

Republic of Korea (1993), Report on the Survey of Research and Development in Science and Technology (Republic of Korea: Ministry of Science and Technology).

Romer, P. M. (1990), "Endogenous Technological Change", Journal of Political Economy, Vol. 98, S72-S102.

Romer, P. M. (1987), "Growth Based on Increasing Returns Due to Specialization," American Economic Review, 77, 56-62.

Rosenberg, N. (1982), Inside the Black Box: Technology and Economics (Cambridge: 
Rosenberg, N. (1976), Perspectives on Technology, (Cambridge: Cambridge University Press).

Ruivenkamp, G. (1986), "The Impact of Biotechnology on International Development: Competition between Sugar and Sweeteners," Vierteljahrsberichte des Forschungsinstituts der Friedrich-Ebert-Stiftung, No. 103, Special Issue on "New Technologies and Third World Development," 89-101.

Sasson, A. (1993), Biotechnologies in Developing Countries: Present and Future, Vol. I: Regional and National Survey, (Paris: UNESCO).

Sasson, A. and V. Costarini (eds)(1989), Plant Biotechnologies for Developing Countries, Proceedings of an International Symposium organized by CTA and FAO, 26-30 June 1989, Luxembourg.

Sasson, A. (1990), "Plant Biotechnologies: Present and Future, Especially of Developing Countries", in Flegel, Tharun and Yuthavong (eds), 19-29.

SBIP (Science Based Industrial Park) (1994), Information Package (Hsinchu: Taiwan).

Scherer, F.M. (1984), Innovation and Growth: Schumpeterian Perspectives (Cambridge: MIT Press).

(1980), Industrial Market Structure and Economic Performance, (Boston: Houghton Mifflin 2nd edition).

Schmookler J. (1966), Invention and Economic Growth, (Cambridge, Ma: Harvard University Press).

Schneider, J. and T. Ziesemer (1994), "What's New and What's Old in New Growth Theory: Endogenization of Technology, Microfoundationa and Growth Rate Predictions - A Critical Overview", MERIT Research Memorandum, RM 2/95-029.

Schumpeter, J. (1934), The Theory of Economic Development, (Cambridge, Ma.: Harvard University Press).

Sercovich, F. (1991), "Industrial Biotechnology Policy: Guidelines for Semi-Industrial Countries" in Issues in the Commercialization of Biotechnology: Proceedings of the Expert Group Meeting on the Commercialization of Biotechnology, UNIDO (Vienna: UNIDO), 168171.

Sharp, M. (1990), Technological Trajectories and Corporate Strategies in the Diffusion of Biotechnology in E. Deiaco, E. Hörnell and G. Vickery (eds), Technology and Investment: Critical Issues for the 1990s (London: Pinter Publishers). 
Sharp, M. (1985), The New Biotechnology: European Governments in Search of a Strategy, Sussex European Paper no. 15, (Brighton: SPRU, University of Sussex).

Shell, K. (1956), "Toward a Theory of Inventive Activity and Capital Accumulation", American Economic Review, May, 62-68.

Shiva, V. (1989), The Violence of the Green Revolution: Ecological Degradation and Political Conflict in Punjab (Dehra Dun, India: Research Foundation for Science and Technology).

Singh, R.B. (1989), "Current Status and Future Prospects of Plant Biotechnologies in Developing Countries in Asia" in Sasson and Costarini (eds), 141-162.

Smits, M-J (1991), "Biotechnology and the Environment: Opportunities and Risks", Development and International Cooperation, Vol VIII, no 13, December, 101-115.

Society for International Development (SID)(1988), Development, Special Issue on Biotechnology.

Soete, L. (1991a), "National Support Policies for Strategic Industries: The International Implications", MERIT Research Memorandum, 91-006.

Soete, L. (1991b), "Technology in a Changing World", MERIT Research Memorandum, 91005 .

Soete, L. (1987), "The Impact of Technological Innovation on International Trade Patterns: The Evidence Reconsidered", Research Policy, No 16, 101-130.

Soete, L. (1981), "A General Test of Technology Gap Trade Theory", Weltwirtschaftliches Archiv, Vol. 117.

Solow, R.M. (1957), "Technical Progress and the Aggregate Production Function", Review of Economics and Statistics, Vol. 39, 312-320.

Solow, R.M. (1956), "A Contribution to the Theory of Economic Growth, Quarterly Joumal of Economics, Vol. 70, 65-94.

Soong, Tai-Sen (1991), "Current Industrial Biotechnology Development in Taiwan", Agro Industry Hi-Tech: International Journal for Food Chemicals, Pharmaceuticals, Cosmetics as Linked to Agriculture through Advanced Technology, 1991, 11-17.

Sorenson, P.B. (1993), "Human Capital Investment, Government and Endogenous Growth", Finanzarchiv, 73-93.

Spence, A.M. (1981), "The Learning Curve and Competition," Bell Journal of Economics, 10 , $1-19$. 
Spence, A.M. (1976), "Product Differentiation and Welfare," American Economic Review, 66, 407-414.

Spencer, B. (1986), "What Should Trade Policy Target?" in Krugman (ed), 69-90.

Stewart, F. (1991), "A Note on 'Strategic' Trade Theory and the South" Journal of International Development, Vol. 3, No. 5, 467-484.

Stewart, F. (1984), "Recent Theories of International Trade: Some Implications for the South", in H. Kierzkowski (ed), 84-108.

Stewart, F. and J. James (eds)(1982), The Economics of New Technology in Developing Countries, (London: Frances Pinter).

Stokey, N. (1991), "Human Capital, Product Quality and Growth," Quarterly Journal of Economics, May, 587-616.

Stokey, N. (1988), "Learning by Doing and the Introduction of New Goods", Journal of Political Economy, Vol. 96, no. 4, 701-717.

Subrahmaniam, K.K. (undated), "Technological Transformation: An Assessment of India's Experience" mimeo, prepared for UNU/WIDER.

Tang, T.B. (1984), Science and Technology in China, (London: Longman Group).

TIFAC (1994), "Role of TIFAC in Accelerating Technological Development" paper presented by TIFAC at ASSOCHAM, 2 September, New Delhi.

Tinbergen, J. (1942), "Zur Theorie der langfristigen Wirtschaftsentwicklung," Weltwirtschaftliches Archiev, 55, 511-549.

Trostel, P.A. (1993), "The Effect of Taxation on Human Capital" Journal of Political Economy, vol. 101, no. 2, 327-350.

United Nations (1991), World Investment Report (New York: United Nations)

UNCTAD (1991), Transfer and Development of Technology in a Changing World Environment: The Challenges of the 1990s, A Report by the UNCTAD Secretariat, 25 January, (Geneva: TD/B/C.6/153).

UNCTAD (1989), Impact of Technological Change on Patterns of International Trade, Note by the UNCTAD Secretariat, 19 May, (UNCTAD/TTP/TEC/3).

UNCTAD Secretariat (1988), "Technology Related Policies and Legislation in a Changing Economic and Technological Environment", Trade and Developent Board, Committee on 
Transfer of Technology, Seventh Session (Geneva: UNCTAD).

UNEP (1990), "Biotechnology: Concepts and Issues for Consideration in Preparation of a Framework Legal Instruments for the Conservation of Biological Diversity," Ad-Hoc Working Group of Experts on Biological Diversity, UNEP/Bio.Div, 3/11, 29 June (Nairobi: UNEP).

US Congress Office of Technology Assessment (OTA)(1991), Biotechnology in a Global Economy, (Washington DC.: US Congress Office of Technology Assessment, US Government Printing Office).

US Congress Office of Technology Assessment and Forecasting (OTAF) (1982), Patent Profiles: Biotechnology, 1982 Update, (Washington DC.: US Department of Commerce, US Government Printing Office).

Vaitsos, C. (1973), "Patents Revisited: Their Function in Developing Countries", in Science, Technology and Development: The Political Economy of Technical Advance in Underdeveloped Countries, (London: Frank Cass).

Vernon, R. (1966), "International Investment and International Trade in the Product Cycle", Quarterly Journal of Economics, Vol 80, 190-207.

Walgate, R. (1990), Miracle or Menace? Biotechnology and the Third World, (London: Panos Institute).

Walsh, V. (1993), "Demand, Public Markets and Innovation in Biotechnology", Science and Public Policy, 20: 3, 138-156.

Ward, M. (1993), "Rhône-Poulenc: From BioScience to Markets; The how, why and when of the world's seventh-largest chemicals company", Bio/Technology, vol. 11, July 1993, 798801.

Watson, J.D. (1968), The Double Helix, (Harmondsworth, UK: Penguin Publishers).

Westphal, L. (1978), "The Republic of Korea's Experience with Export led Industrial Development," World Development, vol.6, 347-80.

Westphal, L., Y.W. Rhee and G. Pursell (1984), "Sources of Technological Capability in South Korea", in Fransman, M. and K. King (eds, 1984), 279-300.

Wheale, P.R. and R.M. McNally (1986), "Patent Trend Analysis: The Case of Microgenetic Engineering" Futures, October, 638-657.

van Wijk, J., J.Cohen and J. Komen (1994), "Intellectual Property Rights for Agricultural Biotechnology: Options and Implications for Developing Countries", ISNAR Research Report, No. 3. 
World Bank (1994), World Development Report (Washington DC.: The World Bank).

World Bank (1993), The East Asian Miracle: A World Bank Policy Report (Washington DC.: World Bank).

World Development (1984), Special Issue on Technology Exports of Newly Industrializing Countries, Vol. 12, No. 5/6.

WRI, IUCN and UNEP (1992), Global Biodiversity Strategy, (Washington DC.: World Resources Institute, International Union for the Conservation of Nature and United Nations Environment Programme).

Young, A. (1993), "Invention and Bounded Learning by Doing", Journal of Political Economy, vol. 101, no. 3, 443-472.

Young, A. (1991), "Leaming by Doing and the Dynamic Effects of International Trade", Quarterly Journal of Economics, May, 369-405.

Yuan, R. and M. Hsu (1991), "Biostrategies in the Pacific Rim", Genetic Engineering News, May 1991.

Yuan, R. (1986), "Biotechnology in Singapore, South Korea and Taiwan", Report Prepared for the International Trade Administration, US Department of Commerce (Washington DC.: US Department of Commerce).

Yusuf, A. A. (1989), "Developing Countries and Trade-Related Aspects of Intellectual Property Rights", Uruguay Round: Papers on Selected Issues, (Geneva: UNCTAD).

Ziesemer, T. (1993), "Endogenous Growth with Public Factors and Heterogeneous Human Capital Producers", MERIT Research Memoranda, RM 93-022.

(1990), "Public Factors and Democracy in Poverty Analysis", Oxford Economic Papers, 42, January, 268-280.

(1987), Economic Theory of Underdevelopment, Volkswirtschaftliche Schriften der Universität Regensburg, Volume 3 (Regensburg: Transfer Verlag). 


\section{Samenvatting (Summary in Dutch)}

Dit proefschrift gaat over de invloed van innovatie in de biotechnologie op economische groei in industrie- en ontwikkelingslanden, en de gevolgen daarvan voor de handels- en technologiekloof tussen deze twee groepen landen.

In hoofdstuk 1 en 2 worden de huidige ontwikkelingspatronen van nieuwe biotechnologie besproken; in hoofdstuk 3 en 4 wordt dieper ingegaan op de veranderingen in de biotechnologie in respectievelijk industrie- en ontwikkelingslanden. Bij de behandeling van biotechnologische innovatie in industrielanden in hoofdstuk 3 wordt een empirische analyse uitgevoerd die is gebaseerd op patenten voor biotechnologische uitvindingen die zijn geregistreerd bij het Europese Octrooi Bureau en het Octrooibureau van de Verenigde Staten. Er is sprake van een toename in het aantal biotechnologische patenten van ongeveer $10 \%$ per jaar, wat tamelijk hoog is voor vindingen in nieuwe technologieën. Het gebrek aan grote aantallen gepatenteerde vindingen door ontwikkelingslanden in deze technologie vraagt echter om een andere methode om biotechnologische innovatie in deze landen te bestuderen. De empirische analyse in hoofdstuk 4 gaat dan ook uit van proeftoepassingen in India waarmee de toekomstige invloed van biotechnologie op de landbouwproductiviteit kan worden bepaald.

Dit proefschrift houdt zich voornamelijk bezig met de invloed van verbeteringen in kwaliteit dankzij biotechnologie op het totale aanbod aan (oude en nieuwe) produkten die consumenten kunnen verkrijgen en kiezen. In hoofdstuk 5 worden dergelijke kwaliteitsverbeteringen bestudeerd, met name in de landbouw en farmaceutica. De resultaten hiervan zijn dat, in tegenstelling tot de nieuwe groei- en handelstheorieën die in hoofdstuk 6 en 7 aan de orde komen, hoogwaardige produkten die dankzij biotechnologie tot stand zijn gekomen een verschillende invloed hebben op het produktaanbod in de economie. In een aantal gevallen leiden verbeteringen in kwaliteit ertoe dat consumenten uitsluitend de hoogste kwaliteit willen, terwijl in andere gevallen de consumenten de voorkeur geven aan diversiteit boven kwaliteit.

In hoofdstuk 8 worden deze observaties in een nieuw model gepresenteerd. In het gesloten economie-model wordt gebruik gemaakt van observaties over kwaliteit en diversiteit vanuit de biotechnologie; de consumentenpreferentiefunctie die daarin wordt gebruikt lijkt op de 'love of variety' functie zoals die in de nieuwe groeimodellen wordt gebruikt, behalve dat de specificatie een kwaliteitsweging inhoudt die consumenten in staat stelt te kiezen tussen kwaliteit en diversiteit. In de nieuwe groei- en handelstheorieën zijn tot nu toe drie soorten resultaten naar voren gekomen: (i) de 'love of variety' nutsfunctie leidt tot een steeds groeiend produktaanbod omdat nieuwe produkten oude produkten nooit overbodig maken; (ii) de voorkeuren voor het ideale aanbod leiden tot nieuwe produkten die een oud produkt altijd overbodig maken; en (iii) een aantal van de nieuwere modellen duiden op resultaten die tussen deze twee extremen in liggen, dat wil zeggen het produktaanbod in de economie blijft constant of wordt groter terwijl elke nieuwe innovatie ertoe leidt dat een of meer oudere produkten worden vervangen, afhankelijk van de modelspecificaties. Uit formele analyse en simulaties met het model dat in hoofdstuk 8 wordt beschreven, blijkt echter dat deze drie typen resultaten speciale gevallen zijn. Het model dat in dit proefschrift wordt gepresenteerd is dus een veel breder model dat veel van de observaties omvat zoals we die in de biotechnologie tegenkomen, omdat deze betrekking hebben op de relatie tussen innovatie en consumentenvoorkeuren en tegelijkertijd kunnen worden uitgebreid naar een aantal andere, 
meer algemene, technologieën.

Hoofdstuk 9 is een uitbreiding van hoofdstuk 8 in een open economie-situatie. Hierbij wordt uitgegaan van twee economieën, noord en zuid. De noord-economie heeft een voorsprong in R\&D omdat verondersteld wordt dat het technologisch verder gevorderd is. De resultaten van de open economie tonen aan dat een toename van innovaties het aanbod aan nieuwe patenten die naar het zuiden worden overgedragen vergroot maar dat daardoor de handelstermen in het noorden verslechteren. Het laatste leidt bovendien tot lagere vaste produktiekosten voor producenten in het zuiden. De algemene conclusie is dat, in het geval van leereffecten en lage tijdsvoorkeur, het aanbod groter zal worden; indien de tijdsvoorkeur hoger is dan het groeitempo, kan het aanbod tijdelijk groter worden, kleiner worden of gelijk blijven.

Een andere belangrijke conclusie heeft betrekking op het aandeel in de export van ontwikkelingslanden in de internationale handel. Hoewel uit het model blijkt dat ontwikkelingslanden de enige producenten zijn van gedifferentieerde produkten en dus nieuwere soorten produkten maken die vanuit het noorden worden gepatenteerd, is het gevolg dat het totale produktaanbod in alle gevallen kleiner wordt. Omdat nieuwere soorten produkten de oudere verdringen, zullen producenten van nieuwere soorten produkten ook steeds vaker de plaats innemen van producenten van oudere of traditionele produkten. Hiermee wordt in grote mate de observatie ondersteund die vooral in hoofdstuk 5 aan de orde was: R\&D uitgevoerd door biotechnologische bedrijven in industrielanden, zal door de introductie van nieuwere produkten oudere produkten en met name van producenten van de oudere produkten verdringen. In hoofdstuk 10 worden tenslotte beleidsconclusies en implicaties voor verder onderzoek gepresenteerd. 


\section{Curriculum Vitae}

Rohini Acharya was born on May 29, 1965, in New Delhi, India and completed her secondary education in schools in Delhi, Lima, Peru and Glasgow, Scotland. Between September 1983 and May 1987, she completed her Bachelor of Arts in Economics, at Hampshire College, in Amherst, Massachusetts in the USA after which she moved to the UK. She obtained her Master of Arts in Economics, with a specialization in International Economics, at the University of Sussex in Brighton, in the UK, in January 1989.

After completing her MA at Sussex, she joined the Science Policy Research Unit (SPRU), as a research assistant for a period of four months, before coming to Maastricht where she worked as Programme Officer for the International Diffusion of Biotechnology Programme at the International Federation of Institutes for Advanced Study (IFIAS). The research experience accumulated during her time at SPRU and at IFIAS in the international impact of biotechnology, contributed to the development of her $\mathrm{PhD}$ research topic which she began at MERIT in September 1990. She will be joining the Royal Institute of International Affairs, Chatham House, in London, in January 1995. 


\section{THE IMPACT OF NEW TECHNOLOGIES ON ECONOMIC GROWTH AND TRADE}

\section{A case study of biotechnology by Rohini Acharya}

In this book the process of innovation is examined in both developing and industrialized countries. The impact of new technologies on economic growth is studied by using the example of modern biotechnology which is making radical changes in methods of production across a wide range of sectors. R\&D activities and policy efforts that have been undertaken in industrialized and developing countries are discussed. The measures of innovation used, included patent statistics from the European Patent Office and the US Patent Office and because in most developing countries patents for this technology are not recognized, statistics from agricultural field trials in India were used instead. Observable trends in technological change in these countries show that in biotechnology, the production of high quality products does not appear to replace older products immediately. Instead, variety tends in some cases to increase in the short run, although as genetically engineered products become more widely available to consumers, it is likely that variety will decrease in the long run.

A growth and trade model is developed based on these observations about quality and variety. The model builds on recent new growth and trade models and adds a new aspect to this body of literature, namely, that while the new growth models present separate cases of yariety increasing infinitely, decreasing instantly to one, or remaining constant, in the model developed here, all three are presented as special cases. Thus the model presented here, is in fact, much broader and can be extended to a number of different technologies and sectors. Finally, policy implications and issues for further research are examined.

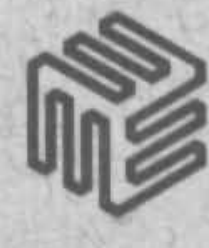

Faculty of Economics and Business Administration

University of Limburg

Maastricht, the Notherland:

Disuertation no. 95 - 25

Datawysie | Univerataire Pens Masulticht

isan 90 s27a Tra ? 